The Arthritis Associated with Crohn's Disease:

A Family study.

D.I. Haslock, M.B., Ch.B.

A thesis submitted for the degree of Doctor of Medicine, University of Edinburgh. Spring, 1972. 


\section{FRONTISP IECE}

From "The Seats and Causes of Diseases Investigated by Anatomy" by John Baptist Morgagni. Translated by Benjamin Alexander. 


\section{Letter XXXI. Article 14, $\mathbf{1}_{5}$.}

Brunnerus faw, in a dyfenteric woman, the mouths of the glands of the duodenum " eroded:" and in others, who had labour'd under a long flux of the inteftines, he alfo found " ulcers of a cancerous nature, as it were ( $k$,", and in one (l) who had been troubl'd with a caliac flux, and in another $(m)$, who had been afficted with a lientery, " an ulcerous difpofition," in the laft mention'd patient, of the colon; and in the former, throughout the whole tract of the inteftines, he reckon'd up " more than fixty little ulcers:" and thefe things I was willing to take notice of, that you might know, what caufes may fometimes happen, fo that the intertines being irritated, where the ulcers are, by the contact of the ingefta, which pafs that way, thefe ingefta may be fo much the fooner expell'd, without giving time for the chyle to be perfeeted, or even extracted, and that you might at the fame time conceive, if in thefe kinds of fluxes, the inteftines are fometimes affected with ulcers, how much more eafily they may be feiz'd with the fame diforders, where the violence of the pain is a proof of there being fo much a greater degree of acrimony, I mean in the dyfentery. And left we fhould feem to digrefs from our fubject, attend to two obfervations of Valfalva's, that is, not only the one which is defcrib'd above $(n)$, of a young man, in whom a diarrhœe, without tormina, fucceeding to a dyfentery, he found the latter part of the ileum, and the firtt part of the colon, ulcerated; but this alfo which I hall immediately fubjoin.

14. A man of thirty years of age, was feiz'd with a dyfentery. This continu'd a long time, till at length he was feiz'd with a fpitting of blood, and with death.

In the belly, the fmall inteftines, indeed, were found to be unhurt: but the large inteftines were, in fome places, ting'd with a black colour, and had fome of their glands entirely eroded, the remaining glands being all drench'd with a bloody humour, in the very excretory orifice. In the gall-bladder was but little bile.

In the cavity of the thorax, towards the inferior part, was no fmall quantity of blood extravafated. At the inferior part, alfo, the lungs were ftuff'd up, and both lobes adher'd, on their fides, clofely to the pleura, which was itfelf, likewife, evidently injur'd. The right ventricle of the heart contain'd a polypous concretion.

15. The appearances of difeafe, which were found in the thorax, refer to another fubject. And, thofe in the belly, to the prefent. But as thefe things which Valfalva has remark'd, of the glands of the inteftines, agree both with thofe that you will fee produc'd from Peyerus, in this fection of the Sepulchretum $(0)$, and with thole that you have feen in the firf, from among the obfervations of Brunnerus, juft now pointed out $\left({ }^{*}\right)$; that one thing only, in regard to little bile being found in the gall-bladder, would be contrary to the opinion of Spigelius, if he, as fome learned men affert, had pronounc'd the gall-bladder to be "large in dyfenteric bodies," whereas he has only faid, that he had " fre"quently" feen it fo $(p)$. Yet, if we examine this whole fection narrowly, we fhall fee it oblerv'd but once by others. For Cummenus $(q)$, was the only perfon

(k) C. 10.

(i) C. 7 .

(m) Exercit. de gland. in duodeno. \$. 6.

(n) N. 2 . (o) Schol. ad obf. 4 .

(*) N. 13 .

(p) De hum. corp. fabr. 1. 8, c. 13 .

(q) Obr. 1. 


\section{Book III. Of Difeafes of the Belly.}

who found " the gall-bladder to be very larese, and very full of bile," and in the body of a woman. Bontius $(r)$, and Lamonjerius (s), found it to be diftended indeed; but the latter with pus, and the former with a white hu. mour, "like a pultice of ftarch, to that no traces of bile were left," whereas Spigelius has declar'd, that the increas'd fize of it was owing to " the " quantity of bile, with which it was fill'd." But Francifcus Platerus $(t)$, not only found it not diftended with bile, as others likewife feem to have found it, who fay nothing upon the fubject, but even " quite empty."

Moreover, the patient of Platerus had the inteftines ulcerated, after a dyfentery, which continued "fome days;" and this I obferve, left you thould be apt to imagine, that this did not happen, but after dyfenteries of long continuance. And there were innumerable little ulcers, for they took up the whole extent of furface in the ileum, and were " the breacith of "three fingers diftant from each other;" fo that this obfervation may be, in fome meafure, compar'd with the obfervation of the celebrated Batfius (u), who, after a dyfentery, faw the fame intertine diftinguifh'd with ulcers, " at the diftance of almoft a finger's breadth from each other, and " fometimes, at the diftance of a joint of the thumb, proceeding nearly in " one tract, or feries," as the figure which he added $(x)$, has alio exprefs'd (except that he feems rather to have reprefented the jejunum, than the ileum) confirming the defcription, in which the fame opinions, of Peyerus, that I pointed out a little while ago, are ftrengthen'd by a probable conjecture, I mean that, as thofe bodies, which he call'd glandular plexuffes, were wanting, and as every ulcer feem'd to occupy one of the feats of thefe glandular plexuffes, it was very fuppofable, that the beginnings of the erofions, had been in the fame plexuffes, which were, at length, entirely confum'd.

Nay, indeed Brunnerus, in that obfervation $(y)$, wherein he number'd more than fixty little ulcers, has teftified that thefe ulcers, " had their fituation in no other part, than in thefe plexuffes." And certainly, that in inteftinal fluxes, the humours are thrown upon the inteftines, by thefe, or other glands, may be even argued from their magnitude being increas'd, as happens in all other glands whatever, while their fecretions are greater than ufual. Thus in the body, wherein, after a long inteftinal flux, the fame Brunnerus found ulcers, about the extremity of the jejunum $(z)$, he not only faw " glandular tuberofities," in that part likewife, but alfo found the internal coat of the inteftine, become much thicker, than it naturally is, and this coat " feem'd, from the beginning, to the end, to be entirely glandu"lar and luxuriant with glands." And of his glands of the duodenum he fays (a), " they are generally found to be much thicken'd, in thole who die " of difeafes in the inteftines, fuch as a diarrhoea, or a dyfentery :" and he fays that the fame glands, had even " become indurated (b)," in that dyfenteric woman, in whofe body he faw the orifices of them "eroded," as I have already faid.

(r) Obr. 6.

(s) Obr. 19

(t) in aduit. obr. 3 .

(i) Obf. auat, chir. med. dec. 3. obr. 7 .

(x) Tiab. xi. fig. I.

(3) Supra ad. n. t3 $^{2}$

(z) C. 7 . ibid. cit.

(a) In earum demonftr, anatom.

(b) Ibid. 
CONPENSS. 
DECLARATION

CrLAPTER I.

INTRODUCTION

CHIAPTER II. REVIEW OF THE ITTERATURS

A. CRCEIT'S DISEASE

1. Introduction

2. History

3. Nomenclature

4. Extension of concept

5. Clinical symptoms

6. Management

7. Pathology

3. Complications

9. Extra-intestinal manifestations

10. Artinitis

. 10.1 Polyarthritis

10.2 Ankylosing spondylitis

42

10.3 Clubbing and hypertrophic ostecarthropathy

10.4 Erythema nodosum

11. Pathology of arthritis

12. Aetiology

13. Associatad diseases

13.1 Miscellaneous

13.2 Ulcerative colitis

13.3 Sarcoidosis

14. Aetiology of the arthritides

B. MEIHODOLOGY

1. Introduction

2. Diagnostic criteria for ankylosing spondylitis

\subsection{Rome 1961}

2.2 Now York 1966

3. Neasurement of spinal mobility

4. Neasurement of chest expansion

5. Radiology of the sacro-illac joints

5.1 Anatomy of the sacro-iliac joints

5.2 Changes in the sacro-iliac joints with age

5.3 Radiological sacro-1littis 
2. Ascertaimment of probands

3. Examination of probands

4. Ascertainment of relatives

5. Radiography

6. Radiographic interpretation

7. Serology

8. Methods of recording data

A. THE PROBAND GROUP 140

1. Ascertainment 140

2. Age and sex distribution 140

3. Crohn's disease 143

4. Musculo-skeletal complications 150

5. Intestinal arthropathy 153

6. Ankylosing spondylitis 159

7. Sacro-iliitis 163

8. Clubbing 165

9. Assessment of New York c10RS criteria for ankylosing spondylitis 166

B. THE REAATIVES 168

1. Completion rate 168

2. Age and sex distribution $\quad 175$

3. Musculo-skeletal complications 175

C. IINTAGE DISORDERS $\quad 179$

D. SEROZOCY 181

CHAPTIR V. $\quad$ DISCUSSION OF RESULTS 182

1. The proband group 183

2. The general musculo-skeletal 184

3. Intestinal arthropathy 186

4. Sacro-ililtis and ankylosing 188

5. Clubbing 189

6. The diagnostic criteria for
ankylosing spondylitis

7. Linkage disorders 191

8. The relatives 192

9. Suggestions for further studies 193 
$\begin{array}{ll}\text { CIAPTIR VI } & 197\end{array}$

ACIANOWLIDGEMANS 203

$\begin{array}{ll}\text { APPENDIX A. CASE HISTORIES } & 207\end{array}$

$\begin{array}{ll}\text { APPENDIX B. } & \text { COMPARISON WITH ULCERATIVE COLITIS } \\ \text { SURVEY } & 235\end{array}$

APPEDIX C. SERONUGATIVE SPONDARIFIRITS 245

APPENDIX D. PROFORMAS 251

BIBLIOGRAPHY $\quad 302$ 


\section{LIBT OF TABLIS.}


CHAPTER II.

II - 1 Histological features reportedly characteristic of Crohn's disease of colon or ulcerative colitis.

II - 2 The interval in years between the onset and diagnosis in ankylosing spondylitis and of regional enteritis.

II - 3 L.G.I. incidence of Crohn's/tuberculosis $1925-50$.

II - 4 Flouride content in water supplies in the survey area.

II - 5 Diagnostic criteria for ankylosing spondylitis in population studies - Rome, 1961.

II - 6 Sensitivity and specificity of C1OMS(Rome) clinical criteria in relation to grade 1-4 bilatera? sacro-iliitis in Pima males. 113

II - 7 Sensitivity and specificity of sacro-iliitis in relation to clinical A.S. grade $2-4$ in Pima Inaians.

II - $\theta$ Evaluation of Rome clinical criteria for ankylosing spondylitis.

II - 9 Comparison of Youden indices derived from Manchester and Pima evaluations of Rome criteria.

II - 10 Diagnostic criteria for ankylosing spondylitis in population studies - New York 1966.117

II - 11 Bvaluation of diagnostic criteria for ankylosing spondylitis.

CHAPTER IV.

IV - 1 Diagnosis of Crohn's disease.

IV - 2 Incidence of complications of crohn's aisease.

IV - 3 Clinical state of Crohn's disease at time of survey.

IV - 4 Number of probands with musculo-skeletal disorders.

IV - 5 Probands and relatives with back pain. 
IV -24 Availability of relatives.

IV - 25 Completion rates.

IV - 26 Incidence of osteoarthrosis.

IV - 27 Incidence of sacro-ililtis.

IV - 28 Positive latex slide tests for rheumatoid factor.

APPENDIX B.

B - 1 Comparison between patients with ulcerative colitis and Crohn's disease with musculoskeletal complications.

B - 2 Comparison of surveys of Crohn's disease and ulcerative colitis: subjects seen and $\mathrm{x}$-rayed in the surveys.

B - 3 Comparison of surveys of Crohn's disease and ulcerative colitis: probands with intestinal arthritis.

B - 4 Comparison of surveys of Crohn's aisease and ulcerative colltis: percentage of patients with ankylosing spondylitis and sacro-iliitis.

APPEMDIX C.

C - 1 clinical linkages described among members of the group of seronegative spondarthritides.

C - 2 Familial linakges described among members of the group of seronegative spondarthritides.

C - 3 References to Tables C -1 and C - 2 . 


\section{IIST OF EIGURES.}


CFAPTER II.

II - 1 An example of familial aggregation of intestinal disease.

II - 2 pedigree of a family showing members with regional enteritis, ulcerative colitis and associated conditions.

II - 3 Proposed pathogenesis of collagen symaromes and mechanism of self porpetuation.

II - 4 Evolution of sacro-iliac changes during the course of ankylosing spondylitis.

CEAPTER III.

III - 1 Numbering systam used in a fanily study. 138 CIAPTIZR IV.

IV - 1 Age distribution of probends: males. 141

IV - 2 Age distribution of probands: females. 142

IV - 3 Age at onset of Crohn's disease. 144

IV - 4 Duration of Crohn's disease. 146

IV - 5 Area of gut with evicence of involvenent on laperotony, radiology or histology.

IV - 6 Area of gut with evidence of involvement on laparotomy, radiology or histology. (both sexses combined)

IV - 7 Onset of Crohn's disease and intestinal arthritis.

IV - 8 Time interval between onset of symptoms from Crohn's alsease and intestinal arthropathy.

IV - 9 Area of gut known to be Involved in probands with and without intestinal arthropathy.

IV - 10 Onset of Crohn's disease and anirylosing spondylitis.

IV - 11 Age distribution: parents.

IV - 12 Age distribution: siblings.

IV - 13 Age distributions children. 
IV - 14 Age distribution: second degree relatives. 173

IV - 15 Age distributions spouses. 174

IV - 16 Comparative incidence of sacro-iliitis. 177

IV - $17 \begin{aligned} & \text { Comparative incidence of sacro-ililtis } \\ & \text { (sesses combined) }\end{aligned}$

IV - 18 Incidence of Psoriasis. 180

APPERDIX A.

A - 1 Case C. lirs. B.R. Part of resected specimen. 214

A - 2 Case D. Mrs. E.D. Hemicolectony specimen. 218

A - 3 Case D. Mrs. E.D. Pelvic X-ray. 220

A - 4 Case E. Mr. T.R.W. Pelvic x-ray. 223

A - 5 Case F. Mrs. B.L. Resected specimen. 226

A - 6 Sacro-ilitis grade 2. 229

A - 7 Sacro-iliftis grade 3. 230

A - 8 Sacro-1liitis grade 4. 231

A - 9 Adolescent sacro-iliac joint. 232

A - 10 Adolescent sacro-illac joint. 233

A - 11 Pelvis affected by Paget's disease. 234

APPEADIX B.

B - 1 Age distribution of patients with ulcerative colitis and Crohn's disease. 
SUMMARY. 
The arthritis associated with Crohn's disease: a family study.

A study is presented of 116 patients with Crohn's disease and the families of 98 of them. The 116 probands, 147 blood relatives and 51 spouses wore personally revieved in specially conducted clinics, and $x$-rays of a further 52 blood relatives and 3 spouses were obtained and examined. The relatives included comprised 73.9 per cent of those available to the study.

The prine purpose of the study was to determine the incidence and clinical pattern of the musculo-skeletal complications of crohn's disease. In the probands, intestinal arthropathy was found in 20.4 per cent. This wes an episodic polysynovitis involving large rather then shall and lower limb rather than upper limb joints. In all cases but one the arthropethy developed after the gut disease. There was a strong association between the onset and exacerbations of the Crohn's disease and the arthropathy. surgery frequently produced amelioration, but rarely complete relief, of the joint symptons. There was no spectal. essociation with any known area of gut involvement nor with fistula formation or proved malabsorption.

Radiological sacro-iliftis was found in 16.4 per cent of the proband group, and eight patients ( 6.9 per cent) had definite ankylosing spondylitis, 5 having perinheral joint as well as spinal involvement. There was no association between onset and activity of the intestinal and rheumatic diseases, the latter often proceding the former. The position of the gut lesions and the incidence 
of complications did not influence the prevalence of the arthritis, and surgery did not modify its course.

Finger clubbing was found in 12.1 per cent of the probands, but none had hypertrophic osteoarthropathy. Periarthritis of the shoulder was found in 6 per cent and psoriasis in 6.9 per cent.

Sacro-iliitis was found in 8.3 per cent of the first degree and 1.9 per cent of the second degree relatives. None had definite ankylosing spondylitis. There was no seronegative polyarthritis in the relatives and the incidence of psoriasis did not exceed that in the population.

The spouses, acting as a control group, showed no sacro-iliitis, ankylosing spondylitis or seronegative polyarthritis.

The main conclusion of the study is that intestinal arthropathy is a common complication of Crohn's disease, and is associated with activity of the gut disease. Ankylosing spondylitis and sacro-iliitis arise on a coincidental genetic basis and proceed independant of the activity of the gut disease. 
Declaration. 
5

In accordance with the regulations of the University of Edinburgh, I declare that this thesis has been composed by myself, and that the work reported in it is my own, excepting those parts contained in Appendix B and Appendix $\mathrm{C}$ where due acknowledgement of the contribution of other workers is made.

Lan traclaes Ian Haslock, M. B., Ch. B. 
CHAPTER 1.

IIITHODUC'? ION 
One of the main interests of the Rheunatism Research Unit at Leeds has been the sero-negative arthritides. Professor Wright's contribution to the understanding of psoriatic arthritis is well known and a continuing interest in patients with psoriasis and arthritis exists in the unit. Professor Wright and Dr. Geoffrey Watkinscis made some of the earliest clinical descpiptions of the arthritides associated with ulcerative colitis, and their follow-up series, which now contains more than 200 patients, is one of the largest and most thoroughly studies in the world. Work in the field of bowel disease in Leeds is greatly enhanced by the existence in the Department of Surgery of a unit who's head. Professor J.C. Goligher, has had a life-long experience of the investigation, diagnosis and treatment of gut disorders. T'ne long-term follow-up policy of that department is allied to a comprehensive system of case recording which makes retrospective analysis of patients' records a less inaccurate procedure than is usua1. The departmental policy has also been for many years the achievement of a tissue diagnosis wherever possible. As a logical extension to the clinical descriptions of the seronegative arthritides produced from the unit, it was decided to study the families of patients with psoriasis and arthritis and ulcerative colitis. These family studies have been completed, that of psoriasis and arthritis by Dr. John Moll having been published as a D.M. thesis by the University of cxford, and that of ulcerative colitis by Dr. Ian Macrae being in preparation for an M.D. thesis at the University of Iondon. 
In order to achieve a more complete knowleage of seronegative arthritides it was decided that a clinical and family study of the arthritis associated with crohn's disease was needed. This study is presented in the present thesis. With regard to the patients with Crohn's disease, the probands, its objects were five-fold:-

1. To investigate the incidence and clinical pattern of the sero-negative polyarthritis described in association with Crohn's disease.

2. To interpret the significarce of such factors as major complications of the aisuase, which had been shown to be significant when the similar arthritis associated with ulcerative colitis was studied.

3. To interpret the influence of the position of the lesions in the gut on the development of the arthritis.

4. To assess the incidence of sacro-ilititis and andylosing spondylitis in patients with Crohn's disease.

5. To determine the prevalence of '1inkage disorciers', i.e. those other disorders forming part of the group of sertnegative spondarthritides.

The relatives were to be studies with two objectives:-

1. To investigate the incidence of sacro-ijiitis and ankylosing spondylitis in relatices of different degrees.

2. To detemine the prevalence of linkage disorders. The jatients spouses were included as a control group with a similar immediate enviroment to the probands. They were to be studied in exactiy the same way as the blood relatives. 
It was intended that the overall results of the study would contribute to the past and present work within the unit in three ways.

1. By providing a basis for comparison with the family study of ulcerative colitis, thus resolving the controversy relating to the relative iscidence of the musculoskeletal complications of the two diseases.

2. As an extension to I above, to contribute to, or detract from, the concept of 'Intestinal arthritis', that is an arthritis associated with intestinal diseases rather than separate type of involvement related to different disease entities.

3. To provide a further piece of evidence within the framework of the concept of 'seronegative spondarthritis' which was arising in the unit. Finally it was hoped that the work would geners te further objects for investigation either by the author or by research workers in Leeds or other centres in the Euture. 
CHAPTER 11

REVIEW OF THE LITERATURE

A. Crohn's Disease 
1. Introduction.

The first systematic description of Crohn's disease was presented to the American Medical Association in May, 1932 (Crohn, Ginzburg and Oppenheimer, 1932). Crohn and his colleagues described 14 cases of a disease they named 'Regional Ileitis' which they described as occurring predominantly in young people with a male preponderance. In all their cases, the terminal ileum was involved alone, the process being at its maximum intensity at the ileocaecal valve and extending orally for some 20 - 30 centimetres. Specimens from thirteen of the cases were subjected to pathological inspection and the universal features were of a thick, hose-like section of ileum with internal fistula formation. The histological features were somewhat mixed, but giant cells and granulomas were noted in some of the sections.

\section{History}

During discussion of Crohn's paper, it became obvious that others present had previous experience of the same condition (Bargen, 1932, Friedenwald, 1932). It is difficult to be entirely accurate in assessing historical claims to descriptions of Crohn's disease as both the clinical, operative and pathological findings bear a strong relationship to tuberculosis. It is almost certain, however, that a number of cases diagnosed as abdominal tuberculosis in the past have in fact been cases of crohn's disease. The earliest attributed description is that of Aretaeus of Cappadocia (Goligher, de Dombal, Watts and Watkinson, 1968) and Goldstein (1948), who suggested the 
eponym saunders-Abercrombie-Crohn's Ileitis, reviewed cases as early as the 16th Century. Pride of place in 'modern' descriptions is usually given to Morgagni (1769 see frontispiece).

A description of the case of William Payne Geerges. Esq. was read to the College of Physicians in London in 1806 (Combe and Saunders 1813), the patient having suffered flatulence, abdominal pain and intermittent pyrexias for many years. When he died "... he was more emaciated than any person we had ever witnessed". At necropsy, his stomach, duodenum, jejunum and upper part of the lleum were found to be normal. but, "The lower part of the ileum as far as the colon, was contracted, for the space of three feet, to the size of a turkey's quill. The colon had three contractions, one about three inches long at the distance of seven inches from the caecum, a second about one inch long at the distance of four inches from the former, and a third not quite half an inch long the distance of three inches from the last. Wherever the intestines were constricted, the coats were very much thickened, and exhibited an appearance of inflamation".

Abercrombie (1830) gave a number of excellent descriptions and it is notable that one of his patients who presented with rheumatic symptoms was found at necropsy to have a fistula between the terminal ileum and the bladder. A further patient was described as having involvement of the distal $3 \frac{1}{2}$ inches of the ileum, the orifice of which was "so contracted as but just to admit a large probe". This patient's clinical course was also typical of crohn's disease 
presenting with abdominal pain, vomiting and cachexia. Abercrombie made microscopic differentiation from carcinoma, but did not describe the histology. Norman Moore (1883) undertook microscopy at the necropsy of his patient with typical terminal ileal involvement, and he too was convinced that the condition was distinguishable from carcinoma. Dalziel (1913) described typical Crohn's disease affecting the jejunum, ileum and colon, and was the first to comment on the hose-like thickening of the bowel wall and mesenteric involvement. He co-orainated his operative findings with the clinical sign of palpation of the thickened loop of bowel and also described the histological characteristics of ulceration, oedema and lymphatic aggregates.

An association with malabsorption was described by Blumgart in 1923, and spread of the disease from the 11eocaecal region to the colon following resection, with a good description of the histology, was given in the same year by Moschowitz and Wilensky. They supplemented their four clinical and pathological reports with a review of all the cases of a similar nature described to that date in the literature, giving pride of descriptive place to Braun (1908).

Mock (1931) reviewed granuloma formation in the gut in general, and his case 7 is a further typical description of involvement of the distal 2 inches of the ileum, occurring in a 22 year old female, with the histological picture we now associate with crohn's disease. 
3. Nomenclature

Crohn's chosen name of "Terminal Ileitis" was criticised by Bargen as having the connotation of an agonal condition. He suggested the substitution of 'regional' for 'terminal' and Crohn's paper was eventually published using this title. In the years that followed a number of papers were presented suggesting alternative names for the disease, including Chronic Cicatrizing Enteritis (Bell. 1934). Ileocolitis Ulcerosa Chronica (Rosenblate, Goldsmith and Strauss, 1936), Non-Specific Granuloma, Regional Ileocolitis, Infective Granuloma, Regional Enterocolitis, Segmental Enteritis, Pseudocancer, Regional Enteritis, and Crohn's disease (Pugh, 1945). The last term is the most frequently used, particularly in the European literature, and in view of the extension of the concept of the disease both within and outside the bowel, the eponymous term is preferred until such tine as a proven aetiology provides a logical name.

\section{Extension of Concept}

Although involvement of the terminal ileum either alone or in combination with other parts of the gut remains the classic lesion of Crohn's disease, it soon became obvious that a similar pathological process could involve almost all the gastrointestinal tract. In 1934, Colp described a case which he claimed to be the first showing definite spread of Crohn's disease beyond the ileocaecal valve, but the colonic involvement was limited to the caecum only.

Oral extension of the disease to the jejunum was first described in 1933 (Harris, Bell and Brunn) and was well. 
recognised by the following year (Brown, Bargen and Weber, 1934). Disease in the jejunum alone, without involvement of the terminal ileum, was found in three of the 39 cases reported from the Nayo clinic in 1937 (Pemberton and Brown 1937). Crohn was at first unwilling to accept any extension of the disease concept, but by 1941 recognised combined ileo-jejunal involvement and published 17 cases (Crohn and Yunich, 1941). Reports of single cases still appeared, however, (Johnson, 1943, ortmayer, 1945) and some discussion centred about the radiological signs of apparent 1solated jejunal involvenent (Janus, 1948). Recognition of duodenal involvement was somewhat delayed, probably reflecting the greater rarity of this condition (Brown and Sims, 1954, Berk, 1956). Only 18 cases could be found in a review of the literature to 1954 (Segal and Seribin, 1956) although by 1957 Anderson, Mullinger and Bagoch had found reports of 28 cases of gastric or duodenal involvement. Although many modern reviews accept gastric involvement quite casually (Bartholomew, 1959), well authenticated examples are not common. The case reported by Comfort and his co-workers in 1950 was claimed as the first verified example of Crohn's disease of the stomach, but the description given is not entirely convincing (Comfort, Weber, Baggenstoss and Tiely, 1950). Similarly the case reported by Ross a year earlier gives a brief report of microscopy which is of dublous significance (Ross, 1949). One of the cases of Goldgraber and his colleagres, however, appears to fulfill the most stringent criteria for crohn's disease (Goldgraber, Kirener and Rasken, 1958), and Martin and Carr 
(1953) described two cases in one of which there is good histological evidence of gastric involvement. These last authors comment that both their cases occurred during the course of relatively non-specialised surgical practice in an eighteen month period, and speculate that some cases of gastric Crohn's disease are remaining undiagnosed. In view of the extensive investigations that take place in many centres, however, it seems unlikely that gastric involvement is common. Oesophageal involvement in the disease is claimed as an even rarer phenomenon (Heffernon and Kepkay, 1954, Dyer, Cook and Kemp Harper, 1969), and at least one case of oral involvement, with apparently typical histology, has been described (Lennard-Jones, 1970 B).

Colonic involvernent in Crohn's disease has proved a much more controversial subject. crohn was again unwilling to accept this extension of the initial disease concept, but by 1936 described cases in which involvement spread beyond the ileocaecal valve into the colon (Crohn and Rosenak, 1941). He had at this time already foreseen difficulties in distinguishing Crohn's disease of the colon, ulcerative colitis, especially if combined with back-wash ileitis, and the combination of Crohn's disease of the small intestine with idiopathic ulcerative colitis. Both Cave (1945) and Janowitz (1955) appeared to find little difficulty in distinguishing backwash ileitis, and both authors confidently described patients in whom idiopathic ulcerative colitis and Crohn's disease

A careful study of ileal lesions associated with 
ulcerative colitis was produced by Counsell (1956) who found retrograde ileitis in 17 per cent of 107 patients with ulcerative colitis. of 230 patients with idiopathic ulcerative colltis from whom histological material was available, three showed undoubted Crohn's disease in the terminal ileum. This 2.3 per cent coincidence rate far exceeds the estimated $I$ in 600,000 cases which should have occurred if coincidence of the two conditions was by chance alone, but the combination remains uncommon and should not be overdiagnosed simply because its occurrence is recorded. Despite these studies this remains an area open to diagnostic confusion, and only those case reports supported by the most careful histology can be accepted with any degree of confidence (Locthart, Mummery and Morson, 1964). The occastonal misdiagnosis of colonic Crohn's disease as diverticulitis (Schmidt, Lennard-Jones, Morsen and Young, 1969) further complicates this subject, as does the apparently true difference in incidence of colonic Crohn's disease between the United Kingdom and the United States, proportionally more cases being diagnosed in Britain (Crohn, Bargen, Brooke, Cattell, Kirsner and Templeton, 1969).

It has become apparent that colonic involvement may occur in the absence of small intestinal lesions, Cornes and Stecher (1961) describing a series of 45 patients in whom the disorder was entirely confined to the large intestine. Right-sided colitis (Cooke and Brooke, 1955) is no longer accepted as a spectfic disease entity, but is a part of the spectrum of Crohn's disease and colitis 
(Lee and Roy, 1964).

The importance of anal lesions had become apparent by 1943 when a series of 114 cases had been subjected to sigmoldoscopy with the demonstration of anal abscess or fistula in 31.6 per cent (Jackman and Smith, 1943). Although anal involvement has usually been accepted as a part of involvement of the intestine generally, it has recently been postulated that Crohn's disease may involve the amus alone (Gray, Lockhart-Munmery and Norsen, 1965). As a curiosity, Crohn's disease has also been described Involving a Meckel's diverticulum alone (Elman, 1958).

Crohn's disease is now accepted to involve any or all of the portions of the gastrointestinal tract from the mouth to the anus. Although involvement of the terminal ileum either alone or in combination with some other part of the gastrointestinal tract remains the conmonest site for the disease, such involvement is not necessary for diagnosis. 5. Clinical symptoms

The classical symptoms of abdominal pain, diarrhoea, weight loss and fever were described in crohn's original paper and remain the hallmarks of the disease. In Van Patter's review of 600 cases, 74 per cent had diarrhoea, 66.9 per cent colicy abdominal pain and 62.7 per cent fever. The outstanding sign was of a palpable abdominal mass which was present in about a third of his cases (Van Patter. Bargen, Dockerty, Feläman, Mayo and Waugh, 1954). The onset of the disease is often insidious, which may make it impossible to decide whether an associated condition preor post-dated the onset of Crohn's disease symptoms. In 
a small proportion of the patients the bowel disease is asymptomatic and it is for this reason that Jayson, Salmon and Harrison (1970), recommended routine examination of the bowel of all patients with ankylosing spondylitis. particularly in young people the condition may present as a pyrexia of unknown origin, sometimes associated with erythema nodosum and arthralgia (Austad, Thompson and Joseph, 1968).

Primary lesions in sites other than the classical one of the terminal 1leum may cause variations in symptomatology. Duodenal involvement may present with signs of upper intestinal obstruction. symptoms of colonic involvement are often indistinguishable from those of idiopathic ulcerative colitis (Javett and Brooke, 1970). Presentation with one of the anal complications of the disease is not infrequent, the disease presenting either as chronic or recurrent anal fissure, anal abscess or fistula, or as an extra-rectal mass (Jackman and Smith, 1943). Nany cases of crohn's disease are found at operation for "acute appendicitis", and this is particularly so in the case of acute ileitis. Controversy exists as to what proportion of patients with acute ileitis go on to develop chronic Crohn's disease. Crohn considered that acute ileitis was "undoubtedly an individual phase of regional ileitis". despite the fact that 45 per cent of the patients with acute 1lettis in his combined (1949 and 1957) series were adjudged to be cured 8-19 years after the acute episode. Lyall (1945) went even further in describing chronic regional ileitis as the end process of acute ileitis with superimposed repair 
processes and fibrosis. In contrast, Warren and somers (1948) reported resolution in 12 of their 15 cases, one of the others dying and two progressing to the chronic form of the disease. The other series quoted by Crohn show remission rates of 25-66 per cent (Crohn and Yarnis 1958). In view of the doubt about the outcome in a significant proportion of cases of acute lleitis it was considered inappropriate to include any such cases in the present study and they have not therefore been considered further.

Despite the presence of classical symptomatology in the majority of cases a discuietingly large number of patients are either initially misalagnosed or the correct diagnosis is delayed for many years (Dyer and Dawson 1970). Radiology may be of value in the diagnosis of Crohn's disease, the classical sign being the string sign of Kantor (1934) while the colon might show discontinuous lesions, often forming strictures, and thickening of the intestinal wall to differentiate the condition from ulcerative colitis (Lennard Jones 1970). The only other investigation of consistent diagnostic value is biopsy of a lesion seen at sigmofdoscopy or of the anus, even if clinically uninvolved (Gray, Lockhart-Mumery and Morson, 1965). Many nonspecific abnormalities may be detected in the blood, particularly accelerated E.S.R. and alteration in plasma proteins, but the search for a diagnostic test, such as a skin test, has so far proved fruitless.

6. Management

There is at present no known cure for Crohn's disease, and in absence of any generally acceptable aetiological 
theory, no definitive treatment is as yet in sight. As the majority of the early descriptions of the disease were made by surgeons, the literature is filled with controversy as to the best type of operation to be performed. As it became appreciated that the disease could involve larger and larger portions of the gut, the tendency to recormend an attempt to complete excision of the diseased tissue became less. Although some surgeons from the earliest days of the disease were in favour of a conservative approach (Iross, 1938), others were more radical, and Trafford (1956) described two patients who had had 89 per cent and 93 per cent respectively of the small bowel resected. Predictably the complications of such radical surgical procedures rivals the disease process itself in causing deleterious affects on the patient. It is often difficult to judge the results of surgery due to both the lack of agreement as to whether clinical or radiological evicience of recurrence should be accepted in the assessment of surgical techniques (Garlock and Crohn 1945) and also to the lack of distinction that is made in some papers between Crohn's disease and ulcerative colitis (Hinton, 1952). While the main surgical controversies involved the proponents of exclusion and excision, some of the surgical techniques described were based on novel aetiological theories, an example being the use of pelvic autonomic neurectomy by Hinton (1952) basing his techniques on the colonergic theory proposed by Yonkman (1952). In a review in 1962. Neely and Goldman suggested the following indications for surgery: "Progressive symptomatic terminal ileitis, 
enteric or perirectal fistulas, haemorriage, intestinal obstruction, post-operative recurrent progressive or recurrent enteritis, perforation and abscesses." They felt that extensive diffuse disease, particularly combined 1leocolitis, and rapid progression were contra-indications to surgery and suggested that the natural history of gastric, jejunal and duodenal lesions was such that surgical intervention at these sites should be avoided wherever possible. It has never been aisputed that surgery has a place in the treatment of Crohn's disease, but from the earliest days of its description, medical treatment has had its advocates. Felson (1936), in furtherance of his view that bacillary dysentery was of aetiological significance, suggested that "the Ideal therapy is the prevention of bacillary dysentery" . Bercovitz (1950) suggested that the use of chloramphenicol to eliminate E. Coli from the stools was attended by clinical improvement wich continued after therapy was discontinued. As with most disorders of the gastro-intestinal tract, the use of special diets has held sway at various times. Brown and Daffner (1958) recommended a low residue, low fat, high protein, high carbohydrate, vitamin supplemented diet. Their medical regime also included the use of mild sedation, anti-spasmodic arugs, superficial psychotherapy, sulphonamides, steroids and other antibiotics. Radiotherapy hes also had its exponents (Brown and Daffner, 1958, Crohn, Bargen, Brooke, Cattell, Kirsner and Templeton, 1969) and more recently dramatic results have been claimed for the use of immunosuppressive agents such as Azothioprine, 
particularly in desparately ill patients (Brooke, Hoffmann and swarbrick, 1969). A recent, balanced review (LennardJones, 1970A) points out that gross structural change in the gut in Crohn's disease is compatible with good general health and few symptoms. It is more important that the patients symptomatology, rather than the radiological appearance of their intestine, is the guide to treatment. The current medical treatment regime includes general measures such as rest, low residue, low fat diet, and, where malabsorption or protein loss supervene, high protein, high calorie diets. Supplements of Iron, potassium and various vitamins may be needed, and anti-bacterial drugs have been shown to have a place in treatment. These are frequently combined with a small dose of corticosteroids. Surgical treatment is required perticularly where structural complications of the disease such as stenosis, fistulae or abscess formation supervene. Major intra-abdominal catastrophies, of course, recuire the appropriate emergency surgery. Although the older diversionary operations had, unt1] recently, given way to more definitive resections, there has been a recent recurrence of interest in these procedures.

It is germane to discuss one school of thought which is in some measure of disagreement with the consensus as expressed by this review, as it is of consicerable influence in the region from which we have draw our patients. Goligher (1967) has advocated the more widespread use of surgical techniques in the treatment of crohn's disease pointing out that, as there is no effective medical 
treatment, medical management is merely symptomatic treatment in the expectation of remission as part of the natural history of the disease. He feels convinced that surgery offers a 50 per cent chance of cure and advocates its use where disease is not extensive, particularly if the large bowel is affected. His surgical technicque is also more radicel than most, in that he advocates the use of total procto-colectomy and ileostomy where colonic resection is required, having discovered that further surgery is required in more than two thirds of the patients in whom a portion of rectum or colon is left in situ (De Dombal, Burton and Goligher, 1971).

In general, little attention is paid in reviews of the managoment of Crohn's disease to treatment of the extraintestinal complications. While some, such as osteomyelitis, have established methods of treatment irrespective of their primary cause, in others the underlying disease process may considerably modify treatment. Articular complications enter this latter group for three reasons. Firstly the treatment of the intestinal disease may modify the arthritis. The use of systemic corticosteroids for control of the gut disorder might be expected to influence the inflamatory -intestinal synovitis" and ankylosing spondylitis, though its effect on this disease will be mainly symptomatic rather than curative. Immunosuppressive agents also heve their advocates in the treatment of rheumatic diseases (currey, 1971). Their use in the therapy of the intestinal lesions might affect the course of concomitant ankylosing spondylitis, although few trials of these drugs in spondylitis are 
available (Demetriades, Vesiroglou, Mitseas and Kontomertios 1971). Abdominal radiotherapy may also iniluence the spine beneficially, while enforced periods of recumbency could have disastrous effects on future spinal mobility if florid spondylitis has already occurred. Secondly the presence of arthritis may modify the treatment of the Crohn's disease. In ulcerative colitis it has been domonstrated that excision of all the affectable gut, i.e. total proctocolectomy, removes all chances of recurrence of intestinal synovitis. Although total disembowelling would be recuired to guarantee similar relies in Crohn's synovitis, the presence of troublesome joint disease may encourage an attempt at surgical removal of the diseased tissue. It is very rare for the peripheral manifestations of ankylosing spondylitis to include finger involvement of such severity that a colostony or ileostony could not be managed if required. Finally the presence of the intestinal disease may interfere with the therapy of the locomotor disorders. The dangers of recumbency to spondylitis has already been mentioned, but of greater practical importance is the possible effects on the diseased gut of the drugs used in the treatment of rheumatic disease which are, almost without exception, gastro-intestinal irritants. This particularly applies to phenylbutazone, which would otherwise be the drug of choice in the treatment of spondylitis and all drugs of this type must be used with great caution in Crohn's disease. Increased intestinal transit time may also modify arug absorption, as may intestinal resection. As a therapeutic problem, the association of severe Crohn's disease with 
painful arthritis may be formidable in the extreme.

\section{Patholocy}

Crohn originally considered that "regional ileitis" was a pathological as well as a clinical entity, although by 1954 he had been forced to abandon this view (Crohn and Janowitz, 1954). The original description of the gross pathology cannot be bettered. The early stages of the disease showed the involved gut to be soggy and oedematous with a blotchy red serosa. The mesentery showed thickening and hyperplastlc glands. This could progress to a fully developed hypertrophic process in which the involved intestine appeared as a soggy hose-like mass. As a result of the inflammatory hyperplastic changes, the wall of the bowel became thickened with consequent narrowing of the lumen. Perforation and fistula formations were common as were abscesses. Microscopically, Crohn described various degrees of acute, sub-acute and chronic inflammation. In some cases he noticed the presence of giant cells and granulomas. He was at pains to point out that these latter structures did not indicate a tuberculous aetiology of the disease and he went to considerable lengths to exclude any suspicion of tuberculosis.

The best histological study of Crohn's disease remains that of Hadfield (1939) who sumarised the changes as

\section{follows:-}

1. The earliest and probably the specific histological lesion of regional lleitis is lymphadenold hyperplasia and the formation of non-caseating giant cell systems in the submucosa. 
2. Acid-fast bacilli cannot be demonstrated histologically in these lesions.

3. This lesion is also present in the regional lymph nodes.

4. Vlceration and fistulae are secondary to this lesion in the submucosa and the obstructive Iymphoedema which it produces.

5. Ulceration often obscures and sometimes obliterates the primary lesion in the subrucosa. When this has happened the lesion is not uncommonly found in some or all of the regional $1 \mathrm{ymph}$ nodes. Jones-Williams (1964) differentiated 3 histological types, belng non-specific, diffuse granulomatous and focal granulomatous. He failed to show any progression of one type to another and therefore preferred the term "Crohn's syndrome", as he felt that the different histological types might represent different aetiological agents.

The combination of gross pathological appearances and histology are usually sufficient to give a clear cut diagnosis of Crohn's disease when it occurs in the small intestine. The situation is more complex when the colon is involved and clinical differentiation is often impossible. Even in examples of granulomatous colitis and ulcerative colitis which would be accepted virtually unanimously, there may be some features of the other disease present. The validity of differential diagnostic features has recently been studied and diagnosis on the basis of cummulative features of one or other disease has been suggested (Schachter, Goldstein, Rappaport, Ferness and 
Kirsner, 1970). This approach accords well with that which has been employed in our own pathology department. This overlap in pathological features is well illustrated by the following table:-

\section{TABLE II - I}

\begin{tabular}{lll} 
Histological Feature & $\begin{array}{c}\text { Crohn's Disease } \\
\text { of Colon }\end{array}$ & Ulcerative Colitis \\
\hline Granulomas & often & Absent \\
Lymphangectasia & Sometimes & Absent \\
Iymphoid hyperplasia & $\begin{array}{l}\text { Often: } \\
\text { transmural }\end{array}$ & $\begin{array}{c}\text { Sometimes: Mucosal } \\
\text { \& submicosal }\end{array}$ \\
Fissures & Often & Absent \\
Mucosal ulcerations & $\begin{array}{l}\text { Deep, with } \\
\text { relatively } \\
\text { intact adjac- }\end{array}$ & $\begin{array}{l}\text { Superficial, with } \\
\text { changes. }\end{array}$ \\
ent mucosa & Sometimes & often \\
Crypt abscesses & Sometimal \\
Neuromatous & Sometimes & Absent \\
hypertrophy & Transmural & Mucosal \& sub- \\
Inflammation & mucosal
\end{tabular}

Histological Features Reportedly Characteristic of Crohn's Disease of Colon or Ulcerative Colitis.

\section{Complications}

Malabsorption may complicate Crohn's disease as a result of extensive surgical procedures leaving an inadequate amount of gut for normal absorptive processes to take place, or as a result of the disease 1tself. It has been shown that malabsorption does not of necessity accompany the disease (Aldsberg and sobotka, 1943) but despite the fact that its presence is usually signified by extensive involvement of the intestine, it may on occasion 
be the presenting symptom. The tendency of the disease to cause internal fistulae was noted by Crohn in his original communication, and fistula formation, both internal and external, remains one of the most difficult problems of management in this disease. The internal fistulae may involve not only adjacent segments of bowel but other organs, such as the bladder, which lie adjacent to involved gut. Presenting symptoms such as pneumaturia occasionally occur under these circumstances, though fistulae precipitating the patients presentation are usually to the skin surface. The soggy, friable nature of the inflamed gut makes surgery technically difficult, and fistulae may follow surgical intervention (Berk, 1956). 17 cases have been reported in the world literature where small intestinal carcinoma has arisen in a patient 'with Crohn's disease (Wyatt, 1969). Despite the rarity of small intestinal carcinoma, this number occurring in the many thousand cases reported is of doubtrul significance, and attempts to demonstrate an aetiological relationship are not convincing. A similar conelusion has been reached with respect to colonic Crohn's disease (Hywel Jones, 1969), in contrast to the high risk of carcinoma supervening in ulcerative colitis. Complication of Crohn's disease with virtually any major intraabdominal catastrophe, including perforation, haemorrhage. and occasionally volvulus, may occur (Diamond, 1958).

9. Extra Intestinal Manifestations.

Both clinical and pathological evidence may be found of involvement of extra intestinal structures during the course of Crohn's disease. Although in general, these 
extra-intestinal manifestations are similar to those seen in ulcerative colitis, it has been suggested that their incldence is less frequent (Daffner and Brown, 1958). The picture is further complicated by the fact that the site of involvement in the gut appears to influence these complications both cuantitatively and qualitatively. Thus duodenal involvement is frequently associated with clubbing which is less common, although reported, where lower intestinal sites are involved (Anderson, Mullinger and Bagock, 1957), Unfortunately, the exact extent of the intestinal involvement is frequently not known, so suggestions of certain specific complications being associated with a particular intestinel site of the disease remain speculative.

A necropsy study of 39 cases reviewed evidence of involvement in the liver, pancreas, kidneys and vessels throughout the body (Chapin, Scudamore, Baggenstoss and Bargen, 1956). In general, these pathological changes were of a non-specific nature of the type Erequently found in any chronic debilitating disease. The classic granulomatous type of histological picture found in the gut was not found in other organs. As would be expected with a disease of this nature, secondary amyloidosis has been reported (Cohen and Fishman, 1949). Hepatic changes have been fairly extensively studied, particularly as the liver has been frequently shown to be involved in ulcerative colitis.

Clinical and pathological estimates of the incidence of liver diseave may give very different results. It is 
possible that the presence of serum hepatitis, particularly in American patients who have received several blood transfusions, may bias hospital necropsy figures (Palmer, Kirsner, Goldgraber and Fventes, 1963). A percutaneous liver blopsy study on 20 consecutive cases failed to show any significant hepatic disease in 17, with some fatty infiltration in the other three. This contrasted with the 32 cases of chronic ulcerative colitis studied similarly which showed a wide variety of hepatic pathology. Portal pyaemia has also been found in association with ulcerative colitis, but not with regional enteritis (kleckner, 1956). When Cornell (1955) reviewed the extra-intestinal manifestations of Crohn's disease he was able to find the following:fever, nutritional effects, changes in growth and development, anaemia - both microcytic and macrocytic, chemical changes - tetany and anyloidosis, arthritis, skin lesions, including erythema nodosum and, rarely, pyoderma gangrenosum, clubbing, pyelonephritis and multiple liver abscesses. Endocrine changes were said to be rare and unusually for a disease of this type menstruation was found to be almost unaffected. The author had seen no eye changes although occasional claims have been made in the literature. The incidence of pyoderma gangrenosum was sald to be much less than that in ulcerative colitis.

\section{Arthrit1s}

\subsection{Polyarthritis}

Although large series are occasionally reported in which arthritis is not mentioned (Kiefer and Ross, 1945), this complication has been recognised for many years. 
Dolyarthritis of rheunatola type was found in $4.5 \%$ of the t00 cases reported from the Mayo clinic (Van Patter. Bargen, Dockerty, Feldman, Mayo and Waugh, 1954). It was noticed that the severity of the arthritis reflected the activity of the intestinal disease, that control of the intestinal. portion of the disease resulted in remission of the arthritis, and that exacerbation of joint symptoms subsequently almost invariably heralded recurrence of the intestinal iesion. The two patients with arthritis in Clark's series of 30 (Clark 1938) and the three in his later series of 44 (Clark and Dixon, 1939) are probably included in Van Patter's paper, as they were also Nayo clinic patients. crohn's personal series of 674 patients contained a $2.3 \%$ incicence of arthritis, predominantly affecting large joints (Crohn and Yarnis, 1958). More recently several attempts have been made to study this arthritis in more detail, the best being that of Ansell and Wigley (1964). They reviewed 91 patients with regional enteritis and found 6 patients with a polyarthritis at the time of survey. A past history of polyarthritis was obtained in a further 8 patients, ankylosing spondylitis with peripheral joint involvement in two, and ankylosing spondylitis restricted to the back in three. Of the 14 patients with a history of polyarthritis, the knee was the most comonly involved joint, proximal interphalangeal joints slightly less frequently, and other joints such as wrists, ankles, and hips even less often. There were neither clinical nor radiological residual signs in those joints which had been reported as being involved in past 
episodes of "polyarthritis". The relationship of the arthritis to the bowel symptomatology was variable, but in only one case had the arthritis ante-dated any bowel symptoms. There did not appear to be any correlation between site of involvement in the gut and the incidence or type of arthritis suffered.

Soren (1966) reported 5 patients presenting to a rheumatic clinic who were suffering from crohn's disease. This was about 7.5 per cent of the total number of patients with Crohn's disease seen in the hospitals under review during the period in which the patients discussed were referred to the rheumatic clinic, but no systematic attempt was made to assess the further incidence of musculoskeletal symptoms in the other 92.5 per cent of patients with crohn's disease in the hospitals. Although the number of patients described was small, the pattern of joint involvement appeared to be similar to that described by Ansell and Wigley, the knees being involved in 4 cases as were the ankles, the wrists and fingers being involved in 2. and the shoulders, elbows, and feet each being involved in one case. The onset of the arthritis post-dated the onset of the ileitis in all cases and there was a tendency for simultaneous exacerbation of both intestinal and articular symptoms. In four of the five patients the arthritis remitted when the intestinal disease was controlled, although the fifth required surgery for a severe proliferative synovitis of the knees. A brief comparison was made with the arthritis associated with ulcerative colitis on the basis of a literature review rather than 
personal cases. Soren felt that the long interval from the beginning of the intestinal symptoms to the onset of arthritis in many cases of regional enteritis distinguished it from the onset of the arthritis within a few weeks of the bowel symptoms in some 90 per cent of patlents with ulcerative colitis. He considered that the joint affection in Crohn's disease was less severe as objective signs of joint damage, particularly radiological signs, were rare in this disease although reported in ulcerative colitis. Unfortunately the review of the literature on Crohn's disease omits the paper by Ansell and Wigley which had been published two years earlier and contained the best analysis of the disease from the rheumatologist's rather than the gastro-enterologist's point of view. The review of the arthritis associated with ulcerative colitis was restricted to three papers, only one of which was solely devoted to this subject. In view of this, the differentiation between the two conditions which the author makes cannot be accepted as demonstrated.

Wagner (1969) described 5 cases of arthritis associated with Crohn's disease, the primary diagnosis being proved by histology in four cases. No indication of the incidence of joint complications which this represents is given, though from his review of the literature he considered such complications uncormon. One case would fall within the definition of ankylosing spondylitis used in this study. of the other four, one had minor sacro-iliac joint changes, with a predominance of peripheral joint involvenent, and the other three had peripheral arthritis only. Large 
Joint involvement again predominated, the linee being involved in three cases, the shoulder in two and the hip and talo-calcaneal in one each. Involvement of the metacarpo-ghalangeal joints was noted in one case, and of 'joints of the hand' in another. In all cases the arthritis occurred in well established cases of Crohn's disease, the duration varying from $2-15$ years at the onset of the joint symptoms. In this series the joint and bowel manifestations were not considered to parallel each other, in fact one patient was said to have the impression that her abdominal pains alternated with the pains in her joints. Despite this, two patients foint symptoms went into remission following intestinal surgery. and the bowel and joint symptoms of one patient returning together eight months after an 11 eo-colic resection. The author went to considerable lengths to ascertain the nature of the joint disorder. He could find no serological evidence of rheumatoid arthritis or systemic lupus exythematosus, the only positive blood tests being nonspecific, such as acceleration of E.S.R., and probably due to the Crohn's disease. X-rays of the affected peripheral joints were in all cases normal, and there was no clinical. evidence of a chronic, deforming arthritis in any of the joints, despite the knee effusion in one patient being recurrent and requiring aspiration. The treatment of each case, both by physical and pharmacologie means, was discussed, the general note being one of pessimism about the physician's ability to modify the natural history of the joint disease. unfortunately the follow up of the 
patient treated with azothioprin was too short to draw any conclusions about its efficacy. In comparing his cases with a literature review of arthritis in ulcerative colitis, which he considered to be a totally different and easily distinguished disease, Wagner was impressed more by the differences in the pattern of joint involvement than the similarities, in particular with the relatively high incidence of joint disorders in colitis, and the frequent presentation of both arthritis and colitis together in contrast to the much later onset of the arthritis in his cases.

other papers on Crohn's disease make more casual reference to the presence of arthritis. Rossmiller and Messenger (1948) mentioned that one of their 55 patients had swelling, redness and tenderness of the joint, which was associated with a fever and was of a few weeks duration. Unfortunately the joints involved were not specified, nor was it mentioned whether the disappearance of joint symptoms coincided with the resolution of intestinel symptoms. Cornell (1955) reviewed the extra-intestinal manifestations of Crohn's disease and compared them with those of ulcerative colitis. His review of arthritis referred to Van Patter's series only, and he made no mention of the arthritis associated with ulcerative colitis. The most comon systemic complication suffered by the 100 patients reported by Daffner and Brown (1958) was the small joint "rheumatoid arthritis" suffered by 6 patients. The authors mentioned that arthritis is less frequent in crohn's disease than in ulcerative colitis, but that it 
may parallel the activity of the intestinal disease, and recurrence after resection may indicate recurrence of the enteritis. Groner (1960) considered polyarthritis to be a relatively rare complication, and none of the 72 patients diagnosed as having Crohn's disease in Norway in the period 1956 to 1963 had arthritis, although one gave a past history of "rheumatoid polyarthritis" (Gjone, Myren and orning, 1966). Lennard Jones (1970 A) mentioned the association of polyarthritis with Crohn's disease, the arthritis affecting primarily large joints, and accompanying activity of the 1ntestinal disease. He also cescribed the occasional occurrence of a painful myalgia.

Sprague, Anderson and Aaron (1944) described a 15 year old girl who presented with a polyarthritis thought to be rheumatic fever. Despite high dosage salicylate therapy, she ran a persistent pyrexia and her symptoms failed to subside. She was diagnosed after ten months illness as having Crohn's disease of the terminal ileum, caecum and proximal ascending colon, and her arthropathy was ascribed to her intestinal condition. Presentation of Crohn's disease with an acute arthritis was considered sufficiently uncommon to warrant the publication of a further single case report in 1968 (Austad, Thompson and Joseph, 1968). The authors dismissal of systemic lupus erythematosus as a possible diagnosis does not seem entirely justified in this case, however, as the patient had a false post serological test for syphilis, a positive test for anti-nuclear Eactor. a positive test for rheumatoid factor, a high E.S.R. and, despite the author's claim that there was no renal 
involvement, albuminuria on at least two occasions. Erythena nodosum was also present in this patient. In fact the only evidence that this was an intestinal arthritis was the exacerbation of the joint symptoms associated with increased intestinal symptoms.

The further literature on arthritis associated with Crohn's disease is contained within the context of the association between arthritis and intestinal disease in general and ulcerative colitis in particular. Most authors pre-suppose that the arthritides associated with Crohn's disease and ulcerative colitis are identical although evidence for this point of view is rarely offered. Wilske and Decker (1965) suggested that the articular manifestations of Crohn's disease were the same as those of ulcerative colitis, but less common, occurring in about 5 per cent of patients with Crohn's disease. They considered that nonspecific musculo-skeletal. symptoms were much more conmon. Wright (1966) mentioned that peripheral arthritis "similar to that of ulcerative colitis" is seen in Crohn's disease, but does not specify further. Hawkins (1968) cuotes an incidence of 10 per cent for arthritis associated with ulcerative colitis with an unspectfied lesser incidence in Crohn's disease. Although the paper by Ford and Vallis (1959) is primarily concerned with colitic arthritis, there is a good description of 4 cases of Crohn's disease. Three of these had a peripheral arthritis which lasted for 5 years in one case, substding slowly after bowel resection but leaving some chronic active arthritis. The other two cases had more transitory attacks, although the joints, knee and 
elbow, were specified in one case only. The authors suggest that the arthritis associated with crohn's disease is similar to that of ulcerative colitis, but put this forward only tentatively as the number of observations was 1imited. They did stress, however, that the arthritis is entirely separate from rheumatoid arthritis. The misconception that intestinal polyarthritis is identical with rheumatold arthritis was more widely held in the United States, where the diagnoses "atypical rheumatoid arthritis" and "rheumatoid spondylitis" were still used at a time when they had outlived their usefulness, than in this country. It was, however, necessary for Dixon (1960) to point out that sero-negative rheumatoid arthritis could be confused with enteroarthropathy.

Despite no mention being made of them in the title of the paper, three patients with arthritis accompanying Crohn's disease were described from New York and Chicago in company with 74 ulcerative colitics with articular disease (McEwan, Lingg, Kirsner and Spencer, 1962). Two of these patients had a peripheral arthritis, involving the knees and ankles in both cases, the shoulders and proximal interphalangeal joints being additionally involved in one. The third patient had ankylosing spondylitis, with no peripheral joint involvenent, although the association of psoriasis complicates interpretation of the aetiology of the spinal disease. All had negative tests for rheumatold factor, and the authors concluded that "So far as could be judged from so few patients, the features of joint disease in these three patients were identical 
in every respect with those in the patients with ulcerative colitis". A clear example of the presupposition of the identity of colitic and Crohn's arthritis is seen in the review by Bowen and Kirsner (1965) who made this assumption in their opening paragraph and thereafter referred almost exclusively to uicerative colitis despite their title "The arthritis of ulcerative colitis and regional enteritis". They described an asymetric, reversible, inflamatory arthritis of large joints affecting particularly the knees, hips and ankles, although they state that any single joint or combination of joints could be affected. Involvement of the smaller joints of the hands and feet was less common and the activity of the arthritis and the bowel disease was not always coincidental. They made a reference to the joint inflamation being, on rare occasions, so intense that rupture of the joint capsule with drainage of sterile purulent contents followed by complete remission, occurred. Unfortunately they do not append a case history or reference to their description of this dramatic sequence of events so the intestinal disease with which it occurred is not known. The review of colitic arthritis is, however, good, and although the case for using the term "intestinal arthritis" to include cases of both colitis and enteritis is not well made, the differentiation of this (or these) condition(s) from other specific arthritides, such as rheumatoid arthritis, and non-specific musculo-skeletal disorders, such as fibrositis, is valuable. In the same year, a rather poor review was presented by Houli and Rezek (1965) who studied the case records of 3,900 patients with rheumatic diseases 
finding 8 with ulcerative colitis. On the basis of this retrospective study of gastroenterological case histories they calculate an incidence of arthritis in ulcerative colitis at $0.2 \%$ : They described only one case of arthritis associated with Crohn's disease in wich the patient first presented with pain in the dorso-lumbar spine, later developing transient arthritides in the knees and left foot. This last was diagnosed as gout, and subsided on treatment with colchicine. An unspecified number of further "arthritic crises" were similarly treated, each being accompanied by diarrhoea (presumably before the colchicine therapy) and weight loss. Radiology of the sacro-iliac joints showed mild change only "and revealed also the presence of inflammatory lesions at the terminal jejunum". This statement is the only evidence offered to confirm the alagnosis of crohn's disease. The sequence of events, with spinal involvement first, then peripheral arthropathy and finally intestinal symptoms, suggests that the patient suffered from anjylosing spondylitis with peripheral joint involvement rather than intestinal arthritis. Ihis paper is the only one so far produced in which a third intestinal condition, Whipple's disease, is considered. The one patient, briefly described, with thipple's disease was said to be a "good example of articular symptoms preceding the digestive ones". It is not clear whether the authors considered the three arthritides to be the same, 1.e. all examples of intestinal arthritis, although their mention of the common mesenchymal origin of the gastrointestinal and locomotor systems in their introduction 
might suggest such a view.

The recent paper by Hammer and Naish (1968) is of considerable interest in that this is the first paper in which polyarthritis was found to be more common in patients with Crohn's disease than in those with ulcerative colitis, 22 per cent as compared with 12 per cent. Insignificant polyarthralgia was ignored, as their criteria for recording the diagnosis polyarthritis was a "definite history of multiple jolnt pains and or swellings, causing a disability of more than 3 months duration". Their incidence in a large control population was 2 per cent and despite sharing the intrinsic deficiencies of retrospective studies, the controlled nature of their observations does allow at least tentative conclusions to be drawn. This survey is the only one so far available in which an attempt was made to assess the incidence of polyarthritis in relatives. The method used was to question the probands about the incidence of various diseases in their first degree relatives. Despite the quoted statistical significance for the excess of polyarthritis found in the relatives of patients with Crohn's disease compared with the relatives of the control group, the conclusions drawn by such a potentially misleading method must remain open to doubt unless supported by conclusions from studies such as that described in this thesis.

\subsection{Ankylosing Spondylitis.}

The association between ankylosing spondylitis and Crohn's disease has been studied in somewhat more detail than the peripheral arthritis, both from the point of view 
of the incidence of the joint disease in patients with the intestinal disease and vice versa. One problem does arise when dealing with reports in which the diagnostic criteria for ankylosing spondylitis are either not specified or not of the highest order, that is the fact that non-specific backache is a fairly common condition and that pain may be referred both from the back to the abdomen and in the opposite direction. This reference of pain was noticed as causing diagnostic difficulty as early as the mid nineteenth century (Hilton, 1860) and remained an occasional source of difficulty more than a century later (New England Journal of Medicine, 1965). Difficulty also arises in interpreting the relationship between sacro-ililtis, either found alone or in conjunction with other diseases, and ankylosing spondylitis. It is therefore germane at this point to briefly discuss ankylosing spondylitis itself.

Ankylosing spondylitis is a disease of great antiquity having been described in a lower miocene period crocodile. The radiological findings in Egyptian mumies, who were originally thought to suffer this disease with great frequency, has more recently been disputed (Zorab, 1961). The first description in man was by Bernard Connor (1695), a Kerry physician who published a description of parts of a skeleton he had seen in France, deducing from its appearance that "this person must have been immovable, that he could neither bend nor...... stretch himself out, rise up, nor lie down, nor turn upon his side....". Brodie's description in 1850 was separate from his original description of Reiter's disease, and peripheral arthritis 
complicating the spinal disease was recognised in the early nineteenth century (O'Connell, 1956).

ragge (1877) gave a good clinical and pathological description of a young man with ankylosing spondylitis who presented with abdominal pain and constipation. His abdomen was, however, said to be normal at necropsy. As is frequently the case, the workers whose names are associated eponymously with the disease were not the original describers. Strumpell published two cases in 1884. Bechterew described a single case in excellent clinical detail in 1892 and Marie gave an extensive description of the disease in 1898. Unfortunetely, these author's names are still occasionally used eponymously (Van Weerden, Den Oudsten, Dr Groot and Van de Veere, 1960). Greater confusion in nomenclature has, however, arisen from the fact that Amerfican authors have used the term "rheumatoid spondylitis" with the implication that the disease was a variant of rheumatoid arthritis (Hench, Bauer, Boland, Dawson, Freyberg, Holbrook, Key, Lockie and MCEwan, 1941). This name was officially adopted by the American Rheumatism Association in 1941, although the term ankylosing spondylitis was widely used in Britain at that time, and was not dropped until December, 1963 (Boland, 1966). The concept of various sero-negative erthritides being rheumatoid variants had, however, been under fire from rheumatologists in the United States for some years prior to this (MCEwan, Ziff, Carmel, Di Tata and Tanner, 1958). The main stimalus to progress in understanding of ankylosing spondylitis came with the accumulation during 
the second world war of large numbers of young men in the armed forces. The four cardinal features of the disease, spinal stiffness, diminished thoracic expansion, raised E.S.R. and radiological sacro-iliitis, were enumerated by Hart and his colleagues in 1949 (Hart, Robinson, Alldrin and Maclagan, 1949). A constderable male predominance of the disease was apparent. Hart's own serles showing 9.5 men to 1 woman (Hart and Robinson, 1959). The presentation in $60 \%$ of his patients was with pain and stiffness in the low back occasionally with sciatic radiation, the symptoms being worse after immobility and morning stiffness being a prominant feature. The pain and stiffness sometimes became persistent with progressive loss of mobility in the spine usually starting caudally and spreading cranially (Sharp, 1968). It has been suggested that a form of ankylosing spondylitis affecting women may follow a milder course with more limitation of the disease to the sacro-iliac area and less involvement of the spine (White, 1953).

A further problem is the relationship between sacroilitis and ankylosing spondylitis. Although there are reports of the latter disease occurring without radiological involvement of the sacro-iliac joints (Polley and slocumb, 1947. Adler and Carmon, 1961) such diagnoses are extremely rare. What is more common is to find a radiological sacro1liltis without the clinical criteria for ankylosing spondylitis. Sacro-iliitis is usually an early, if not the earliest, objective sign of ankylosing spondylitis and it is tempting to equate bilateral sacro-iliitis with early ankylosing spondylitis. There are, however, other diseases 
known to be associated with sacro-1li1tis and in the present context it is noteworthy that several of them are intestinal diseases. In reviewing the literature, in all cases except those in which the author has some actiological axe to grind, for example brucellosis (Goldfain, 1943), it has been assumed that sacro-lilitis will either lead to the full-blown picture of ankylosing spondylitis or to a forme fruste of this condition. The valialty of this assumption will be discussed later.

Van Patter's compendious review of regional enteritis stated that the spinal column was occasionally involved in the arthritis he described (Van Patter, Bargen, Dockerty, Feldman, Mayo and Waugh, 1954). Crohn's only mention of spinal involvement in his series of 542 cases was of one patient with involvement of the cervical spine. It seems likely that these series contained patients with spondylitis which was overlooked, and this tendency is reflected in some case reports which mention symptoms such as "pains in the back and chest" which were apparently casually attributed to "rheumatism and lumbago" (Barbour and Stokes, 1936). In contrast, several authors have drawn attention to the association between ankylosing spondylitis and crohn's disease. Steinberg and storey (1957) described six cases of chronic inflammatory intestinal lesions associated with ankylosing spondylitis. One of these patients had crohn's: disease and a second a mixture of Crohn's disease and ulcerative colitis. Unfortunately, the spondylitis was not described in great detail in either case with Crohn's disease, although one patient was noted to have been 
referred for radiotherapy. In both patients the intestinal disease preceded the onset of locomotor symptoms. The authors were unable to find any reference in the literature to an association between ankylosing spondylitis and Crohn's disease. Although the single case of Crohn's disease in association with ankylosing spondylitis could have been a chance, they suggested strongly that the association was considerably more than chance in the case of ulcerative colitis, and from there extrapolated that the association with enteritis might also be significant. This opinion would be reinforced in their case of mixed Crohn's and ulcerative colitis was in fact an example of Crohn's disease of colon, and as the diagnosis of the colitis as Idiopathic ulcerative colitis was entirely on the basis of sigmoidoscopy and barlum enema without the benefit of histolcgy, It is quite possible that this was in fact the case. In the following year Daffner and Brown (1958) described two patients with ankylosing spondylitis in their series of 100 patients with Crohn's disease, although they followed their national custom of the time by tabulating them as a subdivision of rheumatold arthritis. In a study of patients with inflammatory disease of the intestines in Western Canada, Ford and Vallis (1959) described one patient with ankylosing spondylitis without peripheral joint disease and one patient who had two attacks of sub-acute peripheral arthritis and, although left with no resldual peripheral joint disease, had "blurring" of the sacro-iliac joints on $x$-ray. Unfortunately the method of selection of patients by these authors prevents assessment of the incidence of 
the arthritic complications in their patients with crohn's disease. If it is assumed that idiopathic ulcerative colitis was about 10 times more common than regional enteritis in their catchment area then this group would be expected to have contained about 35 patients with Crohn's disease. It is interesting that these authors dismiss as coincidence the patient in whom ulcerative colitis was preceded by the development of ankylosing spondylitis.

Powerful statistical support for an association between both ulcerative colitis and Crohn's disease with ankylosing spondylitis was provided by Acheson (1960A) who reviewed the records of 2320 male patients discharged from Veterans Administration Hospitals, finding that of the 1175 patients with ulcerative colitis, 23 ( 2 per cent) had also been diagnosed as having ankylosing spondylitis. of the 742 patients diagnosed as having regional enteritis, $17 \mathbf{2 . 3}$ per cent) had also been diagnosed as ankylosing spondylitics. The temporal relationship of the onset of the two diseases is shown in table II-2. The criteria for the diagnosis of ankylosing spondylitis were bilateral sacro-ililtis with or without radiological evidence of spinal involvement. 요 the patients with regional enteritis, 13 had radiological evidence of spinal involvement and 9 did not. Seven of the patients had an associated finding of disease in their hips or shoulders and three had additional symetrical involvement of the peripheral joints. Further survey evidence was provided from Edinburgh (McBride, King, Baikie, Crean and Sircus, 1953) where two groups of patients were investigated, 870 who had had radiotherapy for ankylosing 
TABIE II-2

Regional Enteritis

Diagnosis Approx. onset

$\begin{array}{lccc}\text { Ankylosing Spondylitis } & 20+ & 2 & 3 \\ \text { before Regional } & 10-19 & 2 & 2 \\ \text { Enteritis } & 5-9 & 4 & 8 \\ & 1-4 & 3 & 3 \\ & \text { Less than 1 } & 2 & 1 \\ & \text { Synchronous* } & 1 & 2 \\ \text { Regional Enteritis } & \text { Less than 1 } & 0 & 0 \\ \text { before Ankylosing } & 15-4 & 5 & 0 \\ \text { Spondylitis } & 50+9 & 3 & 0 \\ & 10+ & 0 & 0 \\ & \text { TOTAL } & 22 & 19 \\ & \text { Dates Unknown } & 0 & 3\end{array}$

"During the same stay in hospital.

The interval in years between the onset and diacnosis of Ankylosing Spondylitis and of Regional Enteritis.

Modified from Acheson (1960A)

spondylitis, and 170 from a gastrointestinal unit who had been diagnosed as having either ulcerative colitis or Crohn's disease. From the first group, four patients with both Crohn's disease and ankylosing spondylitis were found, and one of the patients diagnosed in the clinic as having Crohn's disease also had ankylosing spondylitis. Unfortunately, the total number of patients with Crohn's disease in the second group is not stated, but the Incidence of Crohn's in spondylitics was 4.58 per thousand. as opposed to an estimated population incidence of 0.14 per thousand. It was noted that there was a higher proportion of females among the patients with ankylosing 
spondylitis who had intestinal disease as compared with those suffering from idiopathic ankylosing spondylitis.

In reviewing the literature, Acheson found that clinical reports of the association between Crohn's disease and ankylosing spondylitis were extrenely rare, and this was still the case when Stewart and Ansell (1963) described two cases in detail, one of whom had developed the ankylosing spondylitis during the course of Crohn's disease, the other presenting initially with back pain and only later developing the intestinal condition. The careful study from the same unit published a year later (Ansell and Wigley, 1964) in which 91 patients with Crohn's disease were surveyed, described ankylosing spondylitis in one female and four male patients, with possible spondylitis in one further male. Of the five confirmed cases, the articular symptoms ante dated the intestinal ones in two and post-dated them in three. Ihree patients had associated peripheral arthritis. of the patients with Crohn's disease and axthritis described by Wagner (1969), one was initially considered to suffer from ankylosing spondylitis, although the author later discarded this diagnosis. However, the combination of back pain, positive Schober's test and sacro-iliac sclerosis would fit this patient into the diagnostic criteria for anisylosing spondylitis.

All the clinical series mentioned so far have dealt with the occurrence of arthritis in patients with intestinal disease. Although statistical analysis of the reverse relationship have been undertaken, the only systematic 
clinical surveys are those of Jayson and his colleagues (Jayson and Bouchler 1969; Jayson, Salmon and Harrison, 1970). They found inflanmatory bowel disease in 6 of 33 and 8 of 47 patients with ankylosing spondylitis, an incidence of 17.5 per cent. The diagnostic criteria for both spondylitis and bowel disease appear well grounded and the minimal radiological appearances considered adequate for diagnosis were entirely acceptable. The absence of biopsies from the earlier series might have artificially lowered the incidence of Crohn's disease. Throughout these papers the importance, in the author's eyes, of carrying out the full gamut of investigations on even asymptomatic patients is stressed. Several of the cases found would have been missed if such investigations had not been carried out. Unfortunately the authors throughout assume an association between intestinal inflamatory diseases and spondylitis without attempting to study critically the comparative incidence of ulcerative colitis and crohn's disease. This is noteworthy in discussion in the second paper in will the intestinal disease is discussed as 'colitis' throughout although one case of Crohn's disease is described, the evidence for this diagnosis being excellent (Jayson, 1971). Presumably longer series will enable a more aiscriminate analysis of the comparative incidence of the two diseases. 10.3 clubbing and Hypertrophic Osteoarthropathv. clubbing of the digits is a condition associated with many diseases, Crohn's disease being one. There is at present no generally accepted objective method of measuring 
either the presence of clubbing or 1ts severity and progress when discovered. One technique of measurement, using a shadowgraph, has been described (Bentley and Cline, 1970) but is not in general use. The incidence of clubbing, especially in its less florid forms will tend, therefore to vary from observer to observer depending on the index of suspicion and experience of the clintcian and the criteria used to assess the sign. Even considering such variations it remains surprising that van Patter's series of 600 cases of Crohn's disease contained no mention of clubbing being detected. There does, however, appear to be a trend observed in the literature for clubbing to be related more to upper intestinal involvement, particularly of the duodenum (Segal and Serbin, 1956; Kusakcioglu and Norton, 1967) and jejunum (ortmayer, 1945). In reviewing the available literature, Anderson and his co-workers, who contributed a case of duodenal Crohn's disease with finger and toe clubbing, found a variety of estimates of the incidence of clubbing, the highest being found in association with jejunal lesions elther in isolation or as jejunoileitis (Anderson, Mullinger and Bagoch, 1957). The highest incidence in a reported series, as opposed to reviews, was that of Sussman and wachtel (1954) who found clubbing in 40 per cent of their 23 cases of Crohn's disease with combined jejuno-ileal involvement. The trend to a higher prevalence in upper intestinal involvement has been confirmed in a local series (Burton 1971).

In contrast, there is only one report in the literature of true hypertrophic arthropathy occurring in 
Crohn's disease (Neale, Kelsall and Doyle, 1968). This occurred in an adolescent boy whose disease appeared radiologically to be confined to the ileum and colon. The hypertrophic process is well illustrated radiologically and appears particularly florid. The associated finger clubbing was mild. The presence of transient knee effusions in this patient was thought to be due to the symovitis occasionally associated with rapidy developing osteoarthropathy rather than an intestinal synovitis. 10.4. Erythema Nodosum.

Erythema nodosum is a commonly occurring lesion, which may accompany many aiseases. It is most frecuently associated with streptococcal infections, tuberculosis, sarcoidosis, mycoses, enteropathies and viral infections. It may also occur as a reaction to certain arugs, particularly sulphonamides. The aetiology is unknown, but an "allergic" basis is usually postulated, an additional genetic predisposition being suggested by the occasional occurrence of familial cases. Arthralgia occurs in 50-90 per cent of patients with erythema nodosum whatever the underlying cause (Champion and Wilkinson, 1968). The distribution of joint involvement, with the knees, ankles, wrists, fingers and elbows most frequently affected (Truelove, 1960), is reminiscent of the distribution described for the artinropathies accompanying intestinal diseases. A further simlerity is the coincidence of erythema nodosum and arthritis with exacerbations of the bowel disease (Jacobs, 1959) an association frequently described for intestinal arthritis without erythema nodosum. The occasional cases 
in which erythema nodosum and associated arthralgia have preceded the appearance of intestinal symptoms (McGovern and Goulston, 1968) are probably associated with subclinical gut involvement. As both intestinal symovitis and erythema nodosum, with or without joint involvement, appear to be manifestations of "hypersensitivity", no further attempt has been made to differentiate between those arthropathies occurring with or without the skin condition.

\section{Pathology of Arthritis.}

There have been no formal pathological studies specifically directed towards the arthritic manifestations of Crohn's disease. A large number of people with Crohn's disease have been studied at extensive post mortem examinations, and an orientation of these necropsies towards the locomotor system might have provided an answer to some of the outstanding questions with regard to the articular manifestations of this disease. Thus no comprehensive pathological review has been undertaken of the spondylitis and sacro-1liitis wich occurs in conjunction with the disease. This is unfortunate as controversy remains as to whether the spondylitis associated with bowel disease is identical to idiopathic ankylosing spondylitis (Di Tata, McEwan, Lingg, Porrini, Good and Roulson, 1969). A detailed comparison of the two conditions might well yield evidence for or against their ident1ty. It would also be of value to make more detailed studies of the spine in cases where sacro-iliitis has been demonstrated during life in apparent absence of either 
symptoms or signs of the full-blown spondylitic picture. This would not only give information as to the degree of involvement of the spine taking place in this condition but also give some indications as to the time scale between the development and progression of radiologically apparent sacro-ilitis and histologically demonstrable spinal disease.

The pathological information avallable about the arthritis association with Crohn's disease is entirely that published in case histories as a part of the findings at operation, on synovial biopsy or on joint aspiration. The best study is that of Soren (1966) who made a detailed study of five patients, one of whom developed a chronic synovitis of the knees eventually recuiring synovectomy. An intial aspiration of the left knee yielded $140 \mathrm{ml}$. of greenish-yellow viscous fluid with a white cell count of 3.900 per cubic mm. 90 per cent being 1ymphocytes and 10 per cent neutrophils. The joint fluid sugar was $52 \mathrm{mg}$. per $100 \mathrm{ml}$. and the fibrinogen $0.45 \mathrm{gm}$. per $100 \mathrm{ml}$. Culture was negative. At synovectomy, the synovium of both knees was said to be markedly hyperaemic and shaggy around the patella and nearby femoral condyles. The articular cartilage was macroscopicaliy intact. Microscopy revealed hypertrophic synovium with interstitial cedema and infiltration with plasmocytes, histiocytes and lymphocytes. Nodular agglomerations of Iynghocytes were seen surrounded by a rim of plasmocytes and histiocytes. These findings, which are well 1llustrated in the text, cannot be said to arise from a typical case of Crohn's (intestinal) arthritis as the synovitis was sufficiently marked and prolonged to 
require synovectomy at a time when the intestinal symptoms were in complete remission. It was also notable that the arthritis in this case had not borne any temporal relationship to the exacerbations and remissions in the gut symptoms. The latex test for rheumatoid factor was said to be negative, though it is not clear at what stage of the disease this investigation was undertaken. Serology was not undertaken on the joint aspirate. Despite any reservations which might be felt about the typical nature of the case, it would appear to be a seronegative synovitis associated with otherwise uncomplicated Crohn's aisease. It is interesting that the articular cartilage was said to be undanaged, a finding which would have been anticipated from the radiological signs of the disease, and that during the course of follow-up, no recurrence of the synovitis occurred. The only other well documented case report is that of Austad and his colleagues who presented the data from serial symovial fluid aspirates over a period of 26 months. They also carried out two needle biopsies of the knees. The White cell count in the synovial Iluid varied between 5,300 and 12,300 per c.ml., with 60-93 per cent of the cells being polymorphonuclear leucocytes. A good mucin clot was obtained on each occasion. The synovial biopsies showed similar changes, with increasing severity during the two year period between them, of inflammatory infiltration with synovial hyperplasia. This was interpreted as "chronic active synovitis". No test for rheumatoid factor was made on the synovial fluid despite the fact that weakly positive blood serology had been 
obtained. The histological appearances are equally

compatible with systemic lupus erythematosus which is a plausible alternative diagnosis in this case, and therefore must be interpreted with care (Austad, Thompson and Joseph, 1968). Ford and Vallis (1959) mention the presence in one of their patients of swelling of the knees requiring aspiration of $75 \mathrm{ml}$. of fluid on two separate occasions. Unfortunately no details of the aspirates are mentioned. Bowen and Kirsner (1965) in discussing the intestinal arthritides in general note that the composition of the fluid including cell counts, differential count, specific gravity, viscosity, proteins, sugar, and mucin cl.ot formation is similar to that of rheumatoid arthritis. Unfortunately, the only references they give are to patients with ulcerative colitis and hipple's disease and it would appear therefore that these remarks are not based on any direct experience of synovianalysis in Crohn's disease. In one other report of joint aspiration (Wagner 1969) the fluid was described as clear and sterile, tests for rheumatold factor being negative. Thus the clinical impression of Crohn's arthritis as a non-specific reactive synovitis appears to be confirmed by the prevailing evidence. but this is extremely scanty.

\section{Aetiology.}

The aetiology of crohn's disease is unknown. The reason for its non-recognition as a distinct entity until long after clinical cases had been reported was almost certainly its pathological, and to some extent clinical. similarities to intestinal tuberculosis. Crohn's original 
paper mentioned this similarity, and stressed that they did not consider tuberculosis to be an aetiological factor. They looked for histological evidence of tubercle bacilli. and also arranged cultures and guinea pig, rabbit and chicken innoculations. They excluded concomitant pulmonary tuberculosis. The other aetiological factors they had considered were syphilis, actinomycosis, Hodgkin's disease and Iymphosarcoma. They found no evidence of any of these diseases (Crohn, Ginzburg and Oppenheimer, 1932). Apart from more positive evidence against various aetiological theories, there have been no great advances since that time. Despite the similarity to tuberculous histology, most people recognised no aetlological association between the two diseases, an assertion that had been made previously by Moschowitz and Willensky (1923). Gray (1934), however, had studied the gastro-intestinal tract at necropsy of patients dying from pulmonary tuberculosis. He claimed to have seen both tuberculosis of the small bowel and separate lesions with a histology similar to that of regional enteritis. On this basis, he speculated that tuberculosis might be involved in the aetiology. Although by 1945. Pugh was stating that tuberculosis had been proved not to be aetiologically significant, Spellberg and Jackson reopened a discussion with some case reports in 1950. One of their patients who died of miliary tuberculosis showed the histological appearances of entero-colitis not tuberculous enteritis at necropsy. They also presented a patient with jejunal and ileal granulomatous disease, which they considered to have been sarcoidosis, but which appears 
from the description to have been an example of Crohn's disease, who improved on treatment with anti-tuberculous therapy. Examination for tuberculosis, including chest $x-r a y$ and skin testing was negative. In the same year, Armitage and Wilson presented a series of 26 cases from Leeds. They also quoted figures for the number of patients diagnosed as having intestinal tuberculosis or Crohn's disease for each 5 year period from 1925 to 1950 at the Leeds General Infirmary. The figures are summarised in Table II-3.

\section{TABLE II-3}

$$
1925-30 \quad 30-35 \quad 35-40 \quad 40-45 \quad 45-50
$$

Intestinal

\begin{tabular}{lrrrrr}
$\begin{array}{l}\text { tuberculosis } \\
\text { Crohn's }\end{array}$ & 20 & 18 & 19 & 12 & 3 \\
\hline Total & - & - & 3 & 13 & 18 \\
\hline
\end{tabular}

L.G.I. Incidence Crohn's/Tuberculosis 1925-50. Nodified from Armitage and wilson 1950.

These figures may be interpreted as either reflecting more accurate diagnosis of non-tuberculous enteritis or a true increase in Crohn's disease and waning of tuberculosis per se (Fallis 1941). They may also represent an altered reaction by the body to the tubercle bacillus. Crohn persisted in dismissing tuberculosis as a potential cause of regional enteritis (Crohn and Janowitz, 1954) and has continued to do so (Crohn and Yarnis, 1958). Cooke (1955) in his Hunterian lecture, compared the incidence of pulmonary tuberculosis, ( 3.3 per cent) in his series of 90 
patients with Crohn's disease with that in 100 patients with idlopathic steatorrhea (5 per cent), and in patients following gastroectomy ( 3 per cent). These findings all tend to confirm that previous reports of the two diseases found in association were coincidental. The epidemiological association between Crohn's disease and tuberculosis has, however, been stressed again recently (Fielding, 1970) it being suggested that there is a temporal epidemiological relationship between the two diseases, with crohn's disease waxing as tuberculosis wanes. The author's experience of 9 patients with Crohn's disease who had previously had tuberculosis, and 2 patients with Crohn's disease who subsequently developed tuberculosis cannot be evaluated in the absence of information about the incidence of tuberculosis diagnosed in patients with other intestinal disease in his practice. He suggests that Mycobacterium Tuberculosis might be modified in persons with moderate host resistance to $1 t$, the resultant material being attached to a haptane to form an antigenic determinant. The distribution of the lesions in Crohn's disease suggests that the bile salts might contain the haptane. This assertion would obviously bear more careful evaluation.

Although tuberculous infection has never been popular as an aetiological theory, the idea that Crohn's disease has an infectious aetiology has found wide support. The clinical and pathological features were not entirely compatible with the theory that direct infection could cause lymphatic obstruction leading to oedema with consequent ulceration and non-specific superinfection of the 
ulcerated area (Blackburn, Hadfield and Hart, 1939). A review in 1939 suggested that there was a consensus of opinion in favour of an infectious aetiology, although the authors felt this was most likely to be a virus (Clark and Dixon, 1939), while by 1945 Bockus stated unequivocally that "all evidence points to bacterial invasion as a primary or exciting cause". This statement was made despite careful study by Pumphrey (1938) who failed to find any positive evidence of significant bacterial infection, although cultures of faecal contaminants were freely available from the patients he studied. crohn and Yarnis (1958) dismissed the "claims and confutations" of the many authors who had found various bacteria on culture of tissue or tissue exudates from patients with Crohn's disease, and implied subsequently that these were of no aetiological significance. They quote the findings of coliforms, anaerobic streptococci, gram positive cocci, enterococc1, aerobacter aerogenes and streptococcus viridans. Although the dismissal of infection by these authors was in keeping with the feeling of the times, 10 years later Golde (1968) offered a plausible case for reconsidering an infectious aetiology in crohn's disease. He drew parallels with other mycobacterial diseases and showed other special situations in which an infectious aetiology is accepted without all Koch's postulates being extant. An additional factor, such as an immunological deficiency in the patient, could provide an additional. modification to conventional infection (Lancet, 1968). Golde pointed out that human enteritis due to pasteurella 
pseudotuberculosis causes an enteritis which may be mistaken clinically for crohn's disease, even to the extent of appearing predominantly in young adults and occasionally in families. He also mentioned the granulomatous colltis of Boxer dogs which is histologically similar to Crohn's colitis in man. Ihis was not the first occasion on which an animal model for Crohn's disease had been suggested. Even before the definitive description of the disease, Dalziel (1913) had noticed the similarity of Johne's disease, and the suggestion was taken up again by W.J. Mayo In 1939. This disease is caused by Mycobacterium Johnei and is probably transmitted to the foetus. It is characterised by thickened corrugated intestinal mucosa and clinically is a cause of chronic diarrhoea. In contrast to Crohn's disease, however, the organisms are freely found both in the gut and the regional $1 \mathrm{ymph}$ nodes (Doyle, 1956). A more interesting analogy is the terminal or regional ileitis suffered by swine. Emsbo (1957) included 58 cases in his description of an acute. sub-acute, or chronic ulceration extending to the submucosa and associated with fibroblastic granulation, lymphocytic accumulation and epithelioid cells, which would easily pass for a description of crohn's aisease in man. Even more significant was his description of the hose-pipe like segments of gut, usually localised at the terminal ileum but sometimes extending towards the jejunum. It is of interest that "familial" occurrence is common. He felt that the porcine and human alseases are probably identical, but was unable to throw any further light on the 
aetiology. Swine have also interested rheumatologists in that the polyarthritis associated with infection with erysipelothrix rhusiopathiae bears, in 1ts duronic form, many similarities to rheumatoid arthritis, even to the extent of having a positive sheep cell agglutination test. Unfortunately, gut involvement by this organism is not recorded (sikes, 1961).

The association of both Crohn's disease and ulcerative colitis with dysentery, particularly bacillary dysentery, has provided several years of controversy. The chief protagonist of the theory that Crohn's disease is a sequel to bacillary dysentery was Felson who stated unequivocally that "all colitis and ileitis is due to bacillary dysentery" (Felsen 1936). His material was based on long term followup of the 1933 Jersey City bacillary dysentery epidemic, although some of the criteria used in the paper, particularly the agglutination titres, are open to criticism. Although dysentery ma be clinically manifested by no more than a transient bout of mild diarrhoea, thereby rendering it almost impossible to prove that a patient has never had dysentery (British Medical Journal, 1960B), the two cases reported by Crohn and runich (1941) from whom flexner organisms had been isolated remain the only examples in which even this amount of evidence for dysenteric infection has been found in Crohn's series of more than 700 cases. Macisie (1938) suggested that 5 per cent of cases of becillary dysentery developed into a chronic colitis-like disease and Bisgard and Henske (1937) published a case report which they suggested supported the theory of bacillary causation 
of Crohn's aisease in that "dysentery bacilli" were cultured from the urine and from one kidney of their single case. Since the same patient also yielded B Coli. B mucosus capsulatus, B pyocyaneous and staph. aureus, the presence of their unspectfied dysenteric organism can hardly be held to be convincing. Brown and Bargen (1938) in a good review of the relationship of bacillary dysentery to ulcerative colitis in particular, although crohn's disease is mentioned in passing in the text, found the literature on the subject unconvincing, particulariy in view of the enormous world-wide prevalence of bacillary dysentery compared with comparative rarity of Crohn's disease and ulcerative colitis. They followed 140 cases from a single epidemic and only one developed a colitic type picture which was throughout its course atypical. and which went into remission following hysterectomy. Bargen (1938) also found no greater evidence of previous dysentery in his patients with Crohn's disease than in those with intestinal neoplasms or irritable colon syndrome. Acheson (1959A) found an inverse relationship between the mortality patterns of colitis and dysentery, and concluded that the diseases were not inter-related.

other infections have received less attention, although this is surprising in the case of fungal infection, which may closely resemble crohn's disease histologically (Refvum, 1958). Lymphogranuloma venereum may also produce granulomatous intestinal lesions, although these are rarely as high as the ileum (Rodaniche, Kirsner and Palmer, 1943) and investigations using the Frei test have 
been persistently negative in Crohn's disease (Koster, Kashman and Sheinfeld, 1936).

Radiation enteritis may be associated with both stenotic lesions in the gut and fistulae between different segments of bowel and other organs such as vagina and bladder. Although such disease has been reported following radiation dosage within the therapeutic range, it nearly always follows overdosage and has a history in no wey similar to Crohn's disease (Tankel, Clark and Iee, 1965). Blunt trauma to the abdomen may, however, precipitate either diagnosis of Crohn's disease or an exacerbation of 1 t. Crohn was able to find 6 cases following abdominal trauma in the literature, and contributed 11 from his own series. Although trauma may be significant in some small proportion of cases, it seems unlikely that its influence is very large.

The contribution of the intestinal contents to the development of Crohn's disease has been a fleld of wideranging research for many years. Groner (1960) dismissed gastro-intestinal acidity as a contributory cause, but Chess and his colleagues (Chess, Chess, Olander, Benner and Cole, 1950) were able to produce granulomatous lesions maximal in the terminal 1 leum in dogs and rats by feeding them finely divided silicone. They suggested that chronic ingestion of crystalline material in man could be the cause of similar lesions, but apart from the spectfic, but uncommon, ingestion of beryllium by fluorescent tube manufacturers they were able to offer only abrasive tooth powders as a possible source of such material. Coffey 
(1538) described crystal or lipoid particles, which he thought might be food remnants, in many of the giant cells found in Crohn's disease, but was unsure of their significance or precise composition.

Interference with intestinal blood supply does not cause the pathological changes of Crohn's disease (Bell, 1934) but could possibly be a source of cellular modification leading to immological reactions. It has been suggested that some local inmunological injury is a prerequisit to development of an immune diseese in the gastrointestinal tract (Koffler, Minkowitz, Rothman and Garlock, 1962) although auto-inmunity or auto-aggression, is still considered a likely cause of both colitis and Crohn's disease by some authorities (De Dombal, Burch and Watkinson, 1969; Burch, De Dombal and Watkinson, 1969). In general, few immunological differences are found between ulcerative colitis and Crohn's disease (Lancet 1970A) which possibly suggests that the detected abnormalities are responses to the diseases rather than causes of them. Psychological factors are often quoted as being of relevance to both initiation and exacerbation of Crahn's disease (Almy, 1952). Both case reports (Brown and sims, 1954) and series (Paulley, 1950) have been published extolling the relevance of psychiatric factors in Crohn's disease, and theories embodying such concepts as the role of the dominant Jewish mother have been advanced (Paulley. 1948). The prime problem in all psychiatric investigations is a knowledge of the findings in a normal population, and where this has been taken into account the differences 
between the patients with bowel disease and a population drawn from general practice was insignificant (Goldberg, 1970, Goldberg and Blackwell, 1970). Similarly, studies in which rigid criteria are laid down tend to minimise the contribution of psychiatric factors. An example of this is the Leeds study of the 34 cases described by Armitage and wilson (1950), who had a parallel psychiatric assessment from which no support could be elicited for the idea that crohn's disease is caused by a psychiatric upset, (Crockett, 1952).

Crohn's disease appears to spare no ethnic group, but the proportional distribution amongst races still causes controversy. The association with the Jewish race is often held to be so close that the presentation of a Jew with intestinal symptoms biases the diagnosis towards Crohn's disease (New England Journal of Medicine, 1963). Several of the families described containing several members with Crohn's disease have been Jewish (Brown and Scheifley, 1939; Kirsner, Owens and Humphreys; 1948; Sherlock, Bell, Steinberg and AImy, 1963). This fact may be ascribed to their race, particularly where the co-incidence of another uncommon disease, glucose-6-phosphate dehydrogenase deficiency, is found inherited in the same population and to an unexpectedly large extent in the patients (sheehan, Necheles, Lindeman, Meyer and Patterson, 1967) or the common environment produced in close racial groups during early life (Freysz, Haemmerli and Kartagener, 1968). Two reviews of this subject have been undertaken. Boyce (1958) described 29 cases of Crohn's disease in negroes and 
analysed the literature of the previous 10 years, studying reports of 3487 cases in 116 articles. Race was mentioned in 840 cases only, of whom 25 were negroes. Despite the slimness of this evidence, the author speculated that Crohn's disease was probably disproportionately uncormon in negroes. A similar conclusion was drawn by Acheson (1960A) who studied the records of 2,320 male veterans and found a disproportionately low number of negroes, the figures being corrected for the population studied, and a four-fold excess of Jews. In analysing the literature he considered that some of the high figures previously reported could be accounted for by their origin from Jewish foundations. He was unable to analyse the proportions of Ashkenazie and Sephardic Jews in his population or in the 1iterature. Desplte this apparent consensus, the only study including race in a local (Leeds) population contained only one Jew in 34 patients despite 10 per cent of the population being Jewish (Armitage and Wilson, 1950). Familial coincidence of patients produces large numbers of descriptive papers which often contribute little but colloquial evidence to a proper assessment of the proportion of such families in the population, tending to exaggerate their importance. Some interesting curiosities do occur, however, such as Crohn's recollection that the first patient with regional lieitis on whom he operated had a sister who subsequently came to surgery for the same condition (Crohn, 1955). An early case report of a single patient with Crohn's disease (Bockus and Lee, 1935) was followed more than 20 years later by the case report of 
similar disease in her son (Betzger and Frobese, 1956). Critical review is necessary in dealing with case reports, as the author's enthusiasm may allow reporting of cases which do not fall within the strict criteria needed for the diagnosis of Crohn's disease, or the presence of the disease may be a piece of conjecture. Thus Heard and John (1956) guote histological evidence for one of the two patients they describe, but the clinical and operative findings in the second support a diagnosis of acute ileitis associated with a Meckels diverticulum rather than that of Crohn's disease. It must be allowed, however, that family clusters of Crohn's disease occur more conmonly than would be expected from the population prevelance of 9 per 100,000 (Acheson, 1965). Kirsner, Owens and Humphreys (1948) reviewed the ilterature available to them and concluded that family clustering was rare. They presented two case reports of a father and son, and added an interesting family contributed to them by Dr. H. Reich (Fig. II-1). Steigman and shapiro (1961) described 6 cases of Crohn's disease in two family groups while Houghton and waish (1958) considered both Crohn's disease and ulcerative colitis in their literature review which accompanied a description of 7 families of their own. They attempted to estimate the population incidence by the relatively crude method of assuming that one quarter of the patients with colitis or enteritis would be seen in hospital during a period of three years, and calculating the incidence as 4 times the number of people diagnosed in hospital in a three year period divided into the draining 
Fig. II -1

An example of familial aggregation

of intestinal disease. 
Fig II-1

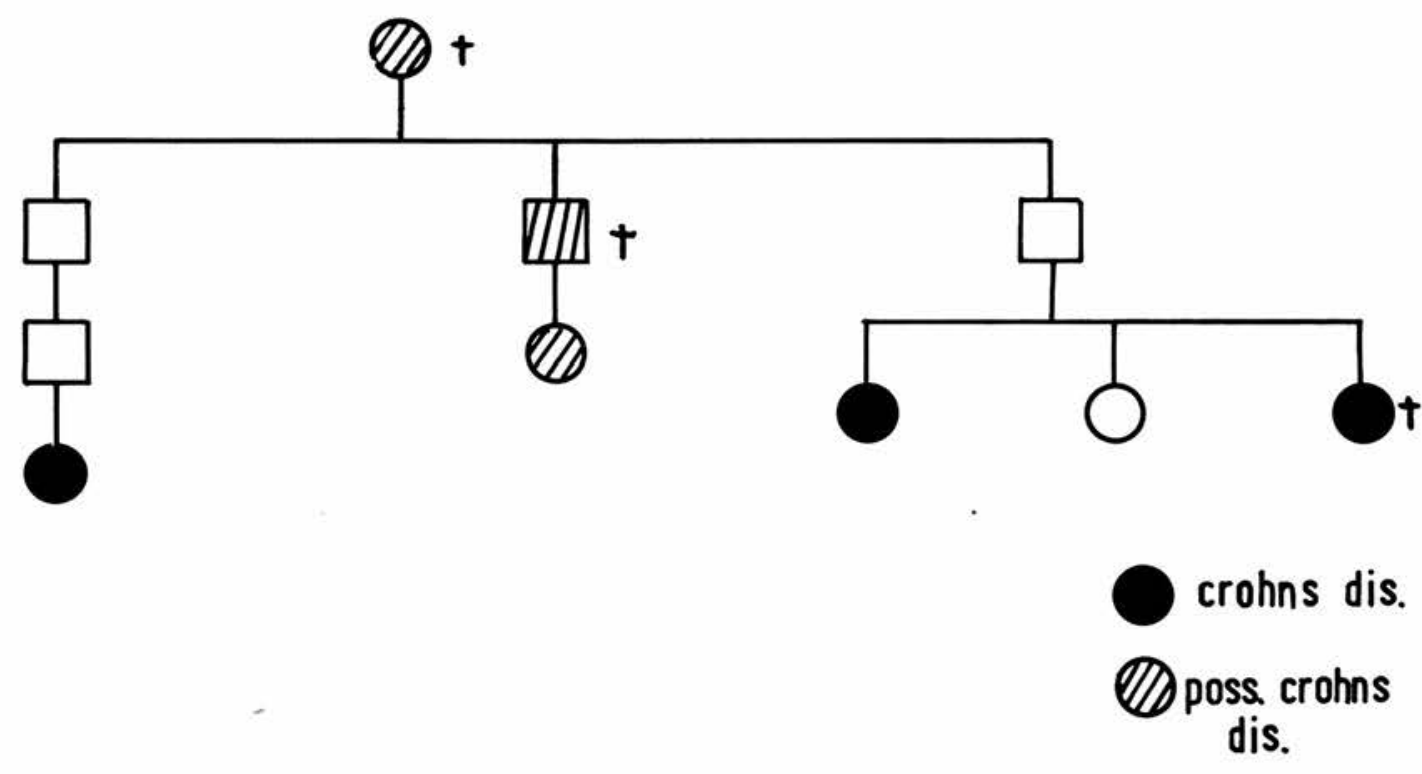

An example of familial aggregation of intestinal disease.

Modified from Kirsner et al (1948) 
population. Using this method, they arrived at a prevalence of 0.85 per 1000 for ulcerative colitis and 0.14 per 1000 for Crohn's disease. By using these figures they calculated that their patients exhibited disproportionate familial aggregation. A slightly lower prevalence was calculated in the oxford region, the overall cumulative prevalence being $9.0 \pm 1.4$ per 100,000. The disease was slightly more common in women $(9.8 \pm 2.5$ per $100,000)$ than men $(8.2 \pm 2.4$ per 100,000$)$ but the incidence rate approximated to 0.8 per 100,000 per year for both sexes (Bvans and Acheson, 1965). Sherlock and his colleagues (Sherlock, Bell, Steinberg and Almy, 1953) reviewed the subject and found 50 instances in which more than one family momber suffered from Crohn's disease. Unfortunately, the many personal commications prevent real critical analysis, but the authors own family of Ashkanazie Jews is well documented and serves to illustrate the association of Crohn's disease with other conditions (Fig II-2). Hinton (1968) found 9 patients suffering from unspecified inflamatory bowel disease in 624 living 'close' relatives of 145 patients with Crohn's disease, which was more than 100 times the prevalence expected.

Support for a genetic tendency to crohn's disease is provided by the review of twins with the disease (Hislop and Grout, 1969) which yielded four pairs of monozygotic twins who were both affected, but only one pair with one twin only affected. There was also marked parallelism in clinical presentation, age at onset and pathological site of the disease in all these cases. While the idea that 
Fig. II - 2 .

pedigree of a family showing members with regional enteritis, ulcerative colitis and associated conditions. 


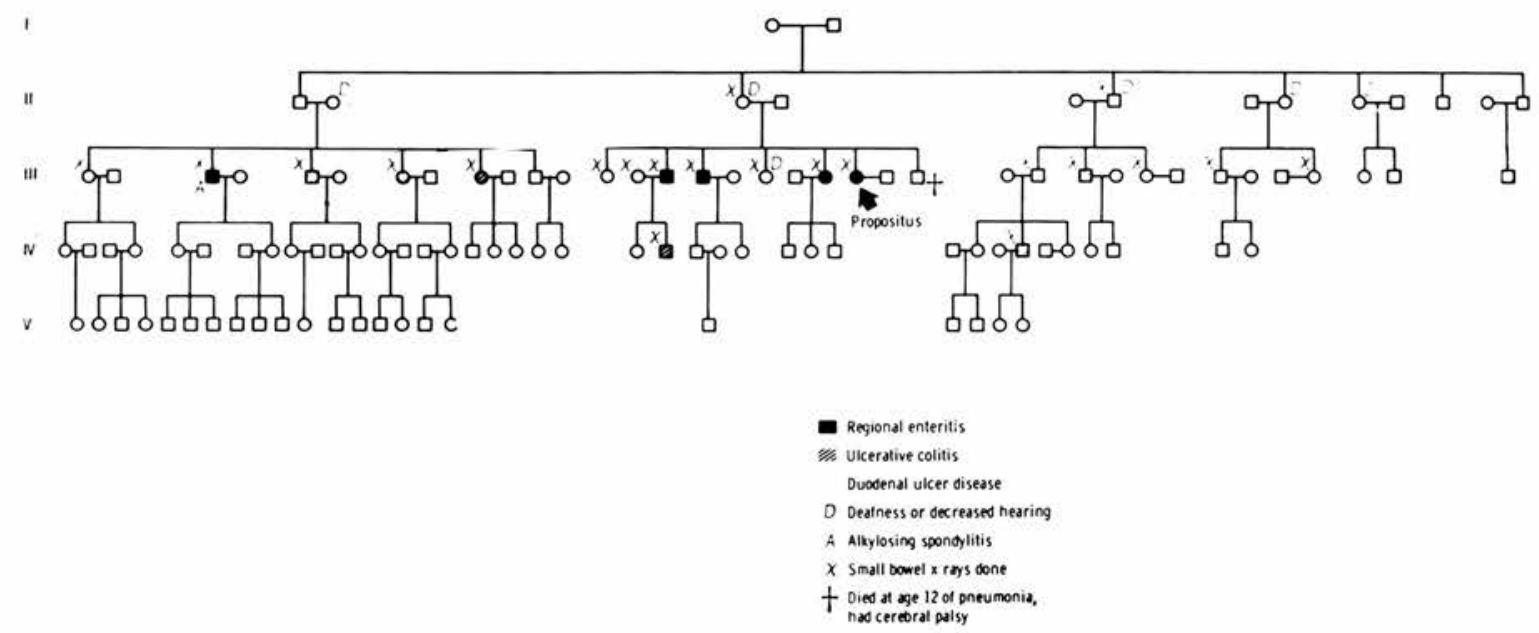
conditions.

Pedigree of family showing members with regional enteritis, ulcerative colitis and associated 
distant environmental factors may be responsible for crohn's disease cannot be disproved, there is no evidence that recent factors can actually initiate the disease, apart from the few cases of severe trauma previously mentioned, and in particular it is noteable that no spouse with Crohn's disease has been reported. It must be allowed, however, that recent environmental factors may precipitate clinical onset of the disease in patients with a pre-existing genetic tendency (Gelfland and krone, 1970).

\section{Associated Diseases.}

\subsection{Miscellaneous.}

Excluding arthritis and those conditions which are considered as complications of crohn's disease which have already been reviewed there are few comments available regarding the association of Crohn's disease with other conditions, The proposed association with dysentery has already been discussed. A possible assoclation with Whipplets disease has been proposed by Avery Jones and Paulley (1949) who point out that "if in place of the fat filled lymphatics in whipple's disease lymphoedema is substituted, the histology is not very unlike that found in Crohn's disease". They suggested that Whipple's disease is a variant of jejunitis and speculate that the later pattern of age incidence in the former disease, which has a peak incidence about 15 years later than Crohn's jejunitis, reflects a chronic process arising on the basis of the latter condition. An association between cuteneous polyarteritis and crohn's disease has been reported, but only four cases have been described (Dyer, Verbon, Dawson 
Barrie and stansfield, 1970). An increased incidence of psoriasis has also been claimed (Wright, 1964). The most comprehensive study of this aspect of Crohn's disease is that of Hanmer, Ashurst and Naish (1968) whose study of diseases associated with colitis and Crohn's disease revealed, in comparison with a control group, an increased incidence of eczema, polyarthritis and hay fever in both the propositi with Crohn's lisease and their relatives, and an increased incidence of psoriasis in the relatives.

\subsection{Ulcerative colitis.}

The clinical and histological similarities between Crohn's disease and ulcerative colitis have already been discussed. There is no doubt, however, that the two conditions may co-exist both in patients and in families (Porritt, Hunt and Morgan, 1960; wherlock, Bell, Steinberg and A.Imy. 1963). Presence of both diseases in one patient is undoubtedly rare (Lockhart-Mumery and Morson, 1960) and can only be convincingly diagnosed where expert histological interpretation is available. Modern histological concepts might exclude the double diagnosis In some of the early cases (Hirschmann, 1932). Familial coincidence is more clearly recognised, the large family iliustrated earlier (IIg. II-2) being a classical example. It is of great interest, however, that McConnell (1968) discovered as a result of an extensive study of the genetics of these two donditions that the index case in families With both diseases almost invariably suffered from Crohn's disease. He explored the reasons for a coincidence between the two conditions and suggested the following 
possible explanations:-

(1) That they are the seme disease with the same genetic besis and the same environmental factors. This seems very unlikely in view of the clinicopathological differences between the diseases. (2) That there are similar causative environmental factors, hence the family aggregation, but that the different pathological manifestations are found in patients with different genotypes. Against this is the problem of different worldwide distribution of the two diseases. (3) Different environmental factors lead to different pathology, but the two polygenic systems which determine liability to the two diseases may have a number of genes in common. This could result in the relatives of patients with one disease having an increased liability to develop the other as compared with the general population. MeConnell favours this last theory, and feels that the association of both conditions with ankylosing spondylitis is further evidence in its favour.

The extent of the association between colitis and Crohn's disease remains a matter of dispute, and the problem inherent in attempting to diagnose idiopathic ulcerative colltis from the history of a relative have been highlighted recently (Macrae and Wright, 1970). The same strictures apply to literature reviews, and the 3.1 per cent familial incidence of colitis and Crohn's disease reported by Felsen and Wolarsky (1955) must be accepted with caution, especlally as quite extensive family reviews, such as the Scandinavtan study of 152 patients with ulcerative colltis and their relatives, have failed to show 
any association between the two diseases (Binder, Weeke, Olsen, Anthontsen and Rils, 1966).

In sunwary, therefore, the association of Crohn's disease and colitis in families has been demonstrated too frecuentiy to be coincidental, but the exact frequency is unknown. It is interesting to speculate that where the association appears to be strong, ankylosing spondylitis tends to be described as a further coincidental disease in these families.

\section{3 sarcoldosis.}

Before discussing the association between Crohn's disease and sarcoidosis it is germane to define the latter condition. The currently accepted definition is that proposed by the International Conference on Sarcoidosis at Washington D.C. In 1960 which 1s:- 'Sarcoldosis is a systemic granulomatous disease of undeternined aetiology and pathogenesis. Mediastinal and peripheral lymph nodes, lungs, liver, spleen, skin, eyes, phalangeal bones and parotid glands are most often involved, but other organs or tissues may be affected. The kveim reaction is frequently positive and tuberculin-type hypersensltivities are frequently depressed. Other important laboratory findings are hrpercalcuria and increased serum globulins. The characteristic histologic appearances of epithelioid tubercles with little or no necrosis is not pathognemonic and tuberculosis, fungal infections, beryllium disease and local sarcold reactions must be excluded. The diagnosis should be regarded as established for clinical purposes in patients who have constant clinical features, together 
with biopsy evidence of epithelioid tubercles or a positive Kveim test'.

The point is well made in this definition that the presence of a sarcoid reaction in a potient does not of necessity mean that the patient suffers from sercoidosis. As the causes of sarcoid granulomata can vary from cat scratch fever to farmers lung and include such different entities as primary biliary cirrhosis, beryllium or zircontum disease and hypogarmaglobulinaemia (James, 1967) the importance of this distinction is obvious. All controversy on this subject has not arisen from ignorance, however, although the interpretation of the histology of regional enteritis as sarcoidosis does occur in some papers (Spellberg and Jackson, 1950). Clinically there appears to be a clear distinction between the two conditions, particulariy in that sarcoidosis rarely affects the gut. Cases of 'sercoldosis' in the gut (Watson, Rigler, Wangensteen and Mocartney, 1945) are often, on close study, indistinguishable from Crohn's disease and unassociated with other features of generalised sarcoldosis. Longcope and Freiman (1952) in a scholarly review of sarcoidosis stated, "Ihe intestinal tract, though rich in Iymphoid tissue, is very rarely the seat of sarcoidosis, and the ouestion always arises in the reported cases as to whether the lestons described may not have been caused by some other agent". Thetr own necropsies revealed no gut sarcoidosis, and the excess incidence in negroes also contrasts with crohn's aisease. Lorber, shay and Wolowin (1954) examined the gastro-intestinal tract 
radiographically in 21 patients with proven sarcoidosis. They found no evidence of gut involvement. In reviewing more than 100 necropsies reported in the ifterature, they found only 8 examples of gastro-intestinal involvement, 4 of thom had proven tuberculosis while the other 4 had syphillis. Of the 9 patients wth "localised sarcoid" reported in the stomach, only 2 had lesions elsewhere. The authors' conclusion was 'Localised lesions associated with chronic inflamatory alsease of the gastro-intestinal tract (peptic ulceration, pyloric obstruction, regional enteritis and Whipple's disease) and their draining Iymph nodes may develop the histological characteristics of the hard tubercle of sercold. These non-specific localised granulomatous reactions must be differentiated from the disease ent1ty referred to as disseminated sarcoidosis". The affection of the perineal region, a cormon site for diagnost1c biopsy, by Crohn's disease (Mountain, 1970) also contrasts with its non-involvement in sarcoidosis (Israel, 1970).

The virtual unenimity of opinion regarding the lack of identity between Crohn's disease and sarcoidosis also extended to studies of their aetiological relationship, 1.e. for evidence of generalised sarcoidosis in patients with established crohn's disease. A pre-war report from London (Blackburn, Hadfield and Hunt, 1939) specifically excluded sarcoidosis as an aetiological factor in Crohn's disease, though the criteria used are open to question, one being the fact that 'No case gave a history of swelling of the fingers or toes". phear (1958) found no evidence 
of sarcoidosis in the 40 patients with Crohn's disease in whom he sought it. He did find, however, that oniy 29 per cent showed a positive reaction to 10 units of old tuberculin, and there is now some evidence that this might be a significant observation.

There are two skin tests wich may be used diagnostically in sarcoidosis, the tuberculin test, which is usually negative, and the Kveim test, which, if well validated material is used, and the test site biopsied irrespective of the presence of a clinically apperent reaction (Drury, 1970) gives a positive response in 72 per cent of patients with sarcoidosis (Mikhail and Mitchell, 1970). The presence of similar diagnostic reactions to the injection of an appropriate antigen in other granulomatous conditions, such as leprosy, led some workers to attempt to devise a skin test for Crohn's disease. Saunders (1964) prepared antigen from the regional lymph nodes of a patient with Crohn's disease while Jones-ivilliams (1965) used both skin tests and precipitin reactions with extracts of Croinn's disease tissue. Neither worker produced positive reactions. The application of tuberculin tests to patients with Crohn's disease has a long history, initially being used as a differential diagnostic procedure then tuberculous aetiology was suggested. Jones-Williams (1965), however, suggested an unusually low incidence of positive tuberculin tests occurred in patients with histologically demonstrated granulomata as part of their Crohn's lesion. While other workers using carefully controlled studies found no difference in tuberculin sensitivity betwoen patients with 
Crohn's disease and controls (Fletcher and Hinton, 1967), investigations continued into the delayed hypersensitivity mechanisms in Crohn's disease, using dinitrochlorobenzene (DNCB) which is a potent chemical antigen. The ability to develop sensitivity to DNCB was abolished in 15 of 26 patients with Crohn's disease, compared with complete sensitivity in a control group, and of the 15 DNCB negative patients, 10 were also unable to develop delayed hypersensitivity to $100 \mathrm{~T} . \mathrm{U}$. of old tuberculin. of the 11 DNCB positive patients, 4 were tuberculin negative (VernierJones, Housley, Ashurst and Hawkins, 1969). This paradox of reduced delayed hypersensitivity to new antigens while presenting the histological features of delayed hypersensitivity as part of the disease is shared by Crohn's disease and sarcoidosis. It was postulated that the delayed hypersensitivity to DNCB was a result of competition for delayed hypersensitivity cells between the new antigen and the, as yet unknown, causative antigen of the disease. Such competitive suppression of delayed hypersensitivity reactions can be seen in the conversion of Mantoux positive individuals to Mantoux negative during the course of infectious hepatitis or glandular fever. Hence an explanation of the immunological abnormalities of both Crohn's disease and sarcoidosis was produced, explaining them as "an exuberent reaction to an unknown antigen rather than as the indolent response of an anergic individual" (VernierJones, 1968).

The investigation of kveim sensitivity in Crohn's disease has been described as a logical development of the 
theme of abnormalities of delayed hypersensitivity as described above (Lancet 1970B). In fact it is nearly 20 years since Crohn first published a personal communication from Dr. L.E. Siltzbach, whose name is often associated with the Kveim test, suggesting that patients with crohn's disease were Kveim negative. Iwenty years earlier, and some six years before Kveim (1941) described the test now associated with his name, Williams and Nickerson (1935) used a similar technicgue and showed positive skin tests in 4 patients with sarcoidosis while four controls were negative. Examination of their case reports, however shows that one patient was a young adult female who had had $23 \mathrm{~cm}$. of 1 leum and colon resected, the specimen showing thickening of the intestinal wall in the region of the 1leocaecal valve and the diagnosis of sarcoidosis being 'confirmed' by the histological recognition of sarcoid nodules. There had until recently been little formal consideration of the Kveim test in Crohn's disease, JonesWilliams (1963) finding such tests to be uniformly negative. Interest has, however, recent $1 \mathrm{y}$ been re-awakened by the work of Mitchell and his colleagues who, using the same antigen as Jones-Williams, but a larger dose $10.2 \mathrm{ml}$. instead of $0.1 \mathrm{~m} 1$ ) found 50 per cent of their patients with Crohn's disease to have a positive Kveim test (Mitchell, Cannon, Dyer, Hinson and Willoughby, 1969, 1970). The same group have also recently demonstrated that injection of an homogenate of sarcoid material into the footpads of mice produced, after a latent period of about 6 to 8 months, similar granulomata at the injection site in a proportion 
of the animals. This reaction was not found in control

animals, and was identical in normal and immunological deficient mice. Kvelm testing of the animals yielded positive results in about one-third of those who developed granulomata, but none of those who did show this reaction (Mitchell and Rees, 1969, 1970B). The logical extension of this work was to repeat it using Crohn's material, and this has been done with similar results (Mitchell and Rees, 1970A). Homogenates were prepared from a crohn's Iymph node and gut material and injection provoked granulomata evolving to their fullest in 6-24 months. Non-Crohn's lymph node homogenates produced no such reaction. Once again, a proportion of the granuloma-forming animals, though none of the controls, developed positive Kveim tests. This series of papers, all of which describe carefully controlled observations, raises very strongly the possibility that Crohn's disease and sarcoldosis are associated, and also that they may be transmissable by some as yet unidentified infective agent (Mackregor, 1970). The long latent period between injection of the homogenates and full development of the granulomata raise the possibility of an influence in early life being the cause of a disease process which does not reach fruition for many years either through natural evolutionor the addition of a further precipitating factor. At least some of the available evidence about racial familial and environmental factors in the aetiology of Crohn's disease could be anassed into such an hypothesis. 14. Aetiology of the Arthritides.

The previous two chapters have discussed in some detail 
the aetiology of Crohn's disease and its association with other conditions. These matters have been explored in order to provide a background for discussion of the aetiology of the arthritis associated with Crohn's disease. Such a prearable is necessary as the arthritides associated with it mast be double unknowns i.e. conditions of unienown aetiology associated with a disease of unknown aetiology. The subject is best approached by attermpting to answer three cuestions:-

1. Are any of the aetiological factors of significance to crohn's disease associated with arthritis?

2. What is known of the aetiology of the specific arthritides associated with Crohn's disease?

3. Is there a special relationship between the gut and the joints?

Several of the infections mentioned in the aetiology of Crohn's disease may be associated with joint manifestations. Post-infective arthritis characteristically occurs 5 to 14 days after the onset of the gut symptoms and affects large joints more frequently than small (Berglof, 1963). This type of arthritis has been described with a large variety of organisms but appears to be most frecuently associated with Salmonella (Saphra and Winter, 1957) either as a distinct entity or secondary to osteomyelitis involving the juxta - articular bones (David and Black, 1960). While osteoryelitis does occur in the course of Crohn's disease (Goldstein, Nasr, Singer, Anderson and Kirsner, 1969) it is an extreme rarity, and has never been reported in association with arthritis. Usually the infectious basis 
is clearly defined, and the syrutoms do not recur after control of the infection. This contrasts with the intermittent chronicity of Crohn's synovitis, and unless Felsen's now discredited concept of chronic dysentery leading to Crohn's disease is accepted the comparison of an acute complication of a well recognised, positivaly diagnosed disease with an intermittent complication of an idiopathic disease does not stand close examination.

With the exception of the rare occurrence of familial clubbing, the only musculoskeletal disorder associated with Crohn's disease in which there is a strong hereditary component is ankylosing spondylit1s. Certain populations, such as the Canadian Indians, have a high incidence of the disease, but the Incidence of Crohn's disease is not reportedly high (Gofton, Robinson and Trueman, 1966). Less speciallsed populations, however, still show evidence of marked femilial aggregation of the disease. Hersh and his colleagues concluded from consideration of the 69 families with multiple involvement with ankylosing spondylitis found in a review of the literature and their own study of the families of 50 spondylitics, that the inheritance was as a Mendelian dominant with a 70 per cent penetrance in men and a 10 per cent penetrance in women (Hersh, Stecker, Solomon, Wolpaw and Hauser, 1950). The same authors reiterated this conclusion after a more extensive examination of a control population (stecker and Hersh, (1955). This explanation proved unacceptable to Graham and Uchida (1957) who reported a large family with a pattern of simple autosomal dominant inheritance. They 
suggested from their own consideration of published

families that in sibships containing at least one affected female, the penetrance was equal for both sexes, and that familial aggregation negated the male predominance found in sporadic cases. The Heberden oration in 1963 (Kellgren 1964) was devoted to the epidemiology of the rheumatic diseases, and was an excellent distillation of the knowledge of the time. The population incidence of ankylosing spondylitis as 0.11 per cent was derived from a total experience of 20,294 people, while the incidence in relatives of spondylitics was 1.99 per cent (of 4621) and in their siblings was 4 per cent (of 2350).

The population incidence cuoted by sharp (1968) sets a slightly higher figure at 4 per 1000 adult men. A family study with probands centred in Nanchester, in which the first degree relatives of 76 spondylitics were studied, found 7 per cent could be diagnosed by the New York C.I.O. M.S. criteria as having ankylosing spondylitis and 16 per cent bilateral sacro-iliftis. The heritability of ankylosing spondylitis was calculated on the basis of the prevalence of spondylitis in their families as $70.0 \pm 9.3$ per cent, whereas that based on the prevalence of sacroiliitis was $72.5 \pm 10.2$ per cent. This suggested a strong hereditary tendency in ankylosing spondylitis (Bremner. Enery, Kellgren, Lawrence and Roth, 1968).

Significant differences have also been demonstrated in the incidence of sacro-ilittis between various populations (Gofton, Lawrence, Bennett and Burch, 1966) and the differences were suggested by the investigators as being 
"almost certainly" attributable to sacro-ilitis characteristic of, and hence probably due to, ankylosing spondylitis (Gofton, Lawrence, Bennett and Burch, 1968). The one alternative mentioned was an increased incidence in sacro-ilittis where the water supply has a high fluoride content. This is unlikely to be of general significance, and is certainly not so in the Leeds region, where the fluoride content (Table II-4) is within the limits previously accepted as of insignificant aetiological signifance in sheumatic diseases (Ansell and Lawsence, 1965).

\begin{tabular}{|lc|}
\hline \multicolumn{2}{|c|}{ TABLI II-4 } \\
\hline Leeds & 0.03 p.p.m. \\
Bradford & 0.1 p.p.m. \\
Halifax & 0.1 p.p.m. \\
Harrogate & 0.1 p.p.m. \\
Huddersfield & 1.0 p.p.m. \\
Wakefield & 0.1 p.p.m. \\
\hline \multicolumn{2}{|c|}{ Fluoride content of water supplies in the } \\
& survey area. \\
\hline
\end{tabular}

Thus, both Crohn's disease and ankylosing spondylitis show hereditary factors, but there is at present no study avallable which allows conclusions to be drawn as to whether the heredity of the two diseases is intermingled.

Discussion in Chapter 13.3 showed that the association between Crohn's disease and sarcoidosis is undergoing reevaluation at this time. Articular complications are well recognised in sarcoidosis, and were classifled by scadding 
(1967) as -

1. Febrile arthropathy with early bilateral hilar adenopathy.

2. Recurrent febrile arthropathy, sometimes with erythema nodosum.

3. Joint changes accompanying bone involvement.

4. Chronic joint changes with sarcoid granulomata in the synovium.

5. All others are coincidental.

The incidence of the various sarcoid arthropathies is open to question, as hospital case records show a much higher incidence than that found in a prospective study of 54,239 children. of 52 who developed sarcoidosis, only three suffered joint pains (British Medical Journal, 1967). The presence of hilar lymphadenopathy may be of diagnostic value where an acute febrile arthropathy occurs, but the combination of erythema nodosum and arthropathy is a common one and may be associated with many diseases, sarcoidosis and Crohn's disease being among them. This association represents one of the few clinical linis between the two diseases. Bone involvement is said to occur in one-sixth of patients with sarcoidosis, but the well defined radiological changes contrast with the absence of $x$-ray changes In the arthritis associated with Crohn's disease (Pygott, 1970). The chronic granulomatous arthritis is readily distinguished at biopsy (Bianchi and reech, 1964) and similar appearances have not been described in Crohn's disease. It seems, therefore, that apart from the occurrence of erythema nodosum syndrome in the two 
conditions, the articular manifestations of Croinn's disease and sarcoidosis do not provide evidence of a link between the two conditions.

Although the link between Crohn's disease and psoriasis is less well documented, there is some evidence available that at least indirect linkage may occur between the two conditions. Occasional reference is made to the presence of psoriasis in patients with Crohn's disease (Ansell and Wigley, 1964) but no systematic study of the association between crohn's disease, psoriasis and arthritis is available. While typical psoriatic arthritis is associated with radiological evidence of joint involvement, in contrast with the absence of such changes in Crohn's synovitis, both conditions may be associated with spondylitis, and the linkage of the conditions may occur through this form of the disease. This linkage is embodied within the concept which the author has entitled "Seronegative spondarthritis" which is discussed in greater detail in Appendix C.

The second question posed was "What is known of the aetiology of the specific arthritides associated with Crohn's disease?". With respect to the synovitis, the available evidence is small. As has been previously mentioned, many writers on this subject assume, without evidence, an identity of this synovitis with that of ulcerative colitis, but until evidence of this association is forthcoming this identity will not be assumed here. Most, though not all, authors have seen exacerbations of the synovitis in association with exacerbations in the 
bowel symptoms (Van Patter, Bargen, Dockerty, FeIdman, Mayo and Waugh, 1954, Ansell and Wigley, 1964) which might suggest either toxic absorption or possibly an abnormality in the antigen - antibody mechanism wherein a sudden excess of antigen is released into the circulation resulting in antigen-antibody complexes being formed, causing a synovitis. A 'model' of this condition is seen in serum siclness in which the characteristic synovitis develops during this time of antigen excess (Payne and Wright, 1971). The absence of clinical evidence of an intestinal exacerbation associated with an attack of synovitis does not of necessity mean that the disease process within the gut is quiescent. Although correlation of clinical and radiological signs of improvement in the disease have been demonstrated (Hywel Jones, Lennard-Jones and Young, 1969) there may be radiologically demonstrable extension of the intestinal involvement during periods of clinical remission (Brahme and Wenchert, 1970).

Ankylosing spondylitis has been the subject of a number of aetiological investigations which have arrived at conclusions about association of this disease with others rather than true aetiological factors. It is probably significant that all the conditions associated with ankylosing spondylitis either have an infectious cause or are associated with an increased incidence of infection during their course. Although reports of spinal involvement precipitated by organisms such as entamoeba histolytica occasionally occur (Oppenheimer, 1938), the classic infectious cause of spondylitis is 
brucellosis. Direct infection of the lumbar spine was described essactly one months after Crohn's original description of terminal ilietis (kulowski and Vinke, 1932) and ten years later spondylitis was clalmed as "the most comon disorder of bones and joints referable to undulant fever" (Fhaien, Priclunan and Krusen, 1942). The similarity with ankylosing spondylitis is enhanced by the frequent association of sacro-iliitis, called "melitococcic sacroilitis" by Rotes - Querol (1957), but this is demonstrably of a suppurative nature as are the spinal lesions. Thus destructive changes tend to be more prominent and sclerosis less so, which may be used to differentiate the condition from ldiopathic ankylosing spondylitis (Steinberg, 1948). Healing may take place by ankylosis, however, in wilch case retrospective diagnosis could be more difficult. The only support for the idea that brucella infection was of significance in 'idiopathic ankylosing spondylitis' was the study of 18 such spondylitics by Goldfein (1943) who undertook skin, agglutination and opsonic index tests for brucellosis. The valiaity of some of the methods used is now questionable, but even if the tests are accepted at face value, the absence of control data from an area in which brucella was endemic detracts seriously from the conclusion of a causarive relationship between the two conditions which the author made. It must be concluded that, although brucellosis can cause both intestinal and osteoarticular, particularly spinal, disease, these can be distinguished quite readily from both crohn's disease and idiopathic 
enkylosing spondylitis.

Intestinal infection and spondylitis may a.lso bo connected through 'Reiter's syndrome', which occurs in association with both post-dysentery and non-spectific urethritis, These are considered to be identical (Ford, 1970). The most extensive survey published is that of Paronen (1948) who studied 344 cases all of whom had the post-dysenteric form of the disease. His description of peripheral joint involvement is of interest in that the distribution was very similar to that of other intestinal arthritides, with lower limbs predominating over upper and large joints over mall. It wes also typical in that complete recovery occurred in the vast majority, although occesional examples of chronic synovial thickening were seen. Differences from Crohn's disease included the development of radiological changes in some affected. joints, and the rarity of recurrent episodes. Although sacro-iliac or back pain does occur in many patients during the acute period, the radiological changes may evolve slowly over a period of years. The development of the picture of ankylosing spondylitis may take several more years (Good, 1965). British writers experience has been nore concerned with the form of Reiter's disease associated with non-specific urethritis and it is in part from this work that considerations of infection in the aetiology of ankylosing spondylitis have grown.

The genital tract has long been considered the site of ingress of infection leading to ankylosing spondylitis, Marie (1898) and other 19th century physicians considering 
It to be a complication of gonorrhoea. While gonococcal infection is now discounted as a cause of spondylitis, genital infection is still considered a probable precipitating cause by many authors (Romanus and Yden, 1955, Mason, Murray, Oates and Young, 1958) although no organisms have been grown consistently (Ford, 1960) even where prostatic massage showed signs of inflammation by an Increased number of white cells in the prostatic fluid (Horvath and wohlstein, 1966). The association of genital infection with spondylitis is now generally accepted, but a causal relationship has not been firmly established (British Medical Journal, 1960A). The sacroiliitis and paravertebral ossification associated with paraplegia is often claimed as an additional piece of evidence for the seductive hypothesis of a causal relationship between pelvic infection and spondylitis but the study of Wright, Catterall and Cook (1965) suggested that the sacroiliac joint changes were appreciably different in these patients and were more likely to be due to mechanical stress than infection.

If pelvic infection is significant, what is the mode of spread to the spine? Forestier (1939) suggested that infection ascended via the lymphatics, but most modern authors favour ascent via the paravertebral venous plexus described by Batson (1940) which he showed to have a significant effect in the spread of metastases from pelvic malignancies (Batson 1942). Both these theories of pelvic infection and spread by the paravertebral venous plexus have been applied to the spondylitis associated 
with ulcerative colitis (Steinberg and Storey, 1957; Jayson and Bouchier, 1968; Jayson, Salmon and Harrison, 1970; Jayson, 1970) although this sequence of events cannot be assumed to occur in this condition. It has been noted in several studies (Wright and Watkinson, 1959, Bowen and Kirsner, 1965) that the recognition of spinal involvement preceded that of the bowel disorder in many cases ("see also Table II-2). It has been argued that both spondylitis and colitis may have an onset in symptoms, such as mild backache and mild diarrhoea, which may have been ignored or misinterpreted by the patients. In this respect the possibility of crohn's disease having been misdiagnosed as acute appendicitis is also relevant. The family study performed by Macrae (1971) is important, however, In showing a distinct familial trend to the ankylosing spondylitis associated with ulcerative colitis (see Appendix A.)

There has been a tendency in most studies to assume the identity of the spondylitis seen in association with such conditions as Reiter's disease with idiopathic ankylosing spondyitis. Considering the spine as an "organ" there must be few ways in which it can react to abnormal stimuli and the spondylitic type of picture could be the end product of several different pathological processes. Evidence on this point is scanty. The distinctive form of early brucellar sacro-iliitis and spondylitis, with its evolution to a typical picture of complete ankylosis, has already been mentioned as an example of a direct infective process. Dixon (1960) 
suggested that the spondylitis of Reiter's disease was not typical of ankylosing spondylitis, while zvaifler and Nartel (1960) found the spondylitis associated with ulcerative colitis entirely compatible with idiopathic ankylosing spondylitis in both its spinal and extra spinal manifestations. McEwan and his co-workers (Di Tata, MeEwan, Lingg, Porrini, Good and Roulson, 1969) suggested on the basis of a careful clinical and radiological study that the spondylitis associated with ulcerative colitis and Crohn's disease was very similar to idiopathic ankylosing spondylitis, but differed significantly from the spondylitis associated with psoriasis and Reiter's disease which strongly resemble each other. In an extension of this study (McEwan, Di Tata, Lingg, Porini, Good and Rankin, 1971) they reached similar conclustons, although they were unwilling to assume ldentity of the spondylitides of the members of each group, commenting only on their high degree of similarity, and also pointing out certain cross-relationships such as the co-exiatence of aortic valve disease which rendered the spinal disease of some members of each group indistinguishable. At present no firm conclusions can be drawn from these studies. The number of patients in each group remains quite small, comprising 39 with psoriasis, 38 with colltis or Crohn's disease and 34 with Reiter's disease, and the need for longitudinal studies, particularly in the mode of progression of syndesmophyte formation, makes further research necessary. Pathological co-ordination with the various stages of radiological development may also be of 
value. From the point of view of the present study, the apparent identity of the spondylitis of the Crohn's patients, who numbered only 4, in Mctwen's series with idiopathic anirylosing spondylitis is of interest. His similar conclusion with regard to ulcerative colitis would also lend some support to Macrae's suggestion of an hereditary link between the two conditions. In conclusion, therefore, the identity of all types of spondylitis can no longer be assumed, but no suggestion has been made that the spondylitis associated with inflarmatory bowel disease is in any wey different from ldiopathic ankylosing spondylitis.

Before investigating the aetiology of clubbing and hypertrophic osteoarthropathy, the association between them should be considered. In most standard texts they are described together and hypertrophlc osteoarthropathy is considered as an extension of the process of clubbing. Howell (1966) considered that clubbing associated with extra-thoracic diseases was only rarely associated with periosteal ossification and arthritis, and that such clubbing could be considered either a form fruste of hypertrophic osteoarthropathy or bear no relationship to 1t. Wile this last statement appears to be the most accurate sumary of the inter-relationship between the two conditions, the relevant literature contains such a paucity of references to the two conditions in isolation that the aetiology will be considered jointly. Until the precise nature of the correlation between the two conditions in each of the diseases with which they may be 
associated is established, such blanket consideration of aetiological theories remains the sole available method of analysing the 11terature.

Iittle advance has been made in defining the cause, or causes, of clubbing since Hippocrates first described the conaition in association with empyema, in the 5 th century B.C. His clinical description of a patient in whom"..... the eyes become hollow, the cheeks have red spots on them, the nails of the hands are bent, the Eingers are hot especlally at their extremities...." (Adams 1849) portrays acute clubbing, but the insidious nature of this condition in the majority of patients places the burden of its recognition firmly on the clinical acumen of the physician. The most extensive review of the subject Is that of Mendlowitz (1942) who considered aetiology under flve headings, trophlc, circulatory, toxic-infectious, mechanical and toxic-mechanical. He concluded that none of these theories provided a plausible explanation backed by scientiflc evidence, most being based on conjecture or misunderstanding, as were the miscellaneous alternative theories varying from endocrine causes involving elmost every known gland to suggestions that the periosteum is raised by Iiberation of Nitrogen gas under it. The author's only contribution was to state that he considered increased peripheral blood flow would heve to form the comerstone of any new theory of the mechanism involved. but he would hazard no theory of his own. A further review of the subject 25 years later (Anderson, 1967) provided a contraction rather than an expansion in 
aetiological theories, although two schools of thought appeared to have increasing support. An association with high oestrogen secretion was suggested, hich coincidentally explained the not uncommon coexistence of gynaecomastia and the occasional occurrence of both clubijing and osteoarthropathy in pregnancy (Cullen and vashmery, 1966). Alternatively, and probably of more relevance to intestinal disease, it was shown that section of the vagus nerve either at the hilum or in the neck during thoracotory for bronchogenic carcinoma was associated with rapld regression of both clubbing and osteoarthropathy. The significance of vagal factors was investigated in ulcerative colltis by Young (1966) who undertook a retrospective study of 156 patients with ulcerative colitis of whom 7 showed finger clubbing. All the patients were within the group of 77 who's disease involved parts of the colon innervated by the vagus, whereas none of the 79 patients ho's disease was restricted to the area outside vagal supply showed evidence of clubbing. Ihis was held to be a piece of supportive evidence to the theory of vagal involvenent in the aetiology of at least some forms of clubbing, although the figures are by no means conclusive. No similar study has been undertaken with respect to Crohn's alsease, the diffuse rature of the intestinal involvement, often in areas unaffected clinically or radiologically, and the rarity of isolated left colonic involvement nilitating against the production of meaningful information. The other intestinal diseases associated with clubbing. multiple polyposis, chronic bacillary dysentery, amoebic 
dysentery, tuberculosis, Hodgkin's disease, carcinomata, sprue, ascariasis, duodenal ulceration with pyloric stenosis and idiopathic steatorrhoea (Young 1966) all involve vagal territory, but the increasing popularity of vagotomy in upper gastro-intestinal tract surgery has so far failed to produce any reports of the influence of this procedure on either pre-existing clubbing or the development of clubbing, particularly in association with malabsorption, thereafter.

In the critical review associated with their case report, Neale, Kelsall and Doyle (1968) doubted the existence of a common pathogenesis for both hypertrophic ostecarthropathy and clubbing. Their search of the worlds literature revealed only three cases of intestinal disease with demonstrated bone changes (Teleky, 1897, Temple and Jaspin, 1948, konska, Strenge and Hammarsten, 1957) and no case has been added since. In view of this, the quoted association between intestinal disease and hypertrophic osteoarthropathy must be in grave doubt, and the degree of association with clubbing awaits the publication of more accurate surveys of its incidence. It is possible that such surveys will have to take cognisance of any local areas of high fluoride ingestion, as clubbing may be seen in as many as 5 per cent of the adult population in areas where the drinking water contains large amounts of fluoride (Latham 1966).

The third question which has been posed is "Is there a special relationship between the gut and the joints?". Evidence for such a relationship has been offered in a 
piecemeal form by authors discussing joint manifestations of gut diseases or disorders of the gastro-intestinal tract in joint diseases, and in a more organised way by authors building aetiological theories on such an association.

The joint manifestations of several gastro-intestinal disorders have already been mentioned, but some other conditions should also be considered. One oddity is the appearance of joint disorders after jejuno-colic bypass used in the treatment of obesity. Shagrin, Frame and Duncen (1969) described this complication in six of 31 patients submitted to bypass, the arthritis being of symetrical "rheumatoid" type, but with negative tests for rheunatoid factor. The most interesting feature of this condition was, however, its complete remission postoperatively in the single patients who underwent reconstruction of tireir bowel. The possibility of itoxic absorption' from the large stagnant loop formed by this operation is a tempting hypothesis thich would be in accord with other explanations of gut-associated arthritis. Unfortunately detailed studies of the joints and gut of these patients are not yet available.

The intestinal disease with which arthritis is most frequently associated is undoubtedly mipple's disease, and hipple's original description in 1907 was of a physician who presented with transient attacks of arthritis. This disease has attracted considerable attention, as evidenced by a world literature containing more publications dealing with the condition then cases 
reported (Hendrix and Yardley, 1970). The characteristic intestinal histology, with the presence of PAS positive macrophages, is a diagnostic feature of whipple's disease which has even been retrospectively cemonstrated in the original case (Yardley and Fleming 1961). These PAS positive cells have not been found in needle biopsy specimens of the synovium of affected joints, the changes described being those of mild synovial hyperplasia with minimal infiltration by inflammatory cells (Caughey and Bywaters, 1963). An excellent review of the articular manifestations of the disease was produced by Kelly and Weisiger (1963) who tabulated the details of the arthropathies described in all the 95 cases reported in the English Language 11terature until 1961 and three cases of their own. Sixty-four of the cases in the literature review were reportedly associated with arthritis, and no statement as to presence or absence of this complication was made in 25 cases. The incidence is, therefore, at least 70 per cent. The joint involvement was of inflammatory type in at least 40 of the cases, was often migratory and episodic and was associated with no consistent radiological changes in the affected joints. The joints involved were frequently not specified. The avallable information suggested that the knees were involved most frequently, followed by the ankles, "fingers", hips, wrists and elbows in that order. spondylitis was found in 18 patients all males, all of whom had peripheral arthritis. A similar distribution of peripheral joint involvement was described in a recent review of the world's 
literature on Whipple's disease since 1950 (Maizel, Ruffin and Dobbins, 1970), although spondylitis was not mentioned. The strong possibility that whipple's disease is an infection was mentioned in this review, but no explanation was forthcoming for the appearance of joint symptoms up to ten years before intestinal symptoms occurred.

The possibility of a linkage between Crohn's and Whipple's aisease has received little support, although there are cases reported of diagnostic confusions between the two diseases (Amsterdam and Grayzel, 1945). Avery Jones and Paulley (1949) stated that "if in place of the fat filled lymphatics in Whipple's disease Iymphoedema is substituted, the histology is not very unlike that found in Crohn's disease". They went on to suggest that Thipple's disease is a variant of crohn's jejunitis, but further support for this view has not appeared.

The arthritis associated with ulcerative colltis has also recelved considerable attention, and has already been mentioned because of the frecuent association between colltis and Crokn's disease in publications relating to their musculoskeletal complications. Although arthritis associated with colitis was recognised in the last century (White, 1895), it is only relatively recently that its exact nature has been evaluated. One major problem has been the wide differences in prevalence quoted by different authors, ranging from no arthritis in a total of 236 patients (Feder, 1938, Flood, Lepors, Hiatt and Karush, 1956) to a 22 per cent incidence in three series totalling 447 cases (Fischel, 1949, Bockus, Roth, Buckman, Kalser, Staub, 
Finkelstein and Valdes-Dapera, 1956, Kirsner, Sklar and Palmer, 1957). A local series of 108 patients showed an arthritis, called "colitic arthritis", in 15.7 per cent (Wright and Watkinson, 1959). This condition was further investigated in an enlarged series of 269 ulcerative colitics, being found in 11.5 per cent (Wright and Watkinson, 1965A). It was characterised by recurrent attacks of acute synovitis, commonly assymmetrical, and involving large and lower limb joints more frequently than small and upper limb ones. The condition was conmoner in patients with more severe or extensive colitis, and those with local or systemic complications in contrast to associated spondylitis which proceeded in a fashion unrelated to the activity of the gut disease or to surgery (Wright and Watkinson, 1966). It generally bore a close temporal relationship to exacerbations of the gut disease, and always disappeared following total procto-colectomy. Th1s last point is of part1cular importance in discussing the incidence of colitic arthritis, as a less radical surgical approach may leave diseased tissue in situ thus predisposing to further attacks of synovitis. A radiographic survey of the sacro-illac joints of 234 of these patients showed sacro-illitis in 18 per cent, clinical ankylosing spondylit1s being diagnosed in 6.4 per cent (Wright and Watkinson, 1965B). Other authors have made similar observations, the incldence of the arthritis and the accuracy of its description being relatively high where careful assessment by rheumatologists was carried out (Bywaters and Ansell, 1958) and lower, but still 
significant, where the descriptions were of incidental findings in gastro-enterology departments (sloan, Barglot and Gage, 1950). In view of these findings, little support can be found for the contention that there is "No data to support the idea of an arthritis specific to patients with ulcerative colitis......" (Rotstein, Entel and Zeviner, 1963).

Behcet's syndrome is more noted for its articular than its intestinal manifestations, although gut involvement has been described in flfty patients from a review of 85. Of perticular interest is the case of a 12 year old boy tho had arthralgia and signs of ileal disease on barium enema (Oshima, Shimizu, Yokohari, Matsumotor, Kano, Kagami and Nagaya, 1963). Behcet's disease is an unconmon cause of erythema nodosum, which may also be associated with arthralgias (Strachen and Wigzell, 1963).

The gastro-intestinal lesions of lymphogranuloma venereum are caused by direct spread of the organisms following genital infection. Certain superficial resemblances to Crohn's disease may be found, such as stenotic lesions and recto-vaginal fistulae, but the positive Frei test removes any possible diagnostic doubt. Reports from a surgical clinic dealing with those patients with intestinal spread of the disease showed 9 per cent to develop arthritis, while of those patients who were seen in the dermatology department of the same hospital, in whom intestinal involvement was absent or minimal, only 1.6 per cent developed arthritis (Barker and Murphy, 1941). Although no details of the pattern of articular involvement 
were given, the joints were said to suffer no permanent damage (McEwan, 1941). Speculation arises as to whether the arthritis is a manifestation of the intestinal component of the disease.

Although gut and joint involvement has been reported in both systemic sclerosis (Bluestone, Macmahon and Dawson, 1969) and Ehlers-Danlos syndrome (Beighton, Murdoch and Votteler, 1969) their pathological dis-similarity from other members of this group of diseases is so great that a linkage between them is unlikely.

Studies of the digestive tract in joint diseases with the exception of ankylosing spondylitis are less frequent. The broader group of 'collagen diseases', such as dermatomyositis, systemic lupus erythematosis and polyarteritis, all have gastro-intestinal manifestations with relatively specific features, although all may be misciagnosed in their early stages as idiopathic ulcerative colitis (Patterson and wierzbinsiti, 1962). A study of this group of diseases from Finland included patients with both rheumatoid arthritis and "rheumatoid" spondylitis in the "collagen disease" group. Although small intestinal lesions were found on blopsy in several cases, the heterogenous nature of both the group of patients studied and the intestinal signs and symptoms discovered makes interpretation of the results, beyond the bald statement that the gastro-intestinal tract may be affected by collagen diseases, difficult (Siurala, Julkunen, Tiovonen, Pelkonen, Soren and Pitkanen, 1965).

Proposals of an aetiological association between the 
gut and the locomotor system have also received scant attention. Pemberton (1934) felt that the gastrointestinal tract was involved in some way in the causation of arthritis, and suggested that restoration of the gut to normal would produce a return to normal general health, presumably including the joints, in arthritic patients. The bulk of the paper is a vague ramble through the byways of visceroptosis and hypochlorhydria, and really offers no concrete suggestions apart from the importance of a balanced diet.

An all embracing theory implicating intestinal factors in the causation of a wide range of "collagen syndromes", including many diseases such as valvular heart disease and neuropathies as well as the recognised para-rheumatic diseases, was elaborated by shatin (1964). His hypothesis, represented diagramatically in figure II-3, is that gluten enteropathy heterozygotes suffer an enteropathy precipitated by what ingestion causing malabsorption of collagen precursors. This in turn leads to maldevelopment of collagen which results in both recognised collagen diseases and the manufacture of poor gastro-intestinal collegen which increases the liability to enteropathy and thus establishes a vicious circle.

The same author later expanded his concept by interpreting it in immuno-pathological terms, and applying it more specifically to rheumatoid arthritis (Shatin, 1966). The aetiological implication of gluten has received a little support (Binder, O'Brien, Spiro and Hollingsworth, 1966) but the consensus of opinion would support Boyle and Buchanan (1971) in their contention that "none of these 
hypotheses to date has provided a satisfactory explanation for the disease".

\section{FIGURE II-3}

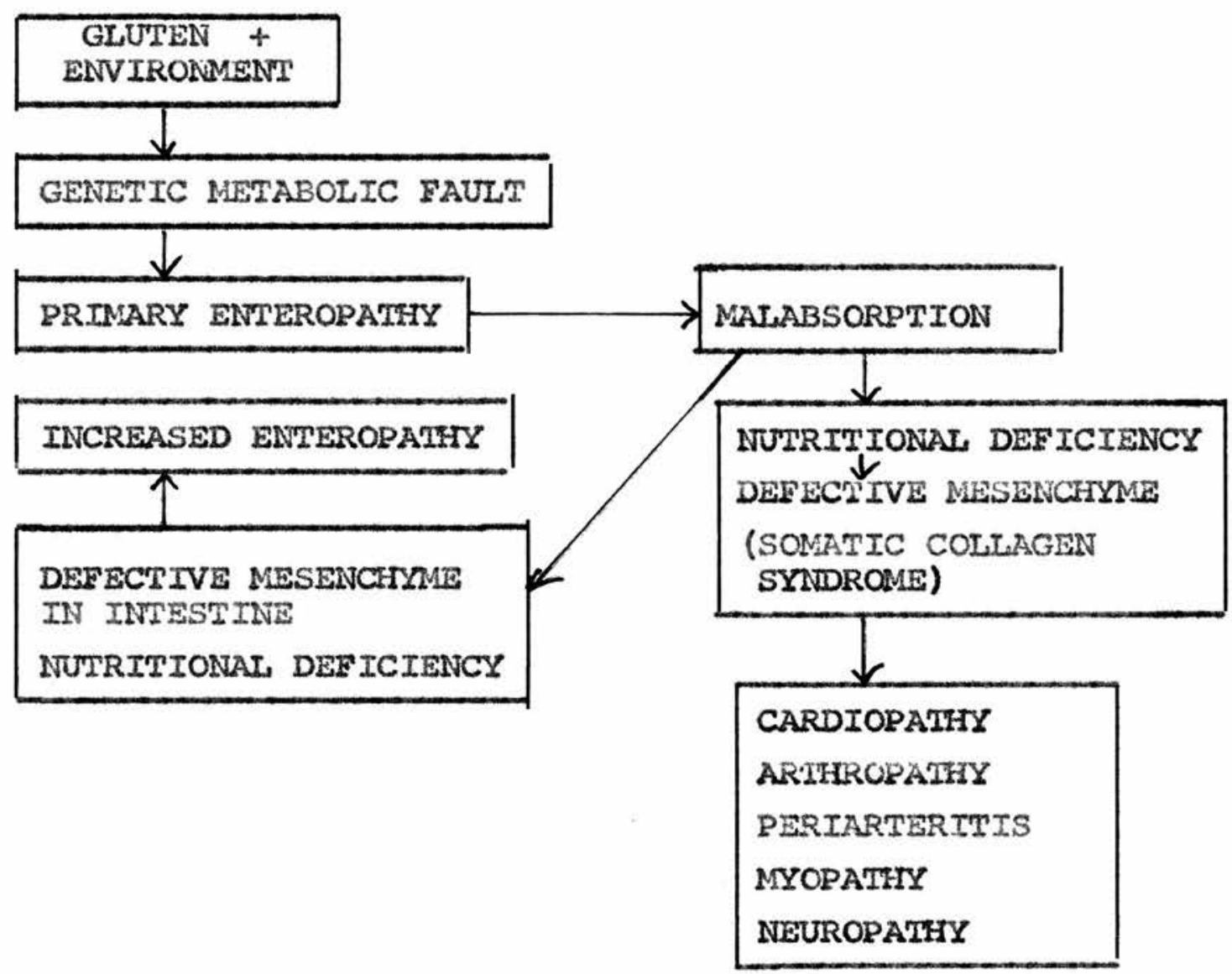

PROPOSED PATHOGENESIS OF COLIAGEN SYLDROMES AND MECHANISM OF SELF PERPETUATION (SHATIN 1964)

On the basis of the evidence presented there is at the moment no evidence of general association amounting to a special relationship between gut and joints. There is no doubt, however, that arthropathy, usually in the form of a synovitis with minimal radiological evidence of joint damage, does accompany many intestinal diseases, and the intestinal phase of some diseases which are not considered as primary gut disorders. Ankylosing spondylitis, both in idiopathic form and in the possibly different form 
associated with such conditions as Reiter's disease, provides an exception to this rule in that radiologic changes are a prominent feature of the condition. It appears that so-called intestinal arthritis is an inmune phenomenon precipitated by the ingress of antigen from the diseased gut. In contrast, genetic factors appear prominent in the aetiology of spondylitis, and it might be that this condition occurs as a result of infection ascending to the spine from the affected gut or pelvic organs, in patients with a genetic predisposition to the disease. It must be further postulated that the gut of some patients who will later develop intestinal disease is already abnormal many years before the appearance of clinical or histological evidence of disease. Such an abnormality may well be in the immune reactions taking place in the gut, which is constantly colonised with a wide spectrum of organtsms, for although the gut is a poor site for the experimental production of chronic hypersensitivity reactions, which in any case give rise to a histological picture different to that of Crohn's disease (Goldgraber and Rirsner, 1958) an excellent case can be made for the implication of immunological reactions in many of the diseases which have been discussed (Taylor and Truelove, 2962). 
B. Methodology 


\section{B. METHODOLOGY}

\section{INTRODUCTION}

"The primary purpose of epidemiological studies of the aetiology of disease is to discover generalisations that will hold true for a population larger than the one on which the study is based" (Dorn, 1959). A corollary to this is the fact that, where extrapolation from small to large numbers is to be undertaken, it is essential that the small group is studied with extreme care, as any errors are magnified in general application. Diagnosis is not a precise science. Under normal clinical circumstances a working diagnosis may be reached and subsequently modified by investigations of varying complexity and, most important, by the evolution of the disease with the passage of time. Under the circumstances of epidemiological surveys, a diagnosis must be reached at a single visit using the minimum of investigative interference, especially where a hazard such as radiation is involved. This has called for the elaboration of diagnostic criteria for disease entities, preferably with international agreement, so that the condition under discussion can be recognised by workers separate temporaliy or geographically from the diagnostician. No such diagnostic criteria have been agreed for Crohn's disease. Certainty of diagnosis can be ensured only by skilled interpretation of histological specimens. Attempts have been made to classify the diseases as definite where histological evidence is available, 
probable, where the clinical features are confirmed by laparotomy (without histology) or radiology, and possible where a typical history is unconfirmed by investigation. No such classification is universally used, and the criteria for diagnosis of crohn's disease will, therefore, be discussed in relation to the diagnostic features present in each patient rather than in relation to an accepted classification. It is this lack of accepted epidemiological criteria which necessitates the careful checking of diagnoses made by other workers, where this is possible, as in the Veterans Administration studies by Acheson (1960 B) and the series reported more recently from Bristol (Jayson, 1971).

The epidemiological diagnosis of ankylosing spondylitis has been studied, and some degree of international agreement of diagnostic criteria agreed. These will, therefore, be critically evaluated.

2. DIAGNOSTIC CRITERIA FOR ANKYLOSING SPONDYLITIS

2.1 Rome 1961.

The first internationally agreed set of diagnostic criteria were produced at the Rome conference of 1961, and these are shown in Table 11- 5

Definite ankylosing spondylitis was diagnosed if four of the five clinical criteria were fulfilled, or if criterion 6 was present with one of the criteria $1-5$. It was suggested that the number of subjects fulfilling each separate criterion or combination of criteria should 
TABLE $11-5$

1. Low back pain and stiffness of over three months duration which is not relieved by next.

2. Pain and stiffness in the thoracic spine.

3. Limited motion in the lumbar spine.

4. Limited chest expansion.

5. A history or evidence of iritis or its sequelae.

6. $\mathrm{x}$-ray showing bilateral sacro-iliac changes characteristic of ankylosing spondylitis. (This would exclude bilateral osteoarthrosis of the sacro-iliac joint).

DIAGNOSTIC CRITERIA FOR ANICYLOSING SPONDYLITIS IN POPULATION STUDIES - ROME 1961. (KELLGREN, 1962). 
be stated in any publication utilising these recommendations so that the fall spectrum of the disease would be demonstrated (Kellgren, 1962). These criteria were evaluated by Bennett and Burch (1968) in relition to their studies of the Black Feet and Pima Indians. They pointed out that the clinical criteria are each given equal diagnostic weight, but that bilateral sacro-iliitis was weighted three times as heavily as each clinical criterion. A table of sensitivity and specificity * of the clinical criteria was drawn up (Table 11- 6).)

The small number of observations relating to chest expansion was due to this criterion being excluded from the original Rome C lOMS recommendations. It was, however, used in the later part of the Pima survey as an additional parameter. Radiological sacro-iliitis was subjected to similar analysis with respect to clinically diagnosed ankylosing spondylitis, and the results are shown in Table 11- 7 .

On this basis they recommended the use of bilateral grade $1-4$ or unilateral grade $2-4$ sacro-iliitis as the screening rriteria for ankylosing spondylitis. They also found a large number of patients in whom a firm clinical diagnosis of ankylosing spondylitis was made in whom the sacro-iliac joints appeared normal but the cervical spine showed spondylitic changes. No standard grading films for ankylosing spondylitis of the cervical spine were in existence at that time, however, and the criteria for this diagnosis wera not stated. Both limited chest expansion 
焉离

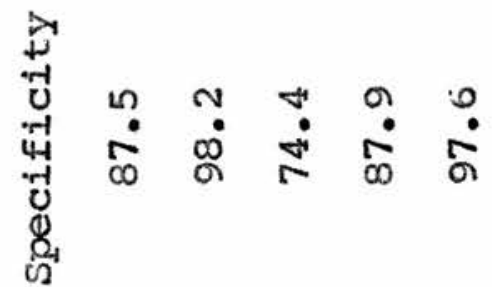

|

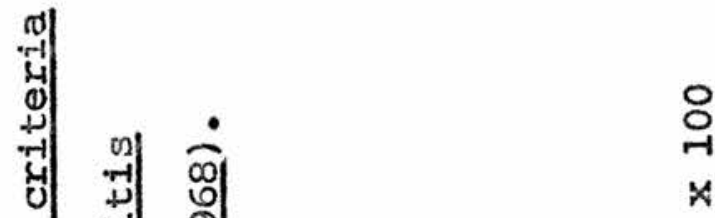

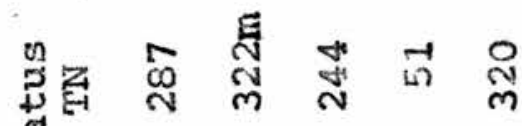

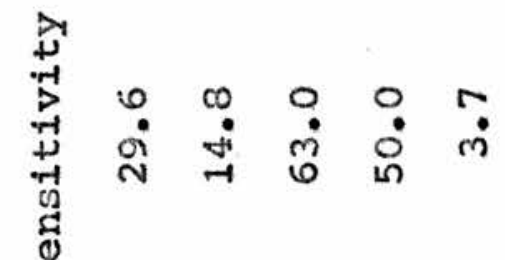

㞼

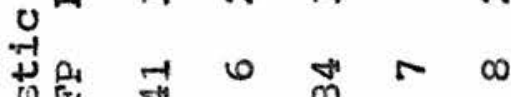

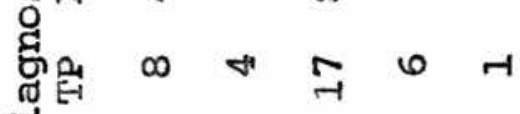
a
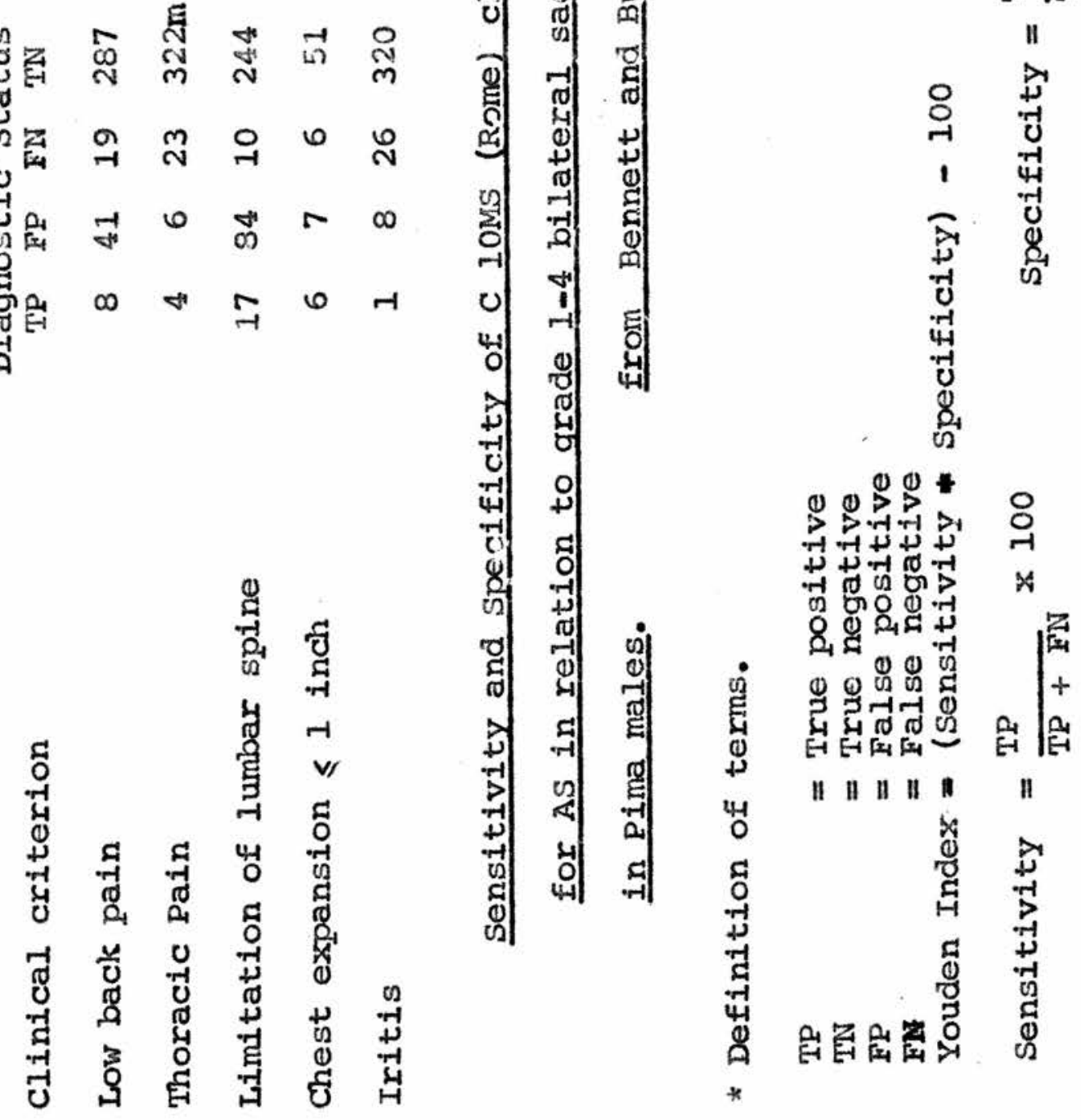

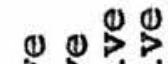

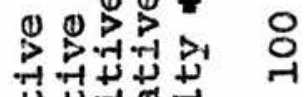

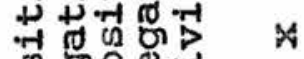

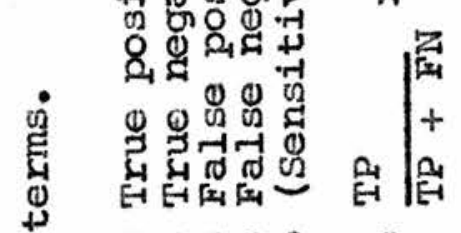

| || || || | 


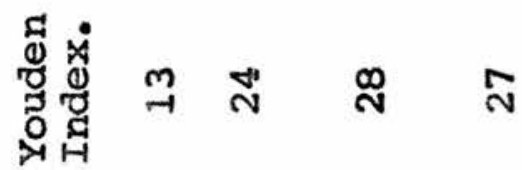

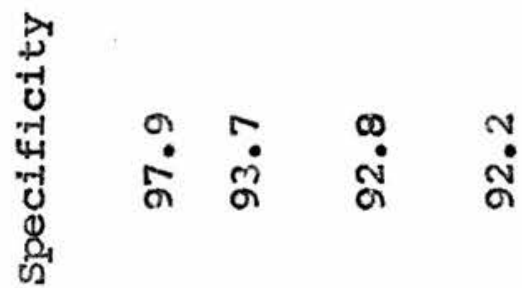

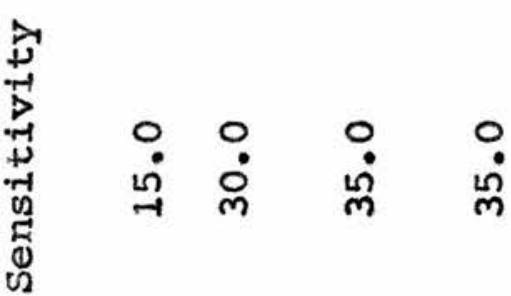

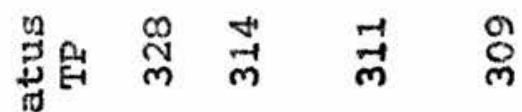

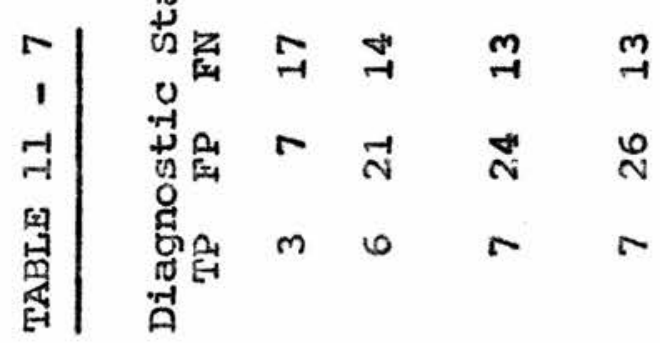
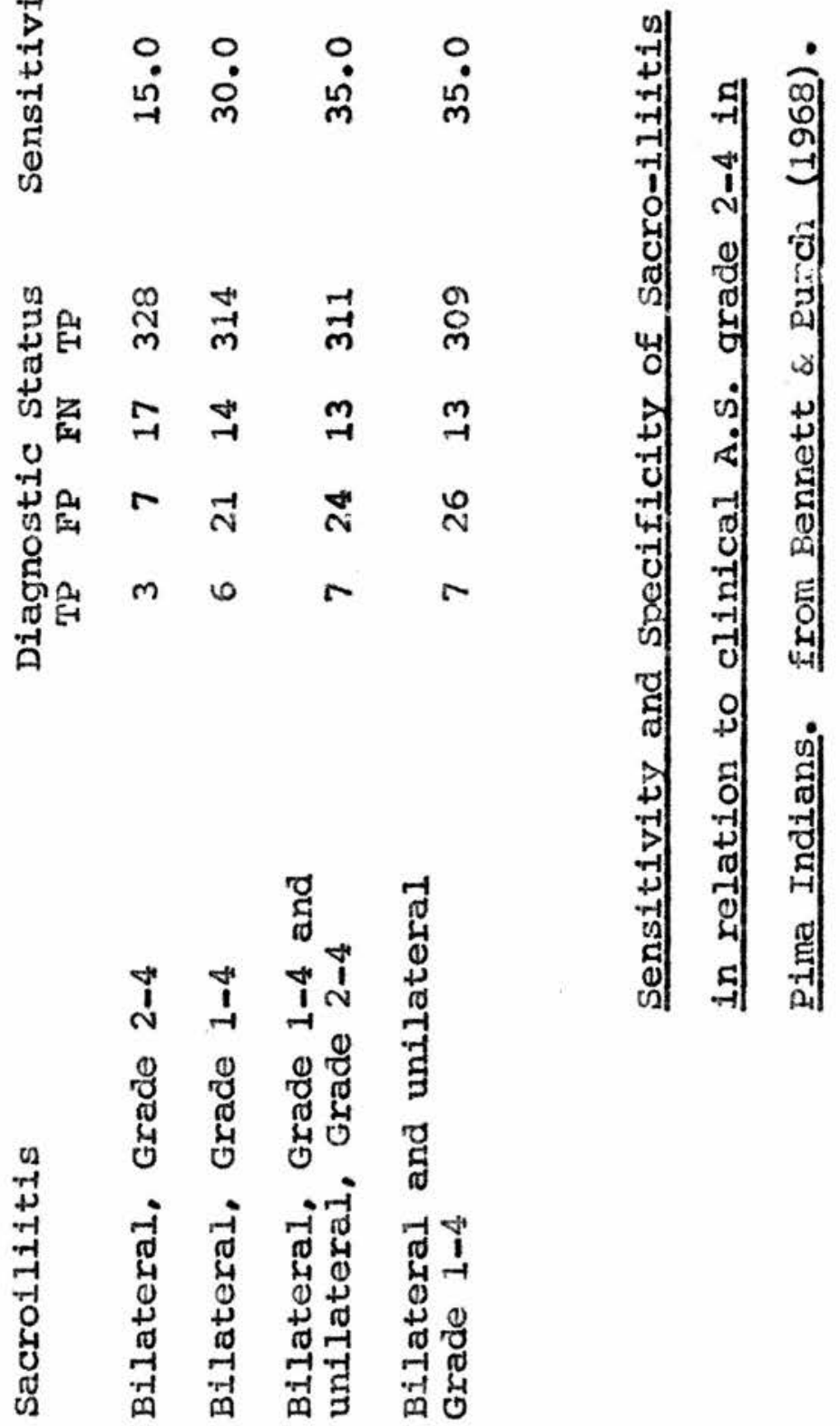
and limitation of lumbar spine movement were felt to be useful diagnostic points, but the categorisation of low back pain as stated in the Rome C lOMS (Table 11 - 5) proved difficult. A past history of iritis appeared to be of no value. Their final conclusion was that an AP radiograph of the sacro-iliac joints was the screening method of choice in population surveys.

The Rome Criteria have also been evaluated by the Manchester epidemiological group (Chalmers, Darchot, Kellgren, King, Pikhlak, Sievers, Strevens, Tait and wood, 1969). They also used sensitivity and specificity as indices of the accuracy of the diagnostic criteria, ranking the criteria on this basis. They compared their ranking with the pima survey and found quite wide discrepancies. (Table 11 - 8).

With the exception of iritis, which both groups rate as the least valuable of the criteria, their findings disagree widely with the Pima survey. A comparison of the Youden indices derived from each set of data shows such wide discrepancies both in the actual figures obtained and their ranking (Table 11 - 9) that grave doubt must be cast on the accuracy of any or all of them.

\subsection{New York, 1966.}

At the Hew York C IOMS a sub-committee was set up to discuss the diagnostic criteria for ankylosing spondylitis and to modify the Rome recommendations. Goften (1968), stressed the dependance which must be placed on radiographs, as clinical symptoms in absence of radiological confirmation are rarely specific enough to be reliable. The criteria 


\section{TABLE $11=8$}

Sensitivity Specificty Pima Rank

1. Low back pain and stiffness 72 90 3

2. Limitation of lumbar spine 74 77

2

3. Thoracic pain and stiffness 49 97 4

4. Limited chest expansion 44

Evaluation of Rome clinical criteria for Ankylosing Spondylitis from Chalmers et al. 1969.

\section{TABLE II-9}

Criterion Youden Index Manchester Pima

1. Low back pain and stiffness 62

2. Limitation of Lumbar spine

3. Thoracic pain and stiffress

4. Limitation of chest expansion 
elaborated are shown in Table 11 - 10.

\section{TABLE $11-10$}

1. Limitation of motion of the lumbar spine in all three planes - anterior flexion, lateral flexion, and extension.

2. A history of, or the presence of, pain at the dorso-lumbar juntion or in the lumbar spine.

3. Limitation of chest expansion to 1 inch $(2.5 \mathrm{~cm})$ or less, measured at the level of the fourth intercostal space.

4. Radiographic sacro-iliitis.

Diagnostic criteria for ankylosing spondylitis in population studies - New York, 1966.

Erom Bennett and Wood, 1968. 
In applying these criteria it was suggested that the frequency of occursence of each should be reported separately, but for the purpose of comparison between surveys, ankylosing spondylitis should be defined as radiographic sacro-ilititis accompanied by physical signs in the back. Definite ankylosing spondylitis was defined as grade 3-4 bilateral sacro-iliitis with at least one clinical criterion, or grade 3-4 unilateral or grade 2 bilateral sacro-iliitis with clinical criterion 1 or both clinical criteria 2 and 3. Probable ankylosing spondylitis was defined as grade $3-4$ bilateral sacro-iliitis without any clinical criteria.

An international collaberative review of the New York and Rome criteria has been undertaken (Kanev, Tronchev, Sebo, Sitaj, Sievers, Danchot, Delbarre, Astapenko, Pikhlak, Kellgren, Strevens, and Wood, 1969) the results being shown ial Table 11 - 11. It is of interest that the Youden index for radiography alone shows it to be not only the most useful overall criterion for use in surveys, but also to be detracted from, rather than enhanced, by the additional use of the various clinical criteria. 3. MEASUREMENT OF SPINAL MOBILITY

Both the New York and Rome criteria include limitation of movenart of the lumbar spine as one of the clinical criteria, the former demanding limitation in three planes anterior flexion, lateral flexion and extension.

Forward flexion is usually assessed by eye, either from simple observation of the patients' attempts to touch 


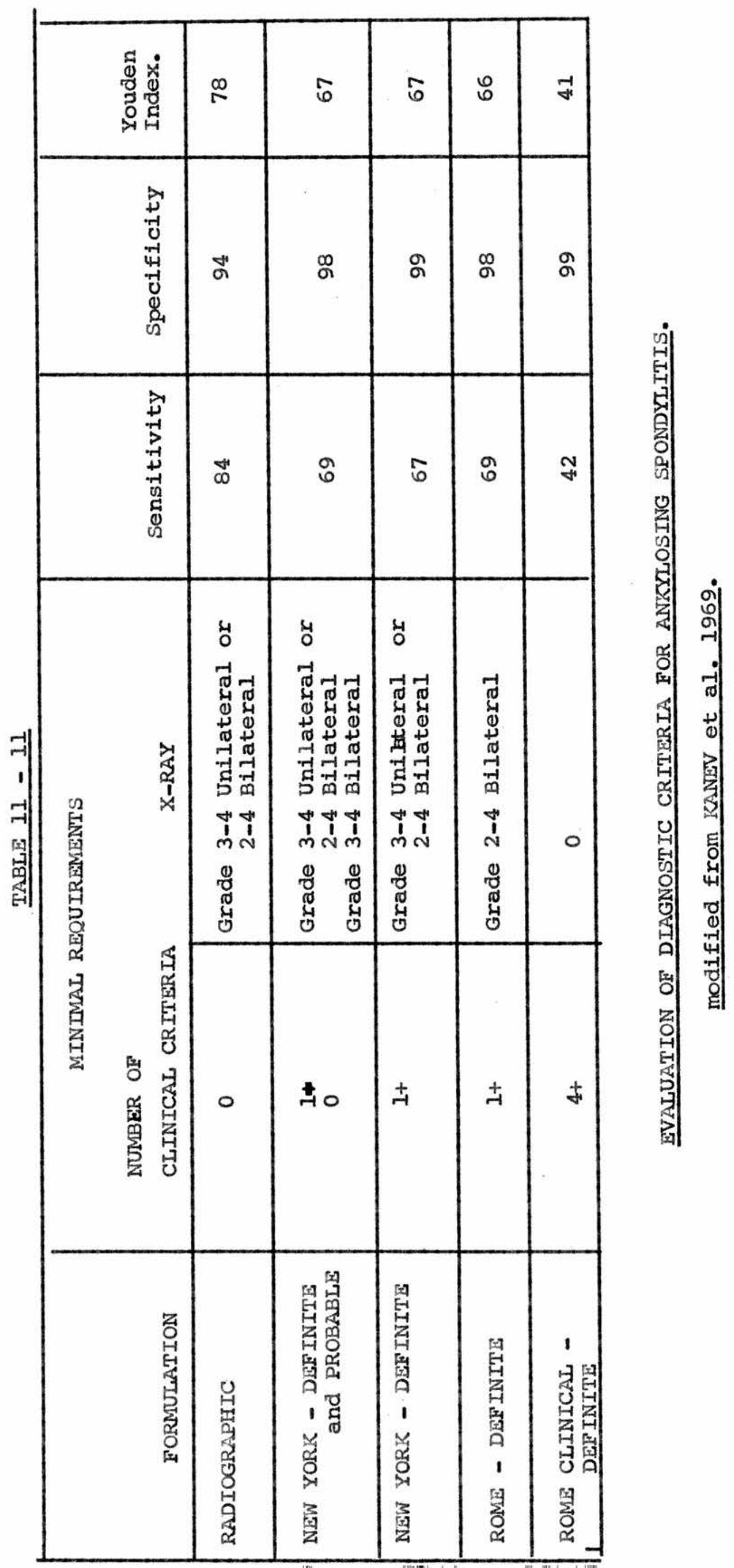


their toes, or by measuring the distance of the fingertips from the floor. These methods are highly subjective, and neither has been exposed to any form of evaluation. The subjective interpretation often placed on the latter method was highlighted by Newton (1957) who stated "One very common misconception is that a man who can touch his toes cannot be suffering from ankylosing spondylitis". Radiographic methods of measurement were not considered, as they are inappropriate to population studies. The remaining methods all call for the use of some measuring device ranging from photography (Goff, 1952; Sharp and Easson, 1954; Hart and Maclagan, 1955) to spondylometers (Dunham, 1949; Goff and Rose, 1964; and inclinometers (Loebl, 1967). The goniometric method of Troup, Hood and Chapman (1968) is simple to use, but the athletic postures required for some of the measurements, while easily adopted by the remedial gymnasts used in the study, are unlikely to be achieved by the average patient. The method selected was that devised by Macrae for his family study of ulcerative colitis (Macrae and Wright, 1969). This is a modification of the technique of schober (1937) and has the advantages of simplicity and accuracy, and requires only a tape-measure for measurement. Further advantages to the author included familiarity in use of the method and the desirability of using, wherever possible, the same methods for comparative surveys carried out from the same centre.

No simple methods of measuring extension or lateral flexion were reported at the commencement of this study, 
although the parallel fanily study of psoriatic arthritis (Moll, 1971) yielded methods for both measurements which require only simple apparatus. These showed a satisfactory degree of intra-personal reproducibility, but inter-personal variation was not determined. This study showed that, although movement in all three planes was restricted in ankylosing spondylitis the degree of restriction in each plane was approximately equal. The normal range of movement in normal subjects of both sexes and all ages was determined, a significant difference between the sexes and a large diminution in mobility with advancing age being observed (Moll and Wright, 1971A). It is apparent that such objectivesstudies with their hichlighting of the wide range of normality are desirable if clinical criteria are to be applied in an epidemiological sltuation with any degree of scientific accuracy.

\section{MEASURPMINTT OF CHEST FXPANSION}

Bernard Connor (1695), in his orlginal description of ankylosing spondylitis, accurately predicted from his examination that movement of the thoracic cage would be impaired. Chest expansion limited to $\frac{1}{2}$ inch was one of the clinical features described in a case of ankylosing spondylitis by Davies-Colley (1825). Although limited chest expansion is a frequent finding in patients with ankylosing spondylitis, being present in 70 per cent of 180 patients when first seen (Hert, Emerson and Gregg, 1963), methods of measurement are generaily haphazard and have been subjected to no evaluation. The position of measure- 
ment recommended for clinical examination varies from the xiphi-sternum (Browning, Catheart and Findlay, 1926) to the nipple level (Hunter and Bomford, 1968). The position recommended for population studies is the level of the fourth intercostal space, an arbitrary lower limit of normal of $2.5 \mathrm{~cm}$, expansion being applied irrespective of age or sex (Bennett and Wood, 1968). Pelvimeter calipers have been used in an attempt to increase accuracy, particularly in minimising the effects of the breasts in women and powerful muscles in men (Malone, 1904; Moll, 1971). Both tape and pelvimeter methods have been critically examined, and normal ranges for men and women of different ages constructed (Moll and Wright, 197.B. The conclusion drawn from this analysis was that the circumferential measurement at the fourth intercostal space was, despite its theoretical drawbacks, a sufficiently accurate measurement for use in population surveys provided allowance was made for the age and sex of the patient.

5. RADIOLOGY OF THE SACRO-ILIAC JOINT

Study of the diagnostic criteria for ankylosing spondylitis shows quite clearly that the accurate interpretation of sacro-iliac radiographs is the most crucial part of the diagnostic process.

5.1 Anatomy of the Sacro-iliac Joint.

The sacri-iliac joint is a synovial joint in its lower two-thirds, with ear-shaped articular surfaces, the iliac articulations being convex (Inkster, 1964). The joints: diverge from the midline at an angle of 30-580 (Solonen, 1957). 
The detailed anatomy has been reviewed by wells (1965) who demonstrated that some earlier controversy as to whether the joint was diarthrodial or amphiarthrodial arose from the difference in age in the skeletons dissected. The joint has been described as 'The most difficult major joint both to demonstrate and interpret radiologically' (Grainger, 1967), and despite several reviews of its normal and abnormal radiological anatomy this statement remains true. Solonen (1957) took a series of radiographs of the sacro-iliac joint of skeletons with lead strips attached to the joint margins. These demonstrated not only that the joint is not planar, but also that a clear view of the structure and shape of the joint is not possible. In view of this, it is not surprising that there is controversy as to the best radiological technique for demonstrating the sacro-iliac joints. Romanus and Yden (1955) advocated a P-A view on the grounds that the $x$-ray beam then diverged parallel with the plane of the joints, although the non-planer nature of the joints and their varying angle make this contention unlikely. The customary clinical sacro-iliac joint radiograph is taken $A-P$, and the use of an unconventional view deprives the observers of their previously acquired experience of normality. It also loses the usual source of 'control' films in sacro-iliac joint studies, that is the preliminary films taken before intravencus pyelography (Cohen, McNeill, Calkins, Sharp and Schubart, 1567; Macrae, Haslock and Wright, 1971.) Oblique views have been advocated on the 
basis of case reports in which they have been of diagnostic importance (Beetham and Achkar, 1969) but even the most experienced observers find these views misleading (Wilkinson and Bywaters, 1958) and they have never been evaluated in an epidemiological study. Although tomography may increase diagnostic accuracy to a small extent (Wilkinson and Meikle, 1966) it has no place in epidemiology. Iimiting the film to the sacro-iliac joints denies the observers valuable information regarding the age of the patient and the presence of alsease in the hips and pelvic bones. These radiographs are technically more difficult to take as the centering of the beam becomes more crucial as the area becomes smaller. While repeat films with better positioning may be allowed in clinical practice, all population surveys are, ethically, limited to a single exposure, and any technique which reduced the yield of readable films is unacceptable (Macrae, Haslock and Wright, 1971). Although the view of the sacro-iliac joints obtained on A-P films of the lumbar spine has been used for the assessment of sacro-iliitis(Dixon and Lience, 1961) the view of the joint obtained is not always satisfactory as part of it may be either cut off laterally, or distorted by the proximity of the edge of the maskec area. Throughout this study the A-P pelvic film, as recommended by the New York C lOMS, has been used, and is considered the best technique available. 
5.2 Changes in the Sacro-iliac joints with age.

Dissection series of large numbers of sacro-iliac joints have been carried out, and a constant feature reported is the increased incidence of partial or complete ankylosis of the joint which takes place with advancing age (Brooke, 1924; Willis, 1933). On anatomical grounds, therefore, an increasing incidence of radiological ankylosis would be anticipated, but this is not found unless tomography is used, when small patches of ankylosis may be observed (Wilkinson and Meikle, 1966). It must be presumed that this is due to these adhesions being fibro-cartilagenous rather than bony (Walmsley, 1964).

In contrast, the joints of young people provide great difficulty in interpretation. The appearance of cloudy sacro-1liac joints with irregular areas, a hazy irregular joint space and a "moth eaten" appearance of the margins was described as a pathological entity by Rogers and Cleaves (1935). This is now recognised as normal (Carter, 1962; Jacobs, 1963) but may remain a source of error in interpretation, a factor recently stressed by Riley, Ansell and Bywaters (1971).

The precise age at which the 'adolescent' appasance becones adult is not know. Rolleston (1947) suggested the transition took place at the age of $17-20$, but the appearance has been observed in the third decade. It has not been reported after closure of the iliac event epiphyses, and this observation further stresses the need to examine the whole of the pelvic film when reading sacro-iliac joints (Macrae, Haslock and Wright, 1971). 


\subsection{Radiological sacro-ilitis.}

Changes in the sacro-iliac joints have long been recognised as a major diagnostic feature of ankylosing spondylitis. Small numbers of patients have been reported in whom apparently typical ankylosing spondylitis was unaccompanied by radiologic sacro-iliitis, but the rarity of this is emphasised by the report of only 9 cases in a series of 1,035 from the Mayo clinic (Polley and Slocumb, 1947). Less agreement is found in the correct interpretation of unilateral sacro-iliitis. Its diagnostic importance in ankylosing spondylitis is stressed in the New York criteria, but the importance of eliminating other causes, particularly infection, has been stressed by several authors (Polley and Slocumb, 1947; Grainger, 1960; Wells, 1965).

While it is likely that those patients in whom absent or atypical sacro-iliac joint changes are present may during the course of the disease develop more classical changes, this joint is held to be the site of earliest radiological involvement by some authorities (Forestier, 1939). The changes may be arrested at an early stage, that is wilisut progressing towards ankylosis, especialiy in females (Thoonson, 1957) and asymmetric involvement may persist throughout the course of the disease (Grainger, 1957).

The evolution of sacro-iliac changes has been subjected to relatively little study. Thomson (1957) suggested that progression from early sacro-ilititis to full ankylosis took 20 years. Forestier and Deslous-Paoli (1957) studied 30 patients with ankylosing spondylitis over a prolonged period 
in an attempt to map out the progression of the $\mathrm{x}-\mathrm{ray}$ changes. They divided the changes into three categories:Stage 1. Marginal decalcification; contours fuzzy; false widening; bony condensation in subchondral zone of sacrum and ilium.

Stage 11. Joint space wholly or partly eroded; marked bony condensation and mottled decalcification.

Stage 111. Bony fusion; vanished condensation.

Their time scale of evolution of these changes is shown in Fig. 11-4. The authors considered stages 1-11 to be pathognomonic of ankylosing spondylitis, but not stage 111. which they felt could be the end result of several processes. The definition of the radiological changes constituting sacro-iliitis is often not stated. Illustrations of radiographs may fail to satisfy the critical observer (e.g. Fig. 3 in the paper by Wells, 1965 is more reminiscent of osteitis condensans ilii than early spondylitis), although this may in many cases be due to the difficulty in accurately reproducing radiographs in illustrations. The accepted changes are sclerosis, erosions, ankylosis and citesation in joint width. Although these are illustrated in the Epidemiology of Chronic Rheumatism, which remains the standard work of epidemidogical grading of joint radiographs, their interpretation was not evaluated (Kellgren, Jeffrey and Ball, 1963). An evaluation using these parameters has been undertaken (Macrae, Haslock and Wright, 1971.) and has shown that, with practice, a satisfactory degree of inter and intraobserver consistency can be achieved. The one feature on 


\section{F19. II -4}

Evolution of sacro-1llac chenges during the course of ankylosing spondylitis. 
Fig. II-4

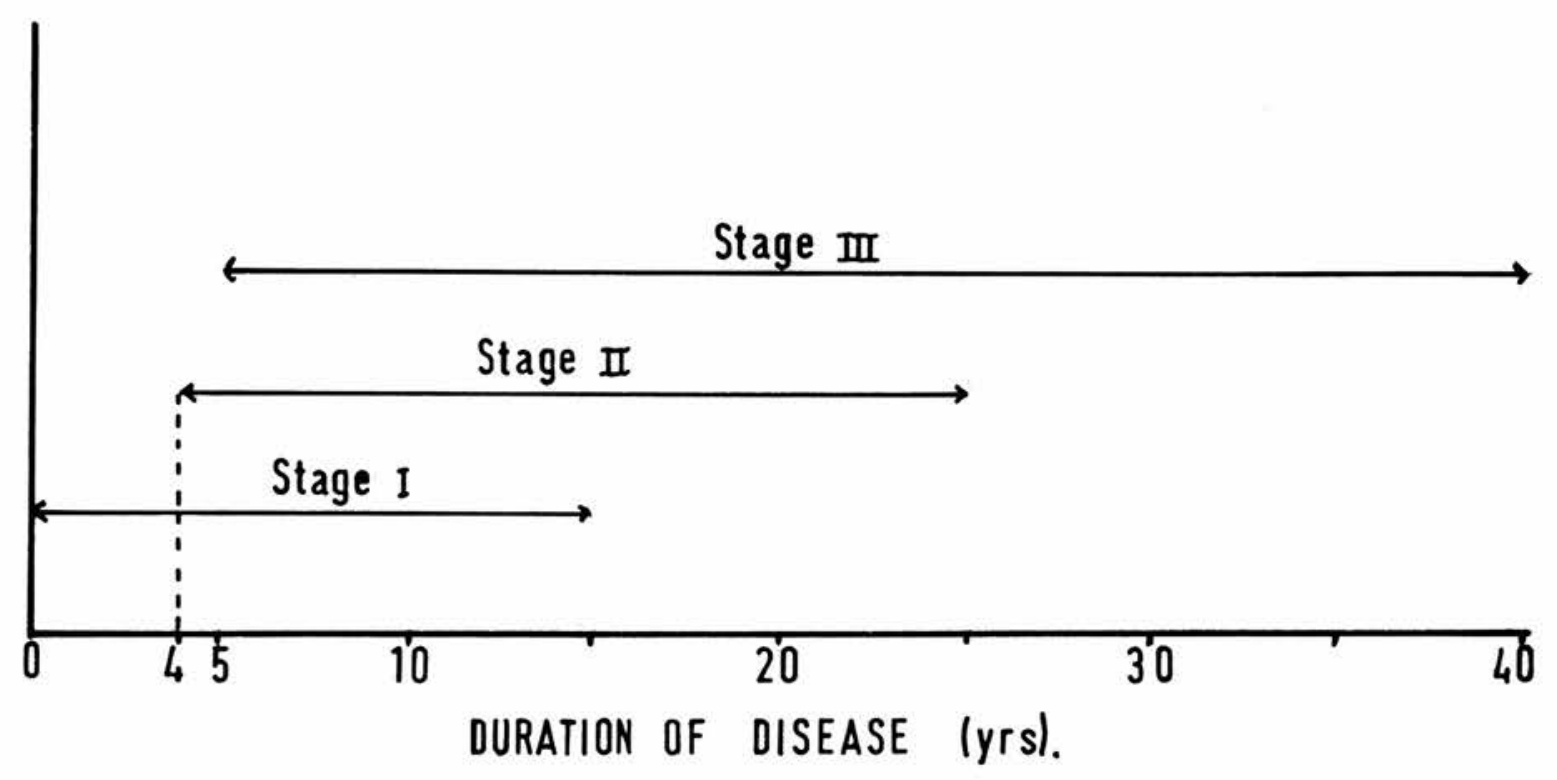

Evolution of sacro-iliac changes during the course of

Ankylosing Spondylitis.

After Forester and Deslous-Paoli (1957) 
which doubt was cast was alteration in joint width, a parameter the importance of which, had previously been doubted by willis (1933). Some authors have attributed diagnostic significance to minor radiographic changes in patients in whom early $x$-rays were considered normal, whereas later radiographs (Romanus and Yden, 1955; Grainger, 1957) or isotype uptake studies (Webb, Collins, Southwell and Dick-Smith, 1972) showed evidence of sacroiliitis. Such minor "abnormalities" are seen so commonly when large numbers of films are read, that great doubt must he cast on their sirnificance (Haslock, 1972). The differential diggnosis of the changes of bilateral sacro-iliitis is limited provided specific infection, especially with brucella, is excluded. One condition which should be recognised as an important differential diagnostic disease is osteparthrosis, especially as sclerosis and narrowing of the joint space are two of the hallmarks of the disease. Changes attributed to osteoarthrosis are common on dissection (Brooke, 1924) and Newton (1957) stated that "Osteoarthritis of the sacro-iliac joint is a cominon radiological finding". Unfortunately, he did not define the appearance he attributed to osteoarthrosis, and no study of this aspect of sacrc-iliac joint disease has been published.

It seems likely that the other 'rheumatological' causes of sacro-ilittis are, in fact, producing the same disease process in the sacro-iliac joint as ankylosing spondylitis (see Appendix $\mathrm{C}$ ), although no firm evidence has so far been 
offered as to whether Still's Disease, when separated from a juvenile onset on ankylosing spondylitis, should be considered within the concept of seronegative spondarthritis. Fluorosis may produce a similar clinical picture to ankylosing spondylitis, but any changes around the sacroiliac joint are manifestations of a generalised increase in bone density in this disease (Blumberg and Rogan, 1956).

Osteitis condensans ilii was first delineated as a separate entity by Barsony and Polgar in 1928 (Rozko and Farkas, 1959). Although histological, microradiographic and tetracyclene-fluorescence studies have failed to distinguish the bone changes of osteitis condensans from those of spondylitis (Julkunen and Rokhanen, 1969) the radlographic differentiation is usually clear despite the occasional encroachment of the process on to the sacrum (Thompson, 1954). Patients with osteitis condensans may show some symptoms but these are usually non-progressive and comprise pain rather than limitation of back movement (Jacqueline and Arlet, 1959). 
CARPPYR 111.

MATERIXT, \& MEYHODS 
CHAPTER 111. MATERIAL \& METHODS

\section{INTRODUCTION}

Throughout the survey standard letters and proformas were used wherever possible. Examples of each type are are show in Appendix D.

Travelling expenses were offered to all participants and. where appropriate, compensation for loss of work was offered, although this was minimised by the timing of the clinics outside normal working hours, and no claims were made under this heading.

Throughout the survey an attempt was made to follow as closely as possible the methods and questions used in the family study of ulcerative colitis which had previously been undertaken from the Rheumatism Research Unit. This approach was used in order to make comparison of the results of the two series as valid as possible. Certain arbitrary restrictions, e.g. the geographic limits and limitation of second degree relatives, arise from following this policy.

\section{ASCGRTAIITMENT OF PROBANDS}

As part of the policy of continuous research into inflammatory bowel disease in the Department of surgery at Leeds (Professor J.C. Goligher), a survey was inftiated of all patients who had a diagnosis of Crohn's disease recorded on the hospital diagnostic index at the General Infirmary at Leeds. It was ascertained how many were alive, and an attempt was made to trace them all. When such patiants were seen, an attempt was made, wherever possible, to validate the diagnosis of Crohn's disease. 
The Department of Surgery this gained an up-to-date list of all the traceable living patients diagnosed as having Crohn's disease at the Infirmary. Th.is list was made available to the author, and patients living within 20 miles of Ieeds were selected at random. These were sent a letter asking is they would participate in the survey.

\section{EXZNIIHATION OF PROBAIDS}

Respondents were seen in a speciaj evening clinic held twice weekly in the orthopaedic out--patient Department at the Infimary, the venue being chosen because of the presence of radiographic facilities in the clinic. Each patient was questioned according to a standard questionnaire. Physical examination concentrated on the locomotor system, measurement being made of lumbar spine forward flexion using the method described by Macrae and Wright (1969) and of chest expansion using the tape-measure and pelvimeter methods described by Moll (1971). The eyes were examined for evidence of iritis and the skin and nails for psoriasis. No specific examination of the cardiovascular, respiratory or neurological systems were included. The gastro-intestinal system was not routinely examined, although examination was occasionally undertaicen if the patients history suggested the presence of interesting physical findings, or at the patients' request.

Each patient was asiced if they would give permission for their families to be contacted with a view to a similar history and examination being undertaken. The purpose of the investigation was clearly explained in each case. 
Those willing to involve their family members were given a proforma to fill in and returi, detailing names and addresses (hhere known) of the required members of the family.

\section{ASCERTAIMMENT OF RTLATTVES}

The relatives used in the survey comprised all first degree relatives, i.e. parents, siblings and offspring, and a small number of second degree relatives i.e. parents' siblings. The probands' spouses were used as a control population from the same environment.

on receipt of the list of relatives, they were initially divided into two groups - available and unavailable. The latter sroup included the dead, those who for reasons of age (under 15) or infimity could not be included, and those who lived abroad or whose wherabouts were unknown. Attempts were always made when other family members were seen to fill in any gaps in knowledge of addresses on the probands' part. Those available were again subdivided into two groups, inner and outer. The inner group was aelected using the same abritrary geographical constraint applied to the probands, that is residence within 20 miles of Leeds. These petients were sent a standard letter requesting their presence at the evening clinics at the Infirmary. The standard cuestionnaire was again used, and similar examination to tilac of the probands was undertaken. If no reply was received a seccnd letter was sent, and in absence of a reply to this a group of medical students visited the relatives homes in an attempt to discover their reason 
for their non-responsiveness. The outer group, i.e. (those living more than 20 miles from Lteds) were sent a standard letter requesting their participation in the survey to the extent of a visit to their nearest hospital for radiography. Non-respondents were sent a second letter, and, in absence of a reply to this, a third letter was sent. Those willing to take part sent a note of the name of their nearest hospital. The radiologists in charge at these hospitals were then sent a letter explaining the purpose of the study and the extent of their commitment, and proved in general extremely co-operative in arranging for the radiographs to be taken.

\section{RADTOGRAPHY}

The radiographic technique used was that reconmended by the Third International Symposium on Population Studies of the Rheumatic Diseases (New rork C lOMS - Bennett and Wood, 1968). Standard explanatory sheets were produced for the use of the radiographers both a survey clinics and in co-operating outer area hospitals. To minimise radiological hazard, no pelvis $x$-rays were undertaken on males aged less than 15 year 3 and females aged less than 45 years unless a clinical indication was present. A lead genadal screen was used for all male patients. All patients were $x$-rayed with their outer clothing removed, as such clothes may contain a plethora of radio-opaque objects. Single films were taken irrespective of the quality of the first film obtained. 
In patients seen at the clinic, radiography was also undertaken of appropriate symytumatic joints.

\section{RADTOGRAPHTC INTEPRRETATION}

The sacro-iliac joints were assessed by two independant observers, viewing the films together but grading them independantly. If significant disagreement occurred the fij.ms were re-read on a later occasion. If disagreement still occurred, a second re-read was undertaken, with discussion of the reasons for the differences in interpretation, in an attempt to produce an agreed grade. If disagreement persisted, provision was made for assessment of the films by an independant radiologist, although this facility was never required. The films were interpreted according to the criteria suggested by the New York Clons (Kellgren, Jeffrey and Ball, 1963) as validated by Macrac, Haslock and. Wright (1871). In an attemt to assess the prevalence of osteo-arthritis of the hip joint and its influence on the diagnosis of sacro-ilittis, the presence or absence of osteophytes at the inferior borders of the sacro-iliac joints was noted.

Assessment of rhewutoid arthritis and osteo-arthrosis was made by a singla observer using prolonged reading sessions. Reference was made to the standard films found in the Atlas of Standard Radiographs (Vol. 2 of the Rome C IOMS Kellgren, Jeffrey and Bait, 1963), their use having been well validated (Kellgren and Bier, 1956; Kellgren and Lawrence, 1957A; Kellgren and Lawrence, 1957B). 


\section{SEROLOGY}

All participants seen in the clinic were asked to give a sample of blood for assessment of rheumatoid factor. One patient was rejected as his arms were covered with an extensive psoriatic eruption, and veinpuncture was considered unwise. The standard Hyland RA test (Baxter Laboratories Ltd.) a well validated latex - fixation test (Morgan 1959) was used for the detection of rheumatoid

\section{factor.}

\section{METHODS OF RECORDING DATA}

Throughout the study subjects were allocated individual numbers (Fig 111 - 1). This was an administrative convenience and provided a simple standard method of $x$-ray identification. It also facilitated transfar of the data to punch cards.

When all the subjects had been examined and x-rayed, the radiographic findings were recorded on standard proformas. Further information about the probands, particularly details of their operative management and histology reports, was obtained from the notes, and the hospital $\mathrm{x}$-rays were reviewed where applicable. The clinical and radiological data, with the result of the latex slide test, was then transferred, using the proforma shown in Appendix D, to standard IBM 80 column punch cards, and analysed using a card sorter. 


\section{FIG $111-1$}

C051038

The prefix $C$ was used for all patients to distinguish

them from the ulcerative colitis survey, which used

the same numbering system without prefix.

051 - this is the family number, allocated to a proband

and all his or her relatives.

03 - designates the order in which the subjects were

seen i.e. 01 first (always the proband), then 02,03 etc.

until the whole family was seen.

8 - denotes the relationship within the family.

The relationship was numbered as follows:-

$1=$ Proband

2 - Mother

$3=$ Father

$4=$ Father's sibs

$5=$ Mother's sibs

$6=$ siblings

7 = Offspring

$8=$ Spouse

Thus in the example quoted above the patient would belong to family number 57, would be the third member of the family seen and would be the proband's spouse. 
CTIAPTER IV

RESULTS 


\section{A. THE PROBAND GROUP}

\section{Ascertainment}

One hundred and twenty two patients were approached directly or sent the standard letter of invitation to attend the research clinic. Of these 116 (95 per cent) attended the clinic. The initial aim was to study 100 families, when 116 probands had been interviewed, 102 had given permission for their family members to be contacted and ascertainment was accordingly terminated. One proband subsequently wrote saying the family did not wish to be involved and one failed to return her list of relatives despite two reminder letters. of the 100 remaining probands, two died in the interval between being seen in the clinic and their relatives being asked to attend. It was considered inappropriate to ask the help of their family members so soon after bereavement, and the final study was, therefore, carried out on 116 patients with Crohn's disease, the probands, and the families of 98 of them.

\section{Age and Sex distribution}

Exactly half the proband group (58 patients) was male and half female. The age distribution at the time of examination is shown in Figs. IV - 1 and $1 \mathrm{~V}-2$. The probands whose families were not seen are represented by the dotted sections in the appropriate age columns. The mean age of the whole proband group was 46 (range 16-74) for the males and 43 (range 15-83) for the females. When the probands whose families were not studied were removed, the mean ages of both male and female groups was 46 years. the range being unchanged. 
Fia. IV -1.

Age Distribution of Probandss males. 
Fig. IV -1

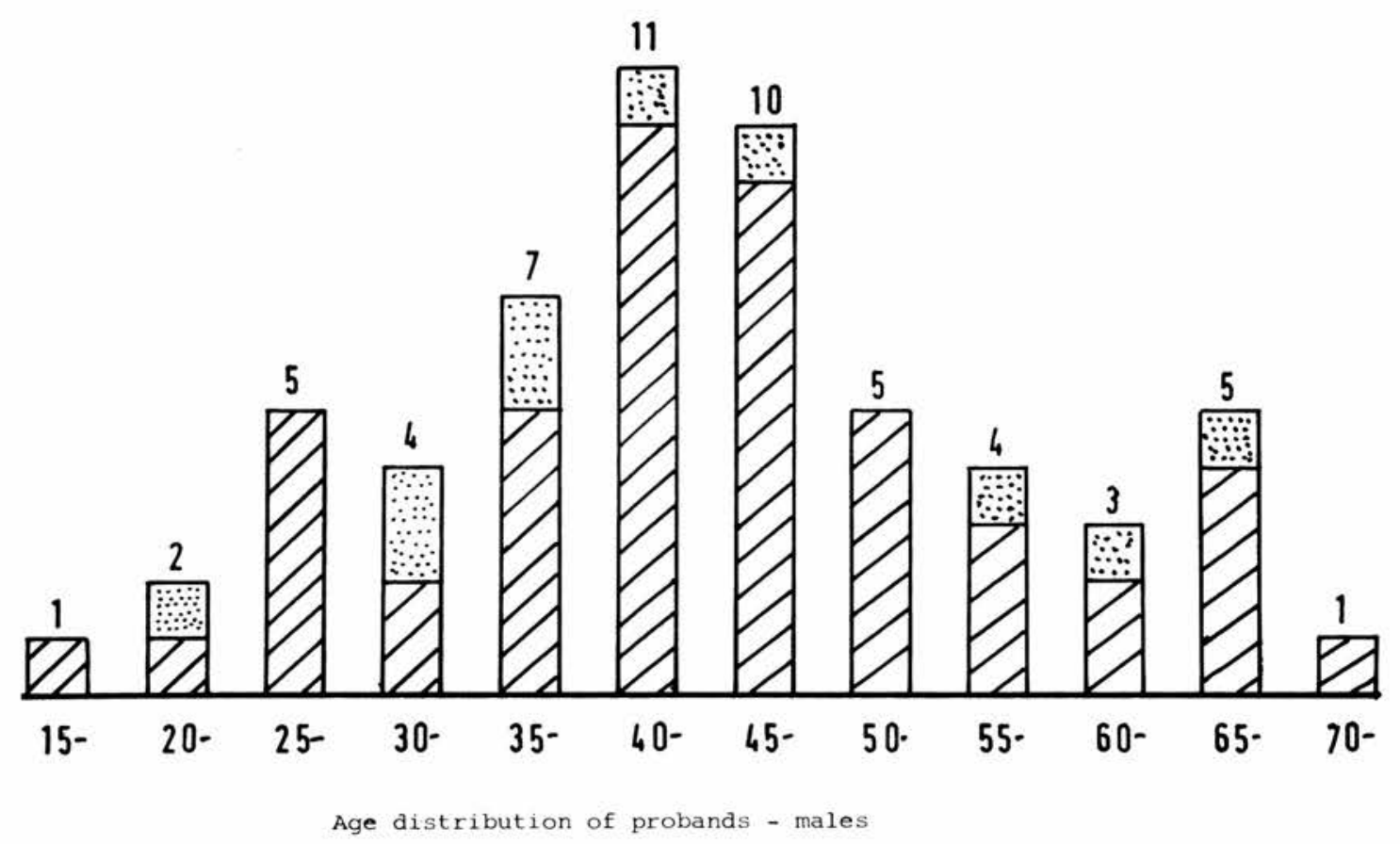


Is. $2 \mathrm{~V}-2$.

Age Distribution of Probandss Lemales. 
Fig. II-2

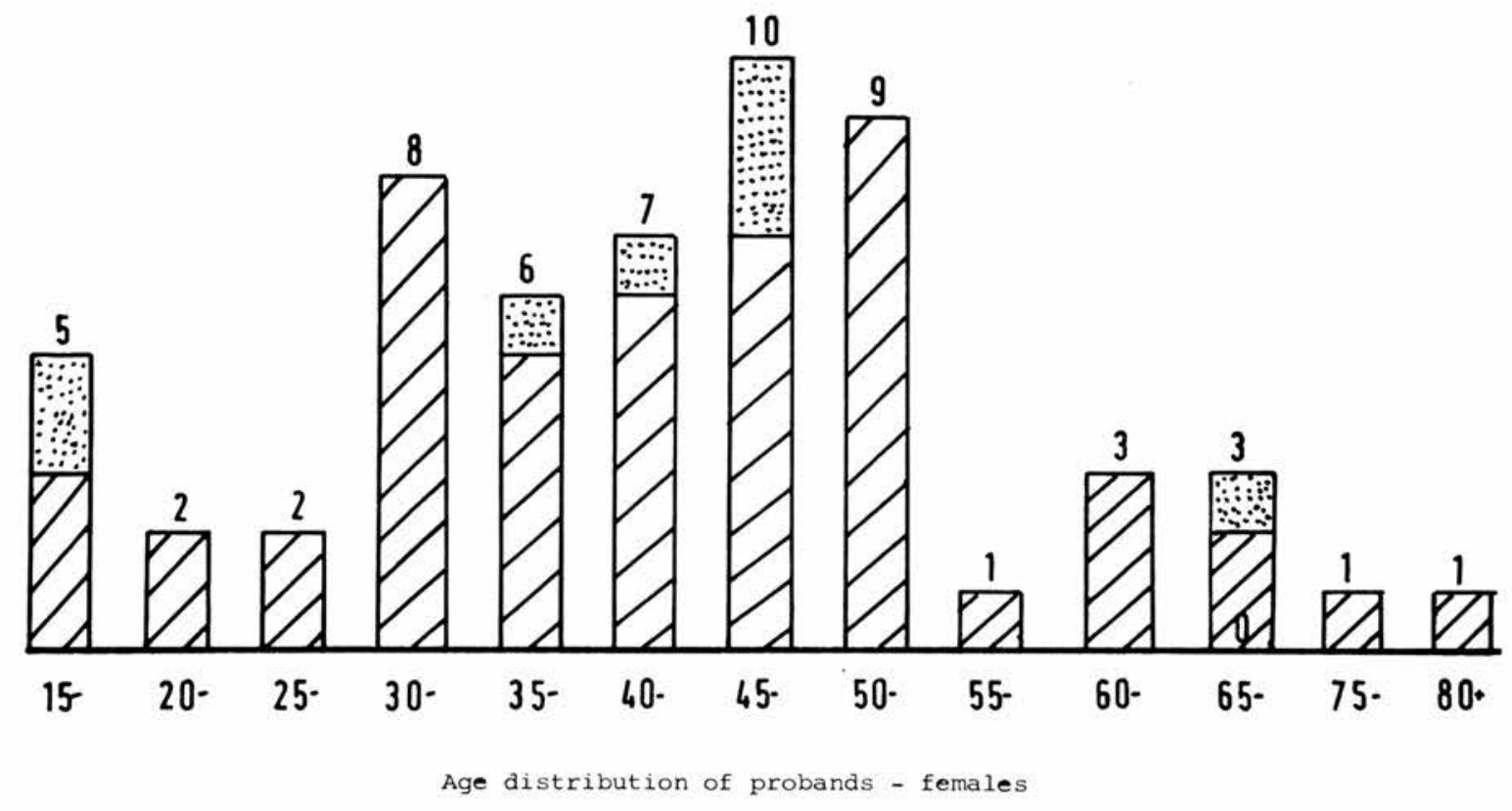




\section{Crohn's Disease}

The method of diagnosis of Crohn's disease is shown in Table $1 \mathrm{~V}-1$.

\section{Table IV - I}

Male

CLINICAL

RADIOLOGICAL

LAPARCTOMY

HISTOLOGICAL

UNINOWN
$5(8.6 \%)$

$5(8.6 \%)$

$21(36.2 \%)$

$24(41.4 \%)$

$3(5.2 \%)$
Female

$5(8.6 \%)$

$5(8.6 \%)$

$14(24.1 \%)$

$34(58.6 \%)$

0
Total

$10(8.6 \%)$

$10(8.6 \%)$

$35(30.2 \%)$

$58(50.0 \%)$

$3(2.6 \%)$

\section{Diacnosis of Crohn's Disease}

Any case in which the histological report was equivocal, irrespective of a confirmatory subsequent course of the disease, is included in the next appropriate diagnostic group. Despite this, an unequivocal tissue diagnosis was obtained in 50 per cent of the patients, and in only 11.2 per cent was the diagnosis made on clinical or incompletely documented grounds.

The age of onset of the Crohn's disease is shown in Fig. IV - 3. The age used is that at which the presenting symptom occured, or the age at which a symptom considered of diagnostic importance at the patients first hospital attendance was noticed. Where the presentation was acute, for example as an acute appendice, the age at the time of admission was used. Although many symptoms elther vaguely remembered or recorded at later interviews may have been caused by the early stages of Crohn's disease, the possibility of the patients' having been biased by a succession of interested observirs was large, and symptomatology of this type was ignored for this purpose. 
EI. IV -3

Age at oaset of Crohn's disease. 
Fig. II -3

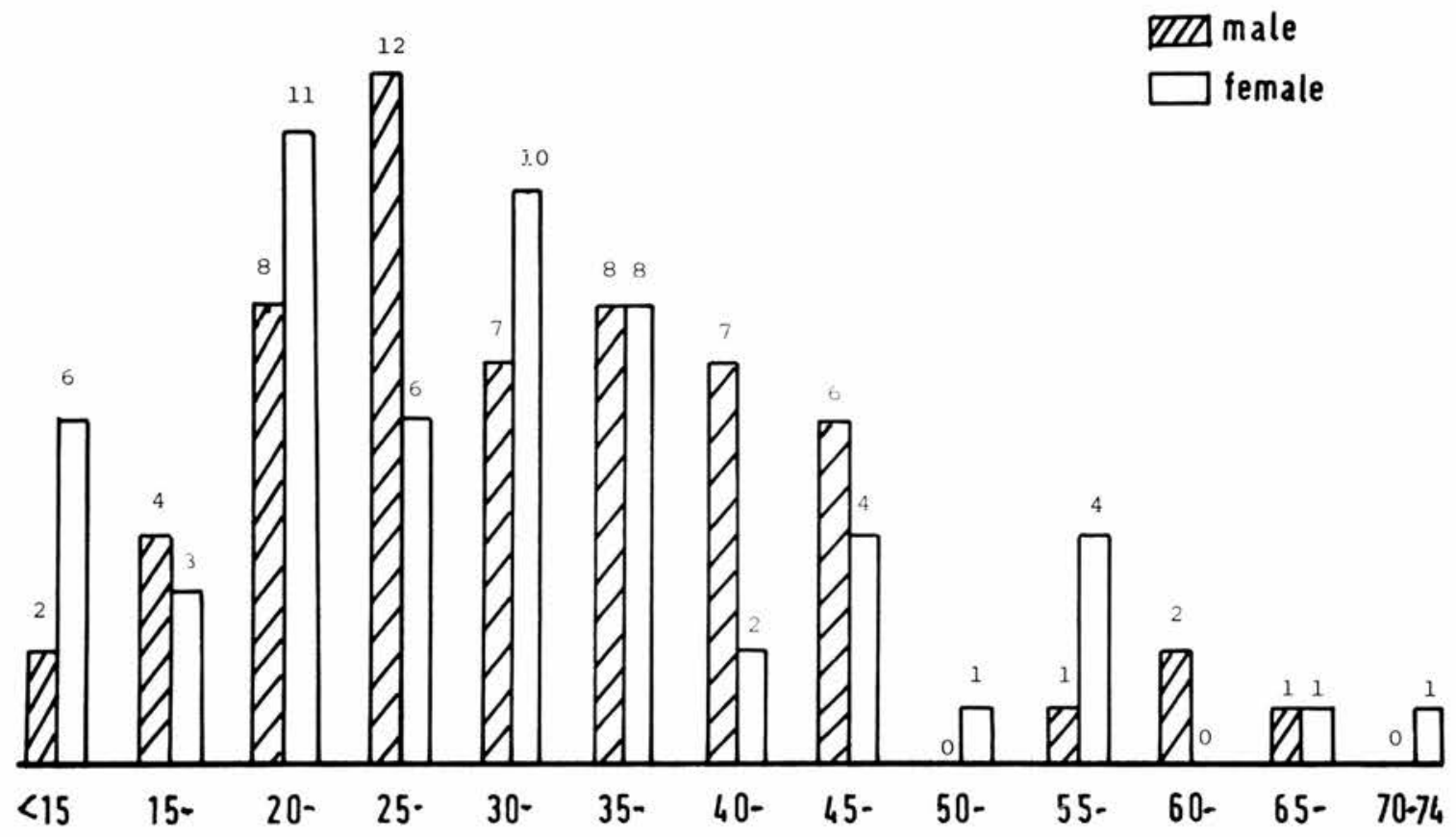

Age at onset of Crohn's Disease 
The mean duration of the Crohn's disease at the time - the patients were seen in the clinic was 12.7 years, with a range of 2 to 45 years. The distribution is shown in Fig. IV - 4.

The area of gut involved in a patient with Crohn's disease cannot be accurately determined. Biopsy studies frequently show histological evidence of the disease at clinically uninvolved sites. An attempt was made, however, to ascertain the area of gut which was found to be abnormal on radiology, direct inspection or histology in each case. The areas of confirmed abnormality are detailed in Figs. IV -5 and IV - 6. It is of interest that 47 per cent of the confirmed areas of involvement were in the colon or rectum. If proven caecal involvement is included in this group, the proportion rises to almost 58 per cent. There was a strong bias towards surgical treatment of the patients, 99 patients having been submitted to some form of surgical procedure. One third of these (13 males and 20 females) had been subjected to total procto-colectomy, this high proportion reflecting the radical approach to Crohn's disease adopted by the professorial surgical Unit at Leeds.

Three major complications were sought by questioning the patients and careful review of their notes. These were internal fistula formation, either between loops of bowel or between bowel and another viscus such as the bladder, external fistula formation and malabsorption. The prevelance of malabsorption, particularly in its lesser degrees, is not 
Hen $2 y=4$

puration of Crohn's al senes. 


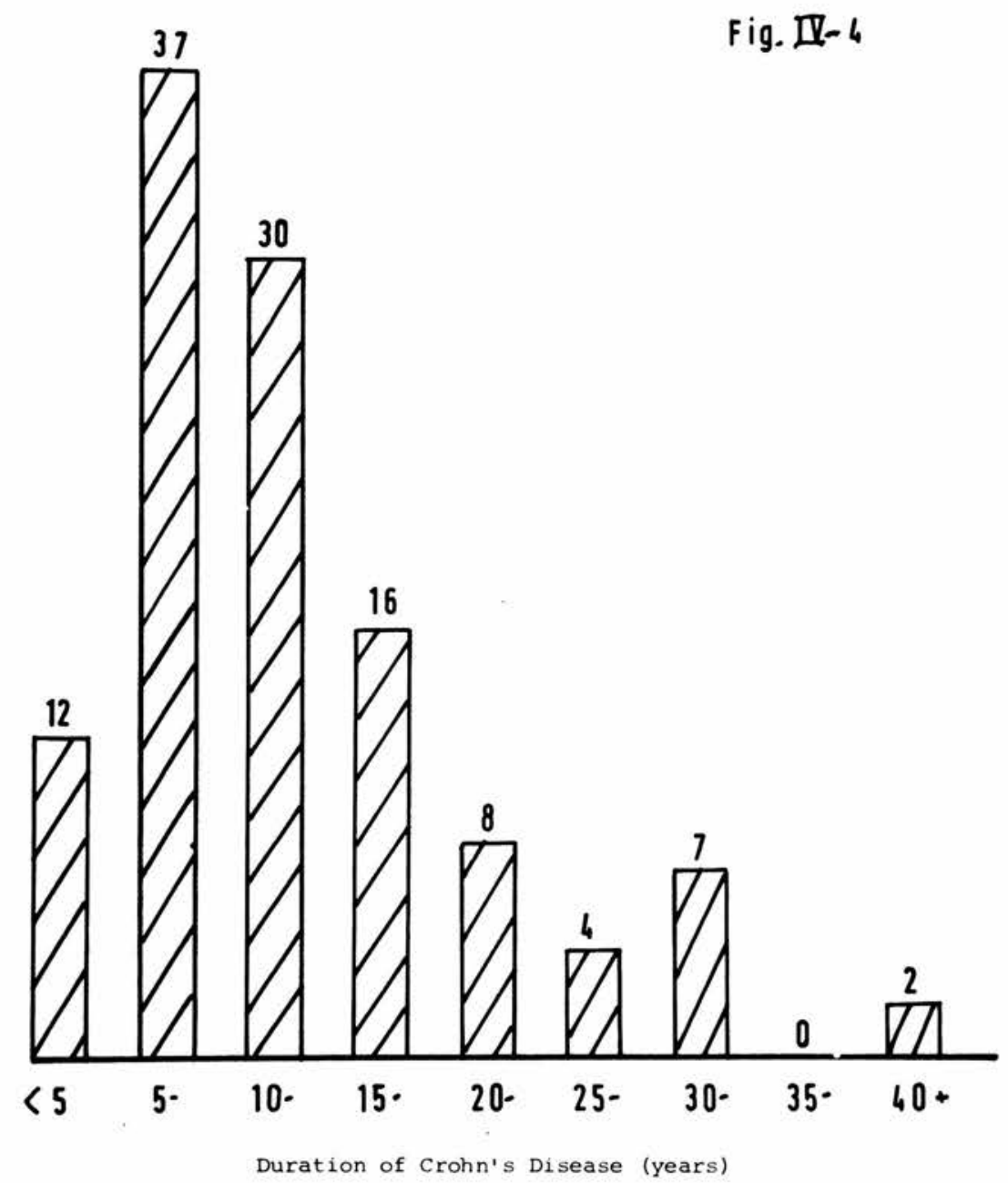




\section{Fig. IV - 5 .}

Area of gut with evidence of involvement on laparotomy, radiology or histology. 


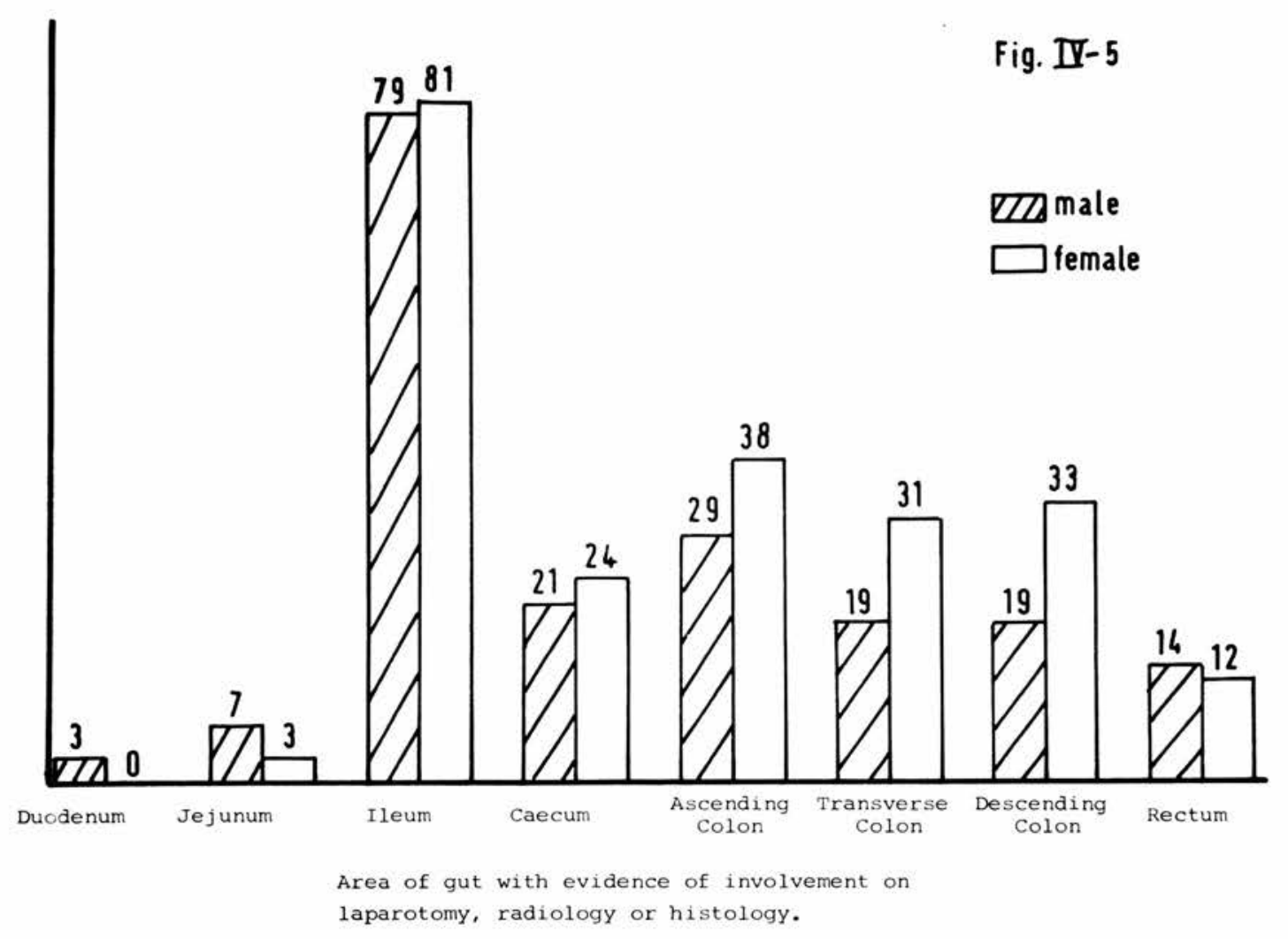




\section{Fig. IV -6}

Area of gut with evidence of involvement on laparotomy, radiology or histology (both sexes combined). 


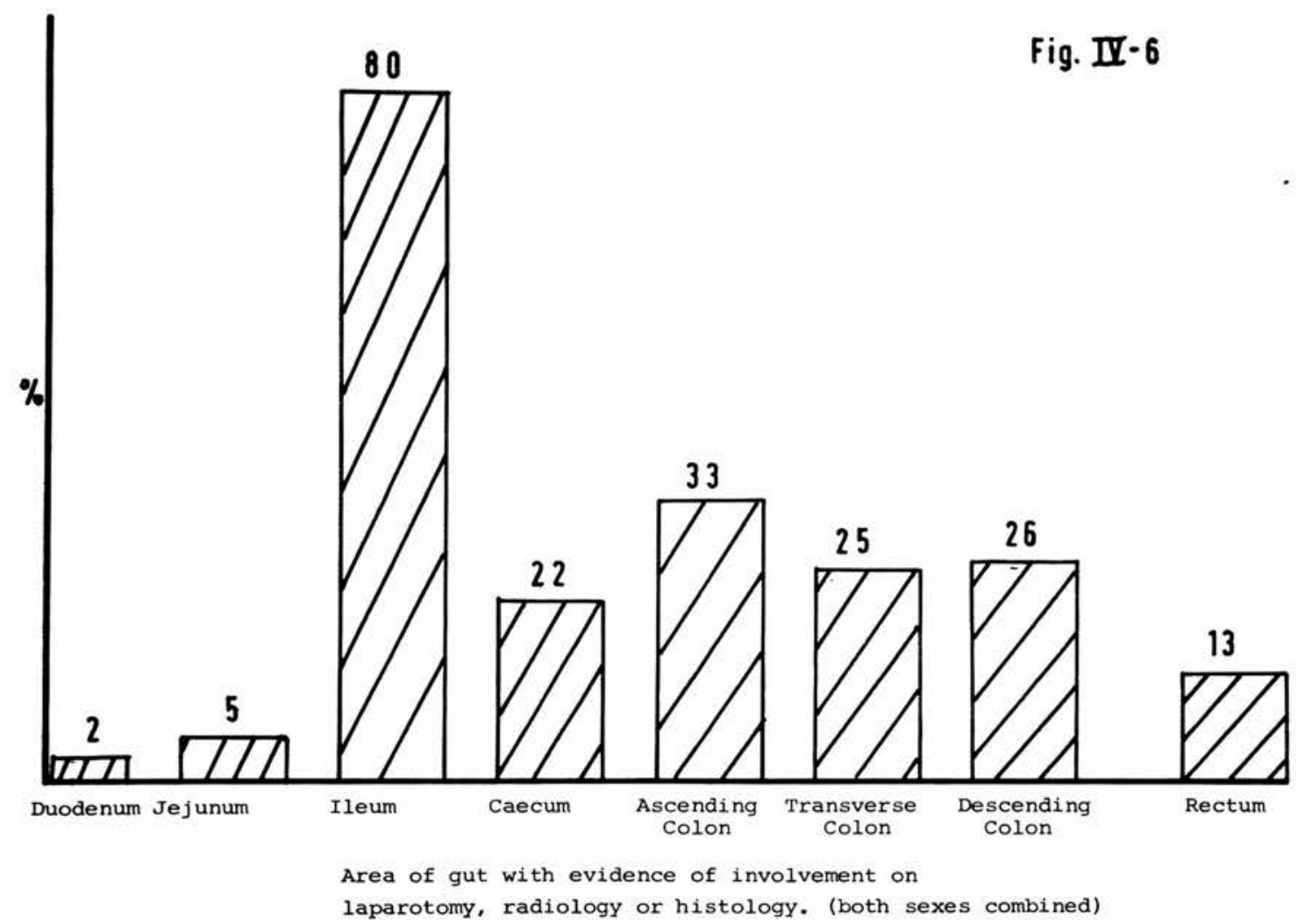


readily obtainable without full metabolic investigations on all patients. The patients included in this group are, therefore, those in whom properly controlled metabolic investigation had shown malabsorption of fat to be occuring. This is obviously an underestimate of the problem. In view of its importance in the sero-negative spondarthritis group, the incidence of iritis was estimated. Where the diagnosis had not been made by an opthalmologist, the patients recollection of the event was matched with the recorded history, and an attempt made to eliminate conjunctivitis. The incidence of these complications is shown in Table IV - 2 .

\begin{tabular}{lcccc}
\hline & Table 1V - 2. & \\
\cline { 3 - 4 } & Male $(58)$ & Female $(58)$ & Total $(116)$ \\
Internal Fistulae & $15(25.9 \%)$ & $14(24.1 \%)$ & $29(25.0 \%)$ \\
External Fistulae & $13(22.4 \%)$ & $9(15.5 \%)$ & $22(19.0 \%)$ \\
Malabsorption & $4(6.9 \%)$ & $4(6.9 \%)$ & $8(6.9 \%)$ \\
Iritis & $5(8.6 \%)$ & $12(20.7 \%)$ & $17(14.7 \%)$ \\
& Incidence of Complications of Crohn's Disease. \\
\hline
\end{tabular}

In no case is there a statistically significant difference between the sexes,. although the incidence of iritis shows a trend towards a higher incidence in females $(p<0.1>0.05)$. The activity of the Crohn's disease at the time of participation in the survey is shown in Table IV - 3. Only one patient was suffering from a significant exacerbation of the disease, but more than one-third were suffering from chronic symptoms, usually diarrhoea or persistent weight loss. 
Table IV - 3

\begin{tabular}{llll} 
& \multicolumn{1}{l}{ Male } & Female & Total \\
Remission & $37(63.8 \%)$ & $38(65.5 \%)$ & $75(64.7 \%)$ \\
Exacerbation & 0 & $1(1.7 \%)$ & $1(0.9 \%)$ \\
Chronic & $21(36.2 \%)$ & $19(32.8 \%)$ & $40(34.5 \%)$
\end{tabular}

\section{Clinical state of Crohn's disease at time of Survey.}

Sixteen patients ( 8 males, 8 female) had symptoms arising from fistulae or malabsorption at the time of examination. 4. Musculo-skeletal Complications

The musculo-skeletal disorders suffered by the probands are shown in Table IV - 4.

Table IV - 4

Male (58) Female (58) All (116)

Intestinal arthropathy Ankylosing spondylitis

$\begin{array}{rrr}10(17.2 \%) & 14(24.1 \%) & 24(20.7 \%) \\ 4(6.9 \%) & 4(6.9 \%) & 8(6.9 \%)\end{array}$

Sacro-ilittis alone

$7(12.1 \%)$

$4(6.9 \%)$

$13(11.2 \%)$

Sacro-iliitis

(t A.S.)

$11(19.0 \%)$

$8(13.8 \%)$

$19(16.4 \%)$

clubbing

$9(15.5 \%)$

$4(6.9 \%)$

$13(11.2 \%)$

Rheumatoid

arthritis

Osteoarthrosis

Miscellaneous

$\begin{array}{lrr}0 & 2(3.4 \%) & 2(1.7 \%) \\ 6(10.3 \%) & 10(17.2 \%) & 16(13.8 \%) \\ 7(12.1 \%) & 7(12.1 \%) & 14(12.1 \%)\end{array}$

- Number of Probands with musculo-skeletal disorders

In addition, a large number of probands complained of backache. The number of complaints of backache in the probands, the relatives and the spouses is show in Table IV -5 . 


\section{Table IV - 5}

$\begin{array}{llccc} & & \text { Back Pain } & & \text { Lumbar Pain } \\ \text { All probands } & (116) & 56 & 44.8 \\ \text { Probands without A.S. } & (108) & 44.4 & 40.7 \\ \text { First Degree relatives } & (107) & 49.5 & 39.3 \\ \text { Second Degree relatives }(40) & 40 & 32.5 \\ \text { Spouses } & (51) & 49 & 37.2\end{array}$

Probands \& Relatives with Back Pain. (per cent)

It can be seen that, when the eight patients in the proband group diagnosed as having ankylosing spondylitis are removed, the proportion of each group suffering from both back pain in general and pain in the lumbar spine specifically is not significantly different.

A number of miscellaneous complaints were recorded which were considered to be coincidental. These are shown in Table IV - 6 .

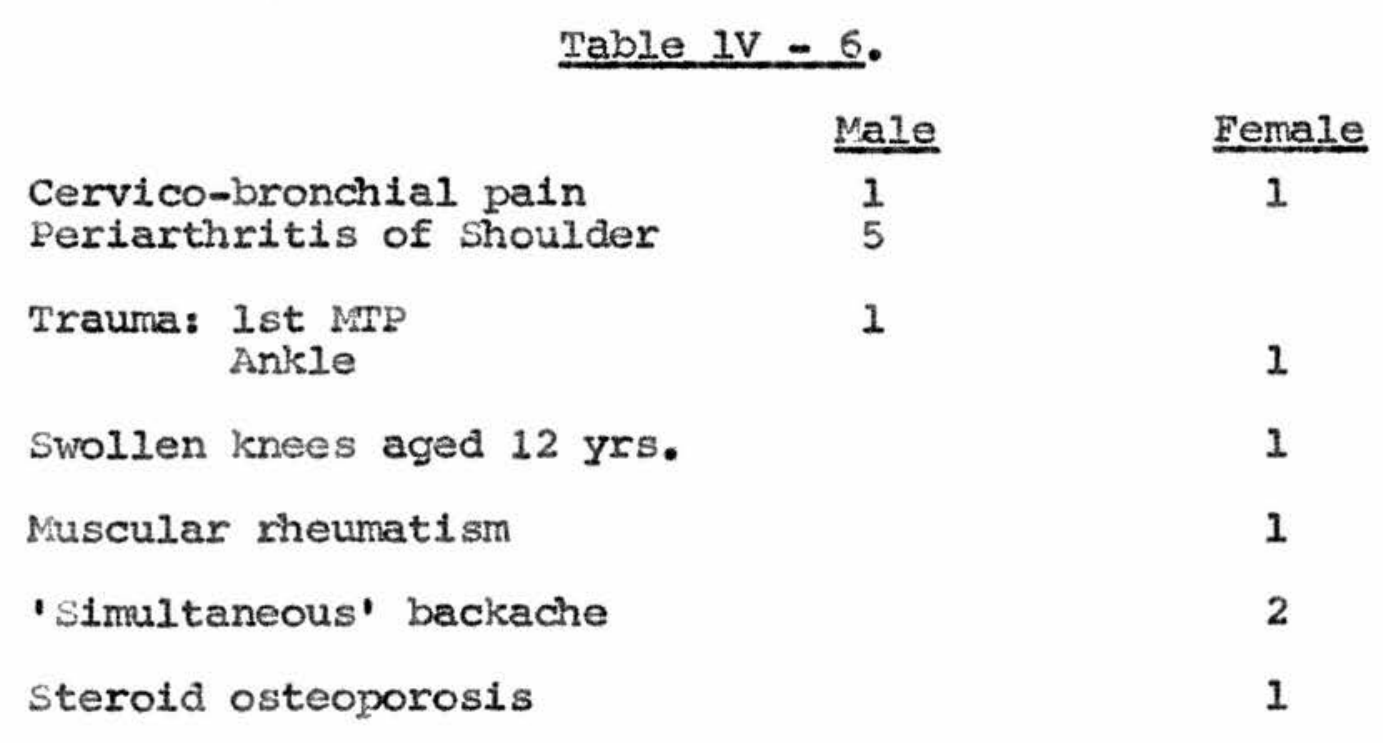


Seven patients had a history of pain in the cervico-brachial region with or without a frozen shoulder. In none of these It was apparent from either the history or examination that this was an inflammatory synovitis rather than idiopathic 'periarthritis' or 'cervico-brachial syndrome'. Where dubiety existed, the patients were classifled in this miscellaneous group rather than as intestinal synovitis. In two patients it was thought that the articular complaints could have been related to trauma. These were an inflammatory episode involving the bunion of a man with a manual job, and an episode of pain and and swelling in the ankle of a lady who gave a vague history of a minor sprain three weeks previously. One patient gave a history of short lived swelling of her knees at the age of 12. Her memory of the distant event was too hazy to be of diagnostic significance. one patient had a history of aching pains involving various muscles, intermittently present over many years. Although painful myalgia has been described in association with Crohn's disease, such histories of non-specific 'muscular rheumatism' are so common in everyday rheumatalogical practice that no special significance was attached to this symptom. There were no abnornal physical signs in this patients' locomotor system. Two patlents gave histories of backache which they were certain bore a close temporal relationship to the activity of their Crohn's disease. The precise nature of this symptom is not apparent, although it appears most likely to be referred pain. One girl had been extensively investigated by the late professor paul Fourman, who had diagnosed steroid osteoporosis as the 
cause of the crush fracture in the dorsal spine.

The two female patients diagnosed as having rheumatoid arthritis would have been classified as A.R.A. probable and classical respectively. Both were under the care of rheumatological clinics. The patient with classical disease had Feltys syndrome. Both were sero-positive.

sixteen patients had a clinical and radiological diagnosis of osteoarthrosis made. Thirteen showed changes of generalised osteoarthrosis, two had clinical osteoarthrosis of the knee confirmed by $x$-rays and one, a keen horse-rider, had severe osteoarthrosis confined to the right hip.

The other musculoskeletal complications were considered to have a causaI relationship to the Crohn's disease, and will be considered in greater detail.

\section{Intestinal Arthropathy}

Twenty four patients were diagnosed as having intestinal synovitis. This was diagnosed if the patients gave a history of an attack of acute painful swelling of synovial joints. Ten patients ( 4 male and 6 female) showed active synovitis at the time of examination. Five males and 5 female patients described their joint disease as being synchronous with exacerbation of their Crohn's disease. These facts are summarised in Table IV - 7 .

\section{Table IV -7}

With intestinal arthropathy Male Female AIl Active synovitis at time of examination synchronous activity of gut and joints

$\begin{array}{rrrr}10 & 14 & 24 \\ 4 & 6 & 10 \\ 5 & 5 & 10\end{array}$


The joints involved are show in Table IV - 8 .

\begin{tabular}{lcc} 
& \multicolumn{2}{c}{ Table IV -8} \\
Joints Involved & Males (10) & Females (14) \\
\hline Knee & 7 & 11 \\
Ankie & 2 & 7 \\
Shoulder & 2 & 2 \\
Wrist & 3 & 0 \\
Elbow & 2 & 1 \\
Metacarpo-phalangeal & 2 & 0
\end{tabular}

Probands with Intestinal Arthropathy:

Joints Involved.

The knee joints were most commonly affected, and a predominance of large over small joints and upper limb over lower was seen. In addition to the information summarised in the table, one of the patients who's synovitis was restricted to his anile at the time of examination was subsequently referred to the rheumatological clinic with an attack of synchronous intestinal arthropathy involving one thumb metacarpo-phalangeal joint. This had been misdiagnosed as gout.

- The relationship of the time of onset of the gut and jolnt symptoms is shown in Fig. IV - 7. In 2 patients only the symptoms from the Jointsantedated those of the Crohn's disease. These patients articular symptoms were recorded 10 and 18 years respectively before the gastro-intestinal ones. The time after the appearance of gastro-intestinal symptoms varied from 2 to 19 years, the mean time being 9 years (F1g. IV - 8). 
Fo. IV -7.

Onset of Crohn's disease and intestinal arthritis. 
Fig. II - 7

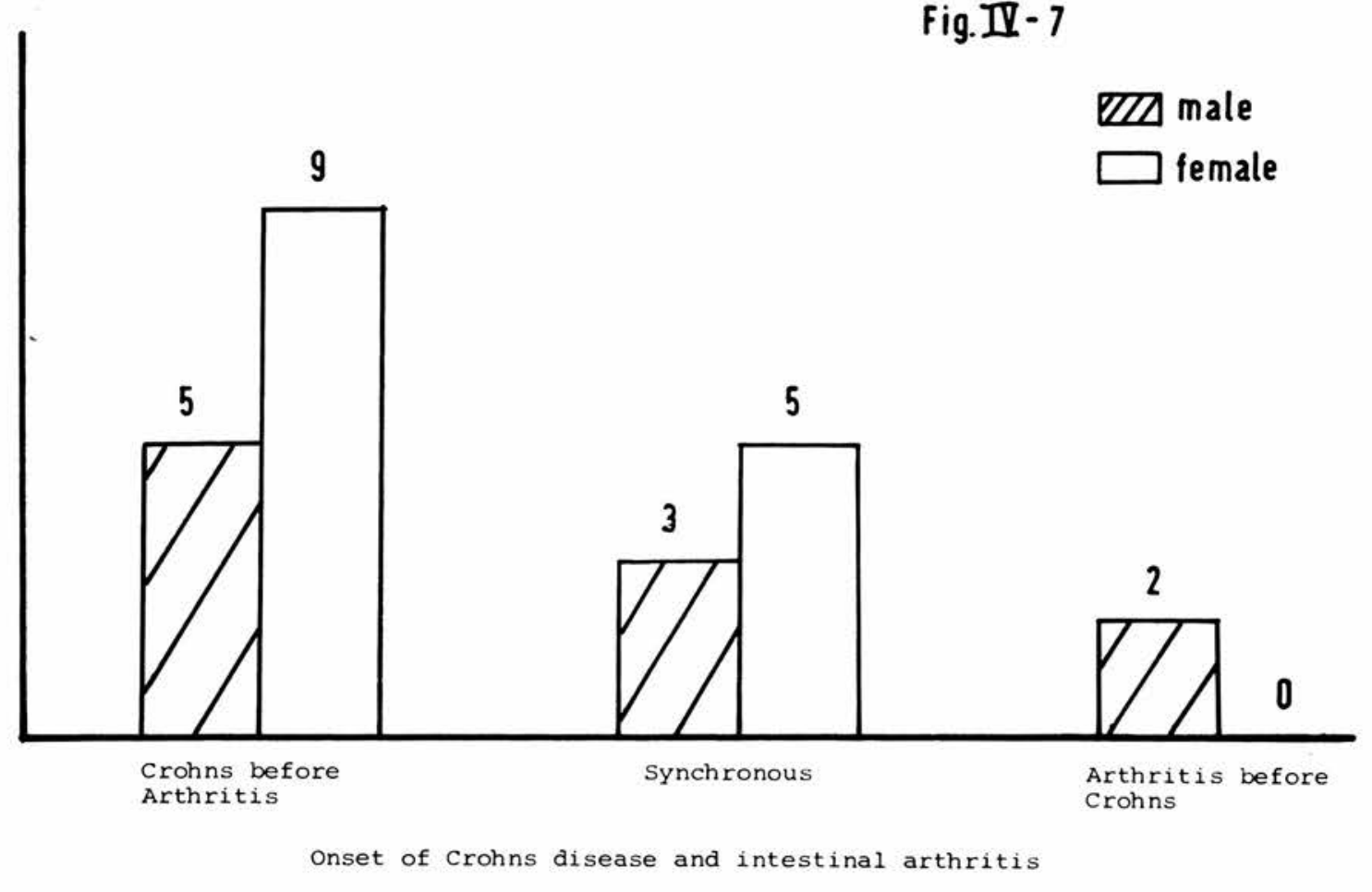


Eig. IV -8 .

Time interval between onset of symptoms from Crohn's disease and intestinal athropathy. 
Fig. II - 8

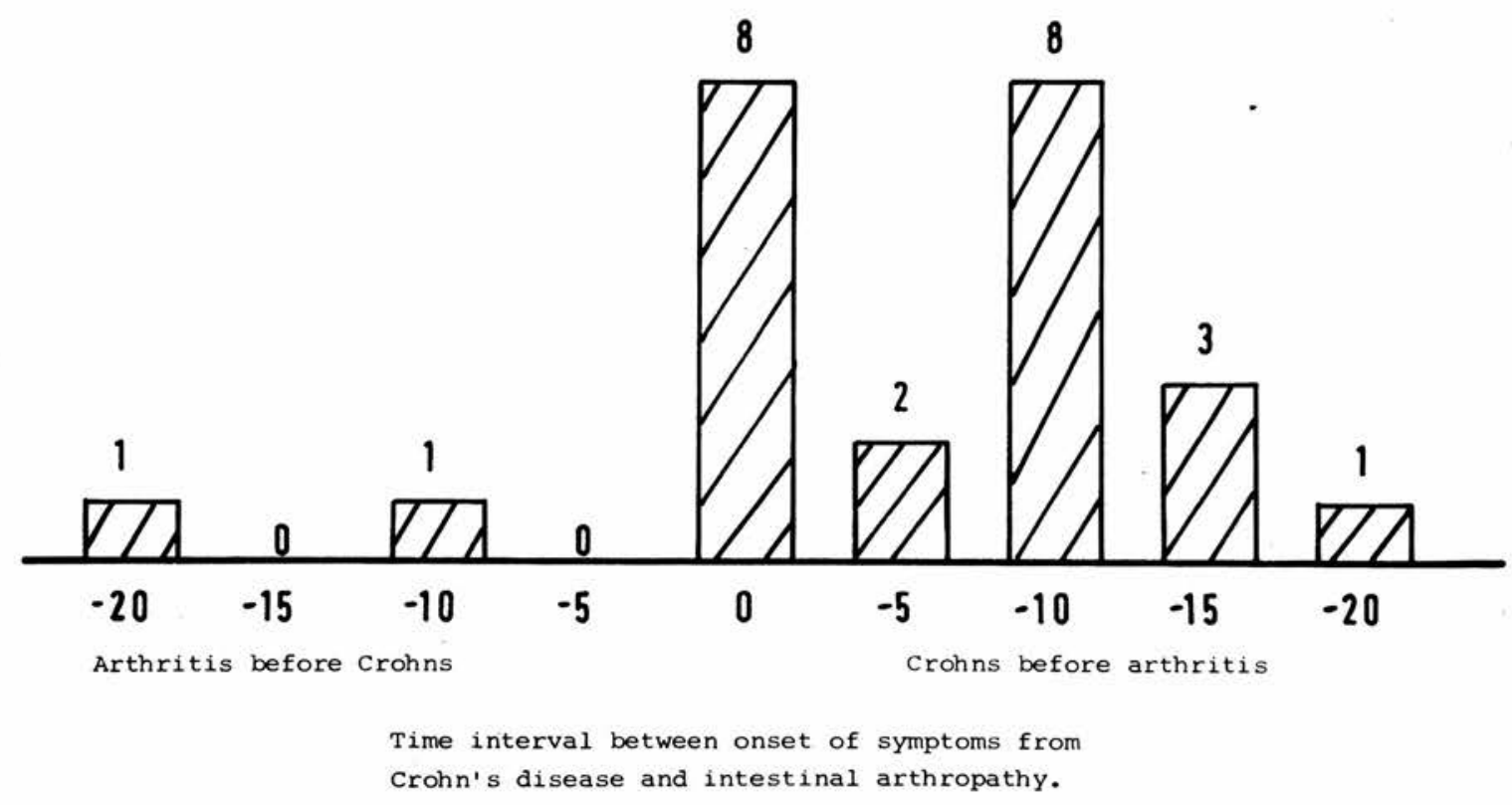


The portions of the gut demonstrated to be involved in patients with intestinal arthropathy are shown In Fig. IV - 9, and compared with the probands without intestinal arthropathy. The overall pattern of involvement is similar, although a trend is shown towards a greater proportion of large intestinal involvement in the patients with arthropathy. The association of the three major complications of Crohn's disease - internal fistulae, external fistulae and proved malabsorption - with intestinal arthropathy is shown in Table IV - 9, and compared with the incidence in probands without intestinal arthopathy. There is no statistical difference between the two groups.

$$
\begin{aligned}
& \text { Table } 1 \mathrm{~V}-9 \\
& \text { Erobands with intestinal } \\
& \text { arthropethy (24) } \\
& \text { Nales(10) Females(14) AlI Males(48) Females(44) All } \\
& \begin{array}{llllll}
3(30 \%) & 7(50 \%) & 10(42 \%) & 21(44 \%) & 15(34 \%) & 36(39 \%)
\end{array}
\end{aligned}
$$


Fig. IV - 9 .

Area of gut known to be Involved in Probands with and without intestinal arthropathy. 


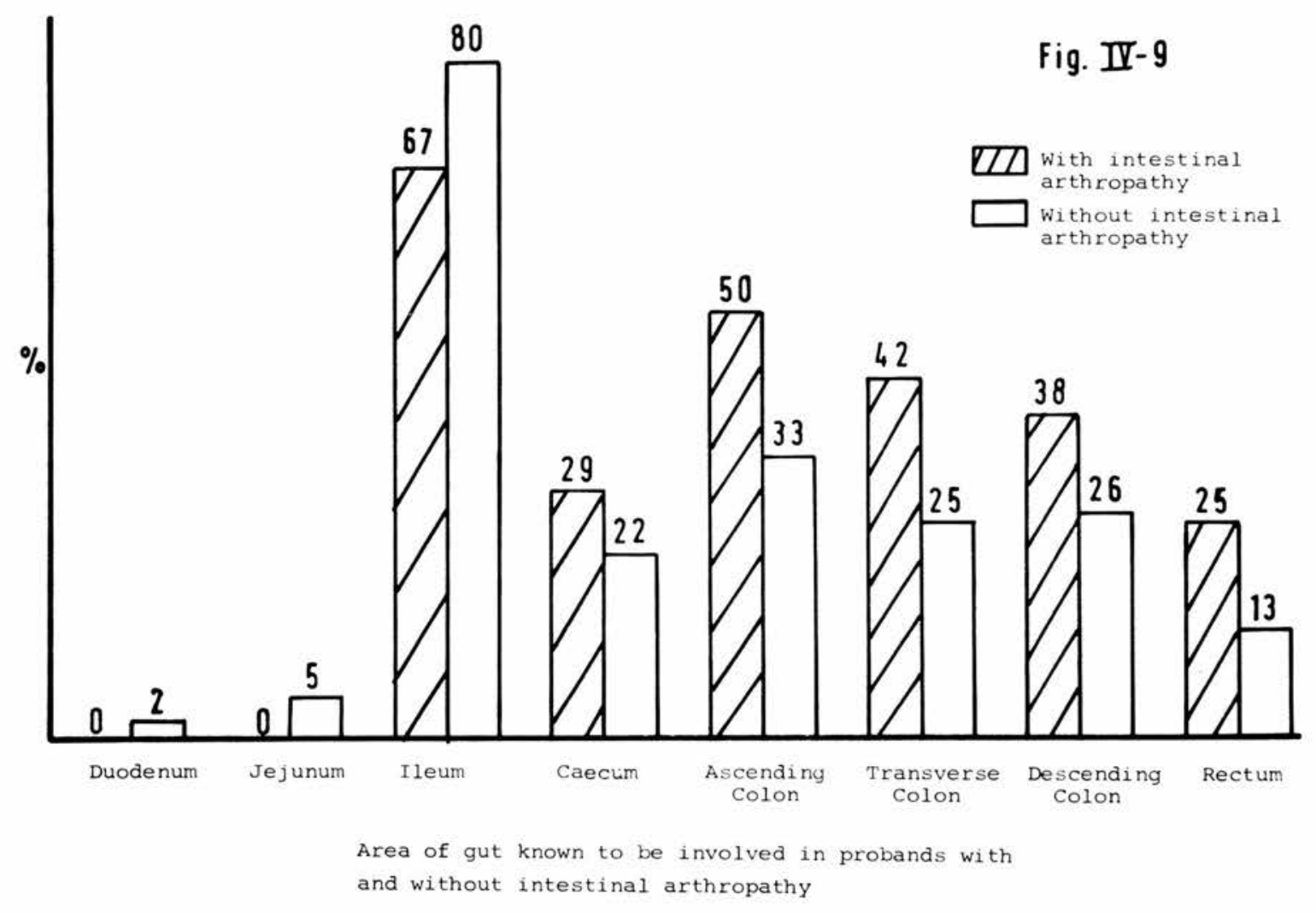


phrased in general terms such as, "Did your operation make any difference to your arthritis" or were your joints better or worse after your operation". Where patients had been subjected to more than one operation at wich gut wa:s resected, the first operation was used as the reference.

\section{Table IV -10}

$\begin{array}{ccccc} & \text { Nales (10) } & \text { Females (14) } & \text { Al1 (24) } \\ \text { Surgery produced exacerbation } & 0 & & 0 & 0 \\ \text { remission } & 4 & & 4 & 8 \\ \text { no effect } & 5 & 9 & 14 \\ \text { Post operative onset. } & 1 & 1 & 2\end{array}$

\section{Effect of surgery on Intestina? Arthropathy}

\section{Ankylosing Spondylitis}

Eight patients, 4 male and 4 female, were diagnosed by New York ClOMS criteria as having ankylosing spondylitis. The criteria fulfilled are shown in Table IV - 11. All the patients could have a diagnosis made on the basis of back pain and sacro-iliftis (grade $2-4$ bilateral or 3-4 unilateral), the combination of these two factors being sufficlent for a diagnosis of'definite ankylosing spondylitis!' In all the male and 2 of the fiemale patients the back pain was localised to the lumbar spine region. One female had pain in the cervical region only, and one combined lumbar and cervical pain. 


\section{Table IV - 11}

$\begin{array}{lccc} & \text { Male (4) } & \text { Female (4) } & \text { All (8) } \\ \text { Pain in the back } & 4 & 4 & 8 \\ \text { Chest expansion < } 2.5 \text { cms. } & 1(2) & 4(4) & 5(6) \\ \text { Limitation of back movement * } & 2(1) & 1(3) & 3(4) \\ \text { Radiological sacro-iliitis } & 4 & 4 & 8\end{array}$

New York cloMs criteria for diannosis of ankylosing spondylitis ( $t$ see text)

The figures quoted for chest expansion utilise the usually accepted criterien of an expansion of less than $2.5 \mathrm{cms}$. The figures in parentheses show the number of patients who would be considered abnormal using the age/sex tables constructed by Dr. John Moll (1971). Similarly, the figures for limitation of back movement are those calculated as abnormal using the regression line calculated by Dr. Ian Macrae (Macrae and Wright, 1969) while those in parentheses show the considered abnormal using the age (sex tables for lumbar spine mobility constructed by Dr. John Moll, (1971).

Bive patients had an associated peripheral arthritis, the joints involved being shown in Table IV - 12. In 3 patients, (I male and 2 female) there were active signs of peripheral arthritis present at the time of examination.

Table IV - 12

Male (2) Female (3) All (5)

Shoulder

Elbow

Wrist

Knee

Ankle $\frac{1}{1}$

1
2

1

1 
The relative time of onset of symptoms attributable to the spondylitis and the Crohn's disease are shown in Fig. IV - 10. The exact temporal relationship is shown in Table IV -13.

Table IV - 13

Male (4) Female (4)

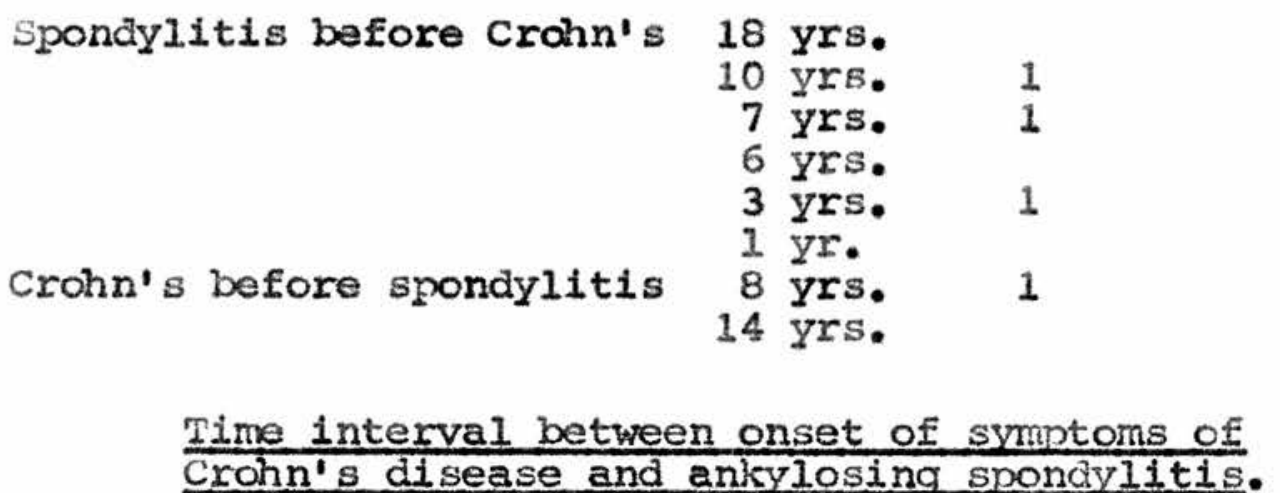

The portion of gut known to be involved in probands with ankylosing spondylitis is shown in Table IV - 14, and the presence of major complications in Table IV - 15.

None of the patients considered the activity of their arthritis and their Crohn's disease to be related, and none considered that surgery had had any effect on the progress of their spondylitis.

Table IV - 14.

Ileum

Caecum

Ascending Colon

Transverse Colon

Descending Colon

Rectum

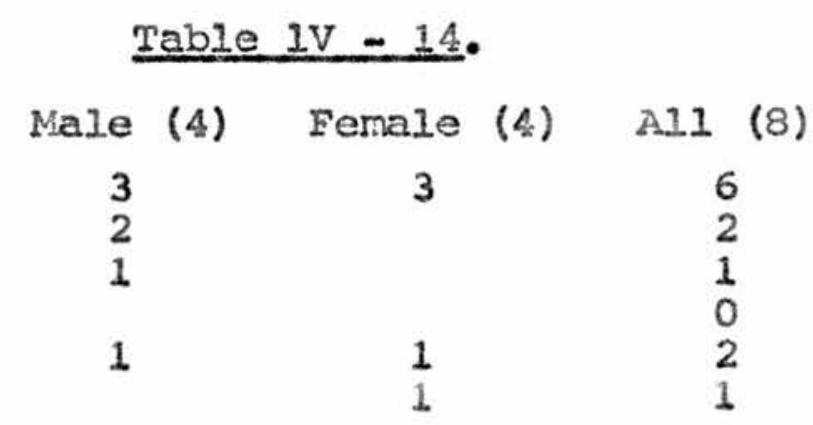

Portion of gut known to be involved in probands with antrylosing spondylitis. 
Fis. IV -10 .

Onset of Crohn's disease and ankylosing spondylitis. 
Fig. II-10

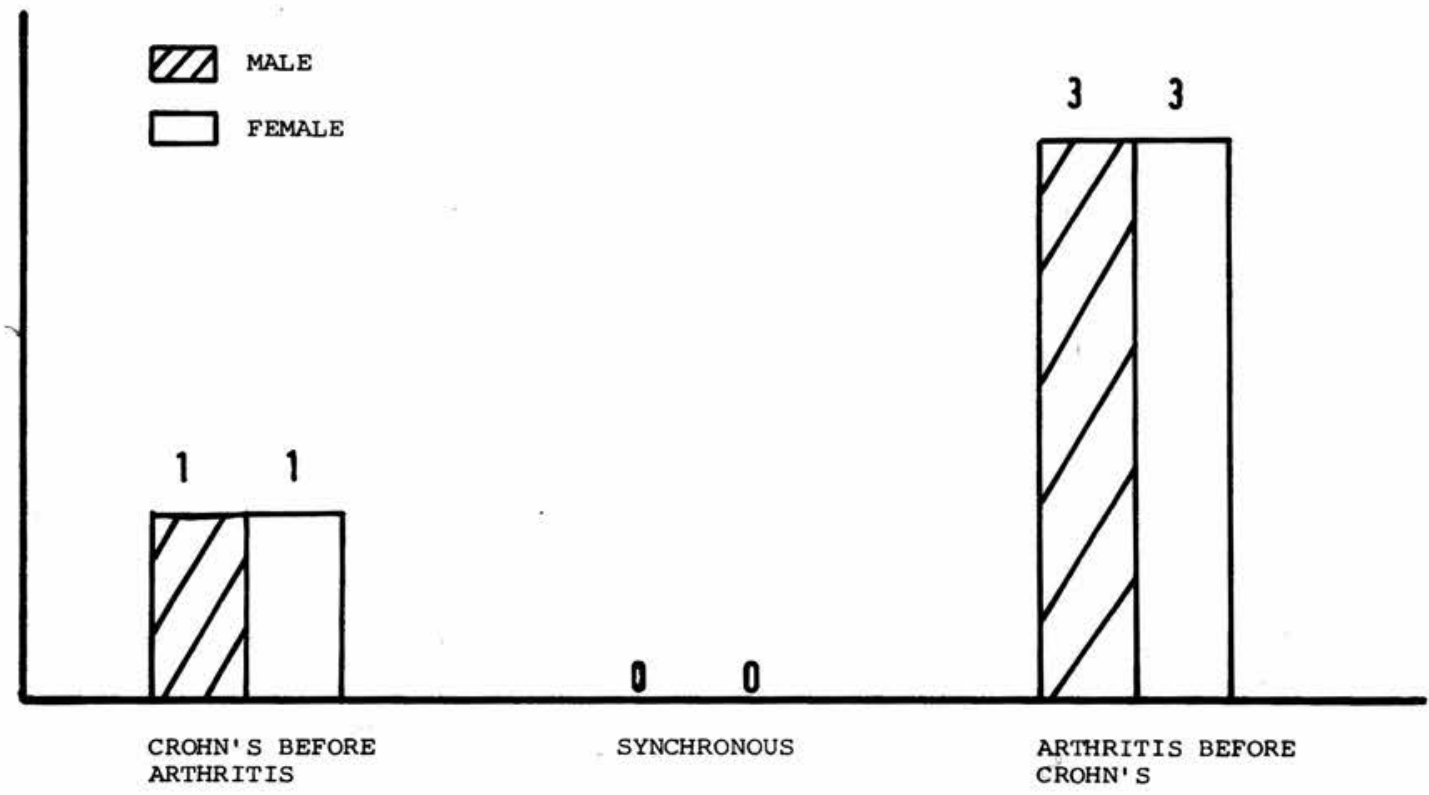

Onset of Crohn's Disease and ankylosing spondylitis 
When the 8 patients with ankylosing spondylitis are added to those with uncomplicated sacro-ilitis, the overall incidence of sacro-ilittis in the proband group is 16.4 per cent. The eleven males comprise 19 per cent of the male probands, and the eight females 13.8 per cent of the female probands.

The portion of gut known to be involved in these patients is shown in Table IV - 16 and the combined figures for all probands with sacro-ilitis in Table IV - 17.

\begin{tabular}{lccc}
\hline & \multicolumn{2}{c}{ Tabie IV -16.} & \\
\cline { 2 - 4 } & Male (7) & Female (4) & All (11) \\
Duodenum & 1 & & 1 \\
Jejunum & 2 & & 2 \\
Ileum & 5 & & 9 \\
Caecum & 1 & 1 & 1 \\
Ascending Colon & 1 & 1 & 2 \\
Transverse Colon & 1 & 1 & 2 \\
Descending Colon & 1 & & 2 \\
Rectum & 2 & & 2
\end{tabular}

Portion of gut known to be involved in probands with sacro-ililits.

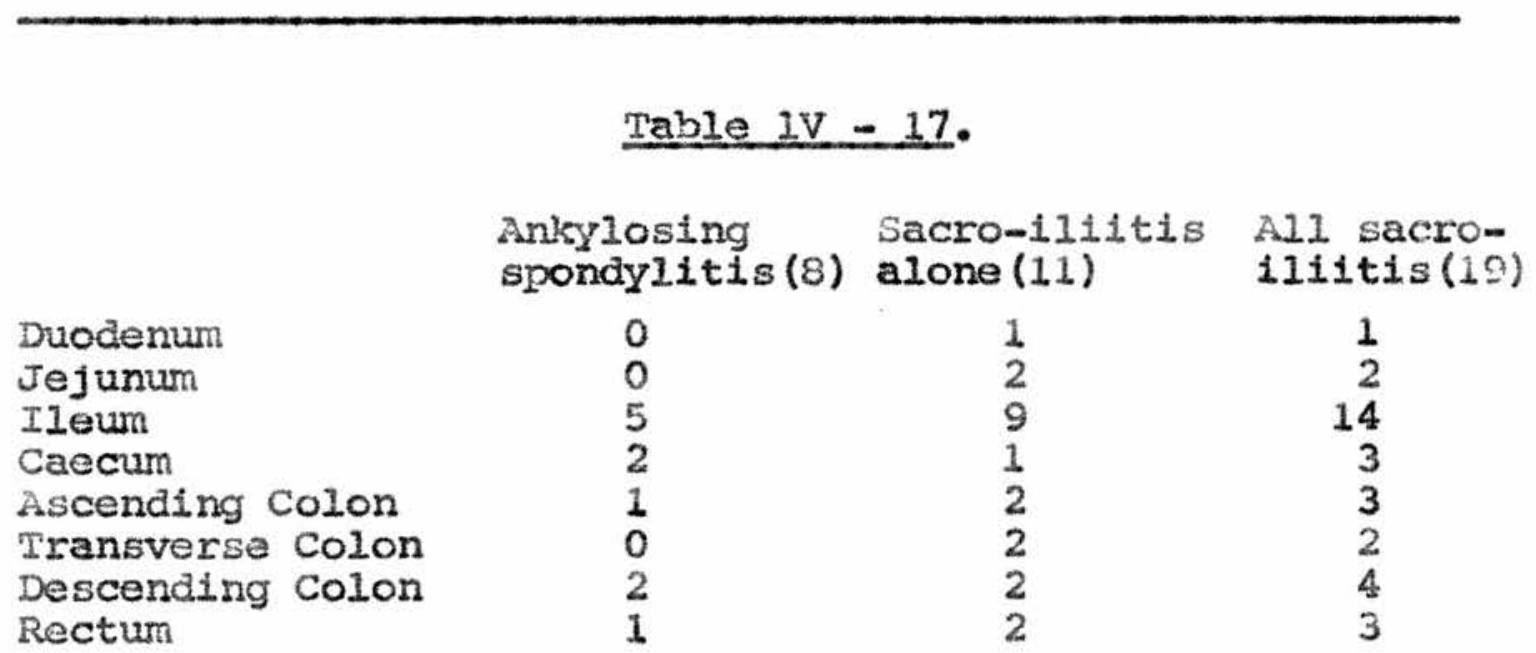

Portion of gut known to be involved in probands with ankylosing spondvlitis and sacro-iliitis. 
The incidence of major complications in probands with uncomplicated sacro-ilitis is shown in Table IV -18 and in all probands with sacro-illitis in Table IV - 19.

No patient with uncomplicated sacro-1liltis had peripheral joint involvement.

Table IV - 18 .

Male (7) Female (4) All (11)

Internal fistulae

External fistulae

4

Malabsorption

2

$\begin{array}{ll}1 & 5 \\ 1 & 3\end{array}$

11

Major complications in probands with

uncomplicated sacro-iliitls.

\begin{tabular}{|c|c|c|}
\hline $\begin{array}{l}\text { Ankylosing } \\
\text { spondylitis (8) }\end{array}$ & $\begin{array}{l}\text { Sacro-iliftis } \\
\text { alone (11) }\end{array}$ & $\begin{array}{l}\text { All sacro- } \\
\text { ilitis (19) }\end{array}$ \\
\hline
\end{tabular}

Internal fistulae External fistulae Malabsorption

$\begin{array}{ll}3 & 5 \\ 1 & 3 \\ 0 & 1\end{array}$

8

4

1

Najor complications in probands with ankylosing spondylitis and sacro-iliitis.

\section{Clubbing}

Thirteen probands (12.1 per cent) were diagnosed as having clubbing. None showed hypertrophic osteoarthropathy on their routine radiographs, although special long-bone views were not obtained. The diagnosis of clubbing is subjective, but the incidence in relatives was one patient only, who had bilateral hilar lymphadenopathy diagnosed as sarcotdosis.

The portions of gut known to be involved in probands with clubbing are shown in Table IV -20 and the incidence of major complications in Table IV - 21. 


\section{Table $\mathbf{~ V}-20$.}

Duodenum

Male (9) Female (4)

All (13)

Jejunum

Ileum

Caecum

Ascending Colon

Transverse Colon

Descending Colon

Rectum

$\begin{array}{rrr} & & 0 \\ 9 & 4 & 0 \\ 2 & 1 & 13 \\ 2 & 1 & 3 \\ & 1 & 1 \\ & 1 & 1 \\ 1 & 1 & 2\end{array}$

Portion of cut known to be

involved in probands with clubbing.

Internal fistulae

Table IV - 21.

Male (9)

Female (4)

All (13)

ixternal fistulae

6

3

Malabsorption

2

2
1
1

8

4

3

Incidence of major complications of Crohn's disease in probands with clubbing.

9. Assessment of New York C10Ms criteria for ankylosing spondylitis.

The proband group has been studied from the point of view of the criteria for ankylosing spondylitis outlined for the New York C10MS conference. Two sets of data are presented. The first gives the sensitivity, specificity and Youden indices for 'definite ankylosing spondylitis' by the C1OMS criteria, those patients with 'probable ankylosing spondylitis' (i,e, radiological sacro-iliitis without the appropriate clinical criteria) being inciuded with the non-spondylitic probands (Table IV - 22). The second includes the probable and definite ankylosing spondylitis groups together, and compares them with those 
probands without sacro-iliitis (Table IV - 23.)

Table 1V - 22

Sensitivity Specificity Youden Index

Back pain

Limited motion of

lumbar spine *

Limited motion of

lumbar spine *k

Chest expansion $<2.5 \mathrm{~cm}$.

Limited chest expansion i*
100

37.5

50

62.5

75

100
47.2

23.6

86.1

86.1

36.1

83.3

45.8

75

* using regression line calculated by Macrae

* using age/sex tables constructed by Moll.

Evaluation of New York C1OMS criteria: definite ankylosing spondylitis v. other probands.

\section{Table $1 \mathrm{~V}-23$}

Sensitivity Specificity Youden Index

Back pain

Limited motion of

lumbar spine

Limited motion of

lumbar spine **

Chest expansion $<2.5 \mathrm{cms}$.

Limited chest expansion **
42.1

41.2

$-16.7$

21.1

85.6

6.7

31.6

91.8

23.4

31.6

82.5

14.1

31.6

100

31.6

* using regression table calculated by Macrae.

$*$ using age/sex tables constructed by Moll.

Evaluation of New York C1OMS criteria: definite and probable ankylosing spondylitis v. other probands. 
In interpreting the tables it should be remembered that the number of probands with the disorder in question is small compared with the normals, the ratio being $8: 108$ and $19: 97$ respectively.

\section{B. THE RELATIVES}

\section{Completion rate.}

A total of 950 blood relatives and spouses were mentioned on the lists returned by the probands. Of these 335 were known to be dead. The remaining 615 were divided into available and unavailable, the reasons for unavailability being specified in Table IV - 24.

\section{Table IV -24}

$\begin{array}{ll}\text { Total number of relatives } & =950 \\ \text { Dead } & =335 \\ \text { Living } & =615\end{array}$

Unavailable: address unknown abroad

business comitments

\section{Availability of Relatives}

Three hundred and forty two relatives and spouse:s remained who were available to the survey. These were further subdivided into inner and outer groups, the same arbitrary geographical criterion (residence within 20 miles of Leeds) 
being used as for the proband group. The overall completion rate was 73.9 per cent, the individual relationship being shown in Table IV -25.

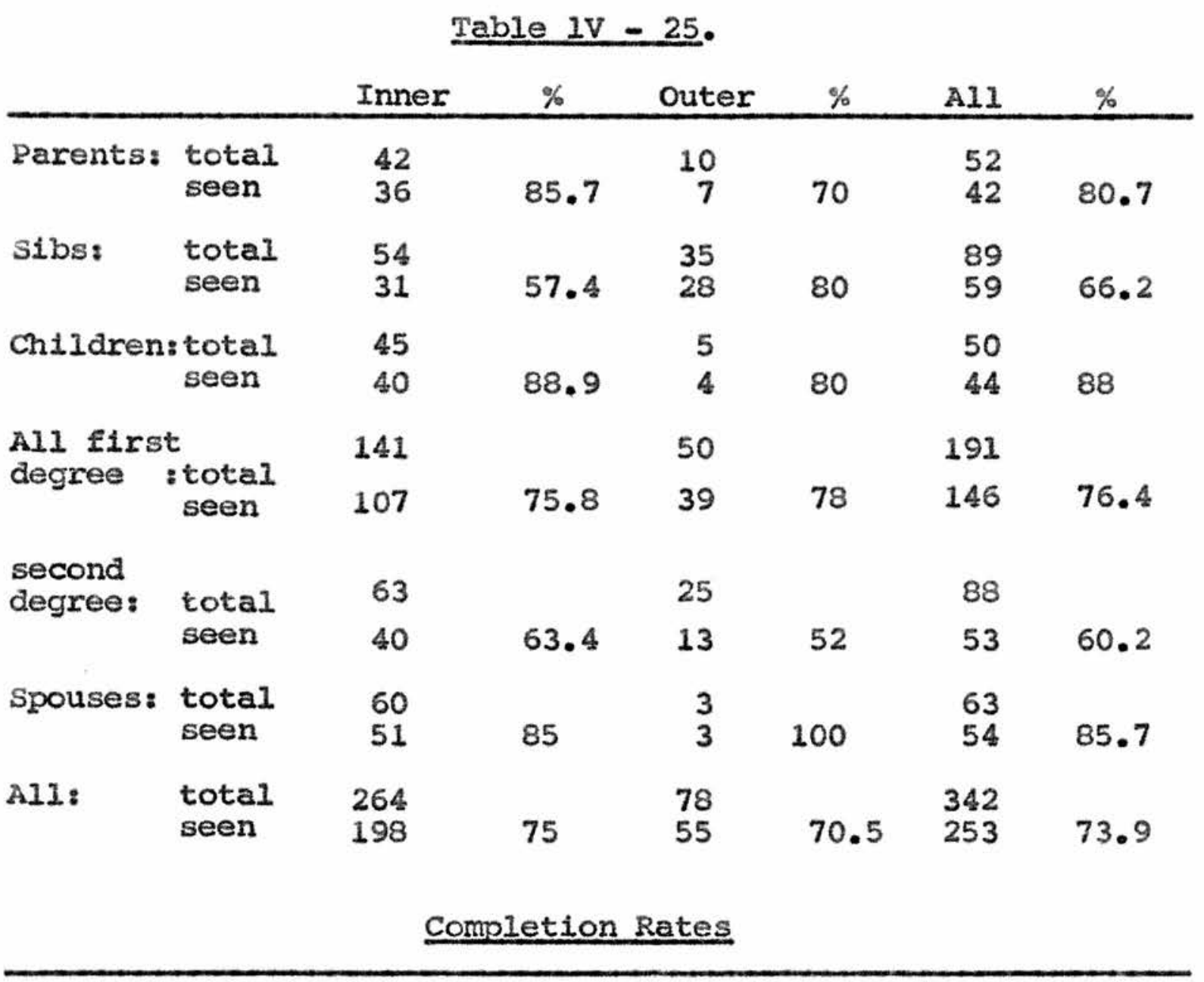

The major cause of non-availability of family members was $10 s s$ of contact between them and the probands and other participating relatives. of next importance was an age below the lower limit set for the survey (15 years) and third cause residence abroad. These exclusions accounted for 198 (84.3 per cent) of the unavailable relatives. Several elderly family members were considered too infirm to make the journey to hospital, and a few probands made specific 
Fig. IV - 11

Age distributions Parents. 
Fig. II-11

III Male

$\square$ Female

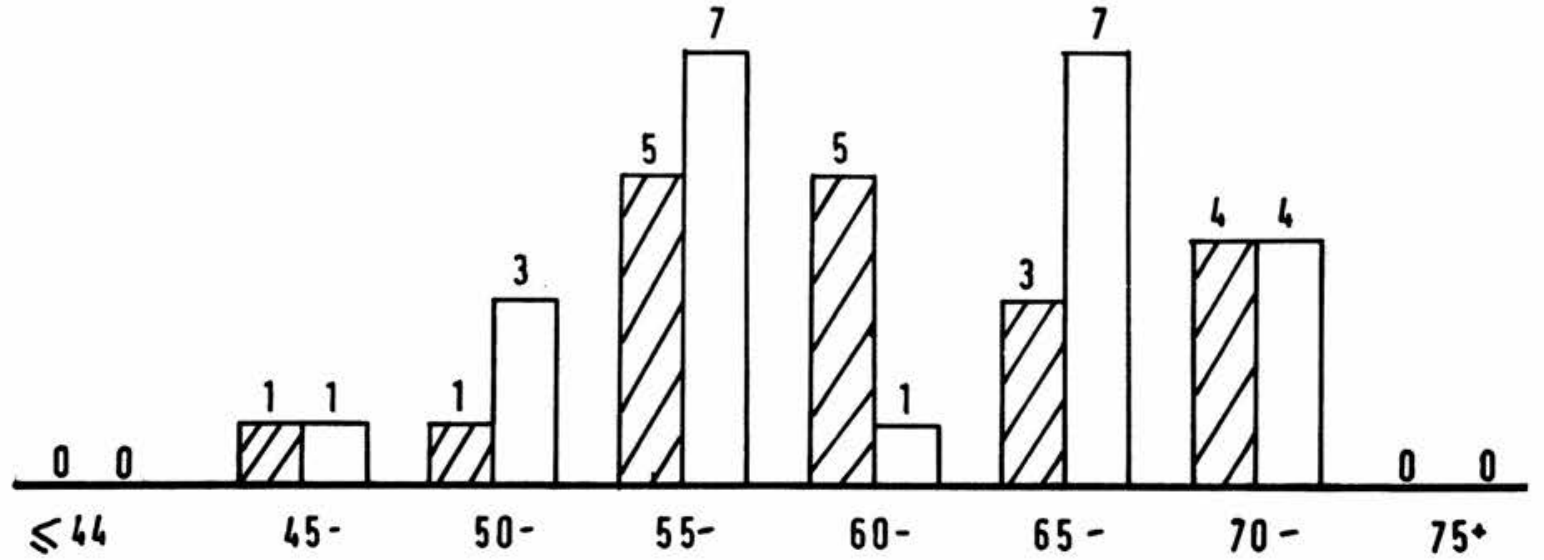


EIg. IV - 12 .

Age distribution: siblings. 
Fig. II-12

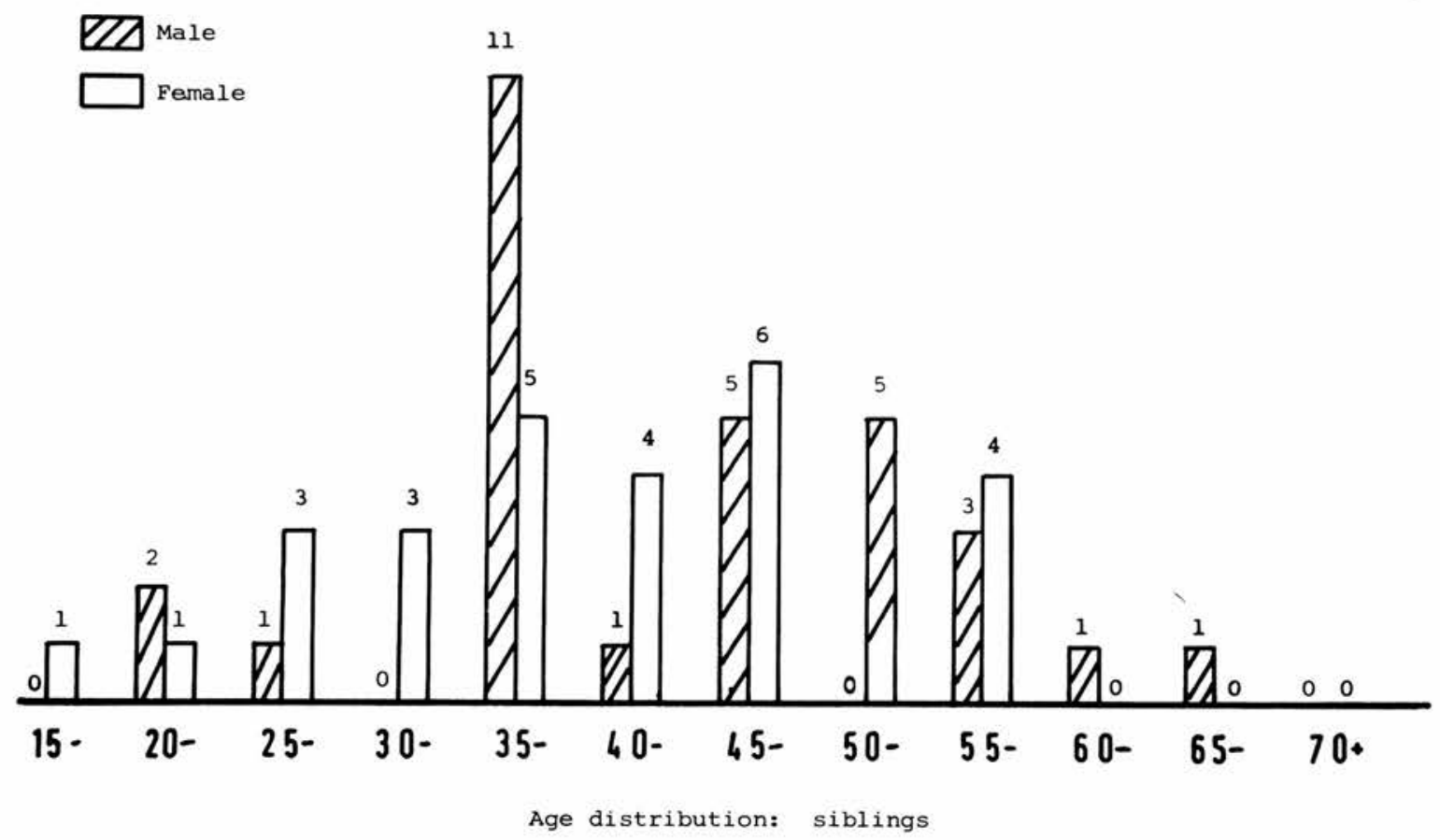


$F 1 g_{2} 1 \mathrm{~V}-13$

Age distribution: chllaren. 
Fig. II-13

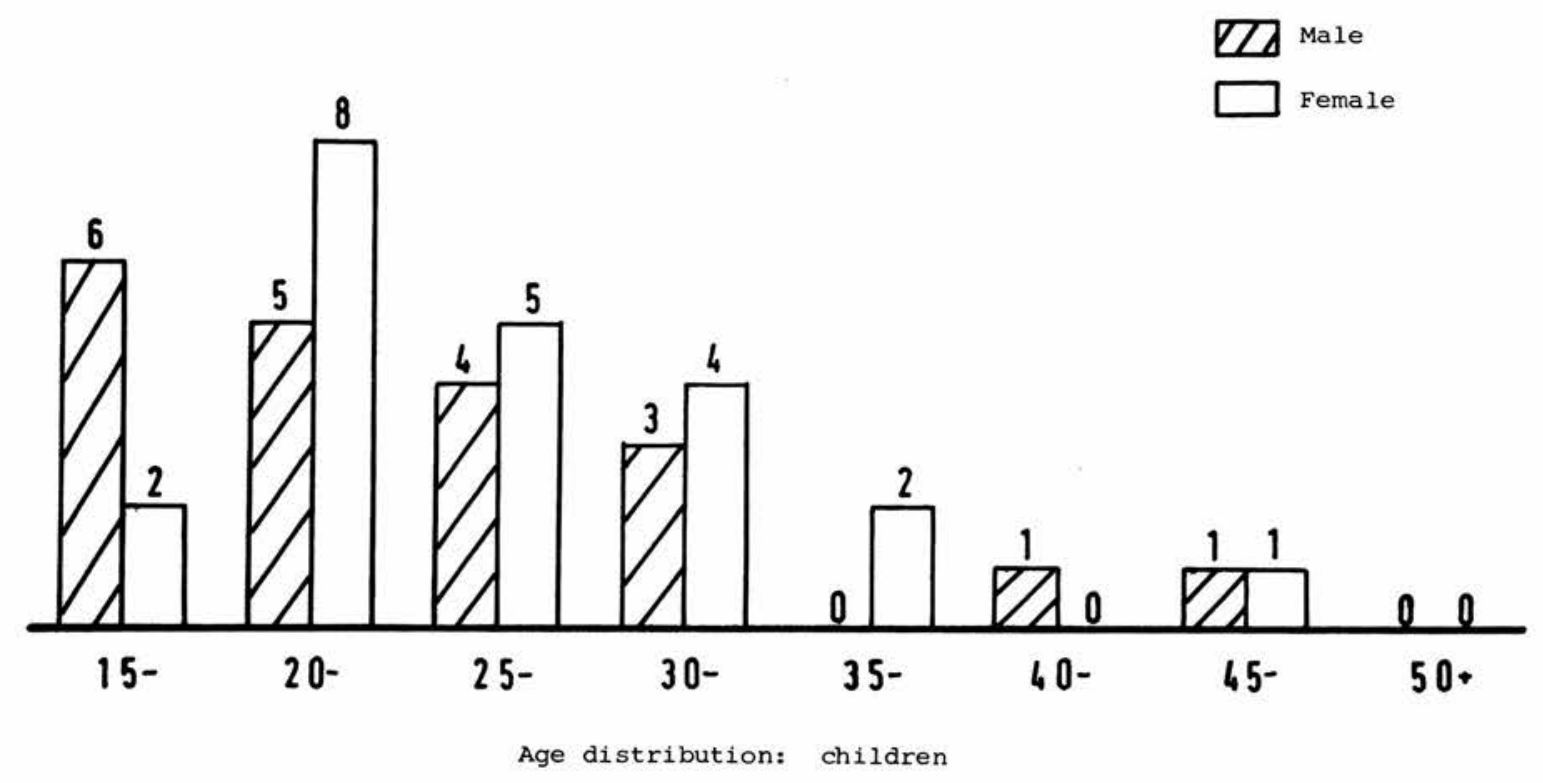


Fig. IV - 14.

Age distribution: second degree relatives. 
Fig. II -14

EZ Male

Female

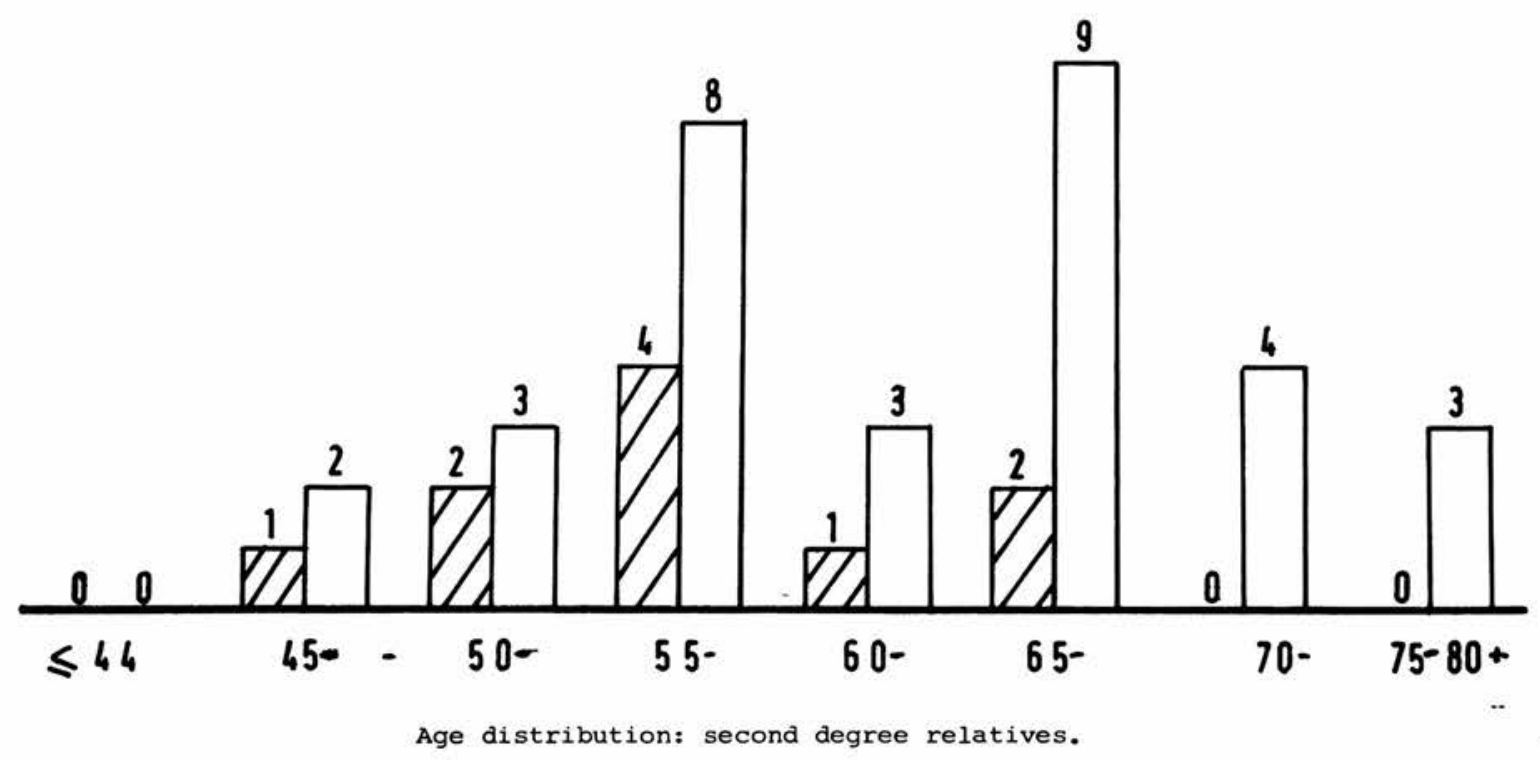


F1a. IV -15 .

Age distribution: spouses. 
Fig. II-15

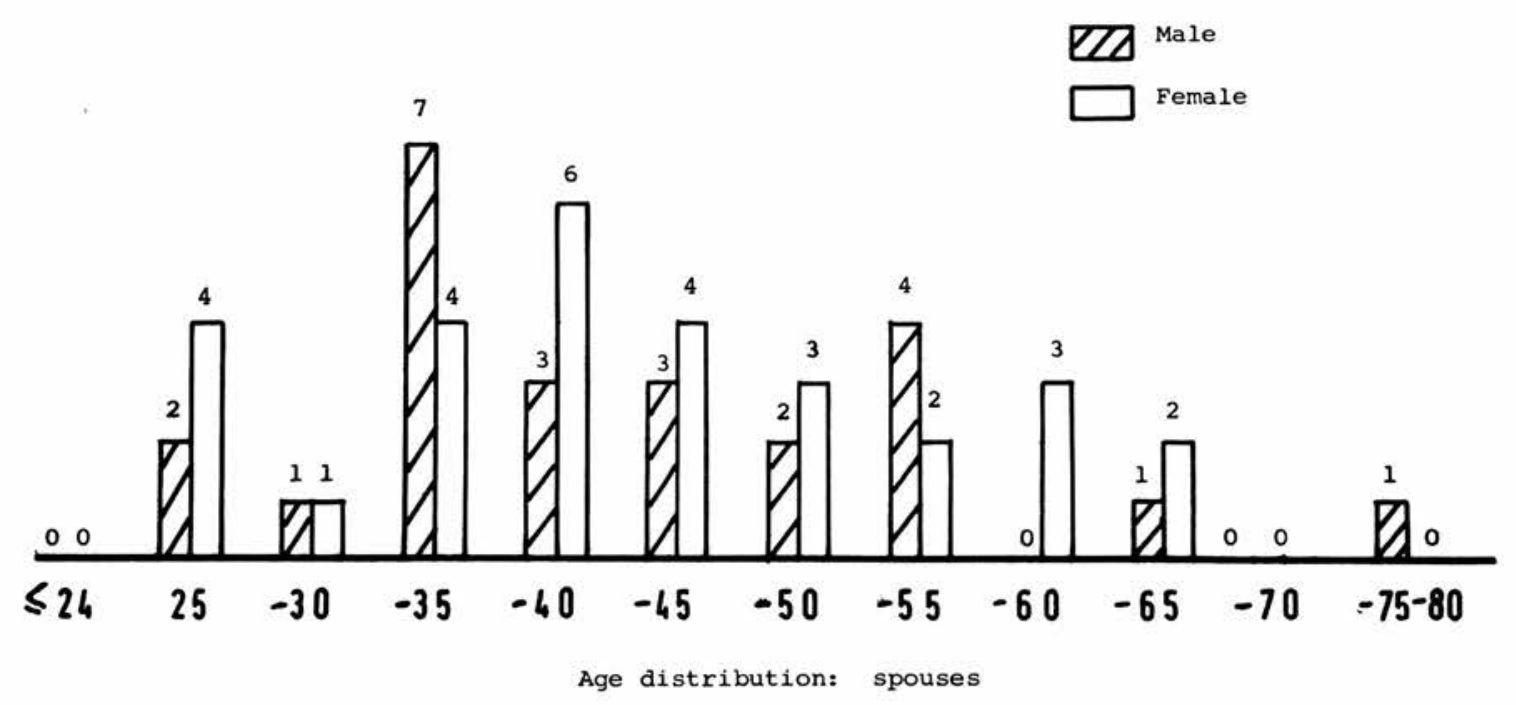


requests that some elderly relatives were not contacted. These requests were always honoured. Other illnesses were usually discovered by the relative writing giving details of an illness, several with hospitalisation, and some suggested that their own family doctors considered their illness too severe for them to attend. Despite the evening timing, business commitments prevented 17 relatives attendance. Several of these resided within the 'inner' area, but commuted out of it to work. Outer area hospitals proved in general very co-operative, but 3 were unable to co-operate, excluding 11 otherwise willing relatives. The two members of the armed forces were at sea and involved in flying duties respectively.

The completion rate was considered satisfactory, the lower figure for second degree relatives having been anticipated from previous surveys undertaken at the Rheumatism Research Unit. The low figure for inner area siblings was not anticipated, however, and is disappointing. This trend was not observed in the other surveys and cannot be explained. 2. Age and sex distribution.

The age and sex distribution of the blood relatives and spouses are shown in Figs. IV - 11 to IV - 15. 3. Musculo-skeletal complications.

The high prevalence of backache has already been mentioned and compared with that in probands.

one spouse was diagnosed as having sero-positive rheumatoid arthritis. The incidence of clinical osteoarthrosis with radiological confirmation is shown in Table IV - 26. 
Table IV -25.

$\begin{array}{lc}\text { Probands } & 13.8 \\ \text { Parents } & 11.9 \\ \text { Siblings } & 13.6 \\ \text { Children } & 0 \\ \text { Second Degree } & 9.4 \\ \text { Spouses } & 3.4\end{array}$

Incidence of Osteoarthrosis (per cent)

Some clinically osteoarthrosic joints in relatives with no or minor symptoms were not $\mathrm{x}$-rayed.

Five miscellaneous musculo-skeletal complaints were recorded. One son had had a transient episode of acute pain and swelling in the left first metacarpo-phalangeal joint. At the time of examination the joint was clinically and radiographically normal, and the latex test for rheumatoid factor was negative. Plasma uric acid was $4.3 \mathrm{mg}$. per $100 \mathrm{mls}$. Three male relatives, one father, one uncle and one son, had periarthritis of the shoulder. One spouse had pain with some tenderness in each heel, present intermittently for many years. There were no radiological signs in the heels and the other joints (including the sacro-iliacs) were clinically and radiographically normal.

No relative had definite ankylosing spondylitis, but radiographic sacro-iliitis was found in 10. Details are shown in Table IV - 27, and compared with the probands in Fig. IV -16 and $1 \mathrm{~V}-17$. 
Fic. $1 \mathrm{~V}-16$

Comparative incidence of sacro-1111tis. 


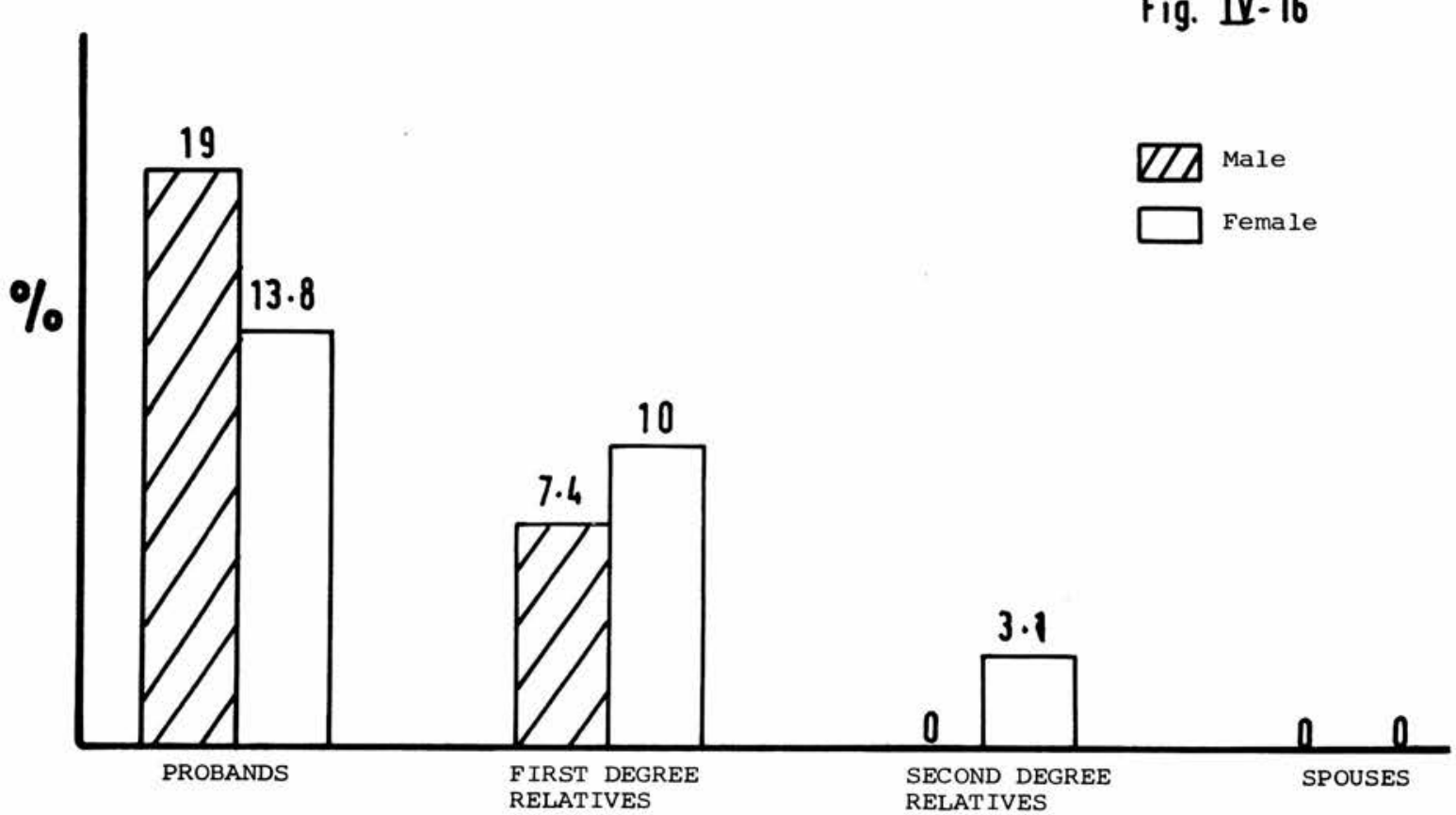

Comparative incidence of sacro-ilitis 


\section{IIf IV - 17.}

Comparative incidence of sacro-illitis (sexes combined). 


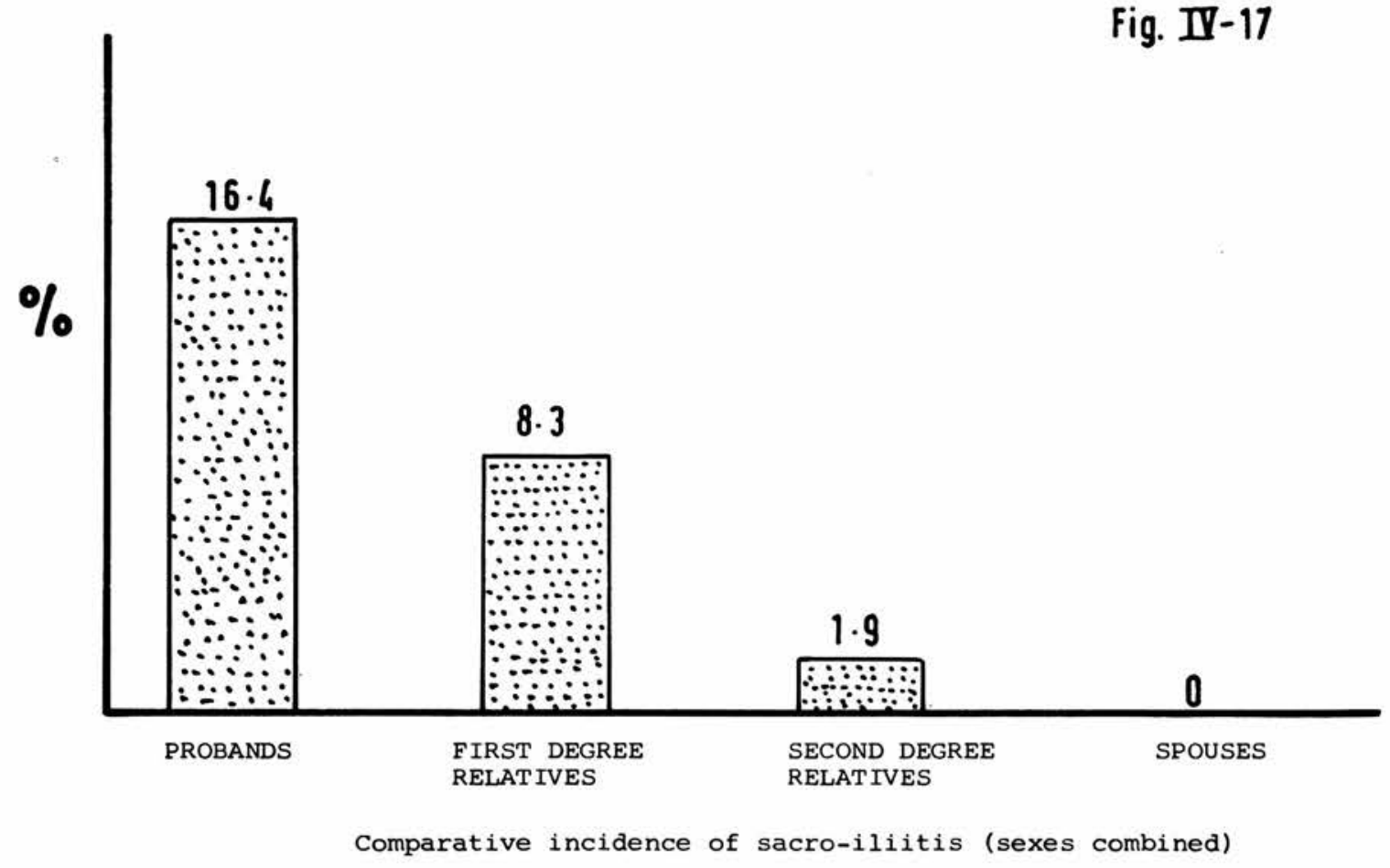




\section{Table IV -27 .}

\begin{tabular}{lccccccc} 
& \multicolumn{2}{c}{ Male } & \multicolumn{2}{c}{ Female } & \multicolumn{2}{c}{ M.I } \\
& x-rayed & S.I. & $x$-rayed & S.I. & x-rayed & S.I. \\
Parents & 20 & $3(15 \%)$ & 23 & $4(17.4 \%)$ & 43 & $7(16.3 \%)$ \\
Siblings & 27 & $2(7.4 \%)$ & 15 & 0 & 42 & $2(4.8 \%)$ \\
Children & 21 & 0 & 2 & 0 & 23 & 0 \\
$\begin{array}{l}\text { All first } \\
\text { degree }\end{array}$ & 68 & $5(7.4 \%)$ & 40 & $4(10 \%)$ & 108 & $9(8.3 \%)$ \\
$\begin{array}{c}\text { Second } \\
\text { degree }\end{array}$ & 21 & 0 & 32 & $1(3.1 \%)$ & 53 & $1(1.9 \%)$ \\
Spouses & 24 & 0 & 15 & 0 & 39 & 0
\end{tabular}

Incidence of Sacro-ililtis

\section{LINKAGE DISORDERS}

Four of the probands showed a blood relationship, C029/01/1, being the mother of $c 100 / 01 / 1$ (female) and c018/01/1 and $c 057 / 01 / 1$ being sisters. No other member of either family had any other linkage disorder. One provend was recorded as having had a typical episode of stevensJohnson syndrome. There was no ulcerative colitis found in any of the relatives, but one of the probands had been diagnosed clinically as having ulcerative colitis, the diagnosis being revised in the light of histology when he was submitted to procto-colectomy. The incidence of psoriasis in the probands and relatives is shown in Figs. IV - 18. The difference between the relatives, spouses and controls achieves statistical significance in no case, 
Fir. IV -18 .

Incldence of Psortasis. 


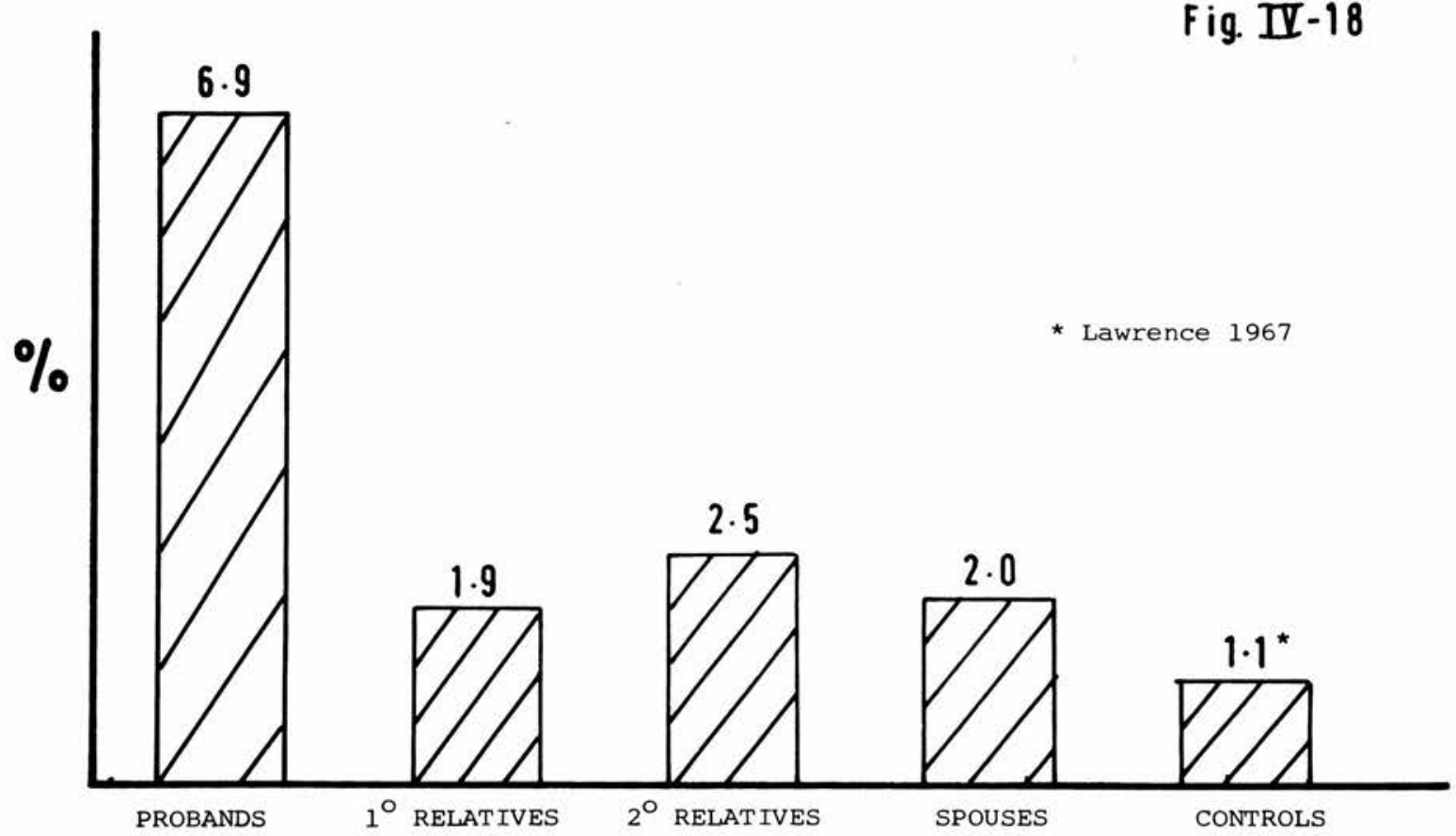

Incidence of Psoriasis 
but that between probands and controls is highly significant $(p<0.001)$. No other linkage disorder was recorded.

D. SEROLOGY

The latex fixation test for rheurnatoid factor was performed on all respondants. The figure for spouses was higher than expected, but when the figures were corrected by removing the thise known cases of rheumatoid arthritis (2 probands and 1 spouse) this difference disappeared. The corected figures are shown in parentheses in Table IV - 28.

$$
\text { Table IV - } 28 .
$$

\begin{tabular}{lccc} 
& Available & & Positive \\
\cline { 2 - 3 } & & Number & $\%$ \\
Probands & $116(114)$ & $9(7)$ & $7.8(6.1)$ \\
Parents & 36 & 3 & 8.3 \\
Siblings & 31 & 2 & 6.5 \\
Children & 40 & 2 & 5 \\
Second Degree & 40 & 4 & 10 \\
Spouses & $51(50)$ & $6(5)$ & $11.8(10)$
\end{tabular}

Positive latex slide test for theumatoid Eactor. 
catapta $y$

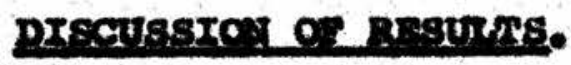




\section{The Proband Group.}

The $h i$ gh ascertainment rate in the proband group renders this a good cross-section of patients with Crohn's disease as seen at the General Infirmary at Leeds. Two biasing factors were introduced by the method of selection. First, the hospital diagnostic index does not include patients seen on an out-patient basis only. Second, the known interest in intestinal diseases by the Department of Surgery encourages the referral of patients from outside the city. The nature of many such referrals is that the 'difficult' cases tend to be referred the 'simple' being treated locally. Both these factors introduce a bias towards more severe sufferers from the disease being included in the survey. The selection policy contains certain balancing advantages, however. Prime among these is the high degree of certainty of diagnosis, coupled in most cases with auxiliary investigations, which results from in-patient investigation at a centre with high standards. Many patients diagnosed as out-patients are sufferers from ill-defined episodes of abdominal discomfort or dysfunction, but their exact diagnosis is open to question. The age distribution is wide and the duration of the disease also shows a broad spectrum. The complete equality of the sex incidence was fortuitous.

Certain aspects of the Crohn's disease itself are open to very wide errors of interpretation unless very rigid criteria are elaborated and followed. Prime among these is the timing of the onset of the disease. Episodic gastrointestinal dysfunction is a univefsal experience, and great 
care has to be exerted if faise retrospective diagnoses of early symrtoms are to be avoided. It is for this reason that the presenting symptom at the first visit recorded was used for timing puxposes, rather than any symptoms 'remembered' at a later date when it might have been implanted by repeated history-taking.

The portion of gut involved is also an area open to wide interpretation. Wherever possible histological reports were used to prepare the tables of 'areas of known involvement'. Unequivocal radiological diagnoses were accepted, but observations of reports by radiologists, surgeons and histologists often showed wide discrepancies. It is probably fair to say that no area of gut can be said to be free of Crohn's disease until histological evidence of its normality is available.

The radical surgical approach to the disease at Leeds has already been mentioned, but from the point of view of this study it has two advantages. First it is similar to the approach made to the treatment of ulcerative colitis, thus enhancing comparison between the diseases. As a corollary to this, it shows the effect of wide excision of diseased tissue from an area of disease so great that total excision is impossible, that is where diseased or potentially diseased gut is, by definition, left in situ after surgery.

2. The general Musculo-skeletal Complications.

It was evident from the survey that backache is a very frequent complaint in the population. In all cases an 
attempt was made to eliminate trivial episodes, such as single periods of pain of a few hours duration only, or those in which backpain had been precipitated for a short period by some known external influence such as sport or gardening. Despite this, almost half the members of every group complained of back pain, mostly in the lumbar region. This observation is of importance in that back pain occupies such a key place in the New York C1OMS criteria for ankylosing spondylitis. Obviously the proportion of patients with radiographic sacro-ililtis diagnosed by these criteria as having ankylosing spondylitis will vary considerably according to the observers criteria for 'insignificant' back pain. Conversely, if all back pain, however trivial, is allowed, the incidence in the population at large suggests that over-diagnosis of definite ankylosing spondylitis in the group with sacroiliitis by some 40 per cent will take place.

One unexpected finding in the proband group was an incidence of periarthritis and allied shoulder conditions of 6 per cent. This was significantly higher than the incidence in relatives $(p<0.01$ ) which was 1.5 per cent. The incidence in the relatives did not difer significantly from the 2.3 per cent incidence in a consecutive series of 600 attenders at a general medical out-patient clinic (Briagman, 1972), and is probably a fair reflection of the Incidence of this complaint in the population. There are two possible explanations for this discrepancy. First, there may be a true increase in the incidence of periarthrtis 
in patients with Crohn's disease. This could be based on diaphragmatic, and hence phrenic nerve, irritation leading to a referred pain in the shoulder region. Alternatively, some of those diagnosed as 'periarthritis' could have had intestinal arthropathy involving the shoulder which was misinterpreted at the patients' review in the clinic. 3. Intestinal Arthropathy.

The 24 patients with intestinal arthropathy comprised 20.7 per cent of the probend group. This figure accords well with the 22 per cent incidence described by Hammer and Naish (1968), both series showing a slightly higher incidence of this complication than the 15.4 per cent described by Ansell and Wigley (1964). The pattern of joint involvement is similar in all well-documented series, the present study confirming the preponderance of lower limb over upper limb and large joint over small joint involvement. It also confirms the observation that there is, in general, no radiological damage to the involved joints.

No support is given to the contention of Cornes and Stecher (1961) that arthropathy is associated exclusively with Crohn's colitis. Although a trend towards more proven colonic involvement was seen, the pattersuof proved gut involvement was similar in those with and without arthropathy.

The time interval between intestinal and joint symptoms was as expected from the review of the literature, i.e. that the majority of cases of arthropathy occur in patients with known gut disease. The one case of Ansell and Wigley (1964) and the two in the present series in whom joint disease apparently preceeded the Crohn's disease 
probably had minc: abnormalities in their gut, which were unrecognised as Crohn's dssease, at the time of onset of the joint symptoms. The bulk of the evidence available certainly suggests that diseased gut is a sine qua non for arthropathy. The synchronous activity of gut and joint disease in 10 patients and the synchronous onset of symptoms from the two conditions in 8 supports this contention. It seems likely that a firm assertion can be ade that any patient with active intestinal arthropathy is suffering from progression of their gastro-intestinal disease at that time, irrespective of symptomatology. The lesser effect of surgery on the progression of Crohn's disease arthropathy when compared with the arthropathy associated with ulcerative colitis would be expected on the basis that diseased or potentially diseased gut is always left behind in the former condition but not the latter. The same expianation may be applied to the higher incidence of intestinal arthropathy in the Crohn's disease patients when compared with those with ulverative colitis (see Appendix B).

One contrast with colitic arthritis is that the association of the arthropathy with major complications of the disease does not appear to occr: in Crohn's disease. The major complication of the two conditions - internal and external fistula formation and malabsorption in Crohn's disease; pseudopolyposis and perianal disease in ulcerative colitis - are very different. Perhaps this difference in type of complication and difference in association of the complications with arthropathy provides 
some confirmation that the two diseases are separate entities. From the results presented here and the review of the literature it appears that intestinal arthropathy is an entity rather than each disease having its own form of articular complication. The preponderance of large over small and lower limb over upper limb joints is universal. There is a general absence of radiological damage to the joints. The activity of the gut and joint disease run approximately parallel courses, and activity of the joints is almost certainly a marker for progressive gut disease. Excision of all the affected gut terminates the arthropathy. The incidence is dependant on the duration for which diseased gut is left in the body and, to some extent, on the activity and extent of the intestinal disease.

4. Sacro-iliitis and Ankylosing Spondylitis.

The high incidence of both sacro-iliitis alone and ankylosing spondylitis was anticipated from the literature review. The proportion of patients with sacro-iliitis who have their diagnosis raised to 'definite ankylosing spondylitis' depends partly on the criteria for back pain considered significant by the investigator. Nonetheless, there seems to be a proportion of patients in whom sacroiliitis does not progress to the full-blown picture of ankylosing spondylitis. This statement is made on the basis that the spondylities date their joint symptoms from before as well as after the intestinal disease. If the same matter is applied to radiographic sacro-illitis, Which is by definition asymptomatic, it may be assumed that 
several of the patients have had this sacro-iliitis for many years at the time of the review without progression to overt ankylosing spondylitis.

The sex ratio of both spondylitis and sacro-iliitis is of interest in that the sex ratio of approximately $10: 1$ male : female usually observed in spondylitis is abolished, much more even figures being obtained. This was also expected from the literature review, especially by analagy with ulcerative colitis.

The lack of temporal association between the activity and onset of the gut disease and ankylosing spondylitis confirms previaus observations that this is a coincidence of two diseases progressing independantly rather than one having a causative relationship with the other.

The areas of gut known to be involved in the patients with sacro-iliitis do not differ significantly from the whole proband group. Although the incidence of internal fistula formation appears high ( 8 of 19 patients) it is not significantly different from the whole proband group $(p<0.2>0.1)$.

5. Clubbing.

The incicience of clubbing at 12.1 per cent was higher than most reported series in the literature review, although it does not approach the 40 per cent incidence in the series of Sussman and wachtel (1954). In contrast to the consensus from the literature, a preponderance of high intestinal sites for the gut lesions associated with clubbing was not 
found. When the incldence of major complications was studied, however, it was found that external fistula formation in the clubbed probands was not found significantly more frequently than in the proband group as a whole $(p<0.4>0.3$ ) but proved malabsorption was found more Frequently $(p=0.05)$ and internal fistula formation much more frequently $(p<0.01)$ than expected. The aetiology of clubbing remains unknown, and no comment can be made on the suggestion by Young (1966) that gut lesions in vagal territories are the only ones associated with clubbing, as no patient had isolated left colonic involvement. The possibility that malabsorption per se might be a contributory feature does arise, however, not only because of the increased incidence of proved malabsorption but also because the nature of internal fistula formation, with the possibility of short circuiting occurring in the gut and consequent malabsorption. It remains a problem, however, to decide under these circumstances whether it is the malabsorption process that is the aetiological factor or the disease causing the malabsorption.

6. The Diagnostic criteria for Ankylosing Spondyilitis. Despite the drawbacks caused by the small number of - definite ankylosing spondylitis' patients in the survey, the evaluation of the Now York criteria does highlight the problem of the clinical criteria of the disease. Back pain, which was given twice the weighting of the other clinical criteria at the conference, has been shown to be of dubious value unless some modifying factors are 
introduced. The measured clinical criteria are of some value, but the general impression is gained that the epideniological diagnosis of ankylosing spondylitis will in future be radiological. A - P pelvis films would remain the screening investigation of choice, those patients with sacro-iliitis being subjected to some form of spinal radiograhy to determine the presence or absence of syndesmophyte formation or bony bridges. It is suggested that the term 'definite enkylosing spondyitis' would be reserved for those patients showing radiological signs in their spine, 'probable' or 'potential ankylosing spondylitis' being applied to those with sacro-iliitis alone. One method of minimising radiological hazard while including some spocial radiography might be to continue to use a 17 inch by 14 inch x-ray plate, but to turn this through $90^{\circ}$. The position then occupied is that of an I.V.P. film, which normally shows the spine to the lower dorsal region, and an adequate view of the pelvis should still be obtainde.

\section{Linjage disorders.}

The incidence of psoriasis in the probands at 6.9 per cent was significantly greater than the incidence in the relatives, spouses and population. Apart from the one case of Stevensmohnson syndrome, no other 1inkage disorder was found. If, however, the two pairs of related probands are considered as two probands and two family nembers, which they would have been had not all four been selected for ascertainment from the list of patients with 
Crohn's disease, the incidence of Crohn's disease in first egree relatives becomes 1.87 per cent which differs significantly from the population incidence of 0.14 per thousand (McBride, King, Baikie, Crean and Sircus, 1963). 8. The Relatives

The response of the relatives gave a satisfactory completion rate, although the response by inner area siblings fell short of expectation. With the exception of sacro-ilittis, there was no greater incidence of 'linkage disorders' in the relatives than would be expected from the population. In particular no 'sero-negative polyarthritis' was found in the relatives. Sacro-iliitis was found, however, in 8.3 per cent of the first degree relatives. The proportion in parents was 16.3 per cent and in siblings 4.8 per cent, none being found in children. This suggests that sacro-ililtis is a phenomenon increasing with age, although the age restrictions imposed decreased the number of children avajiable. Alternativiy osteoarthrosis of the sacro-iliac joints has been misinterpreted as sacro-iliftis. The observation of osteophytes on the sacro-iliac joints was not found useful in this context, being recorded on only 10 occasions none of whom were diagnosed as having sacro-iliitis. On balance it is felt that the interpretation was an accurate reflection of sacroiliitis. As expected, the incidence in second degree relatives was lower at 1.9 per cent, but still exceeded the population incidence of approximately 0.1 per cent (Kellgren, 1964). The spouses had no sacro-1liitis. 
The pattern of involvement of the sacro-iliac joints, with the high incidence in probands, a lessar incidance in first degree relatives and a substantially smaller incidence in secoad degree relatives clearly indicates a genetic tendency. There was no difference, however, between the relatives of patients with and without sacroilitis in their incidence of this complication.

\section{Sugrestions for further studies.}

The methods used in the surveg were in general selected in orier to eninance future comparisons between the several surveys undertaken in the Rheumatism Research Unit at Leeds. While the basic design was felt to ba a good one, sone minor modifications might have enhanced the study. It is felt that the inciusion of a small sample of the second degree relatives is probably not worth while. Their response rate is below that of wie first degree relatives, and their exact whereabouts are often not known. It would probably be better to eliminate all second degree relatives from the routine survey, but make greater effort to trace all members of any special familles in whom inkage disorders or other points of interest arose. Altermativeiy, if the inclusion of inforration about the second degrae relative was considered necessary, they should all be included. The use of rcutine serology is of doubtful valie. Ihe latex screening test was selected for this survey because it was simple and easily performed. Eiao the facilities bsen available for a properly concucted sheep cell agglutination test, this might have been more 
valuabie. The point is by now generally accepted, however, that the arthritides in question are not related to rheumatold arthritis, and the incidence of positive tests, is therefore, of little value except confirming the high population incidence when using this screening method. The radiography could have been enhanced by the inclusion of the forearm bones on the hand x-rays, in an attempt to delineate true hypertrophic arthropathy. A study of this nature has been initiated at St. James (University) Hospital, Leeds under the direction of prof. M.S. Losowsky.

In view of the high incidence of asymptomatic sacroiliitis in the probands, consideration would have to be given in future studies to the ethical proprietry of pelvic radiographs on all probands. In the present survey asymptometic female probands below the age of 45 years did not have such radiographs taken. Seer'h of old films from barium series allowed, in all but one case, a view of the sacro-iliac joint, but some of these films were taken In previaus years and others of limited value technically. A posstble compromise would be to review all the available $x$-rays before the probands visit to the clinic, and request pelvic films on those in whom no adecuate sacro-iliac joint vievs can be ontained on the previous films.

Much remains to be found out about intestinal arthropathy. bopsy studies of involved joints may well be of interest, but are doubtful ethically. Such biopsies may be justified where swelling of a joint was sufficient to benefit from aspiration. The neture of the intestinal dysfunction 
Which initiates the synovitis is not known. The possibility that the crucial factor is some form of abnormal bacterial colonisation in the gut is currently being considered. Urinary indecan excretion may provide a clue to giantitative abnormalities of the becterial flora, but the difficulties of qualitative bacteriology in this field are well known. The opportunity of sampling at a small intestinal level in patients with ileostomies may, however, allow more accurate microbiological studies.

The extent of the problem of malabsorption in Crohn's disease, and its relationship to clubbing particularly, will only be solved by the consuming and complex metabolic studies. Nore might be ascertained about sacromiliftis, however, both by necropsy studies and sertal radiography. of parionts with radiological sacro-ilittis. It is only by this method that the ultimete fate of these patients will be known 1.e. Whether or not they progress to overt ankylosing spondylitis. Whether all patients with Crchn's disease should be subject to routine pelvic radiology, so that early sacro-ililtis cen be spotted, is at present ethically doubtful, although certainty that sponaylitis supervenes in this condition might provide justification in that the appropriate regime of exercices could then be initiated in the anticipation of preserving good spinal function. It should certainly bo a routine part of every barium study of crohn's disease to study the sucro-illac joints, especialiy at screening when still flims including these joints ney not be taken. 
dinally, within the content of the concept of seronegative spondarthritides there is a need for family studies of the other diseases in the group in order to further delineate their inter-reltationship. 
CIAPTER VI

CONCLUSION: 
The objectives of the study were outlined in the introduction, and the cruestions posed have been answered as follows, as regards the probands:-

1. The incidence and clinical pattern of the seronegative polyarthritis described in association with Crohn's disease. The incidence of intestinal arthropathy was 20.7 per cent. The joints involved showed a predominance of large over small and lower limb over upper limb joints. The knee joints were the most commonly involved, followed by the ankles, shoulders, wrists, elbows and metacarpo-phalangeals in that order. Typically the arthropathy was episodic, and did not cause radiological damage to the joint. The coincidence in many cases of the onset or exacerbations of the arthropathy and the gut stmptoms suggests a cansal factor in the gut. In one case only did the joint symptoms precede the gastrointestinal ones.

2. The significance of such features as major cormilications. Three major complications, internal and external fistula formation and proved malabsorption, were sought. There was no greater incidence of these in probands with intestinal arthropathy than in those without. Surgery had some ameliorating effect on the arthropathy, but did. not relieve it completely.

3. The influence of the position of the lesions in the gut. Crohn's disease may involve any or all of the giatrointestinal tract, and involved areas may be detectable only by histological examination. The precise extent of the 
disease is not, therefore, known in any patient. If proved areas of involvement only are considered, there is no great difference between the probands with arthropathy and those without in the areas of gut involved. A trend was observed, however, towards large intestinal involvement belng more cormon in the group with synovitis. No support was lent to the theory that symovitis is a complication of Crohn's colitis not Crohn's disease per se. 4. The incidence of sacro-iliitis and ankylosing spondylitis. Using the Ne:g Yorik ClOMS criteria, sacro-iliftis was diagnosed in 19 probands (11 males and 8 females) of whom 8 (4 male, 4 female) were diagnosed as having definite ankylosing spondylitis. Five of these had peripheral joint, in addition to spiral, involvement. The onset and activity of the spondylitis bore no relationship to the timing of the gut disease, which it frecuently preceeded. The position of the known lesions in the gut, the incidence of major side effects, and surgery had no effect on the progression of the spondylitis. The normal male : female ratio of approximately $10: 1$ for the incidence of spondylitis was abolished, although a male predominance persisted if uncomplicated sacro-ilitis was included as 'probable ankylosing spondylitis'. 5. The prevalence of linkage disorders. Psoriasis was present in 6.9 per cent of the probands, a significantly greater number than was found in the relatives and sp uses and would be expected in the populatidn. One case of Stevens-Johnson syndrome was described, and 14.7 per cent 
of the probands suffered from iritis.

The questions posed of the relative group were answered as follows:-

1. The incidence of sacro-iliitis and ankylosing spondylitis. No definite ankylosing spondylitis was found in the relatives, but 10 cases of radiological sacroiliitis were seen. of the 43 parents, 7 ( 3 male, 4 female) had sacro-iliitis ( 16.3 per cent). 2 siblings ( 4.8 per cent) both male, and no children were similarly diagnosed. One female second degree relative (1.9 per cent) showed sacroiliitis on $x$-ray. This was interpreted as showing a genetic tendency towards sacro-ililtis, the contrasting incidence in the three groups of first degree relatives reflecting the age distribution of these groups.

2. The prevalence of Iintage disorders. If the 4 related probends are considered as 2 probands and 2 first degree relatives, the incidence of Crohn's disease in first degree relatives at 1.87 per cent significantly exceeded the population incidence. The incidence of psoriasis was no greater than in spouses or the population in general. No other linkage disorder was found. In particular there were no ulcerative colitis and no sero-nogative polyarthritis. The spouses were investigated as a control group, and showed no sacro-iliitis or ankylosing spondylitis, an incidence of psoriasis analegous to that in the relatives and the population, and no linkage disorders.

The contribution of the overall results of the survey to the work of the unit was considered under $a$ headings:- 
1. In corparison with the ulcerative colitis survey. The incidence of intestinal arthropathy was higher in the patients with Crohn's disease, but the pattern was similar. The incidence of sacro-iliitis was similar, and the differences in the proportion of patients with ankylosing spondylitis prohably explicable on the basis of differences in interpretation of histories.

2. It was felt that the concept of intestinal arthropathy was a coreect one, the incidence of this complication depending on the time for which diseased tissue remained in situ. The bowel and joint activity appeared to show some parallelism, but on association with complications mist be regarded as applicable to ulcerative colitis only.

3. The co-incidence of polyarthralgia, spondylitis, psoriasis and iritis in the probands and the two family groupings of Crohn's aisease were thought to contribute to the concept of seronegative spondarthritis.

suggestions for future work inciuded possible modification of the method of study used by the Unit, further investigations into the aetiology of the synovitis, longitudinal studies of sacro-ilitis and the performance of further family studies within the seronegative spondarthritis group.

In addition to the anticipated objectives 3 other interesting observations were made:-

1. There is an increased incidence of clubbing in Crohn's disease, although true hypertrophic osteoarthropathy appears 
to be rare. The clubbing was not, in this series, preferentially associated with high intestinal lesions, but appeared to be associated with both proven malabsorption and internal fistula formation, which could predispose to malabsorption.

2. An increased incidence of periarthritis of the shoulder was diagnosed in the probands. Elther this represents an under-diagnosis of intestinal synovitis affecting the shoulder joint, or there is a true increase in the coincidence of the two conditions. If the latter explanation is true, it was speculated that the sequence of events leading to the periarthritis might involve phrenic nerve irritation producing referred pain in its dermatome in the shoulder region.

3. A limited criticue of the New York C1OMS criteria for ankylosing spondylitis was made, and the suggestion put forward that this diagnosis should be entirely based on radiographp in the future. 
ACWNOALTDGEMUNTS. 
I should like to take this opportunity to thank the many people who have made this work possible. The probands and relatives who gave their time to attend the clinics were indispensable - without them there would have been no study, and my thanks to them talkes pride of place.

The Board of Governers of the United Leeds Hospitals provided a generous grant to cover the expenses of this survey, and made the facilities of the orthopaedic outpatient department available to me for the evening clinics.

My thanks are clue to Dr. Winn of the department of diagnostic radiology for his advice, and the use of his departmental facilities. The radiographers in the department provided me with an unfaiing out of hours service and maintained the highest of technical standards throughout. My three chaperones, Mrs. Davey, Mrs. Hargreaves and Miss smith also provided mo with unfafling support in the clinics.

The physicians and surgeons of the General Infirmary were kind enough to allow me access to their patients and clinical rocords. In particular prof. Goligher, Mr. de Dombal and the staff of the professorial surgical Unit proved most helpful in providing the majority of the probands.

Dr. Ian Burton supplied his list of patients with Crohn's disease from which the probands were ascertained, and Dr. Nevalos provided translations fror the German literature.

All the members of the clinical group of the Rheumatism Research unit provided their help and support at all stages 
of the study. Prof. Wright has acted not only as an inspiring head of department but also as an indispensable source of knowledge and encouragement. My debt to him is enormous. The previous experience of Dr. Ian Macrae in his colitis survey proved of immense value in the setting up of the study. Dr. John Noll acted as second reader of the x-rays. Both have been sources of valuable discussion, and generously gave permission for reproduction of work that is partly theirs in Appendix B and C. Dr. Ian Archer has helped with the statistics, and Mr. Arthur Moreton, our Senior Technician, provided valuable help throughout the study, not least in his assistance with the latex slide tests and the compilation of the illustrations in the thesis. Mrs. Antcliffe commenced the arduous task of typing before her departure from the Unit.

Two departments in the Infirmary have been of particular help. Mr. Brian Mortimer and the staff of the records department assisted in the tracing of notes and in the punching and processing of the IBM cards. The department of photography prepared the photographs used in the thesis.

My wife Betty provided more than usual support in this study in that in addition to tolerating my involvement in 1t, she took over the secretarial duties for a prolonged period. My debt to her is great.

Finally I should like to thank Mrs. Marion Howitt who not only took over the secretarial burden of the survey at its halfway stage, but also typed the majority of this work 
in record time, and Miss Jane Hall without who's help and encouragement during the writing of this thesis, it would never have been completed. 


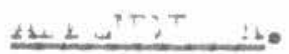

CASA' HITTURT.US 
No useful purpose would be served by detailing the case histories of all the patients and relatives taking part in the survey. A small number of cases will, however, be presented to illustrate specific features. 


\section{CASE A.}

C106/01/1

Mrs. B.W.

Age 29 yrs.

This lady presents a somewhat dramatic illustration of the influence of psychological stress on the clinical progression of Crohn's disease.

Mrs. B.W. was first seen in the medical out-patient clinic at the age of 17 with complaints of weight loss and diarrhoea. Physical examination revealed a sore peri-anal region with first degree piles, and a routine blood test showed an iron-deficiency anaemia with a haemoglobin of 70 per cent. She defaulted from followup but returned with further diarrhoea accompanted by sharp lower abdominal pain three years later. Barlum enema at this revealed contraction and spasticity of the terminal ileum suggestive of Crohn's disease. Her symptoms remitted until four years later, when an anterior anal fistula was discovered. She again went into remission, but one year later at the age of 25 , she was admitted with a pelvic abscess which drained per rectum. She settled well following this for 16 months, at wich time her sister was murdered. She inmediately developed diarrhoea with two-hourly stools and a two stone weight loss in one month. Her condition proved unmanageable by medical means, and she was submitted to surgery, $47 \mathrm{~cm}$. of small bowel and $6 \mathrm{~cm}$. colon being excised. The histological appearance was typical of Crohn's disease.

Comment. Although this lady had had intermittent symptoms for many years at the time of her sister's death, 
the change from a low-grade, grumbling condition to one in which surgery was required as a life-saving procedure was dramatic, and almost certainly provoked by the psychological shock of the sister's murder. 
CASE B.

C $112 / 01 / 1$

Nirs. H.W.

Age 54 yrs.

This lady was first seen at the professorial surgical Unit out-patient clinic in 1967, with a two year history of intermittent diarrhoea and abdominal pain. In the 5 months before her consultation these symptoms had increased in severity. She was passing $5-6$ motions daily, and had lost 2 stone. Examination revealed clinical anaemia, with some tenderness on the right side over the lower ascending colon. Barium meal and follow-through showed the classical signs of Crohn's disease of the terminal ileum. She was admitted, transfused and underwent laparotomy at which $48 \mathrm{~cm}$. terminal ileum and $17 \mathrm{~cm}$. caecum and ascending colon were resected. The histology of the resected lleum showed. typical crohn's disease involving the distal $23 \mathrm{cms}$., but the colon was microscopically normal. She was well postoperatively and gained weight, although she still passed 2-3 stools daily. Fifteen months post operatively, at which time she was aged 52 years, she developed symptoms of a recurrence of her bowel disease. She developed slowly increasing colic, her stools becoming more frequent at 4-6 daily, over the next year. At the age of 53 , in association with a cecrease in her general well being and the beginning of weight-loss she developed pain and swelling of both knees, followed by stiffness in her right hip. At the time of review in the family survey she was having internittent bouts of quite severe abdominal pain. with 1-5 bowel motions daily. Her joints were progressively 
troublesome, and examination revealed some synovial swelling of each knee with restriction of rotation of the right hip by pain. Radiographs of all three joints were normal. Although the onset of this lady's joint disease was after her original operation, she had signs of continuing activity in her gut and the development of her Joint disease colncided with one sign, weight loss, of increasing activity of her crohn's disease. 
CASE C.

$\mathrm{c093/01/1}$

Mrs. B.R.

Age 25 yrs.

This patient was admitted at $12 \mathrm{yrs}$. of age with a two week history of intermittent sub-umbilical pain. The day before admission it settled in her right 1liac fossa, and she vomited in the morning of admission. Examination revealed tenderness in the right lliac fossa and on rectal examination. A diagnosis of acute appendicitis was made, but at operation a normal appendix was found. The terminal 8 inches of lleum were thickened and the mesenteric glands were enlarged. A provisional diagnosis of Crohn's disease was made, and appendectomy performed. She recovered uneventfully, but a barium enema three months later showed changes in the caecum and ascending colon. She returned six years later with intermittent abdominal pain, bowels opening 2-3 times daily, and a 7 pounds weight loss in 6 months. She was treated medically and remained well for 3 years when she was re-admitted following ani increase in her diarrhoea. Radiologically she had Crohn's disease of the terminal ileum and right half of colon. A right hemicolectomy was performed $35 \mathrm{~cm}$. of colon and $100 \mathrm{~cm}$. terminal ileum being excised (Fig. A - 1). The histology was that of Crohn's disease. Two months post-operatively she developed episodes of swelling in her knees and ankles. These occurred for 2-3 days at a time at approximately fortnightly intervals, her bowels being opened a regular 5-6 times daily throughout this time. Over the next two 
214

Ina -1

Case C. Mrs, B.R. part of resected specimen. 


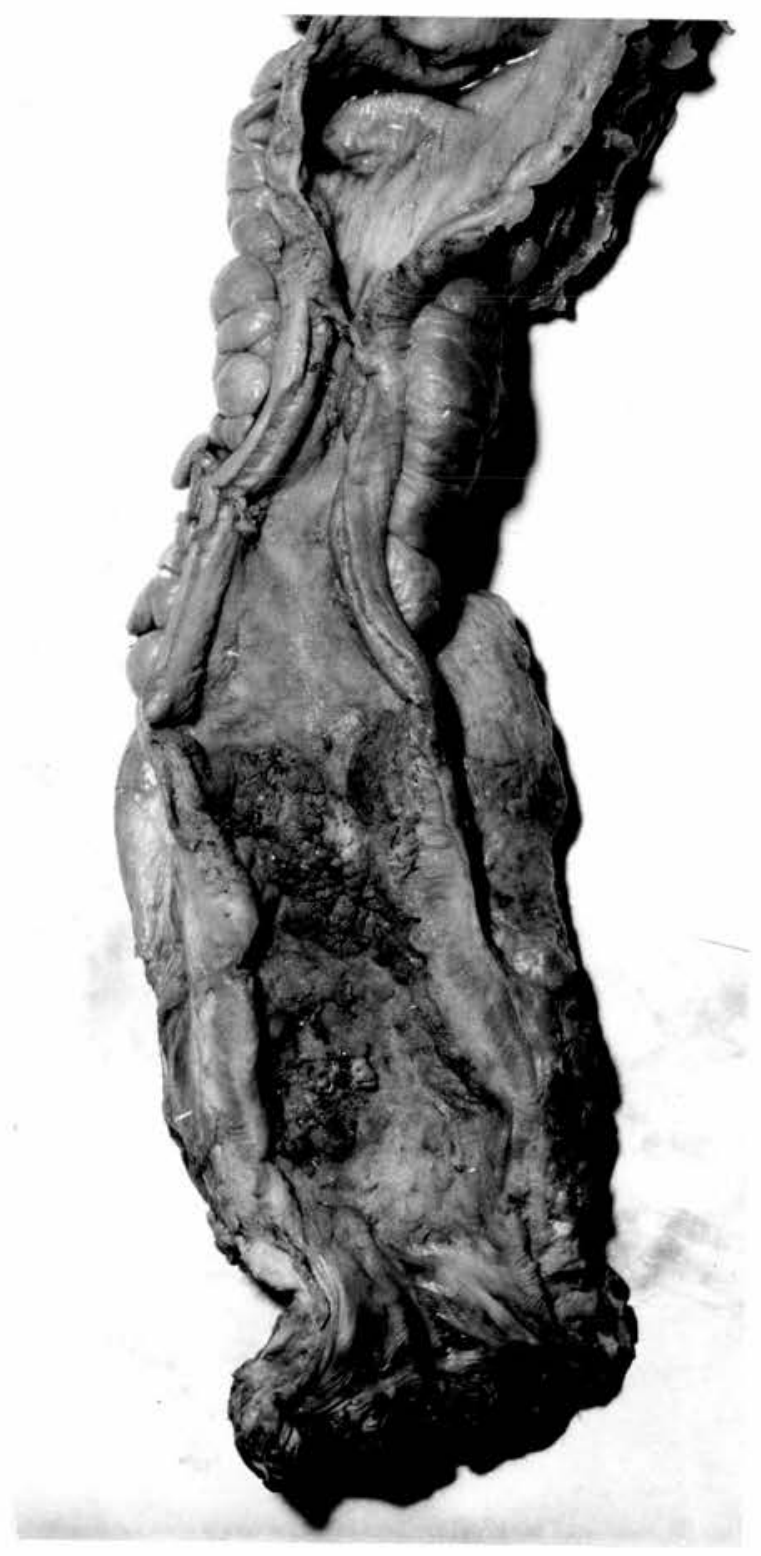


years she presented intermittently with one or more knee or ankle joint as the site of an acute synovitis, all radiographs being normal.

When aged 24 years she had a further resection of of recurrent Crohn's disease from the anastamotic site. Prior to this she had had an uneventful pregnancy and labour, delivering a normal $3.6 \mathrm{~kg}$. daughter. At age 25 she developed erythema nodosum, which continued to trouble her intermittently.

When seen in the family study her skin was clear and her Crohn's disease was in its customary state, that is she was feeling well and maintaining her weight, but opening her bowels 12-15 times daily. Both knees and both ankles were the site of chronic synovial thickening, but radiographs of these joints were normal, as were her hands, feet and sacro-iliac joints. No rheumatoid factor was detected in her blood..

Comment. This lady's history illustrates many features of Crohn's disease. Initial presentation as an acute appendix is well recognised. Progression of the disease without obvious exacerbation is also reported, and the episodes of synovitis may indeed be better indications of increasing intestinal pathology than other clinical signs. Normal pregnancies are carried by many patients with Crohn's disease. The synovitis was typical of the 'intestinal' type, with its predominance of large over small joints and the lower limbs over the upper. The post-operative onset provides a contrast with ulcerative colitis, at which 
radical surgery removes all the diseased tissue and permenently abolishes the synovitis. The fact that the synovitis initially preceeded the erythema nodosum but, when the latter occurred, did show some coincidence with the skir lesions reinforces the idea that synovitis with erytheme noclosum and irtestinal synovitis are not separate entities. The absence of radiological changes in the joints despite long-standing episodes of synovitis and the presence of dironic synovial thickening is characteristic. 


\section{CASE D.}

c035\%01/1

Mrs. E.D.

Age 56 yrs.

This lady was first seen in the Professorial Surgical Unit out-patient clinic at the age of 46 . Her complaint was of frequency of bowel motions for 3-4 weeks, with up to 8 blood-stained stools daily. She had a longstanding tendency to passing one or two loose or soft motions daily. but had no previous episodes of massive diarrhoea or bleeding. Sigmoldoscopy showed appearances thought to be due to early procto-colitis. She was reviewed at that time by Professor Wright in connection with the survey of joint disease in colitis. It was noted that she had had pain in her hips and knees for years, with severe low back pain. she had received previous physiotherapy for her lumbar and cervical spines. Back movement appeared $11 \mathrm{mited}$ and $\mathrm{x}$-rays showed sacro-iliitis.

over the next 4 years she had episodes of bloody diarthoea with increasing frecuency. She had two attacks of iritis and arthritis of her back and peripheral joint increased. In 1966 she was subjected to a left hemicolectomy with high anterior resection (Fig. A - 2). The histology showed a $20 \mathrm{~cm}$. stenotic area vihich was diffusely ulcerated. The walls were fibrotic and had a transmural inflammatory infiltrate. Iymphoid follicles and a few granulomata were seen, the changes being interpreted as those of croin's cisease. Post operatively she continued to have severe symptoms of bloody diarrhoea. and wes subsecquently subjected to total proctocolectomy and ileostomy. Thereafter she 
Fig. $A-2$

Case D. MrS. E.D.

Hemicolectomy specimen. 


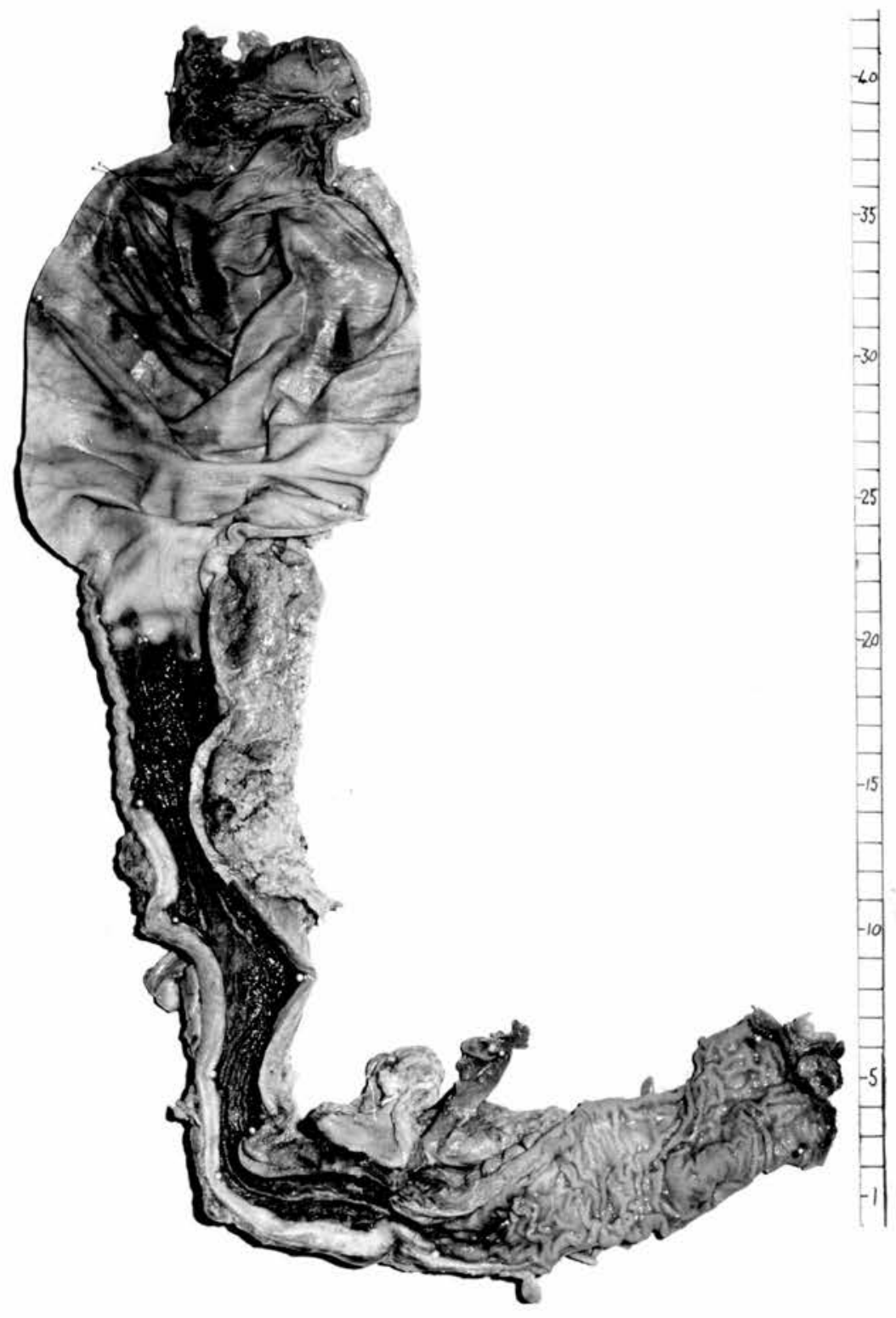


improved steadily, and at the time of review was well with a good ileostomy and steady weight. Her back remained stiff and painful but the pain in her peripheral joints had abated since her ileostomy.

on examination, her chest expansion was $1 \mathrm{~cm}$. and lumbar spine forward flexion abnormal at $2.5 \mathrm{cms}$. There was sone limitation of lateral flexion and severe retraction of rotation of the spine. Her back was painful, but her peripheral joints were quiescent. Her pelvic x-ray is show in Fig A - 3 .

Corment. Th1s lady had ankylosing spondylitis of long duration before any symptoms referable to her bowel occurred. It is of interest that she was initially misdiagnosed as having ulcerative colitis, although the segmental nature of her disease on barium enema had raised the clinical suspicion of crohn's disease pre-operatively. The quiescence of her peripheral joints post-operatively and their radiological normality suggests that, rather than this being spondylitis with peripheral joint involvement, she has spondylitis with co-incidental intestinal arthropathy. 
E1d. $A-3$

Case D. Mrs. E.D. pelvic x-ray. 


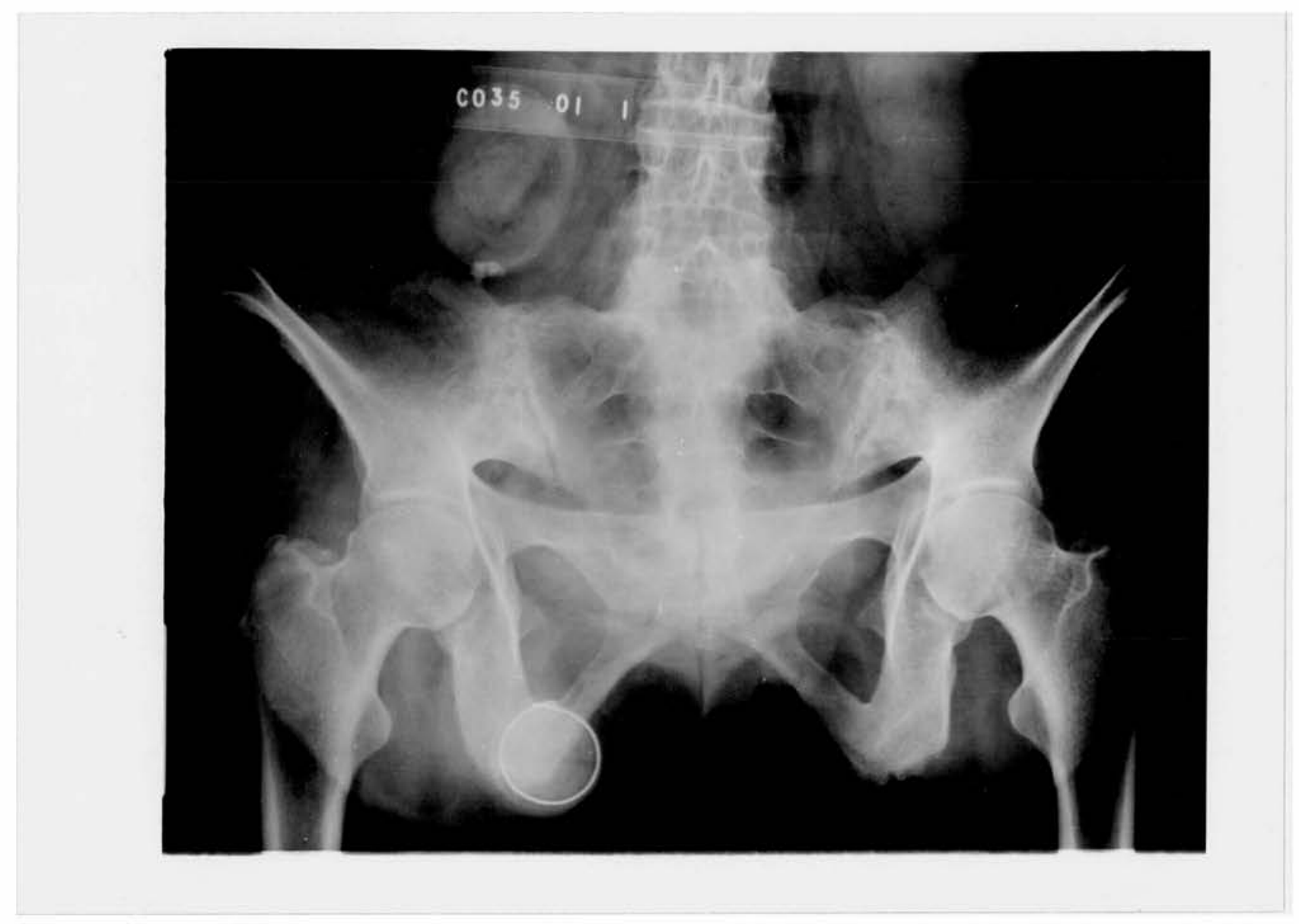


CASE E。

C105/01/1 Mr. T.R.W. Age $59 \mathrm{yrs}$

This man was first seen at another hospital in 1944 at the age of 34 years when he complained of a penile discharge. This was treated by circumcision, but continued unabated. He was referred to the Infirmary 10 years later with a persisting discharge of blood and pusper urethra. It was thought that he had chronic urethritis, and was treated with irrigation. At the age of 47 he was first seen in the medical out-patient department. He complained of 6-8 weeks epigastric pain and vomiting. The pain was sharp, lasting 2-3 minutes and eased by vomiting. It was unrelated to food. His bowels were loose and the motions foul smelling. He had a persistent urethral discharge with "bits of stuff like flesh, and bubbles". For 4 years he had had to hold his anus tightly when passing water, or else his anal region became wet. A diagnosis of vesicocolic fistula was made. On admission, contrast studies were normal, but sigmoidoscopy and cystoscopy both demonstrated the fistula. He was treated with antibiotics and transfusion and no surgery was undertaken. He continued to have symptoms from his fistula and was subjected successively to an attempted closure of the fistula, an ileo-colostomy and a right hemi-colectomy. The histology at the last operation was said to be that of Crohn's disease. Over the succeeding 9 years, he continued to have symptoms from what had now become a true watering can perineum. Not unexpectedly he has refused any further surgery. At 
the time of review in the clinic he was still passing both urine and faeces through his anus, urethra and perineum. He was otherwise well, but was noted to have clubbing of his fingers. He was also having monthly injections of Vitamin $B_{12}$. Review of his notes showed that a shift to the left in his neutrophils had been recorded on two occasions, the haemoglobin being 12.6 and 12.3 grams respectively. A serum $B_{12}$ was in the 'intermediate' range at $130_{\mu \mu}, \mathrm{G}$ per $\mathrm{ml}$. and the folate estimation was technically unsatisfactory. No further haematalogical investigation had been carried out. A record of a single days faecal fat collection on the acute surgical ward in 1962 was also discovered. This was reported as containing 9.8G. Review of the pelvic radiograph showed sacro-iliitis grade 4 bilateral (Fig. A - 4).

Comment. This man's history illustrates one of the most distressing complications of Crohn's disease, the development of a watering can perineum. His clubbing was not recorded in the notes and its progression had not been noticed by the patient, although he realised that his fingers had assumed a different shape. It seems likely that he has some degree of malabsorption, so doubt exists as to whether this or the disease process per se initiated the clubbing. He was asymptomatic from the musculoskeletal point of view, having a normal chest expansion at $5.8 \mathrm{cms}$. normal forward flexion with a distraction of $5.8 \mathrm{cms}$. and normal lateral flexion and rotation of his spine on clinical appraisal. He gave a history suggestive of iritis but in fact had had a Moren's ulcer. His sacro-iliitis was, 
Flo. $A-4$.

Case E. Ir. T.R.W. Felvic $\mathrm{x}$-ray. 


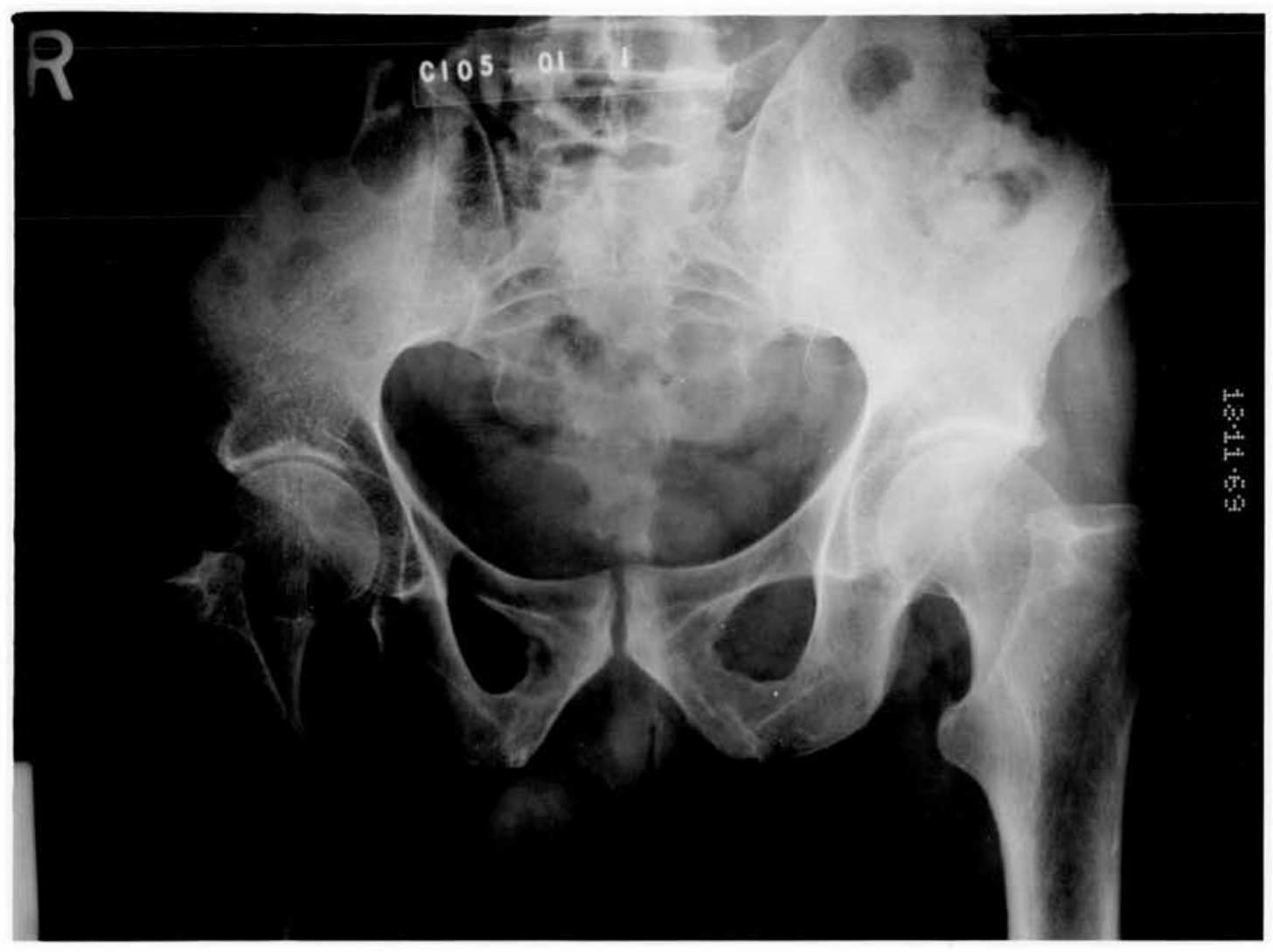


therefore, radiographic only. Although several letters mention that the histology was that of Crohn's disease no report was available for study. His radiographs were initially of little help and later too distorted by his repeated surgery to be of diagnostic value. His diagnosis was, therefore, recorded as clinical only. 
CASE F.

C079/01/1

Miss B.L.

Age 19 yrs.

An example of an association of Crohn's disease with psoriasis, another member of the group of sero-negative spondarthritides.

Miss B.L. first presented to the medical out-patient clinic at the age of 15 years, with a 3 year history of intermittent abdominal pain and a 2 month history of diarrhoea, up to 6 motions daily. Examination was unrewarding, but in view of her anaemia and high E.S.R. she was admitted for further investigation. She developed a pyrexia and right iliac fossa pain, and was subjected to laparotomy at which $70 \mathrm{~cm}$. of small bowel attached to 54 colon was removed (Fig. A - 5). The histology showed Crohn's disease in the ileum and colon. An ileo-rectal anastomosis was performed, and her post-operative course was satisfactory.

When seen in the family survey she was suffering from chronic looseness of the bowel with 2-3 motions daily, and frequent attacks of abdominal pain and flatulance. She described low back pain associated with her gut disorder, and maximal on the few occasions she had become constipated. Clinical and radiological examination of her back, pelvis, hands and feet were normal. There was no rheumatoid factor detected in her blood. Examination of the skin showed typical psoriatic plaques on the elbows with some scattered lesions on the legs. These had been present for many years, were of little trouble to her, and were unrecorded in her 


\section{Mn A -5}

case r. Now. B.t.

Resected specimen. 


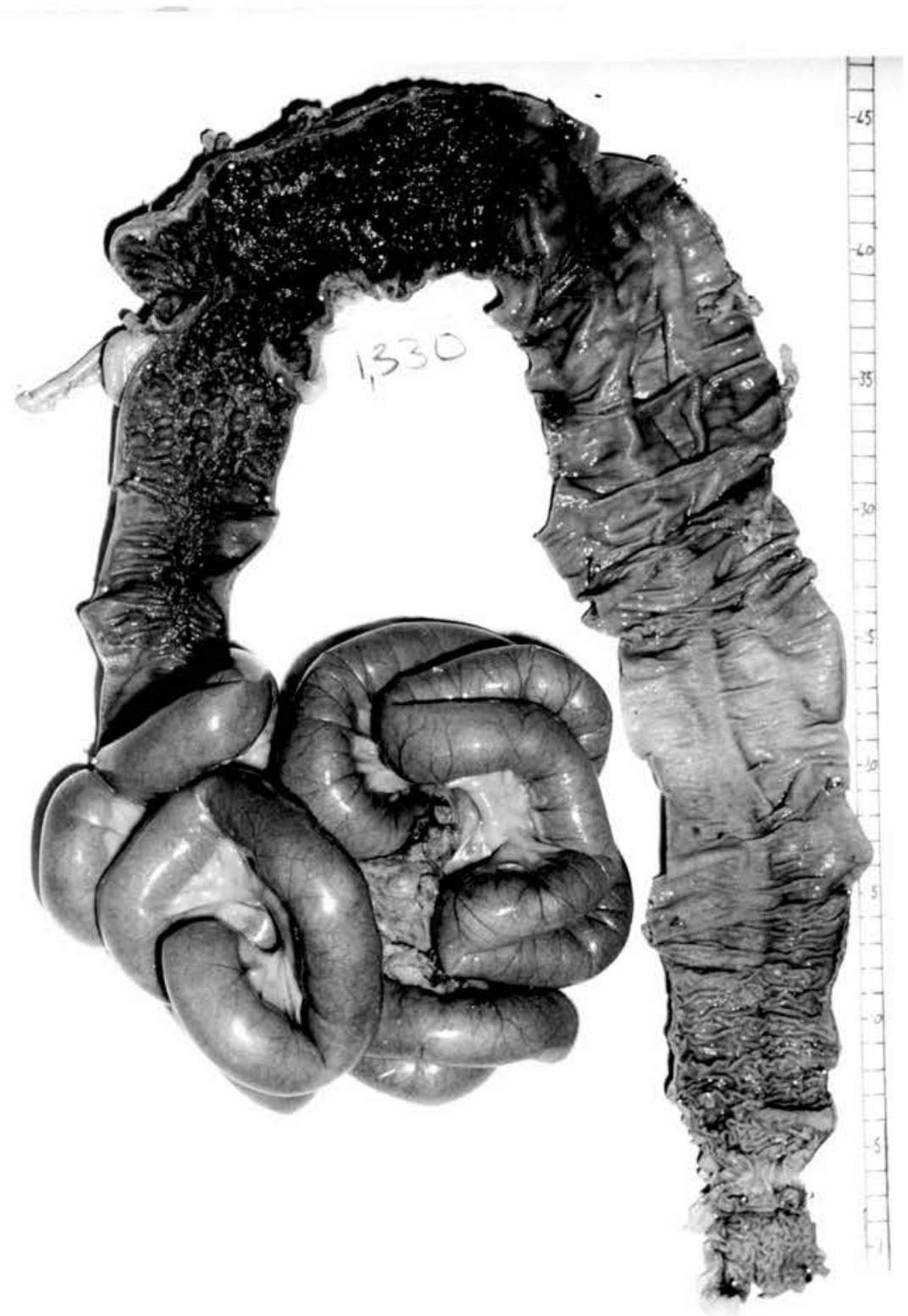


case notes.

Coment. As well as coincident psoriasis, this girl showed a symptom which was not uncommonly found during the survey, that is pain from the gut being referred to the back. This does not constitute intestinal arthropathy, and was associated with no radiological abnormality, appearing to be true referred pain. 
A short series of radiographs are reproduced which show exanples of the grades used in the survey. Fig. A - 6 shows grade 2 bilateral sacro-ilittis, the minimal change held to be significant. Figs. A -7 and A - 8 show examples of grades 3 and 4 respectively. Figs. $A-9$ and $A-10$ show two examples of adolescent sacro-iliac jolnts. Both are normal. Fig. A - 11 shows a pelvis affected by Paget's disease. These acro-iliac joints were also read as normal. 
229

Fic. A - 6 .

Sacro-11iltis grade 2. 


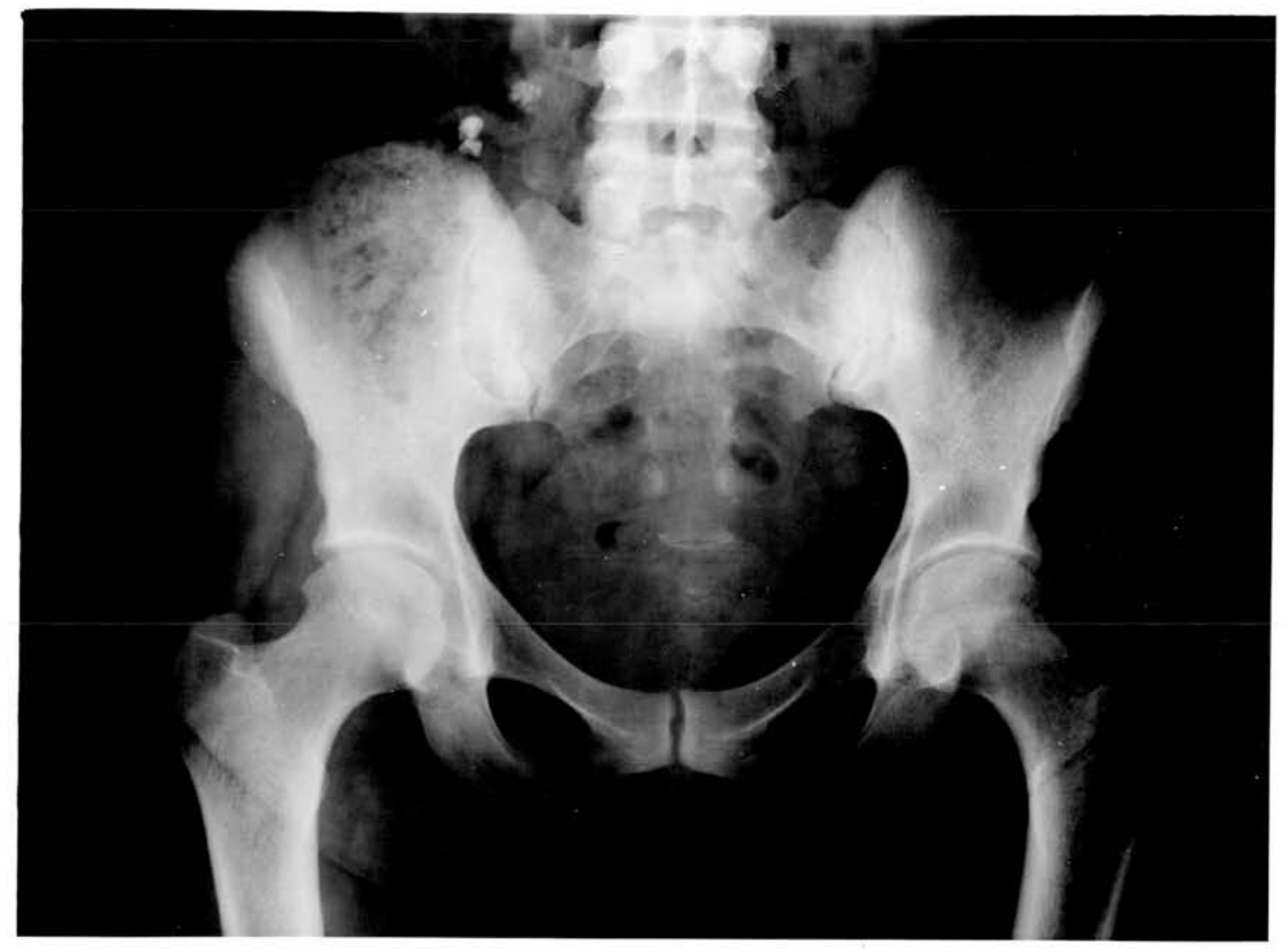


Elo. $A-7$.

Sacro-1111t1s grade 3. 


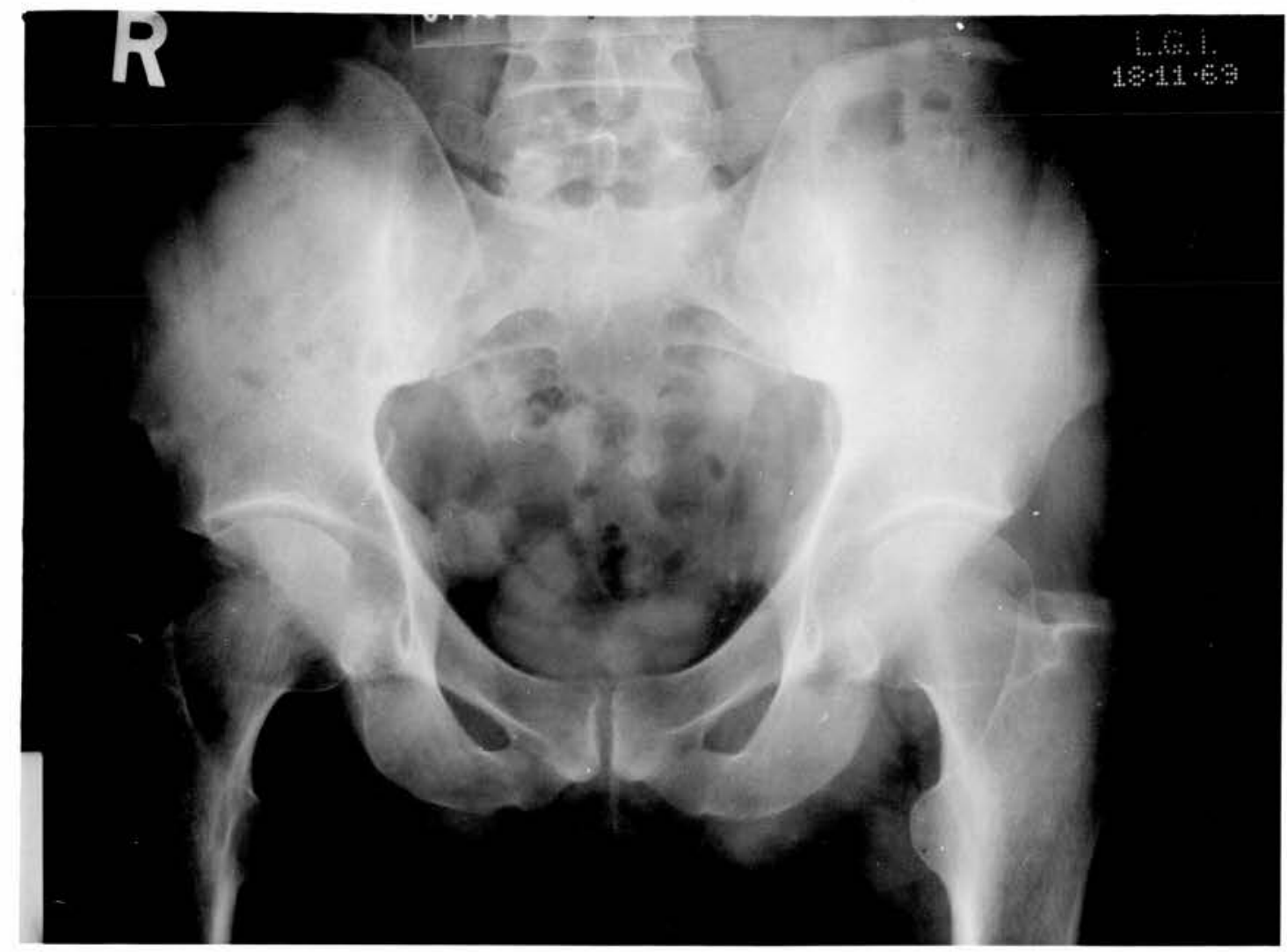


EIc. $A-8$.

Sacro-1111tis grade 4 . 


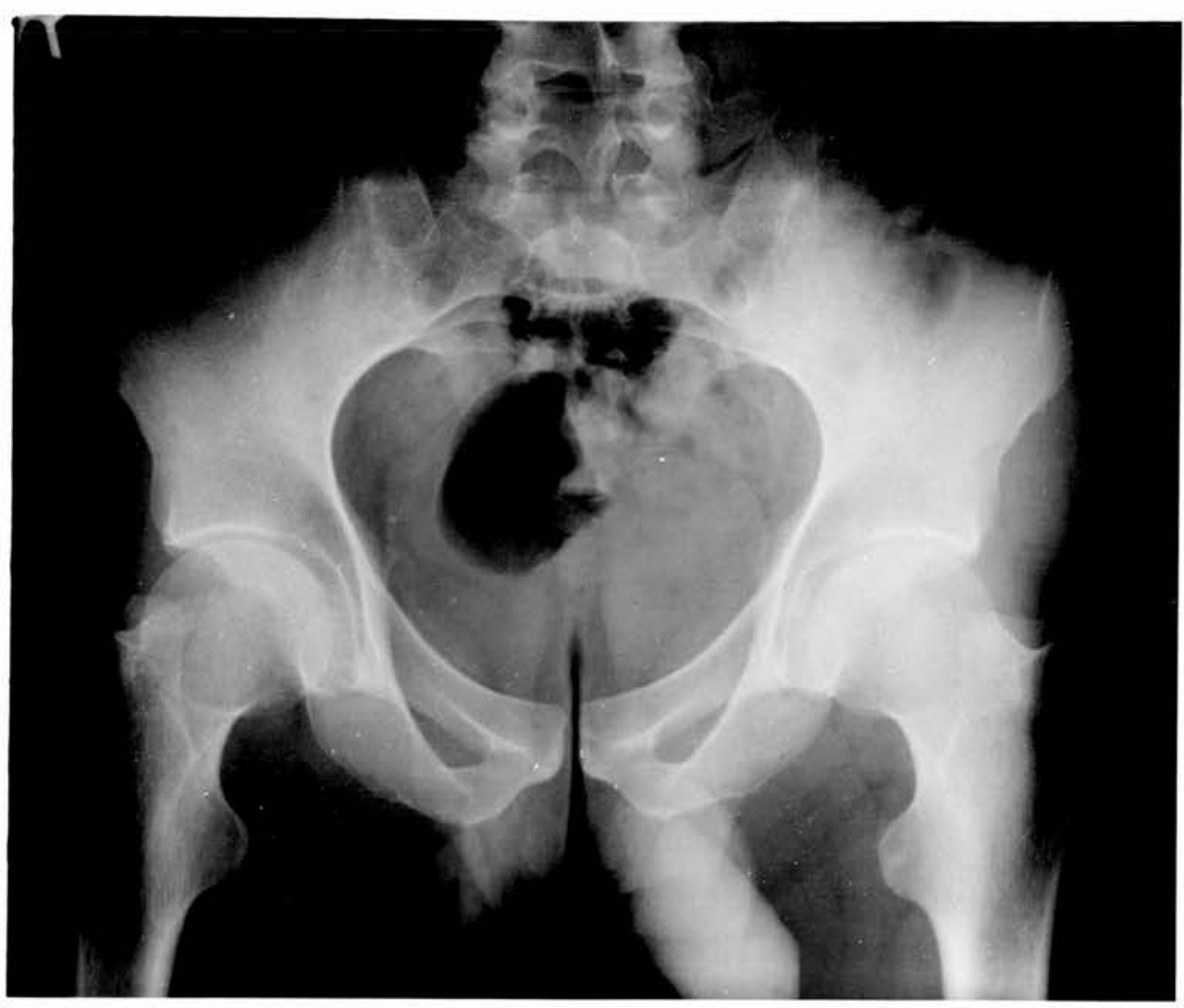


Fig. $A-9$.

Adolescent sacro-111ac joint. 


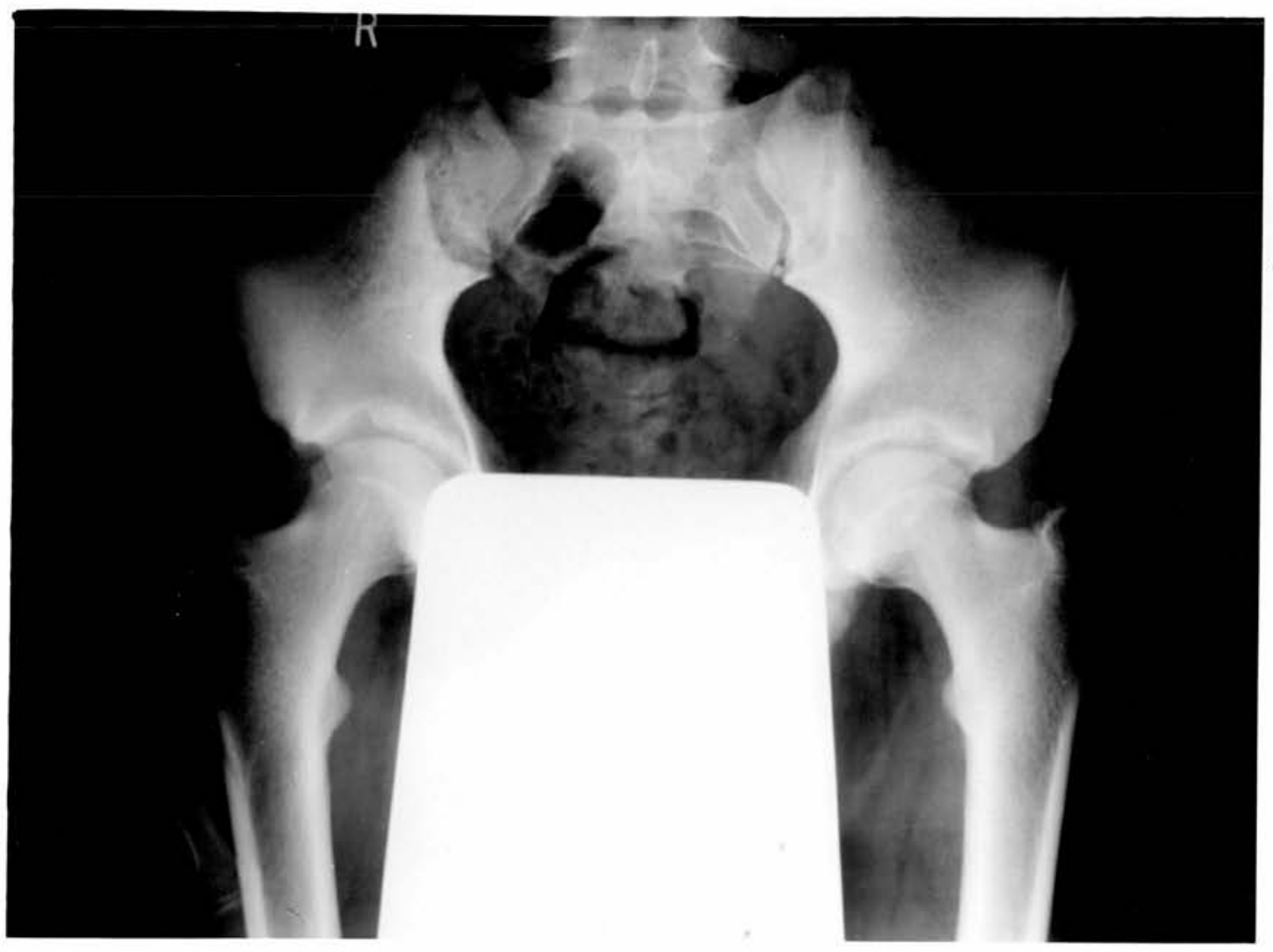


Fig. A - 10 .

Adolescent sacro-iliac jolnt. 


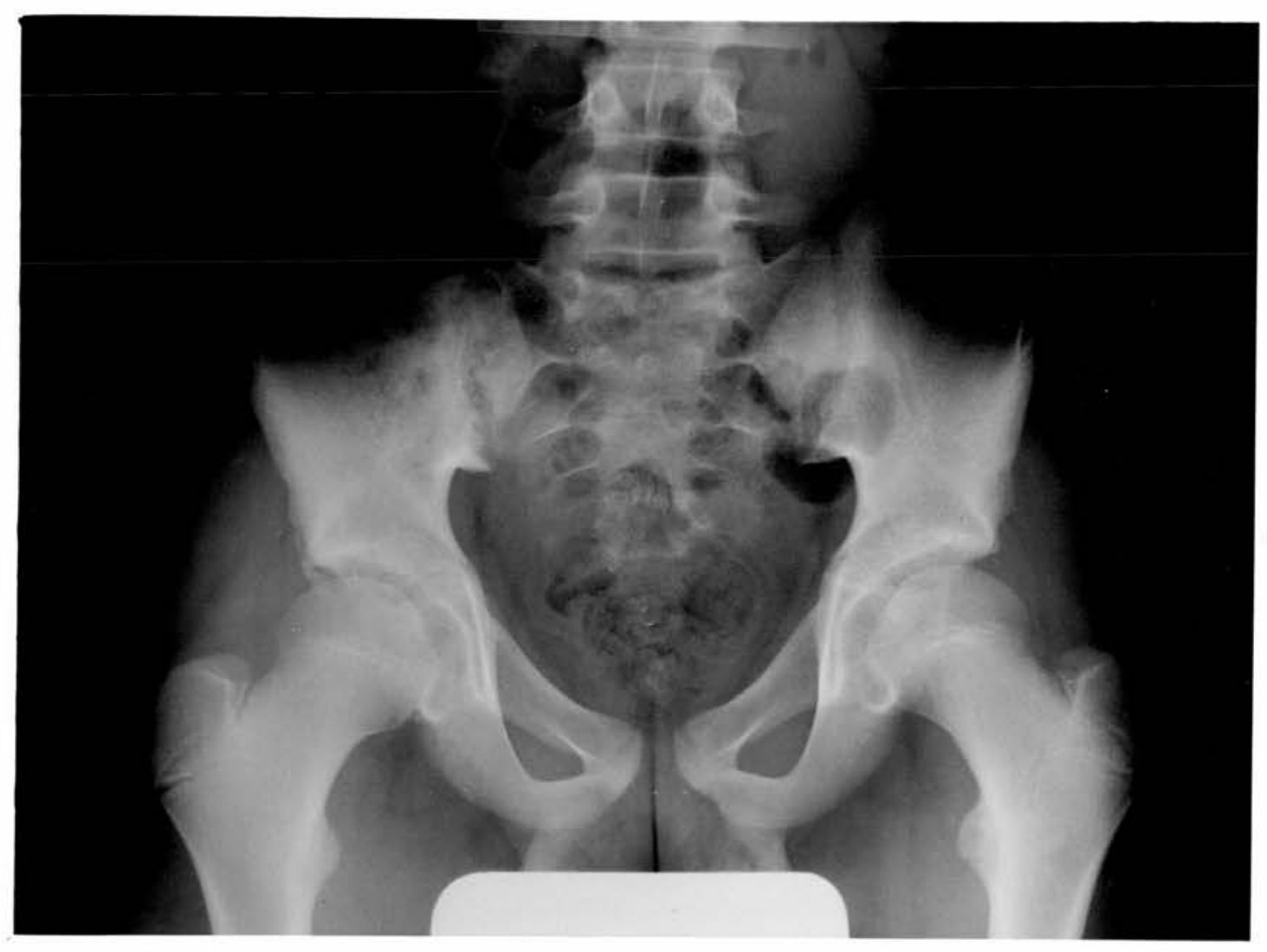


Fir. $A-11$

Pelvis affected by Paget's disease. 


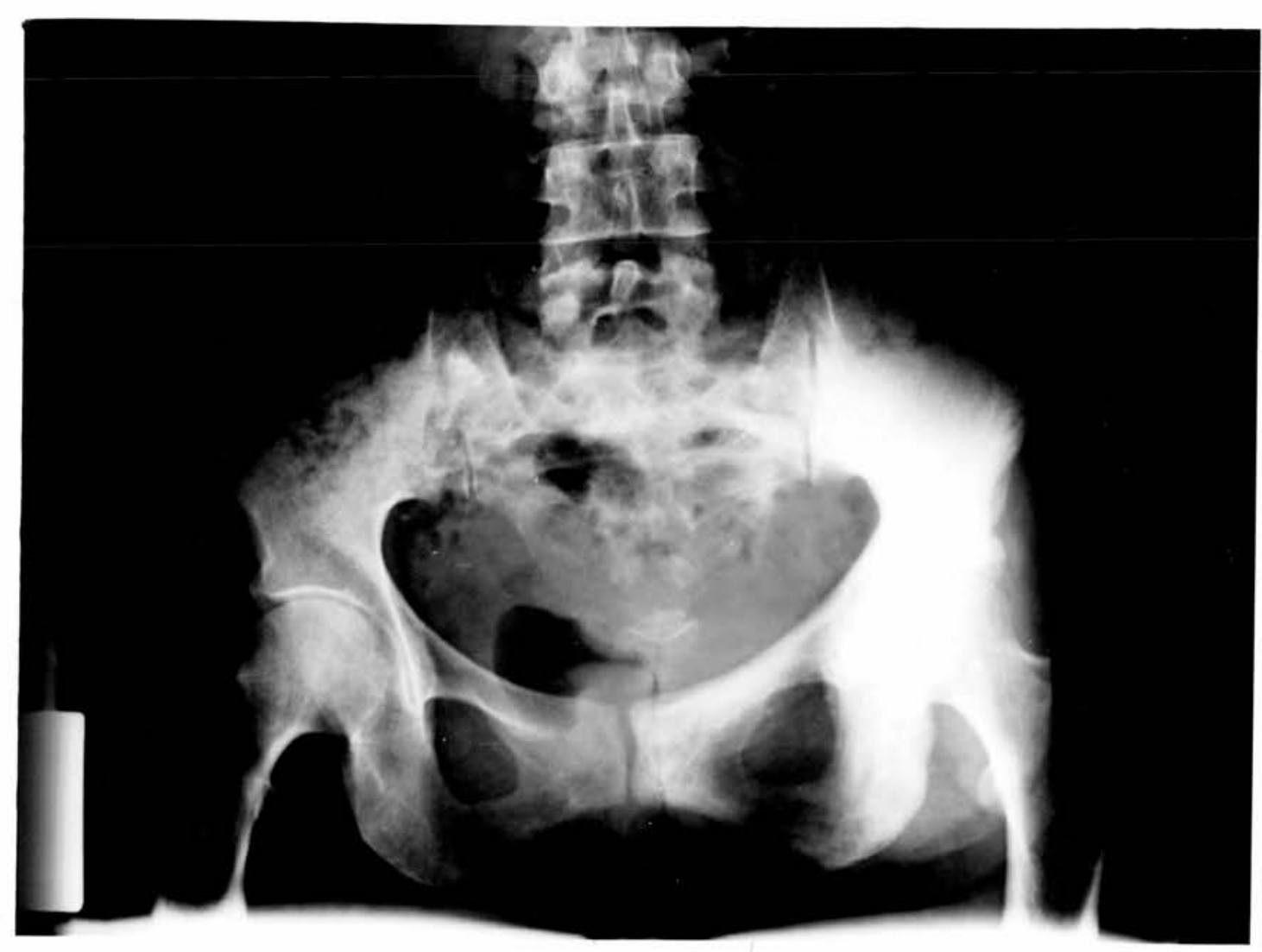


APPENDIX B.

Con-urison of surveys - Crohn's

Disease and Ulcerativo Colitis. 
One of the functions of this survey was to provide a comparison between patients with ulcerative colitis and Crohn's disease drawn from the same geographic area and assessed using the same methods. One of the reasons for the controversy surrounding such facts as the relative incidence of intestinal arthropathy in the two conditions is the lack of such comparative surveys. Most figures are derived from series drawn from different geographical areas, often widely separate temporally. This makes them the subject of possible errors due to re-appraisal of such factors as the incidence of colonic Crohn's disease. They are usually the product of different groups of workers from different clinical backgrounds using varying methods of assessment, and the methods used are frequently inadequately described in publications.

only one pair of publications exists which shows sufficient similarity in personnel and methods to justify a comparison of the results. This pair compised the survey of patients with ulcerative cilitis by Bywaters and Ansell (1958) and that of regional enteritis by Ansell and Wigley (1964). Both investigations included patients from the Canadian Red Cross Memorial Hospital at Taplow, the Hammersmith Hospital and the Central and West Middlesex Hospitals. Both the first two hospitals are specialist centres which attract referrals from a wide area, so the geographical source of the patients may be quite variable. Certain other aspects of the two studies are not comparable. The Crohn's survey set out to discover 
the incidence of musculoskeletal complications in a population of patients known to have gut disease, while the colitis survey was of patients known to have both gut and joint problems only. Although all the patients in the Crohn's survey were seen personally by the authors, seven of the colities had no personal examination by the authors who confined themselves to a review of the case notes. Crohn's disease patients with primary colonic involvement were not accepted. This has led to a possible bias ageinst certain types of crohn's disease, and might have led to some of the patients who were diagnosed as having Idiopathic ulcerative colitis being in fact examples of colonic Crohn's disease.

With these drawbacks in mind, the information which may be compared from the two publications is shown in Table B - 1. Fig. B - 1 shows the age distribution calculated from the publications, that for the patients with Crohn's disease being drawn from the whole series not those with misculoskeletal complications 01:?

It appears that at least two of the patients with ulcerative colitis were suffering from co-incidental rheumatold arthritis. If these are excluded, the number of patients with radiographic changes in their joints remains surprisingly high, and is not born out by other workers. With this exception, the general pattern of joint involvement appears similar in the two diseases. The higher incidence of sacro-iliitis in the patients with Crohn's disease almost certainly arises from the review 
Fig. B -1 .

Age distribution of patients with ulcerative colltis and Crohn's disease. 


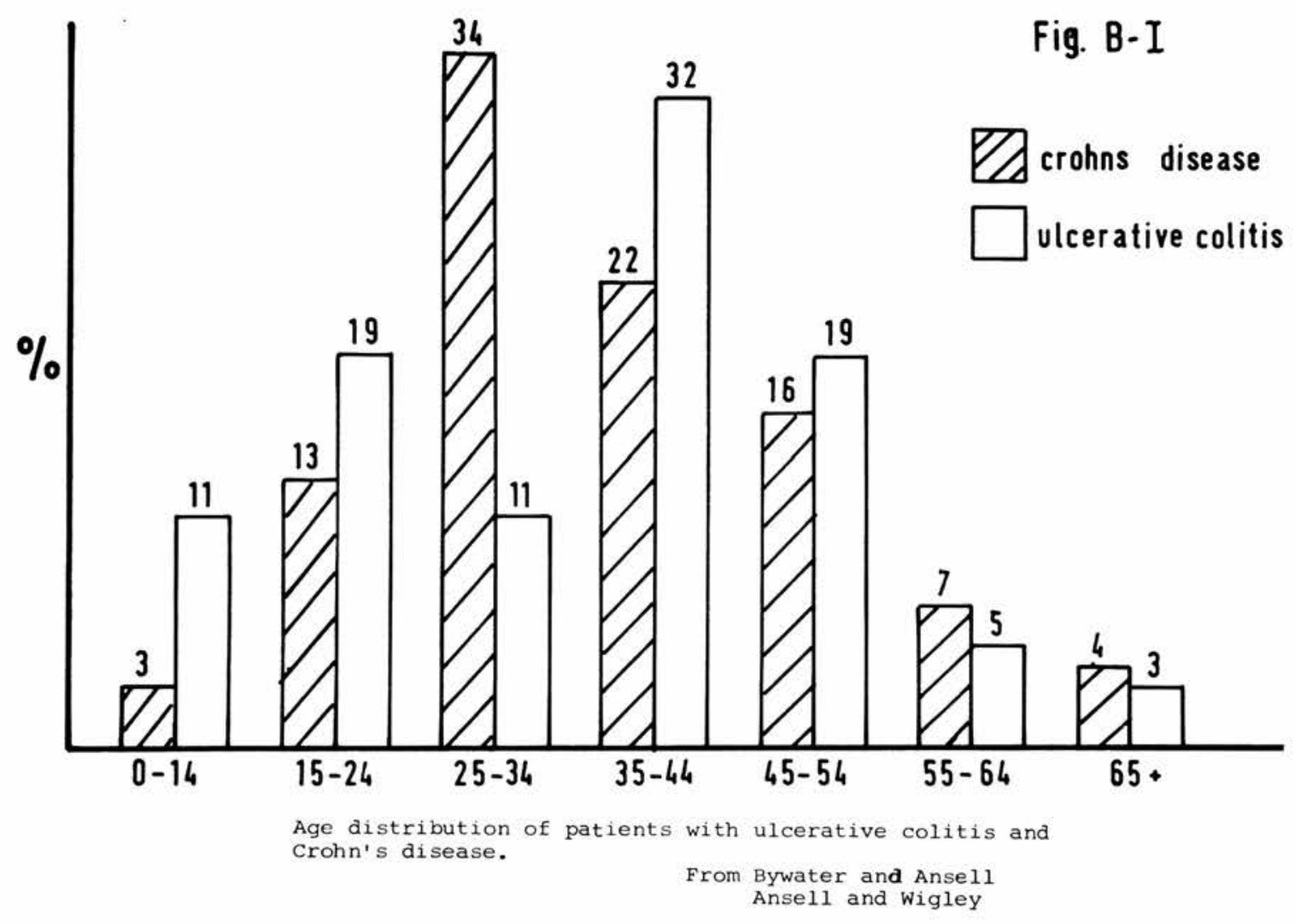




\section{Tovie B - 1.}

\section{Ul cerative Colitis}

Number

Male : Female

clinical findings:

Polyarthritis

Morarthritis

Ankylosing Spondylitis

Arthralgia

Incidental arthritides

Polyarthritis:

with erythema nodosum

before gut disease

simultaneous

after gut disease

Joints involved commonly

Others

Radiology:

Sacro-ilitis

Abnormal peripheral joints

Serology S.C.A.T. + ve

\section{7}

$9: 23$

37

0

0

0

0

\section{7}

7

4

17

Knees

Ankles

Fingers

Toes (a11 I.P)
Crohn's

Disease

36

$16: 19$

18

2

5

3

8

2

$\frac{1}{2}$

11

Knees

Fingers (R.I.P.S)

Vrists

Ankles

Hip

18 *

6

10

0

$3^{* * 4}$

0

Comparison between patients with ulcerative colitis and Crohn's disease with musculosireletal complications.

* = includes the 5 with A.S.

$*^{*}=t 1$ tre of $1: 64$ or greater. 
of the sacro-iliac joints of patients without clinical sacro-iliitis, this condition frequently being asymptomatic. The family studies of ulcerative colitis and Crohn's disease from Leeds are more comparable. The geographical area was identical. The temporal difference was small (3 - 4 years). The observers were both rheumatologists with the buik of their clinical experience in the same unit. The methods of measurement used in the surveys were identical, and the comparability of the interpretation of sacro-iliec joint radiographs was ensured by the participation of the author as one reader of these films in both family studies. Finally, the diagnostic critcria for the diseases studied did not undergo any change during the time of the studies, nor were there any major changes emong the personnel of the hospital, particularly the surgical staff, which could have had a major effect on diagnostic or therapeutic methods.

As the work presented hereafter is collaberative, i.e. the figures given under 'ulcerative colitis' are supplied by Dr. Ian Macrae, and form part of his unpublished thesis, they will be presented in outline only, but will form the basis for a joint puhlication at a later date.

Comparability of the two family studies is shown in Table $B-2$. Ihis demonstrates that the two surveys are highly comparable numerically. The mean size of the families surveyed in the Crohn's disease family study was 2-6 perscns, the comparative figure for the ulcerative cclitts survey being 3.2 persons. The distribution among groups of relatives is very similar. 
Table $B-2$

Uicerative

colitis survey

cuter

Number of spouses

Total

Inner

Outer

First Degrea Relatives

Total
Inner
Outer

Second degree Relatives

Total

Inner

Outer
91

292

251

41

180

155

25

56
54
2

54

$5 \frac{1}{3}$

198

55

disease survey

116

253

55

146

107

39

56

53

40

14

Comperisons of surveys of Cronn's Digesso and Ulcerative colitis: subt cts seen and zereved in tho survers. 
The incidence of intestinal exthronathy in the two surveys is show in Table B- 3. This shows an excess of this condition in patients with Crohn's disease which approaches statistical significance $(p<0.1>0.05)$.

\section{Teble $B-3$}

\section{Vlcerative colitis Crann's disease} survey survey

Number of Probends

$\begin{array}{lrr}\text { Tctal } & 91 & 116 \\ \text { Nale } & 37 & 58 \\ \text { Female } & 54 & 58\end{array}$

Probands with intestinal

arthritis

Total
Naie
Female

Comparison of surveys of Crohn's di sease and Ulceracive colitis: probands with intestiral arthritis.

Such a result would be expected for tro reasons. Firstly the area of gut involved in Crohn's disease is potentially much greater than that involved in ulcerative colitis. A greater area is, therefore, available to generate the abnormal reaction which produces arthropathy. second, and probably more important, the radical surgical approach adopted in Leeds removes the entire diseased area from patients with ulcerative colitis, whereas no such refical removal is possible in Crohn's disease. There is, therefore, potentially diseased gut in situ for the entire-life of a patient with Crohn's disease, whereas the ulcerative colitic 
Eubjected to total procto-nclectom and ileostem has no

further gut remaining wich can initiate the process

leading to colltic arthritis.

The incizence of sacro-t11itis and ankylosing spondylitis In the two studies is shown in Tabie B - 4 .

$2 a b l e B-4$

$\begin{array}{ll}\text { Ulcerative } & \text { Crohn's } \\ \text { collt1s survey } & \text { disease survey }\end{array}$

Males Females Males Females

Ankylosing spondylitis:

Probandis *

$\begin{array}{llll}18.9 & 7.4 & 6.9 & 6.9\end{array}$

Sacro-iliitis:

Probands

First degree relatives

Second degree relatiees

spouses

$\begin{array}{llll}25.7 & 7.9 & 19 & 13.8 \\ 8.2 & 3.0 & 7.4 & 10 \\ 4.6 & 2.9 & 0 & 3.1 \\ 0 & 0 & 0 & 0\end{array}$

Comparison of surveys of Crohn's disease and ulcerative colitis: percentage of patients with ankylosing spondyiltis and sacro-iliitis. (" this group includes those jrobands with ankylosing spondrititis.)

The trend shown in each survey is identical, that is a decreasing proportion of sacro-iliitis in the relatives as their distance from the probands increases. Thus both surveys support the suggestion that sacro-iliac involvement in colitis and crohn's disease arises as a result of cormon inheritance of two conditions. The difference between the numbers of male probands diagnosed as having definite, as opposed to probable, ankylosing spondylitis, 
approaches statistical significance $(p-0.1>0.05)$. It is thought that the difference is due to an alteration in clinical approach between the two groups. After the conpletion of the colitis survey, discuscion between the two authors suggested that the criterion 'back pain' was insufficiently censitive. An attempt was made in the second (Crohn's) survey to eiminate all cases of backache for wich some external cause could be ascribed. As back pain was the comonest cilnicel criterion converting probeble to ciefintte ankylosing spondylitis this probably accounts for the discrepancy.

In sumary, the two studies confirm that intestinal arthropathy has an association with gut disease, but probable ard definite anklosing spondylitis are co-incidentQ.1y inherited and show a pattern of inheritance in the relatives. 
ARPEIDIX C

IHE CONCWPT OS SERONEGATIVE

SPOKOARTHIRITIS. 
The ideas contained within this appendix are the joint results of discussions between the author and Professor V. Wright, Dr. I.F. Macrae and DE. J.M.H. Moll. This material will, therefore, be presented in outline only, but will be the subject of a joint publication at a future date.

The three family studies undertaken from the Rheumatism Research unit (i.e. the present study, the family study of ulcerative colitis - Dr. Ian Nacrae, and the family study of psoriasis and arthritis - Dr. John Moll ) have been considered together as contributory towards a concept which the author has named 'seronegative spondarthritis'. This has been reinforced by consideration of the literature. In essence this theory suggests that there are clinical and familial likages among a number of diseases, i,e. psoriatic arthritis, Reiter's disease, ulcerative colitis, Crohn's disease, Whipple's disease, Behcet's syndrome and Idiopathic ankylosing spondylitis. The clinical features which are shared by some or all members of the group are the presence of an inflammatory polyarthritis or synovitis, absence of detectable rheumatoid factor in the serum, absence of rheumatoid subcutaneous nodules, radiological sacro-iliitis, ankylosing spondylitis, psoriaform skin eruptions, ocular and genito-urinary inflamation and buccal, intestinal and genital ulceration. The evidance for clinical and familial aggregation of the various linkage disorders is summarised in Tables C - I and C - 2 respectively, the appropriate references being found in Table $c-3$. 
The name of the concept was felt to be aposite in that the most constant linking features appeared to be the presence of a seronegative peripheral arthritis or synovitis, in each case clearly distinguishable from rhoumatoid arthritis, and involvement of the sacro-iliac joints and spine.

The inclusion of still's disease in this group was considered. Some patients in whom the diagnosis of still's disease has been made are undoubtedly suffering from ankylosing spondylitis of juvenile onset. Clearly these patients would be included in the group. Evidence is less clear regarding those patients who appear to have juvenile rheumatoid arthritis. Again some appear to have true rheumatold arthritis with an early age of onset, but a high proportion are distinguished by having seronegative disease and an increased incidence of sacro-iliitis. There is also evidence for familial aggregation (Ansell, Bywaters and Lawrence, 1968). It seems likely that the term "Still's disease Includes a heterogenous collection of several different diseases, some of which are related to true seropositive rheunatoid arthritis. These last would be excluded from the group of seronegative spondarthritides, but other members of the group should probably be included. Until such time as there is an agreed method of subdividing these cases, however, the general category "Still's disease" will be excluded.

The further evaluation of the concept of seronegative spondarthritis will rely on family studies of the other members of the group, particular note being taken of the prevalence of each linkage disorder in both probands and relatives. 


\section{TABLE C - I}

Psoriatic Ankylosing Ulcerative Crohn's Reiter's Whipple' arthritis spondylitis colitis disease disease disease.

ehcet's yndrome

ipple's iisease

eiter's iisease

rohn's isease

Lerative $\Rightarrow$ litis akylosing $\rightarrow$ ondylitis

$$
15
$$

$$
\text { 1. } 24
$$

$25-26$

47

47

$16-23$

1. $27-30$

39,46

$12-14$

$31-34$

$40-42$

*

$44-45$

$10-11 \quad 1,35-39$

$1-9$

\section{3}

*

clinical Linkages described among members of the group of seronegative spondarthritides.

(from Mo11. 1971.)

References to each number will be found in Table C - 3 . $*=$ Not yet described. 


\section{TABLE C-2}

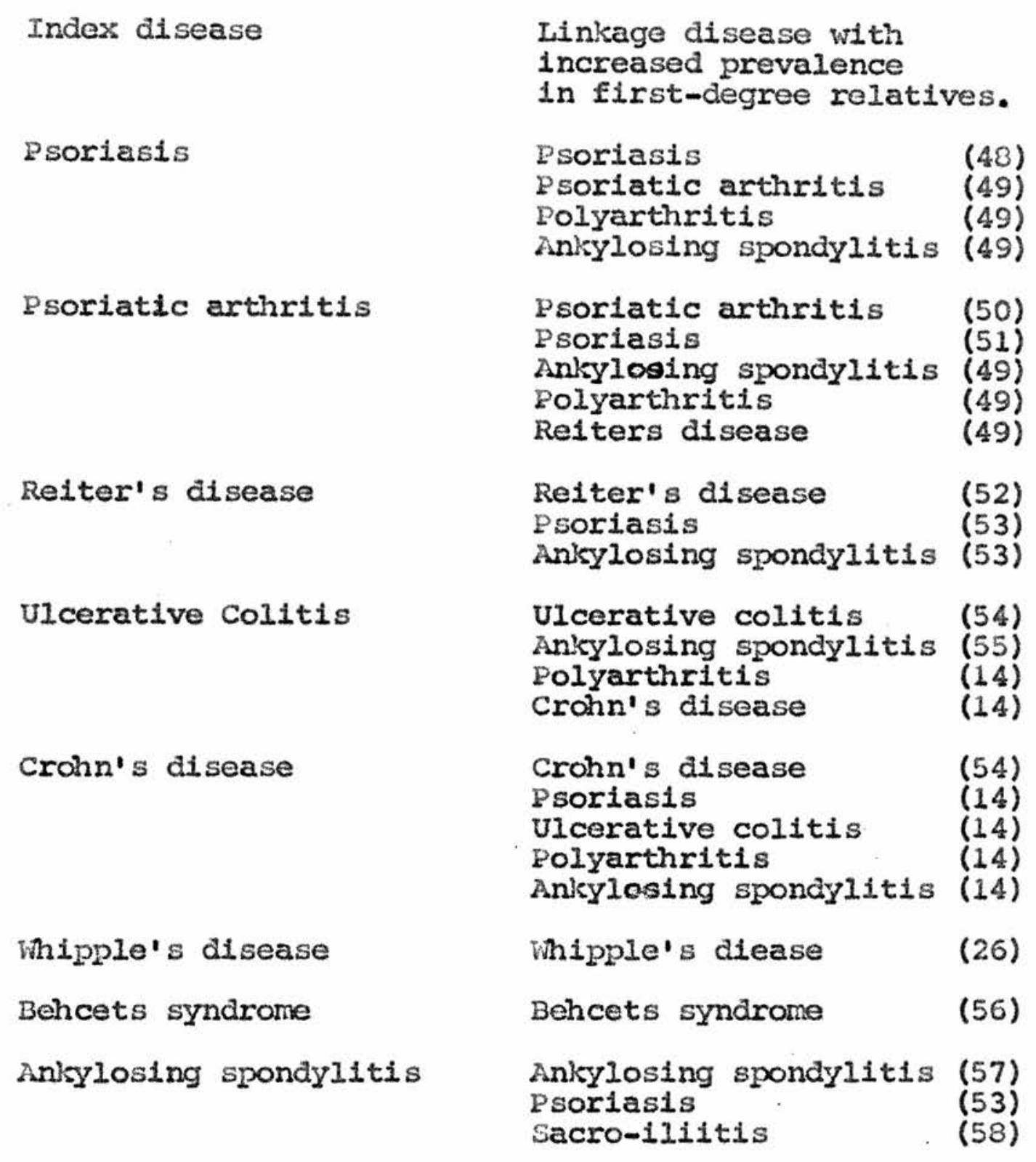




\section{TABLE C - 3}

Wright, 1966 B

Bywaters and Dixon, 1965

vi.ttorio, Viaca and Chiandaro, 1965 Graber - Duvernay, 1957

Reed, 1961

Jajic, 1966

Luckerini and Porzio, 1965

Robecclic and Vittorio, 1965

Fletcher and Rose, 1955

Jayson and Bouchier, 1968

Rolstein, Entel and Zeviner, 1963

ansell and Wigley, 1964

Rossmiller and Meosenger, 1948.

Jammer, Ashurst and Naish, 1968

Washeter, 1959

Pox and Macleod, 1901

opstein, 1939

rall and Finegold, 1953

aright and Reed, 1964

$\rightarrow$ erry and Mayne, 1965

Laxwell et al. 1966

wryll et al. 1969

munlop, Harper and Jones, 1968

'erkins, 1961

iyler and Doub, 1956

ruite and Tesluk, 1955

ing, 1964

right, 1965

ason, 1965
30. Oates and Young, 1959

31. Ford and Vallis, 1959

32. McBride et al. 1963

33. Soren, 1966

34. Bowen and Kirsner, 1965

35. Acheson, 1960

36. Wright et al. 1965

37. Wright and Watkinson, 1965

38. Bywaters and Anse11, 1958

39. Wright, 1963.

40. Bøe, Dalgaard \& Scott, 1958

41. Sulheim, Dalgaard \& Anderson, 1959

42. Todd, 1954

43. Billson et al. 1967

44. Robinson and McCrumb, 1950.

45. Strachan, and wigzell, 1963

46. Stanworth and Sharp, 1956

47. Wilske and Decker, 1965

48. Lomholt, 1963

49. Lawrence, 1967

50. Baker, Golding and Thompson, 1963

51. Reed and Wright, 1966

52. Paronen, 1948

53. Lawrence, 1965

54. Kirsner and Spencer, 1963

55. Macrae and Wright, 1970

56. Forbes and Robson, 1960

57. Hersh et al. 1950

58. Bremner et al. 1968

References to Table $\mathrm{C}-1$ and $\mathrm{C}-2$

(From Moll, 1971) 
APPENDIX D.

PRO-FOTMAS 
Letter to Probands. 
Rheumatism Research Unit

School of Medicine

44 Clarendon Road

Leeds

LS2 9PJ

Professor V. Wright, M.D., F.R.C.P.

Telephone 36171 Ext. 26

Dear

You may already know that arthritis is an occasional complication of bowel disease. Members of the Rheumatism unit have been interested in arthritis and bowel disease for a long time, and have found out quite a lot about some kinds. However, there has never been an adequate study of people with the bowel disorder that you have.

It does seem from what has been written about it that there is an increased incidence of arthritis, particularly in the back. We are not only interested in finding this kind of arthritis but in treating it too. You will see, therefore, that it could be in your interest as well as ours for us to see you, although I must stress that the chances of you having this kind of arthritis are not very great.

We are inviting patients with your bowel disorder to see us at the Infirmary for a brief examination and $\mathrm{X}$-ray to see if any arthritis is present. Unfortunately, it has not been possible for us to arrange this during follow-up clinics, and we have made arrangements to hold our clinics in the evening. Funds have been made available to pay your travelling expenses, and the whole visit should take less than an hour.

Enclosed are full instructions and a card, which I should like you to fill in and post to me as soon as possible.

I am sure you will be pleased to come and see us, not only because this might help you, but also because of the help that our increased knowledge might give to other people in the future.

I look forward to seeing you, and hope very much that you will be able to come.

Yours sincerely,

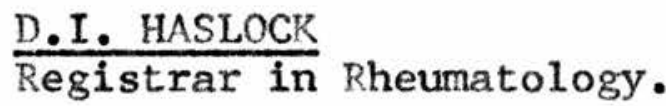


List of Relatives. 


\section{LIST OF RELATIVES (Sheet 1 ).}

NAME

Please write in the TITLE (Mr. Mrs. Miss etc.), NAME and ADDRESS of all your relatives listed on this and the next sheet.

If any of these relatives have died, it would be helpful if you would write in the cause of death, if known, and make a note about whether they had any back trouble by writing BACK YES or BACK NO or BACK DON'T KNOW after each one. If any relative is under 21 YEARS please write in the age.

\begin{tabular}{l|l} 
MOTHER'S SIDE & FATHER'S SIDE \\
\hline MOTHER & FATHER \\
& \\
\hline MOTHER'S BROTHERS \& SISTERS & FATHER'S BROTHERS \& SISTERS
\end{tabular}


LIST OF RELATIVES (Sheet 2).

YOUR BROTHERS \& SISTERS YOUR HUSBAND/WIFE

YOUR CHILDREN 
First Letter to Relatives. 
Rheumatism Research Unit

School of Medicine

44 Clarendon Road

Leeds

LS2 9PJ

Professor V. Wright, M.D., F.R.C.P.

Telephone 36171 Ext. 26

\section{Dear}

The rheumatic diseases cause much suffering and are the second largest cause of loss of work in this country. At present we are sadly ignorant of the causes of rheumatism and desperately need more information about it. We do know that there is a connection between rheumatism and bowel disorders, and we believe that a family study of people with bowel disease will yield valuable information.

Your.............. who has a bowel disorder, has given me permission to ask you to take part in this study and, even if you do not suffer from rheumatism yourself, I do hope that you will agree to do so.

This would involve you in coming to the Leeds General Infirmary one evening, and you would be asked a few simple questions, be briefly examined and X-rayed. This should take less than one hour and we will be glad to pay your travelling expenses. Enclosed are full instructions on a separate sheet, and a card which I would like you to fill in and post to me as soon as possible.

I believe that I am asking you to assist us in something which is really worthwile and I hope very much that you will come.

Yours sincerely,

D.I. HASLOCK,

Registrar in Rheumatology.

Encs. 
Card Enclosed with letter to Relatives. 


\section{RHEUMATISM SURVEY}

Name.................

I will attend the clinic on:-

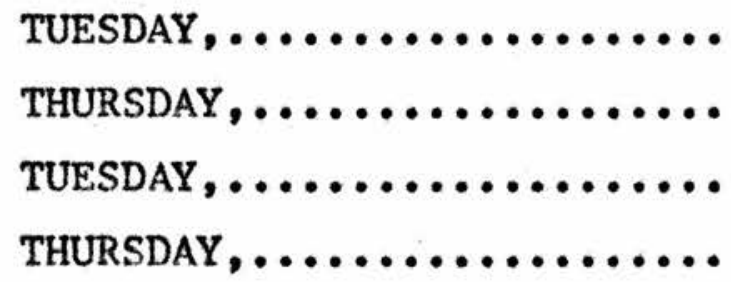

I cannot attend on any of these dates, but will be able to come in about........... weeks ( a further card will be sent nearer the time.

I am unable to attend because:- 
INSTRUCTIONS SHEET 


\section{RHEUMATISM RESEARCH}

\section{PLEASE BRING THIS SHEET WITH YOU}

$$
\text { NAME: }
$$

HOW TO FIND US

Enter the Leeds General Infirmary by the OUTPATIENTS and VISITORS entrance in Calverley Street (opposite Civic Hall).

Just inside the entrance you will see stairs and a lift on your left. Go up to ' $D$ ' floor ORTHOPAEDIC OUTPATIENTS where we will be waiting.

TIME OF YOUR APPOINTMENT

We will be able to see you between $5 \mathrm{p} \cdot \mathrm{m}$. and $6.30 \mathrm{p} \cdot \mathrm{m}$. on TUESDAYS AND THURSDAYS.

On the postcard we have given you a choice of days and I would be grateful if you would mark one of the days and the time you can come. Your appointment will be made as soon as the postcard is returned to me.

As a reminder, you might like to write the date and time of your appointment below:-

TUESDAY

at p.m.

THURSDAY

TRAVELLING EXPENSES:(please enter amount)

2nd class rail fare....................

Bus Far

Petrol

IF YOU ARE UNDER 21

We need the consent of your parent or guardian. Please ask your parent or guardian to give consent by signing below:-

Signed..............Parent/Guardian. 
Second Letter to Relatives. 
Rheumatism Research Unit

School of Medicine

44 Clarendon Road

Leeds

LS2 9PJ

Professor V. Wright, M.D., F.R.C.P.

Telephone 36171 Ext. 26

Dear

I have not received the postcard I sent you recently and I wonder if you have overlooked my letter. In case you have mislaid it I am enclosing a copy.

Perhaps you feel that whether you agree to come or not, it will not make much difference to the usefulness of this study. In fact you form a very important part of this survey since, unless we can see all the close relatives within reach, the survey will be a failure.

It may be that none of the dates we gave you were suitable. If that is the case we would be pleased to see you on any Tuesday or Thursday between $5.0 \mathrm{p} . \mathrm{m}$. and $6.30 \mathrm{p} . \mathrm{m}$.

$\pi$ enclose another stamped postcard and I would be most grateful if you would fill it in and send it to me. As well as giving you the choice of any Tuesday or Thursday, should you never be able to come on either of those days between $5.0 \mathrm{p} . \mathrm{m}_{\text {. }}$ and $6.30 \mathrm{p} . \mathrm{m}$., there is space on the card for you to let me know of any time that you could come. Since we are very anxious to see you some time, it might be possible for us to make special arrangements, though we would like to avoid this if we can. If for some reason you find yourself unable to come to see us at any time, it would be a great help ff you could give us some idea, on the postcard, of your reason for not coming.

I would like to end this letter by thanking you for troubling to read it and I look forward to hearing from you.

Yours sincerely,

D.I. HASLOCK, Registrar in Rheumatology. 
265

Third Letter to Relatives. 
Rheumatism Research Unit

School of Medicine

44 Clarendon Road

Leeds

LS2 9PJ

Professor V. Wright, M.D., F.R.C.P.

Telephone 36171 Ext. 26

Dear

You may remember I wrote to you recently asking if you would be willing to help in our research. Unfortunately I do not seem to have received a reply from you, and I wonder if the earlier letter has been overlooked. I enclose another one in case the first has been mislaid.

We have now arrived at a very important stage in our study. Although a lot of people have attended our clinic, we are still quite a long way short of our target. There is a danger that we will be unable to use the information we have gained so far because insufficient family members have attended to make our results representative of the whole family.= I am sure you will agree that this would be a tragedy not only because of considerable expense and effort which would be wasted, but also in seriously reducing the value of the knowledge we have gained about this important subject. We hope, therefore, that you will do your utmost to attend one of the clinics.

We do appreciate however, that circumstances make it impossible for some people to attend. We are able to make allowance for this when analysing our results provided we know the reason for non-attendance.

If therefore, problems such as illness, inconvenienee due to your work, or inability to travel to the Infirmary because of advanced age or some disability prevent your coming, would you please give your reason on the enclosed sheet and return it to me.

Thank you for giving the time to read this letter. I hope you will be able to participate in the survey, but whether or not you can come please fill in the enclosed sheet and return it to me in the stamped addressed envelope provided.

Yours sincerely,

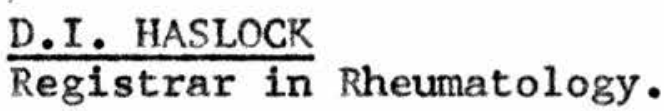


First Letter to Relatives (Outer). 
Rheumatism Research Unit

School of Medicine

44 Clarendon Road

Leeds

LS2 9PJ

Professor V. Wright, M.D., F.R.C.P.

Telephone 36171 Ext. 26

Dear

As you may know, rheurnatism causes a great deal of disablement and suffering, and is the second most important cause of work loss in this country.

Some forms of rheumatism are associated with bowel disease, and we are investigating the families of people with bowel disease in order to find out about these forms of rheumatism and to try and find out more about the cause of rheumatism in general.

Your.............. who suffers from a type of bowel dieease has given permission for us to ask you to take part in this study even if you do not suffer from rheumatism yourself. I hope you will agree, as in order to make our research worthwhile it is important that as many members of the family help us as possible.

Your participation will consist of one short visit to your local hospital for an $x$-ray. This should not take more than about half an hour, and we will do our best to find a convenient time and date for your attendance.

Your help in this study would be very much appreciated particularly as we hope it may produce a really valuable contribution to our knowledge of rheumatic disease.

I should be most grateful if you would fill in and return the enclosed stamped addressed postcasd. If you are able to take part, we will contact you again as soon as possible giving details of the place and time of your visit to the Hospital $\mathrm{X}$-Ray Department.

Looking forward to hearing from you.

Yours sincerely,

D.I. HASLOCK

Registrar in Rheumatology. 
Second Letter to Relatives (Outer). 
Rheumatism Research Unit

School of Medicine

44 Clarendon Road

Leeds

LS2 9PJ

Professor V. Wright, M.D., F.R.C.P.

Telephone 36171 Ext. 26

Dear

You may remember receiving a letter about our Rheumatism survey some time ago, and since you did not return the enclosed postcard, I wonder if you overlooked it. In case you have mislaid the letter I am enclosing a copy.

Perhaps you feel that whether you agree to have the X-rays taken or not, it will not make much difference to the usefulness of this study. In fact, you form a very important part of this survey since, unless we can see all the close relatives within easy reach, the survey will be a failure.

If you do agree to have the $x$-rays taken at your local hospital, we are most anxious that you should not be cut of pocket as a result. We will therefore be happy to pay your travelling expenses and make a contribution towards loss of pay if you had time off work.

I enclose another stamped postcard and I would be most grateful if you would fill it in and send it to me as soon as possible.

I would like to end this letter by thanking you for troubling to read it, and I look forward to hearing from you.

Yours sincerely,

D.I. HASLOCK,

Registrar in Rheumatology. 
Letter to Radiologists. 
Rheumatism Research Unit

School of Medicine

44 Clarendon Road

Leeds

LS2 9PJ

Professor V. Wright, M.D., F.R.C.P.

Dear Doctor,

We are at present undertaking a family study of the arthritis associated with Crohn's disease, particularly in an attempt to assess the incidence of spondylitis and peripheral arthritis in the relatives of Crohn's patients.

For those relatives who live more than 20 miles from Leeds, we are depending on the Radiology Department of their nearest hospital to provide us with a set of $\mathrm{X}$-rays to the enclosed specification.

We should be most grateful if you could assist us in this way, and we would, of course, meet any expenses incurred through use of films, radiographer's time, etc.

I do hope you will be able to assist us, in which case would you please let us know the best date and time for attendance. On receipt of your letter, we shall write to confirm the appointment, giving full details, and we shall make the necessary arrangements informing the relatives of the appointment.

Yours sincerely,

D.I. HASLOCK

Registrar in Rheumatology. 
Radiology Requirements. 


\section{CROHN'S DISEASE FAMILY SURVEY}

\section{RADIOGRAPHIC RENUIREMENTS.}

FILMS (1) A - P Pelvis

(2) Both HANDS on one film

(3) Both FEET on one film on film size $17^{\prime \prime} \times 14^{\prime \prime}$

"12" $\times 10^{\prime \prime}$

"12" $\times 10^{\prime \prime}$

Films taken at $40^{\prime \prime}$ anode film distance with the subject undressed.

\section{MARKING OF FILMS.}

In order to make reading of films as 'blind' as possible -

We are most anxious not to have the films marked so that their hospital of origin can be identified. Neither should the subject's name appear.

The only marking should be " $R$ " denoting subject's right side to appear at top left corner as one views the film in the conventional way, and if possible, for the " $R$ " to be followed by the subject's survey number. The marks should be as small as possible and a photographic type, though ink would do failing this.

We would appreciate having the film corners cut.

\section{RADIATION HAZARD.}

The A - P pelvis film should not be taken on males aged less than 15 years, and females less than 45 years.

MALES A 4" gonadal screen for all males on pelvis film. 
Mestionnaire - Probands. 
NAME.

HOSP. No.

AGE

CONSULTANT.

FAMILY NO.

Portion of Gut involved.

Stomach

Duodenum

Jejunum

Ileum

Colon

SURGERY (with dates)

COMPLICATIONS: Fistulae: internal

external

SKIN : (Pyoderma etc.)

EYES:

OTHERS : 
HAVE YOU EVER HAD PAIN OR STIFFNESS

IN YOUR BACK (Circle)

Yes

No

Don't know

Which part of your back was

Cervical

Dorsal

Lumbar

Sacral

\begin{abstract}
affected.
\end{abstract}
Date

When did you first notice this pain or stiffness

Yrs. ago

Age of onset

Duration

Still present

How long did the pain or stiffness last

Yes No Don't know

Have you had other attacks of pain

or stiffness since then

Does your back feel entfrely

normal between attacks

Yes

No

Don't know

Does your back feel worse on

Rest

Movement

movement or at rest

Same

Don't know

Does your back feel stiff in the -mornings

Yes Duration Hrs. Mins

No

Have you ever consulted your Doctor -about pain or stiffness in your back

Have you ever been seen in hospital mabout your back

Yes No Don't know

Yes No Don't know

Date

Hospital

Doctor

were you told what the trouble was

Diagnosis

-Did you have any treatuent

Treatment

Have you ever had time off work $\rightarrow$ ecause of your back

Yes

No. of times

No

Don't know

-IAVE YOU EVER HAD PAIN, TINGLING OR IUUMBNESS IN YOUR THIGH, LEG OR FOOT (Circle)

Yes

No

Don't know 
Was there any pain or stiffness in your back or bottom at the same Yes

Don't know time.

EXCLUDING BACK TROUBLE, HAVE YOU EVER HAD ARTHRITIS OR RHEUMATISM

Yes

No

Don't know

HAVE YOU HAD SWELLING, ACHING OR PAIN IN ANY OF YOUR JOINTS.

Yes

No

Don't know

Which joints are, or have been affected.

SEE CHART

When did this trouble start

Date

Yrs. ago

Age

When your joints are troublesome, do you feel 111 in any other way

Yes (specify)

No

Don't know

Have you ever seen your Doctor about your joints

Yes

No Don't know

Have you ever been to hospital about your joints

Yes No Don't know

Date

Hospital

Doctor

Were you told what the trouble was

Diagnosis

Did you have any treatment

Treatment

Have you ever had time off work because of arthritis or rheumatism

Yes No Don't know

No. of times

DO YOU FEEL STIFFNESS IN YOUR MUSCLES

OR JOINTS FIRST THING IN THE MORNING

Yes

Hrs.

Mins.

No

Don't know

HAVE YOU EVER HAD ANY SKIN TROUBLE

Yes

No

Don't know

Was this a scaly rash, or psoriasis

Yes

No

Don't know

DO YOU SUFFER FROM INDIGESTION

Yes

No

Don't know 


\begin{tabular}{|c|c|c|c|}
\hline DO YOU HAVE BOUTS OF COLICKY PAIN & Yes & No & Don't know \\
\hline $\begin{array}{l}\text { HAVE YOU EVER HAD AN ATTACK OF } \\
\text { DIARRHOEA AND PASSED BLOOD AT } \\
\text { THE SAME TIME }\end{array}$ & $\begin{array}{l}\text { Yes } \\
\text { Date } \\
\text { Yrs. ago } \\
\text { Age }\end{array}$ & No & Don't know \\
\hline $\begin{array}{l}\text { Have you had further bouts since } \\
\text { then }\end{array}$ & $\begin{array}{l}\text { Yes } \\
\text { Number }\end{array}$ & No & Don't know \\
\hline $\begin{array}{l}\text { HAVE YOU EVER BEEN TO HOSPITAL } \\
\text { BECAUSE OF ANY BOWEL UPSET }\end{array}$ & $\begin{array}{l}\text { Yes } \\
\text { Date } \\
\text { Hospital } \\
\text { Doctor }\end{array}$ & No & Don't know \\
\hline $\begin{array}{l}\text { Were you told what the trouble was } \\
\text { Did you have an } x \text {-ray }\end{array}$ & $\begin{array}{l}\text { Diagnosis } \\
\text { Yes } \\
\text { Ba.Meal }\end{array}$ & No & $\begin{array}{l}\text { Don't know } \\
\text { Ba.Enema }\end{array}$ \\
\hline Did you have any treatment & Treatment & & \\
\hline $\begin{array}{l}\text { HAVE YOU EVER HAD ANY INFLAMMATION } \\
\text { OF YOUR EYES }\end{array}$ & Yes & No & Don't know \\
\hline
\end{tabular}




\section{PROBANDS ONLY.}

PRESENT STATE: Crohn's

$$
\text { Arthritis }
$$

ONSET of Crohn's and Arthritis

Synchronous

Arthritis 1st by

(durn.)

Crohn's 1st by

(durn.)

ACTIVITY OF CROHN'S \& ARTHRITIS

Synchronous

Independant

EFFECT OF SURGERY ON ARTHRITIS

Post-operative onset

surgery exacerbates

relief

None

TYPE OF SURGERY

COMPLICATIONS OF SURGERY

TREATMENT.

STEROIDS 
EXAMINATION SHEET

Chest expansion (cms.)

A.P.

Transverse

Circumference

Lumbar spine flexion (cms.)

\begin{tabular}{|l|l|}
\hline Distance between markers & \\
\hline Erect & \\
\hline Full flexion & \\
\hline Difference & \\
\hline
\end{tabular}

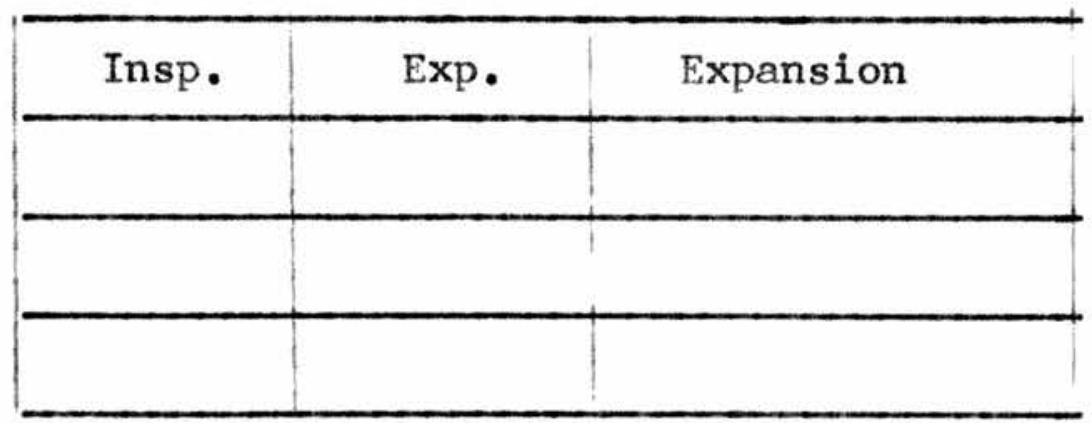

Lateral flexion:

Rotation:

Clubbing:

Eyes

OTHER

Investigations
L.S.T.

$\mathrm{X}$-RAY Pelvis

L. Spine

Hands

Feet

other
L

Normal

Limited

Normal

L Limited

Present/Absent

$\mathrm{R}$.

L. 
Questionnaire - Relatives. 


\begin{tabular}{|c|c|c|}
\hline IN YOUR BACK (Circle) & Yes & Don't know \\
\hline $\begin{array}{l}\text { Which part of your back was } \\
\text { affected }\end{array}$ & $\begin{array}{l}\text { Cervical } \\
\text { Lumbar }\end{array}$ & $\begin{array}{l}\text { Dorsal } \\
\text { Sacral }\end{array}$ \\
\hline $\begin{array}{l}\text { When did you first notiee this pain } \\
\text { or stiffness }\end{array}$ & $\begin{array}{l}\text { Date } \\
\text { Yrs. Ago }\end{array}$ & Age of onset \\
\hline $\begin{array}{l}\text { How long did the pain or stiffness } \\
\text { last }\end{array}$ & $\begin{array}{l}\text { Duration } \\
\text { Sto11 pres }\end{array}$ & ent \\
\hline $\begin{array}{l}\text { Have you had other attacks of pain } \\
\text { or stiffness since then }\end{array}$ & Yes & Don't know \\
\hline $\begin{array}{l}\text { Does your back feel entirely normal } \\
\text { between attacks }\end{array}$ & Yes & Don't know \\
\hline $\begin{array}{l}\text { Does your back feel worse on } \\
\text { movement or at rest }\end{array}$ & $\begin{array}{l}\text { Rest } \\
\text { Same }\end{array}$ & $\begin{array}{l}\text { Movement } \\
\text { Don't know }\end{array}$ \\
\hline $\begin{array}{l}\text { Does your back feel stiff in the } \\
\text { mornings }\end{array}$ & $\begin{array}{l}\text { Yes } \\
\text { No }\end{array}$ & Duration Hrs. Mins. \\
\hline $\begin{array}{l}\text { Have you ever consulted your Doctor } \\
\text { about pain or stiffness in your } \\
\text { back. }\end{array}$ & Yes & Don't know \\
\hline $\begin{array}{l}\text { Have you ever been seen in hospital } \\
\text { about your back }\end{array}$ & $\begin{array}{l}\text { Yes } \\
\text { Yes } \\
\text { Hospital } \\
\text { Doctor }\end{array}$ & Don't know \\
\hline $\begin{array}{l}\text { Were you told what the trouble was } \\
\text { Did you have any treatment }\end{array}$ & $\begin{array}{l}\text { Diagnosis } \\
\text { Treatment }\end{array}$ & \\
\hline $\begin{array}{l}\text { Have you ever had time off work } \\
\text { because of your back }\end{array}$ & $\begin{array}{l}\text { Yes } \\
\text { No }\end{array}$ & $\begin{array}{l}\text { No. of times } \\
\text { Don't know }\end{array}$ \\
\hline $\begin{array}{l}\text { HAVE YOU EVER HAD PAIN, TINGLING OR } \\
\text { NUMBNESS IN YOUR THIGH, LEG OR FOOT } \\
\text { (Circle) }\end{array}$ & Yes & Don't know \\
\hline $\begin{array}{l}\text { Was there any pain or stiffness in } \\
\text { your back or bottom at the same time }\end{array}$ & Yes & Don't know \\
\hline
\end{tabular}




\section{2.}

EXCLUDING BACK TROUBLE, HAVE YOU EVER HAD ARTHRITIS OR RHEUMATISM

Yes No Don't know

HAVE YOU HAD SWELLING, ACHING OR PAIN

IN ANY OF YOUR JOINTS

Yes No Don't know

Which joints are, or have been affected

SEE CHART

When did this trouble start

Date

Yrs. ago

Age

When your joints are troublesome, do you feel ill in any other way

Yes (specify)

No

Don't know

Have you ever seen your doctor about your joints

Yes No Don't know

Have you ever been to hospital about your joints

Yes No Don't know

Date

Hospital

Doctor

Were you told what the trouble was

Diagnosis

Did you have any treatment

Treatment

Have you ever had time off work because

Yes No Don't know of arthritis or rheumatism

No. of times

DO YOU FEEL STIFFNESS IN YOUR MUSCLES

OR JOINTS FIRST THING IN THE MORNING

Yes Hrs. Mins.

No Don't know

HAVE YOU EVER HAD ANY SKIN TROUBLE

Yes No Don't know

Was this a scaly rash, or psoriasis

Yes No Don't know

DO YOU SUFFER FROM IDIGESTION

Yes No Don't know

DO YOU HAVE BOUTS OF COLICKY PAIN

Yes No Don't know

HAVE YOU EVER HAD AN ATTACK OF

DIARRHOEA IRD PASSED BLOOD AT THE

SAME TIME

Yes No Don't know

Date

Yrs. ago

Age 
Have you had further bouts since then

Yes

Number

\begin{tabular}{l|l}
\hline $\begin{array}{l}\text { HAVE YOU EVER BEEN TO HOSPITAL } \\
\text { BECAUSE OF ANY BOWEL UPSET }\end{array}$ & $\begin{array}{l}\text { Yes } \\
\text { Date } \\
\text { Hospital } \\
\text { Doctor }\end{array}$ \\
\hline $\begin{array}{l}\text { Were you told what the trouble was } \\
\text { Did you have an x-ray }\end{array}$ & $\begin{array}{l}\text { Diagnosis } \\
\text { Yes } \\
\text { Ba. Meal Nnow }\end{array}$ \\
\hline Did you have any treatment & Ireatment Enema \\
\hline \\
$\begin{array}{l}\text { HAVE YOU EVER HAD ANY INFLAMMATION } \\
\text { OF YOUR EYES }\end{array}$ \\
\hline
\end{tabular}




\section{EXAMINATION SHEET}

Chest expansion (cms.)

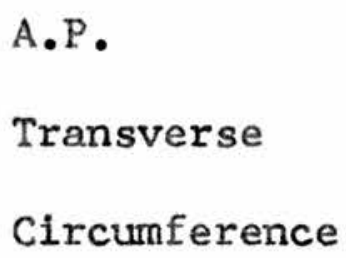

\begin{tabular}{|l|l|l|}
\hline Insp. & Exp. & Expansion \\
\hline & & \\
\hline & & \\
\hline & & \\
\hline
\end{tabular}

Lumbar spine flexion (cms.)

\begin{tabular}{|l|l|}
\hline Distance between markers & \\
\hline Erect & \\
\hline Full flexion & \\
\hline Difference & \\
\hline
\end{tabular}

Normal

Normal

Lateral flexion:

Rotation:

Clubbing:

Eyes

OTHER
R

Limited

Normal

R

Limited

Present/Absent

$\mathrm{R}$.

L.
L

Limited

Normal

L

Limited

Investigations $\quad$ L.S.T.

$\mathrm{X}-\mathrm{RAY}$ Pelvis

L. Spine

Hands

Feet

other 
18. Which joints have been affected.................. CIRCLE

19. What did you notice wrong with the joint

was it painful on movement........P

tender to touch ...............T

swollen........................s

20. How long ago did the joint first trouble you.......... Years

21. Has the joint ever returned completely to normal.... YES $=/ N O=X$
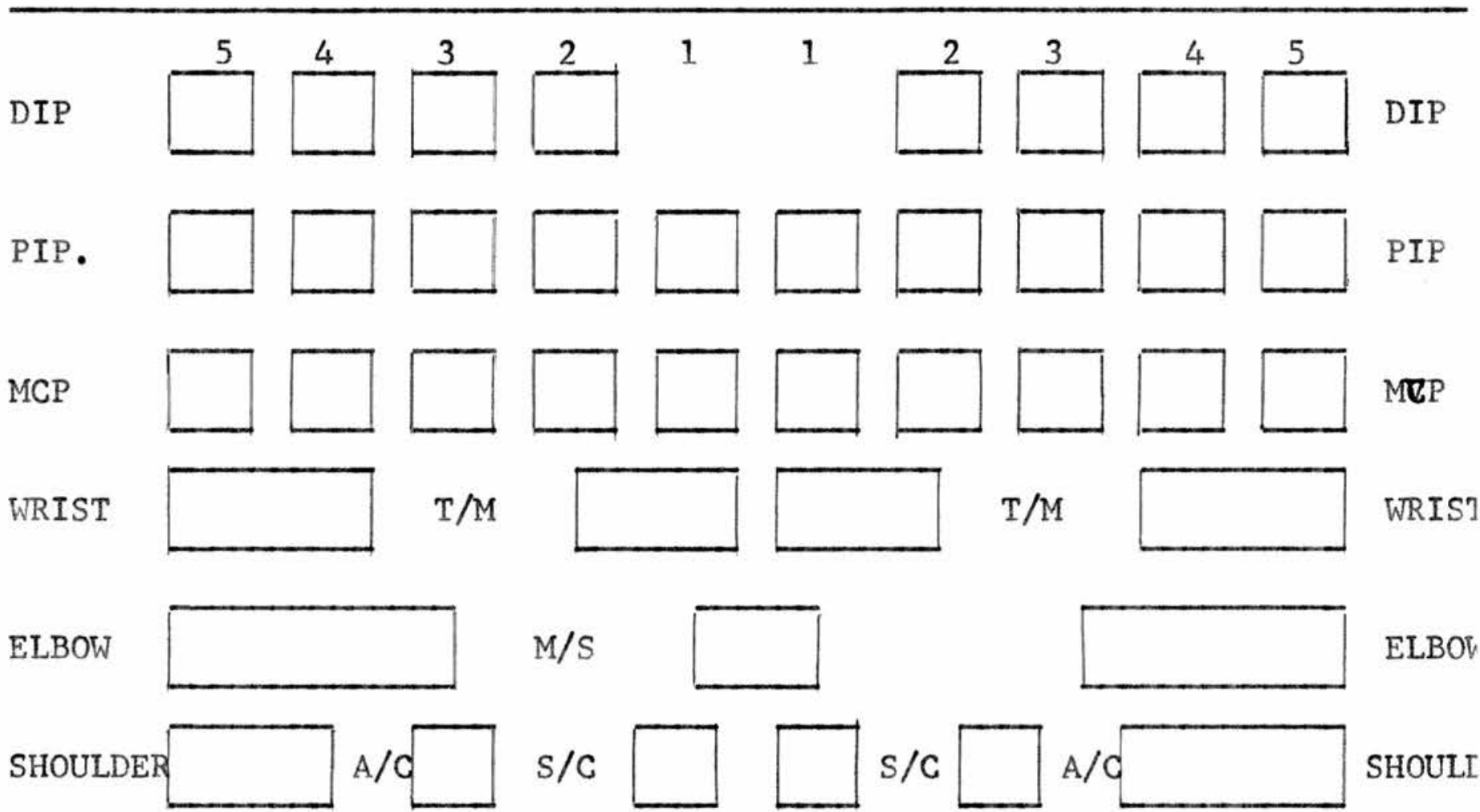

ELBOV

HIP

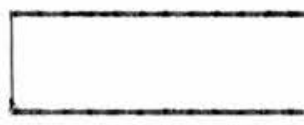

$\mathrm{c} / \mathrm{s}$

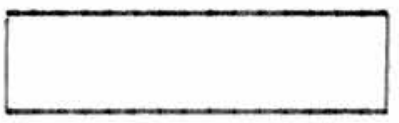

SHOULI

KNEE
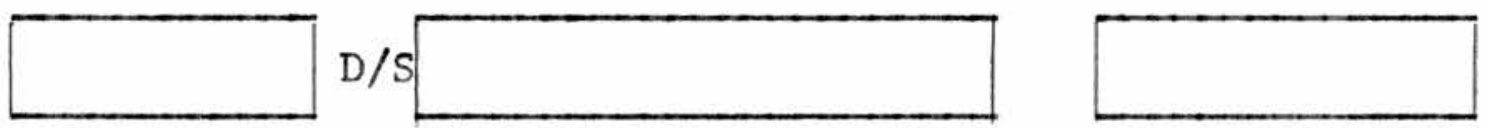

KNEE

S.I.

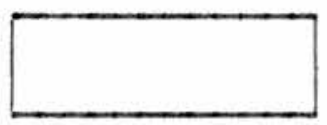

$\mathrm{L} / \mathrm{S}$

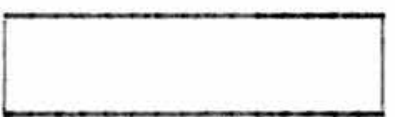

S.I.

ANKLE
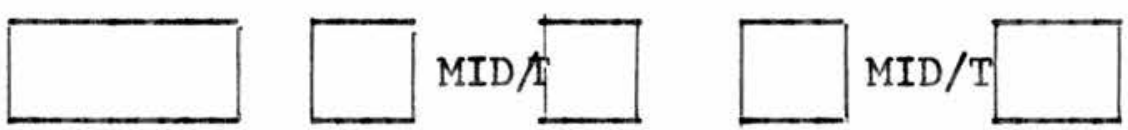

HEEL

ANKLE.

MTP
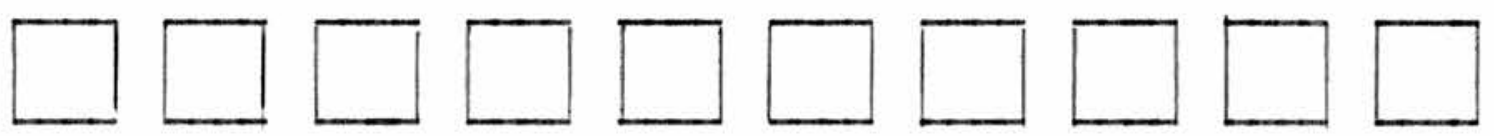

MTP

TOES
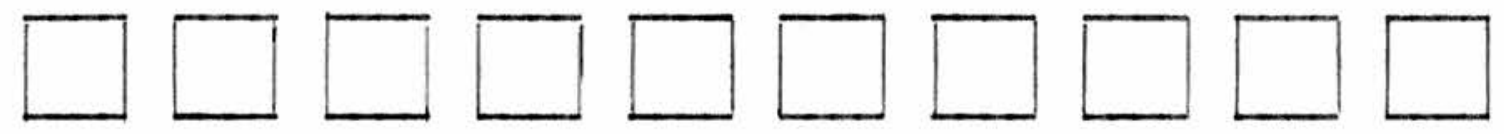

TOES

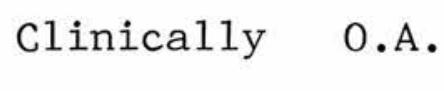

Radiologically O.A.

R.A.

R.A.

Psoriatic

Psoriatic 
X-RAY ANALYSIS SHEET. 


\section{CROHN'S DISEASE FAMILY STUDY}

\section{X-RAY ANALYSIS}

No. C.

$$
\text { GRADES. } \quad \begin{aligned}
& 0=\text { None } \\
& 1=\text { Doubtful } \\
& 2=\text { Minimal } \\
& 3=\text { Moderate } \\
& 4=\text { Severe }
\end{aligned}
$$

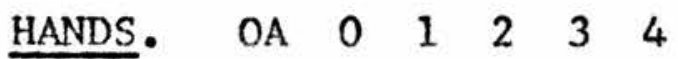

No. of joints: DIP

$$
\begin{aligned}
& \text { PIP } \\
& \text { MCP } 1 \\
& 2-5 \\
& \text { WRIST }
\end{aligned}
$$

\begin{tabular}{|c|c|c|c|c|}
\hline HIPS. & $\mathrm{OA}$ & 1. 0 & 1 & 2 \\
\hline & & R. 0 & 1 & 2 \\
\hline
\end{tabular}

$\begin{array}{llllll}\mathrm{RA} & 0 & 1 & 2 & 3 & 4\end{array}$

$\begin{array}{llllll}\mathrm{RA} & 0 & 1 & 2 & 3 & 4\end{array}$

$\mathrm{OA}$ 1. $010 \quad 1 \quad 2 \quad 3 \quad 4$

R. $\begin{array}{lllll} & 1 & 2 & 3 & 4\end{array}$
No. of joints: PIP

MCP

Carpi Mild Mod. Sev.

No. of joints: MTP

OTHER. 
SACRO-ILIAC JOINT READINGS SHEET. 


\section{FAMILY STUDY OF CROHN'S DISEASE.}

Family No. C

SACRO-ILIACS.

No change Doubtful Mild Mod. Severe

Erosion

Sclerosis

0

1

234

0

1

23

4

No change Doubtful $\begin{aligned} & \text { Definite } \\ & \text { Partial }\end{aligned}$

Ankylosis

0

1

3

4

\section{Normal \\ Narrowing \\ Widening}

Widening

0

N

W

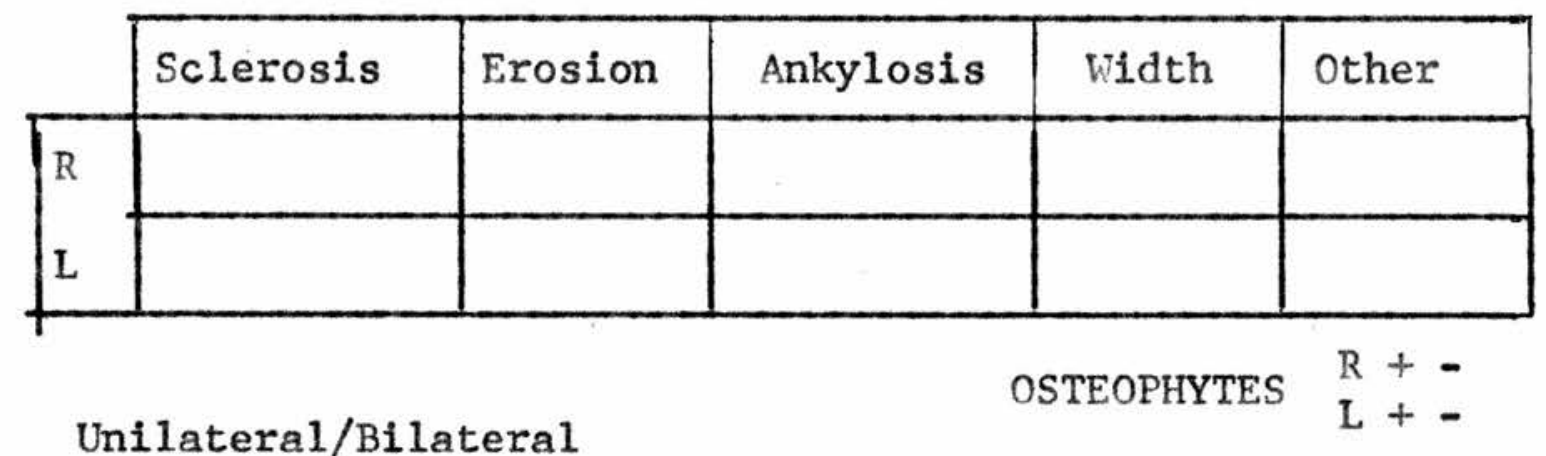

Grade by more severely affected joint.

New York Grading: $0=$ Normal

$1=$ Suspicious

$2=$ Abnormal with erosions or sclerosis.

$3=$ Unequivocal abnormal, moderate or advanced sacro-iliitis showing one or more of erosions, sclerosis, widening, narrowing, partial ankylosis.

4 = Total ankylosis. 
Punch Card Pro-Forma. 


\section{CROIN'S DISEASE FAMILY SURVEY}

All patients Cols. 1-11 25-44

Probands only 12-24

$\mathrm{X}$-rays

SURVEY NO. (Col. 1-6)

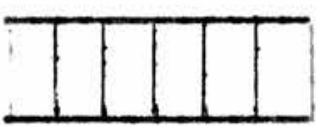

AGE (Col. 7-8)

$\operatorname{SEX}(\operatorname{Col} .9) \frac{M}{\frac{M}{1}}$

(Col. 10)

Inner 0

(Col. 11)

Proband

1st Degree Relative

2nd Degree Relative

Spouse

Control

Parent

Sibs.

offspring

(Col. 16)

Crohn's before arthritis 0

Arthritis before Crohn's 1

Synchronous

Not known

2

3
(Col. 12-13)

Age at onset of Crohn's Disease:

(Co1. 14-15)

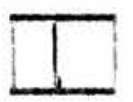

Age at onset of Arthritis:

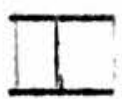

(Col. 17-18)

Years between onset of 2 diseases

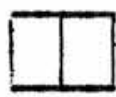

(Col. 19) Portion of Gut involved.

Stomach

Duodenum

Jejunum

Ileum

Caecum

Ascending Colon

Transverse Colon

Descending Colon

Rectum
0

1

2

3

4

5

6

7

8

(Col. 20) Treatment.

Not known

0

None

Medical no steroids

Medical with steroids

Laparotomy

3

Exclusion

4

Excision affected small gut 6

Excision affected large gut 7

Total colectomy 8

Other

(Col. 21) Complications

Internal Fistulae

External Fistulae

Malabsorption

Skin

Eyes

Others
(Co1. 22) Diagnosis

Clinical

Radiological

Laparotomy only

Histology

Unknown

\section{0}


(Col. 23) Clinical state on examination.

$\begin{array}{llr}\text { Crohn's: } & \text { Remission } & 0 \\ & \text { Exacerbation } & 1 \\ & \text { Chronic } & 2 \\ & \text { Not noted } & 3 \\ \text { Symptoms from Complications: } & \text { Yes } & 4 \\ & \text { No } & 5 \\ \text { Arthritis: } & \text { Active } & 6 \\ & \text { Inactive signs } & 7 \\ & \text { Inactive t no signs } & 8 \\ & \text { Not noted } & 9\end{array}$

(Col. 24) Crohn's + Arthritis.

Activity:

Synchronous 0

Independant 1

Effect of surgery on Arthritis: Post operative onset 2

Surgery exacerbation 3

remission 4

none 5

Not known 6

(Co1. 25) Clinical Type of Arthritis (Col. 26) Joint Involvement.

Rheumatoid Arthritis

Osteoarthrosis

Psoriatic Arthritis

Intestinal Arthropathy

Ankylosing Spondylitis

Sacroilitis

Clubbing

other

0

1

2

3

4

5

6

7
(Col. 27)

P.I.P.'s

Number

$\begin{array}{rr}\text { Yes } & 0 \\ \text { No } & 1 \\ 1 & 2 \\ 2 & 3 \\ 3 & 4 \\ 4 & 5 \\ 5 & 6 \\ 6 & 7 \\ 7 & 8 \\ 8 & 9 \\ 9 & 11 \\ 10 & 12\end{array}$

D.I.P.'s Yes 0

$\begin{array}{lrr}\text { Number } & \text { No } & 1 \\ & 1 & 2\end{array}$

2.3

34

45

56

67

78

89

(Col. 28)

$\begin{array}{ccc}\text { M.C.P.'s } & \text { Yes } & 0 \\ & \text { No } & 1 \\ & 1 & 2 \\ 2 & 3 \\ & 3 & 4 \\ & 4 & 5 \\ 5 & 6 \\ 6 & 7 \\ 7 & 8 \\ 8 & 9 \\ 9 & 11 \\ & 10 & 12\end{array}$




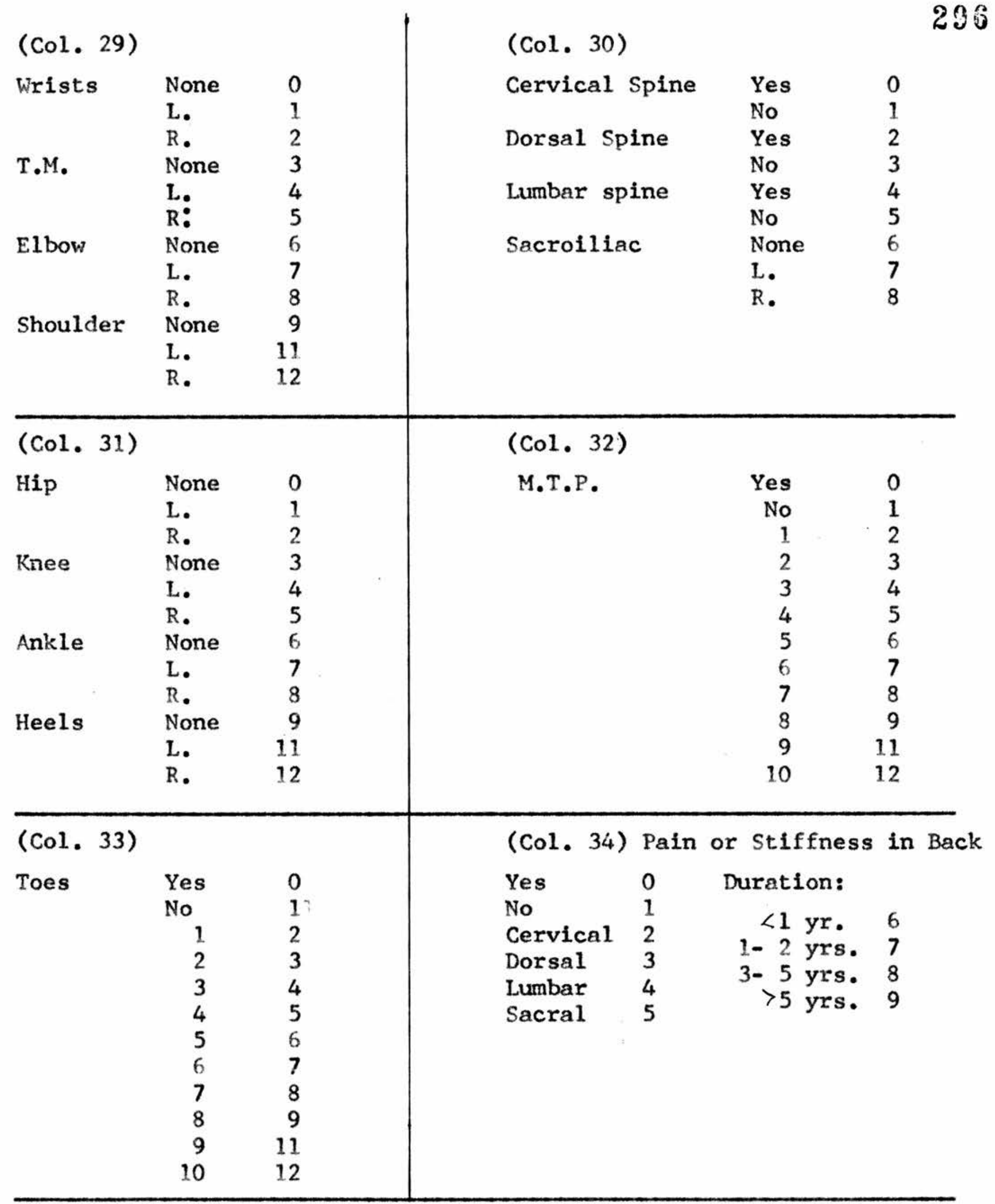




\section{(Col. 35)}

Further attacks

Ever normal

Movement

Rest

Some

don't know

Morning stiffness

Hospitalisation

(Co1. 37)

Arthritis or Rheumatism Yes 0

No 1

swelling etc. of joints Yes 2

Duration:

$1 \mathrm{yr}$.

1-2 yrs.

3-5 yrs.

5 yrs.

Hospitalised

Morning Stiffness

(Col. 39)

Indigestion

Colic

Bloody diarrhoea

Yos

\begin{tabular}{lll}
\multicolumn{2}{c}{ No } \\
\hline (Co1. 41) & & \\
Latex test & + ve & 0 \\
& weak ve & 1 \\
& - ve & 2 \\
& not done & 3
\end{tabular}

(Co1. 36)

Pain down leg Yes 0

with back pain

No 1

independant
(Col. 38)

Skin complaint: Yes 0

scaly rash

No 1

Psoriasis

Eczyma

Contact dermatitis

Other

Unknown
(Col. 40)

Bowel disease hospitalisation Yes 0

Diagnosis given

Treatment: surgical medical don't know

No 1

Yes 2

No 3

3

4

6

Fye inflammation: significant insignificant No

(Col. 42)

Chest Expansion $\quad>2.5 \mathrm{~cm}$. 0 $\leqslant 2.5 \mathrm{~cm}$. 1 JMH normal 2 abnormal 3 not done 4 
(Col. 43)

(Col. 44)

Back movement IFM normal

Clubbing

Rotation abnormal 1 not done 2 normal 3 abnormal 4 not done 5

Lateral flexion normal 6 abnormal 7 not done 8 $\begin{array}{lll} & \text { don't know } 2 \\ \text { Eye lesions } & \text { Present } & 3\end{array}$

Present 0 absent 1 absent 4

Other lesions Yes know 5 No 7

(Col. 45)

$\mathrm{X}$-rays performed: None 0 Hands-yes 1 No 2

Feet-yes 3 No 4

Pelvis-survey 5 department 6 none 7 Others-normal 8 abnormal 9 none 11

(Col. 47)

OA extent DIP's 00

11

22

33

44

55

$\begin{array}{ll}6 & 6 \\ 7 & 7\end{array}$

88

(Col. 46)

$\begin{array}{lrll}(\mathrm{Col} .46) & & & \\ \text { X-ray hands } & \text { OA grade } & 0 & 0 \\ & 1 & 1 \\ & 2 & 2 \\ & 3 & 3 \\ & 4 & 4\end{array}$

\begin{tabular}{|c|c|c|c|c|c|c|c|}
\hline & & $\begin{array}{l}7 \\
8\end{array}$ & $\begin{array}{r}7 \\
8 \\
9 \\
10\end{array}$ & 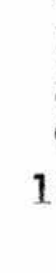 & & $\begin{array}{l}4 \\
5 \\
6 \\
7 \\
8\end{array}$ & $\begin{array}{r}7 \\
8 \\
9 \\
11 \\
12\end{array}$ \\
\hline (Col. 50) & & & (Col. 51) & & (Col. 52) & & \\
\hline Wrists & $\begin{array}{l}\text { None } \\
\text { L. } \\
\text { R. } \\
\text { Both }\end{array}$ & $\begin{array}{l}0 \\
1 \\
2 \\
3\end{array}$ & $\begin{array}{l}\text { HANDS } \\
\text { RA grade }\end{array}$ & 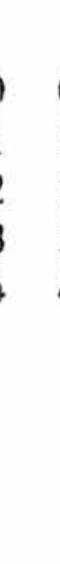 & Extent PIP's & $\begin{array}{r}0 \\
1 \\
2 \\
3 \\
4 \\
5 \\
6 \\
7 \\
8 \\
9 \\
10\end{array}$ & $\begin{array}{r}0 \\
1 \\
2 \\
3 \\
4 \\
5 \\
6 \\
7 \\
8 \\
9 \\
11\end{array}$ \\
\hline
\end{tabular}


(Col. 53)

MCP's $0 \quad 0$

11

22

33

44

55

$6 \quad 6$

$\begin{array}{ll}7 & 7\end{array}$

88

$\begin{array}{ll}9 & 9\end{array}$

$10 \quad 11$
(Col. 54)

X-Ray Feet

RA grade $0 \quad 0$

$$
\begin{array}{ll}
1 & 1 \\
2 & 2 \\
3 & 3 \\
4 & 4
\end{array}
$$

(Co1. 55)

Joints involved

MTP's $0 \quad 0$

11

22

33

44

55

66

77

88

99

$10 \quad 11$

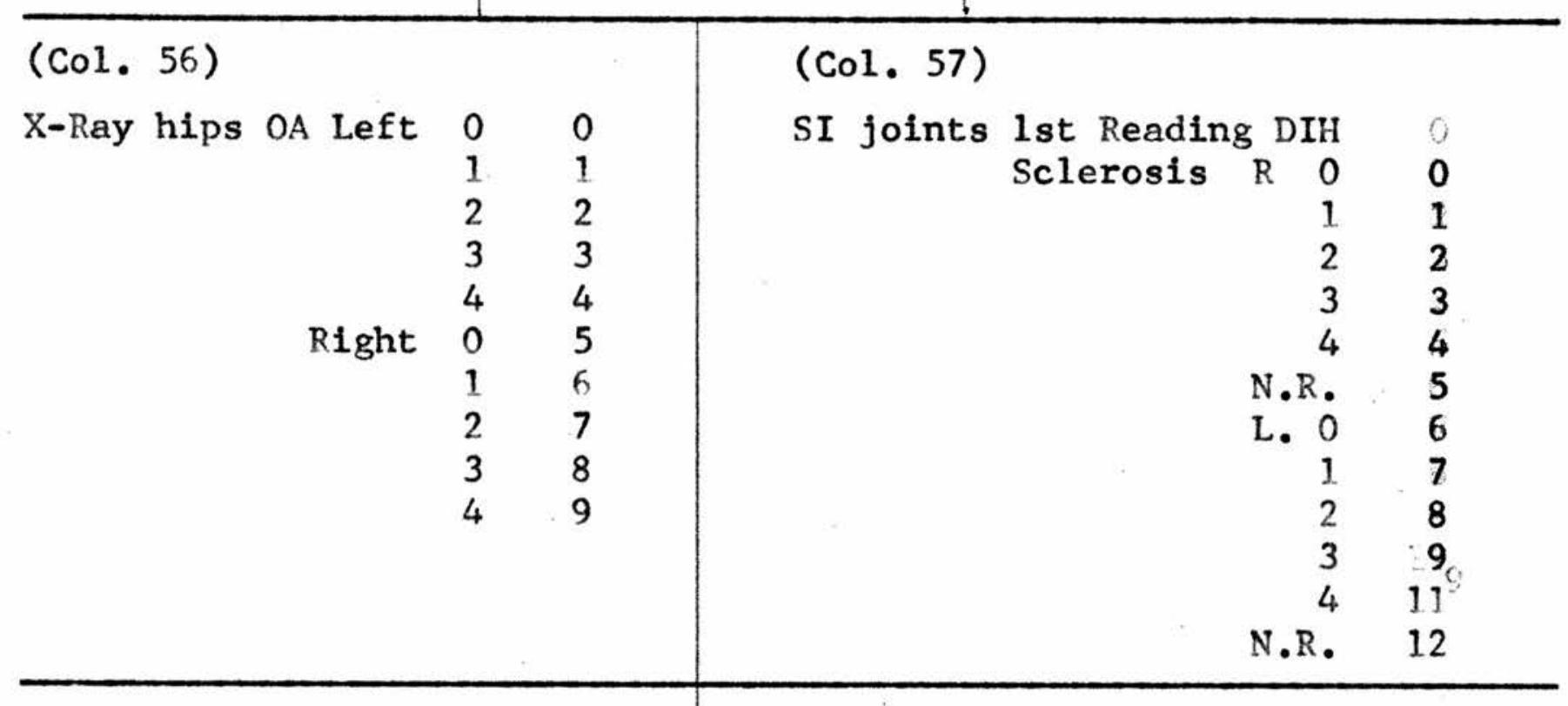

(Col. 58)

SI joints 1st Reading DIH Erosion R. 00 $\begin{array}{rr}1 & 1 \\ 2 & 2 \\ 3 & 3 \\ 4 & 4 \\ \text { N.R. } & 5 \\ 0 & 6 \\ 1 & 7 \\ 2 & 8 \\ 3 & 9 \\ 4 & 11 \\ \text { N.R. } & 12\end{array}$

CCol. 60)

SI joints 1st Reading DIH Width

$\begin{array}{lll}\text { R. } & \text { O } & 0 \\ & \mathrm{~N} & 1 \\ \mathrm{~W} & 2 \\ \mathrm{NR} & 3 \\ \mathrm{~L} . \quad \mathrm{O} & 4 \\ \mathrm{~N} & 5 \\ \mathrm{~W} & 6 \\ \mathrm{NR} & 7\end{array}$

(Col. 59)

SI joints 1st Reading DIH Ankylosis R. 00 $\begin{array}{ll}1 & 1\end{array}$ 43 N.R. 4 L. 05 16 37 48 N.R. 9
(Col. 61)

SI joints lst Reading DIH Osteophytes R $\mathrm{R}$ $-1$ NR 2

$\mathrm{L}+3$

$\begin{array}{cr}- & 4 \\ \text { NR } & 5\end{array}$ 
(Co1. 62)

lst Reading $\mathrm{MHM}$

Sclerosis R 00 11 22 33 44 NR 5 B 06 17 28 39

$\begin{array}{ll}4 & 11\end{array}$ NR 12
(Co1. 63)

1st Reading JMHM

Erosion $R 0$ O $\begin{array}{ll}1 & 1 \\ 2 & 2\end{array}$

33 44

NR 5

L 06

17

28

39

$4 \quad 11$

NR 12
(Col. 64)

1st Reading JMHM

Ankylosis R 00 $\begin{array}{ll}1 & 1 \\ 3 & 2\end{array}$ 43 NR 4

L 05 16 37 48 NR 9

\section{(Col. 65)}

1st Reading JMHM

Width R. 00

$\begin{array}{rr}\mathrm{N} & 1 \\ \mathrm{~W} & 2 \\ \mathrm{NR} & 3 \\ 0 & 4 \\ \mathrm{~N} & 5 \\ \mathrm{~W} & 6 \\ \mathrm{NR} & 7\end{array}$

\section{(Col. 66)}

1st Reading JMHM

Bsteophytes R +0 $-1$ NR 2 $\mathrm{L}+3$ $-4$ NR 5
(Col. 67)

2nd Reading $\mathrm{DWH}$ Sclerosis R $0 \quad 0$ $\begin{array}{ll}1 & 1 \\ 2 & 2\end{array}$ 33 44 NR 5

I $0 \quad 6$ 17 28 39 $4 \quad 11$ NR 12

\begin{tabular}{|c|c|c|c|c|c|c|}
\hline \multirow{2}{*}{\multicolumn{2}{|c|}{$\begin{array}{l}\text { (Col. 68) } \\
\text { 2nd Reading DIH }\end{array}$}} & \multirow{2}{*}{\multicolumn{2}{|c|}{$\begin{array}{l}\text { (Col. 69) } \\
\text { 2nd Reading DIH }\end{array}$}} & \multicolumn{3}{|c|}{$(\mathrm{Col}, 70)$} \\
\hline & & & & 2nd Rea & ding & DIH \\
\hline Erosion R. 0 & 0 & Ankylosis $\mathrm{R} 0$ & 0 & Width $R$ & 0 & 0 \\
\hline 1 & 1 & 1 & 1 & & $\mathrm{~N}$ & 1 \\
\hline 2 & 2 & 3 & 2 & & W & 2 \\
\hline 3 & 3 & 4 & 3 & & NR & 3 \\
\hline 4 & 4 & NR & 4 & & 0 & 4 \\
\hline NR & 5 & L 0 & 5 & & $\mathrm{~N}$ & 5 \\
\hline L. 0 & 6 & 1 & 6 & & W & 6 \\
\hline 1 & 7 & 3 & 7 & & NR & 7 \\
\hline 2 & 8 & 4 & 8 & & & \\
\hline 3 & 9 & NR & 9 & & & \\
\hline 4 & 11 & & & & & \\
\hline NR & 12 & & & & & \\
\hline
\end{tabular}


(Col. 71)

2nd Reading JMHM

Sclerosis R 0 o

\begin{tabular}{rrr}
1 & 1 \\
2 & 2 \\
3 & 3 \\
4 & 4 \\
$\mathrm{NR}$ & 5 \\
$\mathrm{~L}$ & 6 \\
1 & 7 \\
2 & 8 \\
3 & 9 \\
4 & 11 \\
$\mathrm{NR}$ & 12 \\
\hline
\end{tabular}

(Col. 74)

2nd Reading JMHM

Width $R \quad 0 \quad 0$

$\begin{array}{rr}\mathrm{N} & 1 \\ \mathrm{~W} & 2 \\ \mathrm{NR} & 3 \\ \mathrm{~L} & 4 \\ \mathrm{~N} & 5 \\ \mathrm{~W} & 6 \\ \mathrm{NR} & 7\end{array}$

(Col. 72)

2nd Reading JMHM

Erosion R 0 O

11

22

33

44

NR 5

L 06

17

28

39

$4 \quad 11$

NR 12
(Col. 73)

2nd Reading JMHM

Ankylosis R 0 o

$\begin{array}{ll}1 & 1\end{array}$

32

43

NR 4

L 05

16

37

48

NR 9

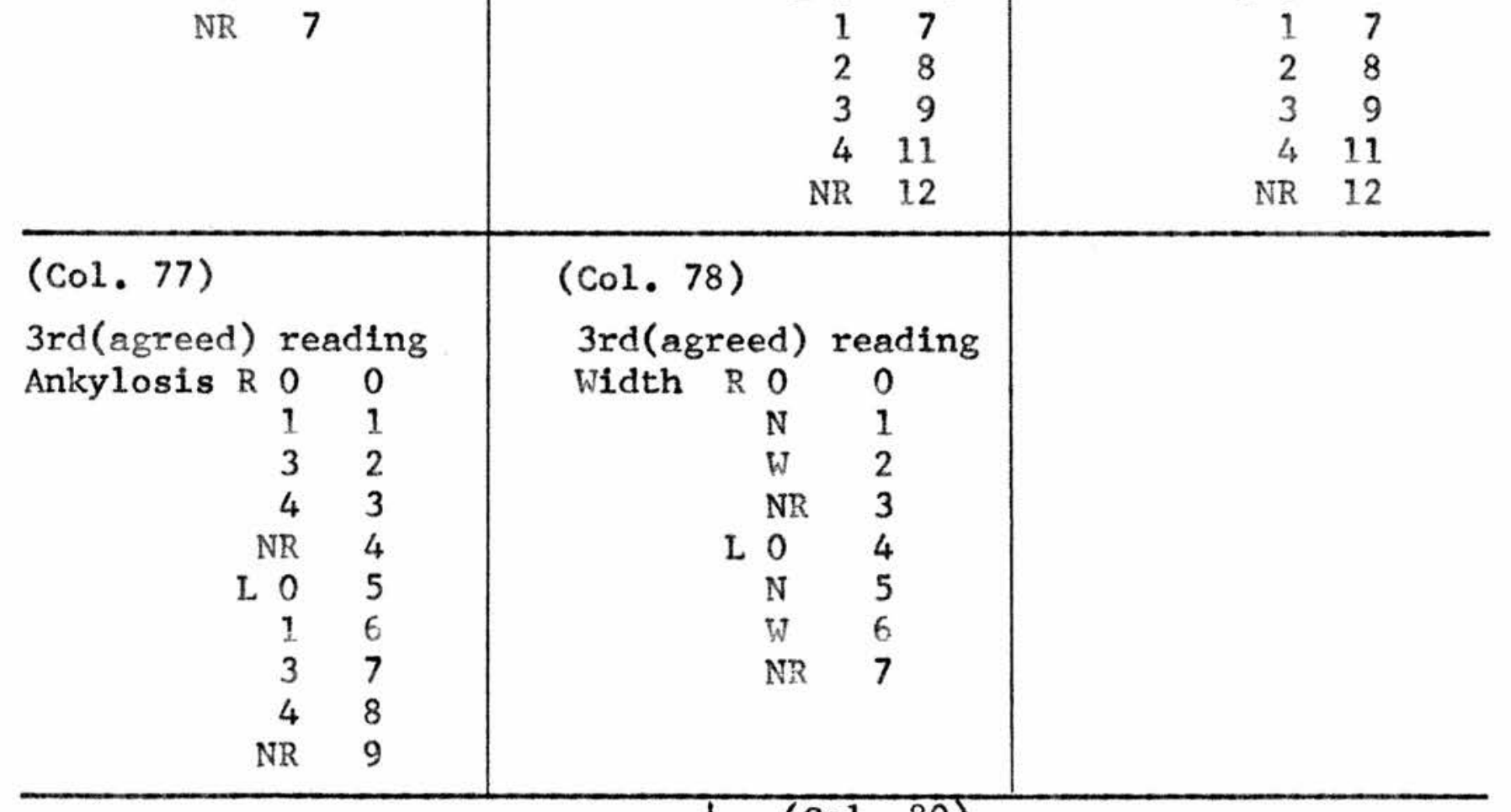

(Col. 79) Proband

Uncomplicated

with intostinal arthritis 1

with spondylitis

with sacroilitis

with RA

with $O A$

with clubbing

with psoriasis
(Col. 75)

3 rd(agreed) reading

Sclerosis R 0 0

11

22

33

44

NR 5

L $0 \quad 66$

17

28

39

$\begin{array}{ll}4 & 11\end{array}$

12
(Col. 76)

3 rd(agreed) reading

Erosion R 0

$\begin{array}{ll}1 & 1\end{array}$

22

33

44

NR 5

L 06

17

28

39

411

NR 12

(Col. 78) 
PIBLTOCRUYYYY. 
ABERCROMBIE, J. (1830)

Pathological and Practical Researches on Diseases

of the Stomach, the Intestinal Canal, the Liver and

other Viscera of the Abdomen.

2nd Edition. Waugh \& Innes., Edinburgh.

ACHESON, Z.X. (1959 A)

on the Mortality ascribed to Ulcerative Colitis.

Journal of Chronic Diseases., 10 469-480.

ACHESON, E.D. (1959 B)

On the Mortality ascribed to Regional Enteritis.

Journal of Chronic Diseases., 10 481-487.

ACHESON, E.D. (1960 A)

The Distribution of Ulcerative Colitis and Regional

Enteritis in Untted States Veterans with Particular

Reference to the Jewish Religion.

GUT.. 1 291-293.

ACHESON, E.D. (1960 B)

An Association betveen Ulcerative Colitis, Regional Enteritis, and Ankylosing Spondylitis.

Quarterly Jouraal of Medicine, (N.S) 29 489-499 ACHESON, E.D. (1965)

The Epidemiology of Ulcerative Colitis and Regional Enteritis in Recent Advances in Gastroenterology. Badenoch, J. Brooke, B.N. (Eds.) Churchill, London 202-226.

ADAMS, F. (1849)

The genuine works of Hippocrates.

The Sydenham Society, Vol. 1, London. ADLER, E. and CARMAN, A. (156I)

Ankylosing Spondylitis - A review of 115 cases.

Acta Rheumatologica Scandinavica. 7, $219-232$ 
ADLERSBIRG, D. and SOBOTKA, H. (1943).

Fat and Vitamin A absorption in sprue and jejuno-

ileitis.

Gastroenterology, 1, 357-365.

ALMY, T.P. (1952)

The Recilcal Management of Ulcerative Colitis and

Regional Enteritis.

Bulletin of the New York Academy of Medicine. 28, 691-699 AMSTERDAM, H.J. \& GRAYZZL, D.M. (1945)

Intestinal Lipodystrophy (Lipophagia Granulomatosis

or Whipple's Disease).

American Journal of the Medical Sciences. 210,605-611

ANDERSON, D.O., MULIINGER, M.A. \& BAGOCH, A. (1957)

Regional Enteritis involving the Duodenum, with clubbing

of the fingers and steatorrhoea.

Gastroenterology, 32, 917-926.

ANDERSON, G. (1967)

clubbing and hypers=ophic pulmonary osteoarthropathy.

Hospital Medicine, 1, 698-699.

ANSELL, B.M. \& LAWRENCE, J.S. (1965)

Flouridation and the Rheumatic Diseases.

Annals of the Rheumatic Diseases, 25, 67-75.

ANSELI, B.M. \& WIGLEY, R.A.D. (1964)

Arthritic Nanifestations in Regional Interitis.

Annals of the Rheumatic Diseases, 23, 64-72.

ARMITAGE, G. \& WILSON, M. (1950)

Crohn's Disease: A survey of the literature ard a report of 34 cases.

British Journal of Surgery, 38, 182-193. 
AUSTAD, W.R.. THOMPSON, G.R., \& JOSEPH, R.R. (1968)

Regional Enteritis Presenting as Acute Arthritis.

Michigan Medicine, 67, 324-329.

AVERY JONES, F., \& PAULLEY, J.W. (1949)

Intestinal Lipodystrophy (Whipple's Disease).

Lancet, I, 214-217.

BAKER, H., GOIDING, D.N. \& THOMPSON, M. (1964)

The nails in psoriatic arthritis.

British Journal of Dermatology, 76, 549-554.

BARBER, W.H. \& MURPHY, W.B. (1941)

Lymphogranuloma Venereum.

Annals of Surgery, 113, 30-40.

BARBOUR, R.F. \& STOKES, A.B. (1936)

Chronic cicatrising enteritis.

Lancet, $\underline{2}$, 299-303.

BARGEN, J.A. (1932)

Discussion of Crohn, Ginzburg \& Oppenheimer.

Journal of the American Medical Association, 99, 1328. BARGBN, J.A. (1938)

Regional Enteritis: Diagnosis, Complications and Medical Suggestions.

Proceedings of the Staff Meetings of the Mayo Clinic, 13. 550-551.

BARTHOLOMEW, LlOYA G. (1959)

Review of Lesions of the Small Intestine.

Gastroenterology, 36, 232-244.

BATSON, 0.V. (1940)

The function of the vertebral veins and their role

in the spread of metastases.

Annals of Surgery, 112, 138-149. 
BATSON, O.V. (1942)

The role of the vertebral veins in melastatic processes. Annals of Internal Medicine, 16, 38-45. BEETHAM, W.P. \& ACHKAR, E.J. (1969)

Importance of oblicue views in the radiological examination of the sacro-1llac joints. Lahey Clinic Bullet1n, 18, 79-83. BEIGHTON, P.H., MURDOCH, J.L. \& VOTTELER, T. (1969)

Gastrointestinai complications of fhlers-Danlos syndrome. Gur., 20, 1004-1008.

BELL, H.G. (1934)

Chronic Cicatrising Enteritis.

Callfornia and Western Medicine, 41, 239-241. BZMDIXEN, G. (1969)

Cellular hypersensitivity to components of intestinal mucosa in ulcerative colitis and Crohn's disease. GuT, 10, 631-636.

BMNETT, P.H. \& BUE

New York Symposium on Population studies in the Pheumatic D1seases: New diagnostic criteria. Bulletin on Rheumatic Diseases, 17, 453-458. BEMNATT, P.\&. and BURCH, T.A. (1968)

The Epiderisologicni Diagnosis of Ankylosing Spondylitis In Population Studies of the Fheunatic Diseases. Bemett, P.H. \& Wood, P.H.N. (eds.). Excerpta Hedica Foundation. Amsterdam, Wew York, Londion, Paris, Milan, Tokyo, Buenos Aires. pp. 305-313. 
BENNETT, P.H. \& WOOD, P.H.N. (1968)

Recommendations in population studies of the

Rheumatic Diseases'.

Excerpta Medica Foundation. Amsterdam.

BENTLEY, D. \& CLINS, I. (1970)

Estimation of Clubbing by Analysis of Shadowgraph.

British Medical Joumal, $3,43$.

BERCOVITZ, Z.T. (1950)

Discussion of kiefer, Marshall and Brol ma: The

management of chronic regional ileitis.

Gastroenterology, 14, 118-130.

BERGLOF, F-E. (1963)

Arthritis and Intestinal Infection.

Acta Rheumatologica scandinavica, 2, 141-149.

BERIK, M. (1956)

Regional Enteritis involving the Duodenum.

تastroenterology, 30, 508-516.

BIANCHI, F.A. \& KEECH, M.K. (1964)

Sarcoidosis with Arthritis.

Annals of the Rheumatic Diseases, 23, 463-479.

BILLSON, F.A., de DOMBAL, F.T., WATKINSON, G. \& GOLIGHER, J.C. (1967)

ocular complications of ulcerative colitis. GUT, $\underline{8}, 102$.

BINDER, H.J., OMBIEN, W.M.. SPIRO, H.M. \& HOllingsworth, J.W. (1966)

Gluten and the small. intestine in Rheumatoid Arthritis. Jounnal of the American Nedical Association, 195, 857-858. 
BINDER, V., WEEKE, E., OLSEN, J.H., ANTHONISEN, P., and RIIS, P. (1966)

A genetic study of ulcerative colitis.

Scandinavian Jourmal of Gastroenterology, 1, 49-56. BISGARD, J.D. and HENSKE, J.A. (1937

Reglonal Ileitis.

Journal of the American Medical Association, 108, 550-551. BLACKBURN, G., HADFIGLD, G., and HUNT, A.H. (1939)

Regional Ileitis.

St. Barts Hospital Reports, 72, 181-224.

BLUESTONE, R., MACMAHON, M., and DAWSON, J.M. (1969)

Systemic sclerosis and small bowel involvement. GUT. 10, 185-193.

BLUMBZRG, B.S. (1958)

Bernard Connor's description of the pathology of ankylosing spondylitis.

Arthritis and Rheumatism. 1, 553-563. BLUMBBRG, B. and RAGAN, C. (1956)

The natural history of rheumatoid spondylitis. Medicine, 35, 1-31.

BLUMGART, H.L. (1923)

Three fatal adult cases of malabsorption of fat. Archives of Internal Medicine, 32, 113-128. BOCKUS, H.L. (1945)

Present status of chronic regional or cicatrizing enteritis. -

Journal of the American Medical Association, 127, 449-456 BOCKUS, H.L. \& LES, W.E. (1935)

Regional (Terminal) Ileitis. Annals of surgery, 102, 412-421. 
BOCKUS, H.L., ROTH, J.L.A., BUCHMAN, E., KALSER, M.,
STAUB, W.R., FINKELSTEIN, A., and VALDES-DAPENA, A. (1956)

Life history of non-specific Ulcerative colitis:

Relation of progress to Anatomical and Clinical varties. Gastroenterologia, 86, 549-581.

BøE, J., DALGAARD, J.B. and SCOTT, D. (1958)

Mucocutaneous - ocular syndrome with intestinal

involvement.

American Journal of Medicine, 25, 857. BOLAND, I. W. (1966)

Ankylosing Spondylitis in Arthritis and Allied Conditions.

Ed. J.L. Hollander, London - Henry Kimpton.

BOWEN, G.E. and KIRSNER, J.B. (1965)

The Arthritis of Ulcerative Colitis and Regional

Enteritis ('Intestinal Arthritis').

Medical Clinics of North America, 49, 17-32. BOYCE, F.F., (1958)

Regional Enteritis in a large General Hospital. Surgery, 44, 834-843.

BOYLE, J.A. and BUChLANAN, W.W. (1971)

in Clinical Rheumatology,

Blackwell. Oxford and Edinburgh. BRAEME, F. and WENCKKSRT, A. (1970)

Spread of lesions in Crohn's disease of the colon. GUT, 11, 576-584.

BREMINER, J.M., GMERY, A.E.H., KELLGRIN, J.H., LAWRENCE, J.S. and ROMH, H. (1968).

A family study of ankylosing spondylitis in population studies of the Rheumatic diseases. Bennett, P.H. and wOOD, P.N.H. (Eds.) 
BRITISH MEDICAI JOURNAI (1960A)

leading article - ankylosing spondylitis and urogenital infection.

1. 865-866.

BRITIST MGDICAI JOURNAI (1960B)

Editorial - More Dysentery.

1. 1034-1035.

BRITISH MEDICAI JOURNAL (1967)

Leading article - Arthritis \& Sarcoldosis.

4. $368-569$.

BROOKE, B.N., HOFYMANIN, D.C. and SWARBRICK, M.B. (1969)

Azothioprine for Crohn's Disease.

Iancet, $2,612-614$.

BROORE, R. (1924)

The sacro-iliac joint.

Journal of Anatorry, 58, 299-305.

BROWN, C.H. and DAFENGR, J.F. (1958)

Regional Enteritis: Resuzts of Medical \& Surgical

Treatment in 100 patient:

Annals of Internal Medicine, 49, 595-606.

BROWN, C.H. and SIMS, J.R. (1954)

Regional Enteritis Involving the Duodenum.

Cleveland Clinic Quarter1y, 21, 95-102.

BROWN, P.W. and BARGEN, J.A. (1938)

Bacillary Dysentery: Late Results and Relationship

to chronic ulcerative Colitis.

American Journal of Digestive Diseases, 5, 562-567. 
BROWN, P.W., BARGEN, J.A. and WEBER, H.M. (1934)

Chronic Inflamatory Lesions of the Small Intestine (Regional Enterit1s).

American Journal if Digestive Diseases, 1, 426-432. BROWN, P.W. \& SCHEIFLEY (1939)

Chronic Regional Enteritis occurring in three siblings.

Americen Journal of Digestive Diseases, $6,257-261$. BROWIING, C.H., CAIIICART, B.P. and FINDLAY, L. (1926) Eds.

Finlayson's clinical manual for the study of medical cases.

Be11. Iondon.

BURCH, P.R.J., de DOMBAL, F.T. and WATKINSON, G. (1969)

Aetiology of ulcerative colitis: a new hypothesis. GUT, 10, 277-284.

BURTON, I.F. (1971)

Personal Communication. BYWATERS, E.G.L. and ANSELI, B.M. (1958)

Arthritis associated with Ulcerative Colitis.

Annals of the Rheumatic Di.seases, 17, 169-183. BYWATERS, E.G.L. and DIXON, A. St.J. (1965)

paravertebral ossification in Psoriatic arthritis.

Annals of the Pheumatic Diseases, 24, 313-331. CARTER, M.E. (1962)

Sacro-ililtis in Still's Disease.

Annals of the Pheumatic Diseases, 21, 105- 120 CAUGHEY, D.E. and BYWATERS, E.G.L. (1963)

The Arthritis of thipple's syndrome.

Annals of the Rheumatic Diseases, 22, 327-335. 
CAVE, H.W. (1945)

Inflarmatory Lesions of the small intestine.

Journal of the American Medical Association, 127, 456-458. CHAMPION, R.II. \& WILRIIEON, D.S. (1968)

Disordors affecting blood vessels; Erythema Nodosum. in Textbook of Dermatology. A. ROOK, D.S. WILKINSON and F.J.G. EBLING (Eds.) Blackwell scientific Pubs, Oxford and Edinburgh.

CHAPIN, L.E., SCUDAMORE, H.H., BAGGHNSTOSS, A.H. and BARGEN, ¿.A. (1956)

Regional snteritis: Associated Visceral Changes. Gastroenterology, 30, 404-415.

CHESS, S., CHESS, D., OLANDER, G., BEMNER, W. and COLE, W.H. (1950)

Production of chronic Enteritis and other systemic

lesions by ingestion of finely divided foreign materials. Surgery, 27, 221-234.

CLARK, R.C. (1938)

Regional Enteritis: Symptomatology and Review of Cases. Proceedings of the Staff Meetings of the Mayo Clinic, $13,535-538$.

CLARK, R.L. and DIXON, C.F. (1939)

Regional Enteritis. surgery, 5, 277-304. COFEE, R.J. (1938)

Pathological Manifestations of Regional Enteritis. proceedings of the Staff Meetings of the Mayo Clinic, $13,541-544$. 
COEIEN, A.S., MCNEIIL, J.M., CALKINS, E., SHARP, J.T. and SCHUBART, A. (1967)

The "normal" sacrolliac joint.

Anerican Journal is Roentgenology, Radium Therapy and Muclear Medicine, 100, 559-563.

COHEN, H, and FISHMAN, A.P. (1949)

Regional Bnteritis and Amyloldosis.

Gastroenterology, 12, 502-508.

COLP, R. (1934)

A chso of non-specific granuloma of the terminal 11 eum and the caecum.

Surgical clinics of North America, 14, 443-449. COMBE, C. and SAUNDERS, W. (1813)

A singular case of stricture and thickening of the 1leum. Medical Trans. Royal College of Physicians, $4,16-21$. CONFORT, M.H., WESER, H.M., BAGGENSTOSS, A.H. \& KI.HLY, W.F. (195C

Non-speciflc granulomatous Inflamation of the Stomach and Duodenum: Its relation to Regional Enteritis. American Journal of the Ridical Sciences, 220, 616-632. CONwOR, Bernerd (1695)

An Extract of a Ietter from Bernard Connor, M.D. to Sir Cherles Walgrave, published in French at paris: Giving an account of an extraordinary zumane skeleton, Whose vertebrae of the back, the ribs, and several bones dows to the os Sacrum, were all fimly united into one solid bone, without joynting or cartilage. Philosophicel Transactions. 10, 21-27. 
COOKE, W.T. (1955)

Nutritional and Metabolic Factors in tije aetiology and treatment of Regional Ileitis. (Hunterion Lecture) Annals of the Royral College of Surgeons, 17, 137-158. COOKE, W.T. and BROOYCS, B.N. (1955)

Non-specific Enterocolitis. Quarterly Journal of Medicine, 24, 1-22. COOKE, W.T., FOWLER, D.I., COX, E.V., GADDIE, R., and METWELI, M.J. (1958)

The clinical signiflcance of seromucoids in Regional Ileitis or Ulcerative colitis. Gastroenterology, 34, 910-919. CORNEI, A. (1955)

The extra-intestinal manifestations of Regional Ileitis: Some comparisons with chronic Ulcerative Colitis. Journal of the Mount Sina1 Hospltal, 22, 170-174. CORNES, J.S. and STECHER, M. (1961)

Primary Crohn's Disease of the Colon and Rectum. GUT, 2 , 189-201. COUNSET.L, B. (1956)

Lesions of the Ileum associated with Ulcerative Colitis. British Joumal of Surgery, 44, 276-290. CROCIETT, R.W. (1952)

Psychiatric findings in Crohn's Disease.

Lancet, 1, 946-949. CRaIN, B.B. (1955)

The Early Days of Regional Ileitis at the Mount Sinai Hospital.

Journal of the Mount Sinai Hospital, 22, 143-146. 
CRCHN, B.B., BARGBN, J.A., BROOIE, B.N., CATTEII, R.B., KIRSNaR, J.B. and THRLITON, F.E. (1959)

Panel Discussion: Regional Enteritis.

Gastroenterology, 36, 398-408.

CROHN, B.B., GINZBURG, I and OPPENHIMRR, G.D. (1932)

Regional Ileitis: A pathological and clinical entity.

Journal of the American Medical Association, 99 1323-1328. CROEN, B.B. and JANOWITZ, H.D. (1954)

Reflections on Regional Ileitis, Iwenty years later.

Journal of the American Medical Association, 156, 1221-1225

CROHN, B.B. and ROSENAK, B.D. (1936)

A combined form of ileitis and colitis.

Journal of the American Medical Association, 106, 1-5. CROHN, B.B. and YARNIS, H. (1958)

Regional Ileitis, 2nd. Edition.

New York, London. Grune \& Stratton.

CROIN, B.B. \& YUNICH, A.M. (1941)

Ileojejunitis.

Annals of Surgery, 113, 371-380.

CRONIN, E. (1970)

Skin changes in sarcoidosis.

postgraduate Medical Journal, 46, 507-509.

CUILEN, D.R. and MASKERY, P.J.K. (1966)

clubbing of the fingers and hypertrbphic osteoarthropathy

in pregnancy.

Lancet, $2,473-475$.

CURREY, H.L.F. (1971)

Immunosuppressive Drugs in Theunatoid Arthritis. In

Modern trends in Rheumatology - 2. (A.G.S. Hill Ed.)

Iondon, Butterworths. 
DAFFNIR, J.E. and BROWA, C.H. (1958)

Regional Enteritis: Clinfcal Aspects and Diagnosis in 100 patients.

Annals of Internal Nedicine, 49, 580-594.

DAL ZIISI, T.K. (1913)

Chronic Interstitial Enteritis.

British Medical Journal, 2, 1068-1070.

DAVID, J.R. and BLACK, R.L. (1960)

Salmonella Arthritis

Nedicine, 39, 385-403.

DAVIIES-COLLEY, N. (1885)

Synostosis of vertebrae.

Transactions of the Pathological Society of London, 36, 359-363.

de DOMBAL, F.T., BURCH, P.R.J. and WATKINSON, G. (1969)

Aetiology of ulcerative colitis: a review of past and present hypotheses.

GUT, 10, 270-277.

DIAMOND, M.T. (1958)

Regional Ileitis associated with volvulus of the terminal ileum.

Gastroenterology, 34, 126-129.

Di TATA, D., MCEWAN, C., LINGG, C., PORRINI, A., GOOD, R., and RAULSIN, T. (1969)

A comparative study of ankylosing spondylitis and spondylitis associated with ulcerative colitis and Reiter's disease.

Abstracts XII Congressus Rheumatologicus Internationales. 554 
DIXON, A.St.J. (1960)

'Rheumatoid Arthritis' with negative serological reaction. Annals of the Rheumatic Diseases, 19, 209-228. DIXON, A.St.J. and LIENCE, E. (1961)

Sacro-iliac jolnt in adult rheumatoid arthritis and psoriatic arthropathy.

Annals of the Rheumatic Diseases, 20, 247- 257

DORN, H.P. (1959)

Some problems arising in prospective and retrospective studies of the etiology of disease.

New Ingland Journal of Medicine, 261, 571-579. DOYLE, T.M. (1956)

Johne's disease

Veterinary Record, 68, 869-886. DRURY, R.A.B. (1970)

Problems in histological interpretation in sarcoidosis. Postgraduate Medical Journal, 46, 478-483.

DRYLI, A., KAHN, M-F., SOLNICA, J., MITROVIC, D. and de SEZE, S. (1969)

Les formes de passage entre l'oculo -urethro -synovite de Fiessinger -Leroy -Reiter et la rhumatisme psoriasique

a propos de 7 observations personelles.

Semaine des hopitaux de Paris, ㅇ․ 499-514. DUNHAM, W.F. (1949)

Ankylosing spondylitis: Measurement of Hip and Spine movements.

British Journal of Physical Medicine, 12, 126-129. DUNLOP, B.M.C., HARPER, I.A., and JONES, B.R. (1968)

Sero-negative polyarthritis. The Bedsoria (Chlamydia) group of agents and Reiter's disease. Annals of the Rheumatic Diseases, , 27, 234-240. 
DYER, N.H., COOK, P.L. and KEMP HARPER, R.A. (1969)

Desophageal stricture associated with Crohn's disease. GUT, 10, 549-554.

DYER, N.H. and DAWSON, A.M. (1970)

Diagnosis in Crohn's disease: A continuing source of error. British Medical Journal, 1, 735-737.

DYER, N.H., VERBOV, J.L., DAWSON, A.M., BORRIE, P.F. and STANSFIELD, A.G. (1970)

Cutaneous polyarteritis nodosa associated with Crohn's disease.

Lancet, $1,648-650$.

ERMAN, C.N. (1958)

Regional Enteritis associated with Meckel's Diverticulum. Gastroenterology, 34, 130-134.

EMSBO, POul. (1951)

Terminal or Regional Ileitis in Swine.

Nordisk Veterinarmedicin, $3,1-28$

EPSTIIN, E. (1939)

Differential diagnosis of Keratosis blenorrhagica and psoriatic arthropathy.

Archives of Dermatology and Syphilology, 40, 547-559. EVANS, J.G. and ACHESON, E.D. (1965)

An epidemiological study of ulverative colitis and regional enteritis in the oxford area.

GUT, ㄷ, 311-324.

EYLER, W.R. and DOUB, H.P. (1956)

Extraintestinal roentgen manifestations of intestinal lipodystrophy.

Journal of the American Medical Association, 160, 534-536. 
FAGGE, H. (1877)

A case of simple synostosis of the ribs to the

vertebrae and of the arches and articular processes

of the vertebrae themselves, and also of one hip joint.

Transactions of the Pathological Society of London,

28, 201-206.

FAIIIS, L.S. (1941)

Regional Enteritis

Annals of Surgery, 113, 1061-1062.

FEDER, I.A. (1938)

Ulcerative Colitis: An analysis of 88 cases.

American Journal of Digestive Diseases, $\underline{5}, 239-245$. FELSON, J. (1936)

Discussion of Crohn \& Rosenak

Journal of the American Medical Association, 106, 6. FELSEN, J. and WOLARSIY, W. (1955)

Familial incidence of ulcerative colitis and ileitis.

Gastroenterology, 28, 412-417.

FIELDING, J.F. (1970)

Aetiology of Crohn's Disease.

Lancet, $2,424$.

FISCHEL, E.E. (1949)

Ulcerative Colitis.

American Journal of Medicine, 6, 481-494:

FLETCHER, E. and ROSE, F.C. (1955)

Psoriasis spondylitica.

Lancet, 1. 695-696.

FIETCHER, J. and HINTON, J.M. (1967)

Tuberculin Sensitivity in Crohn's Disease.

Lancet, 2. 753-754. 
FLOOD, C.A., LEPORE, M.J., HIATT, R.B. and KARUSH, A. (1956) Prognosis in Ulcerative Colitis.

Journal of Chronic Diseases, 4. 267-282.

FORBES, I.J. and ROBSON, H.N. (1960)

Fanilial recurrent orogenital ulceration.

British Hedical Journal, 1, 599-601.

FORD, D.K. (1960)

The relationship of human genital pleuro-pneumonia-like.

organisms to arthritis complicating urethritis.

Arthritis and Rheumatism, 3, 395-402.

FORD, D.K. (1970)

Reiter's syndrome.

Bulletin of Rheumatic Diseases, 20, 588-591.

FORD, D.K. and VAILIS, D.G. (1959)

The clinical course of Arthritis Associated with

Ulcerative Colitis and Regional Ileitis.

Arthritis and Wheumatism, $\underline{2}, 526-536$.

FORESTIRR, J. (1939)

The importance of Sacro-Iliac changes in the early

diagnosis of Ankylosing Spondylarthritis: Marie-

Strtmpel-Bechterew Disease.

Radiology, 33, 389-402.

FORESTIER, J. \& DESIOUS-PFOII, P. (1957)

Radiological Study of sacro-iliac joints in ankylosing

spondylitis with reference to the evolution of the disease.

Annals of the Rheumatic Diseases, 16, 31-34.

FOX, T.C. and MACLEOD, J.M.H. (1901)

on a case of parakeratosis variegata.

British Journal of Dermatology, 13, 319-346. 
FREYSZ, Von H., HADMRERLU,A. and KARTAGENER, M. (1958)

Ileitis Regionalis Bei Einem Weiblichen Zwillingspaar.

Gastroenterologia, 89, 75-82.

GARDNER, D.L. (1960)

The experimental production of arthritis.

Annals of the Rheumatic Diseases, 19, 297-317.

GARLOCK, J.H. \& CROHN, B.B. (1945)

An appraisal of the results of surgery in Regional Ileitis.

Journal of the American Medical Association, 127, 205-208. GELFAND, M.D. and KRONE, C.L. (1970)

Inflammatory Bowel Disease in a family.

Annals of Internal Nedicine, 72, 903-907.

GJONE, E., MYREN, J. and ORNING, O.H. (1966)

Crohn's Disease in Norway - clinical Eeatures.

Scandinavian Journal of Gastroenterology, 1, 101-105.

GOFF, G.W. (1952)

Orthograms of Posture.

Journal of Bone and Joint Surgery, 34A, 115-122.

GOFF, B. and ROSE, G.R. (1964)

The use of a modified spondylometer in the treatment

of ankylosing spondylitis.

Rheumatism, 20, 63.

GOFTON, J.P. (1968)

Report from the subcomittee on diagnostic criteria for

ankylosing spondylitis in Population studies of the

Theumatic Diseases.

Bennett, P.H. and Wood, P.H.N. Eds. 314-316.

GOFTON, J.P. (1971)

Personal Conmunication. 
GOFTON, J.P., IAWRENCE, J.S., BENNETT, P.H. and BURCH, T.A. (1966) Sacro-iliftis in eight populations.

Annals of the Rheumatic Diseases, 25, 528-533. GOFTON, J.P., LAWRENCE, J.S., BENNETT, P.H. and BURCH, T.A. (1968) Sacro-iliitis in eight populations, in Population studies of the Rheumatic Diseases. Bennett, P.H. and Wood, P.H.N. (Eds.) Excerpta Medica, Amsterdam.

GOFTON, J.P., ROBINSON, H.S. and TRUßMAN, G.E. (1966)

Ankylosing Spondylitis in a Canadian Indian population. Annals of the Rheumatic Diseases, 25. 525-527. GOLDBERG, D.P. (1970)

A psychiatric study of patients with diseases of the small intestine. GUT, 11. 459-465. GOLDBERG, D.P. and BLACKWELL, B. (1970)

Psychiatric illness in General Practice. A detailed study using a new method of case identification. British Medical Journal, 2, 439-443. GOL.DE, D.W. (1968)

Aetiology of Regional Enteritis.

Lancet, 1, 1144-1145.

GOLDFAIN, E. (1943)

Chronic Brucellosal type of ankylosing spondylitis. Journal of Laboratory and Clinical Medicine, 23, 1226-1231 GOLDGRABER, M.B. and KIRSNER, J.B. (1958)

The Histopathology of the Experimental Hypersensitive State in the Gastrointestinal tract. Archives of Internal Medicine, 102, 134-148. 
GOLDGRABER, M.B.. KIRSNER, J.B., and RASKIN, H.F. (1958)

Non-specific Granulomatous Disease of the Stomach.

Archives of Internal Medicine, 102, 10-24.

GOLDSTEIN, H.I. (1948)

The history of Regional Enteritis (Saunders-AbercrombieCrohn's Ileitis) In Victor Robinson Memorial Volume:

Essays on Hisbory of Medicine. 99-104. Froben Press Inc. New York.

GOLDSTEIN, M.J., NASR, K.. SINGZR, H.C., ANDERSON, J.G.D. and KIRSNER, J.B. (1969)

Osteomyelitis complicating regional enteritis. GUT. 10, 264-266.

GOLIGHER, J.C. (1967)

Some cases of Ulcerative Colltis and Crohn's disease. Hospital Medicine, 1. 419-422.

GOLIGIER, J.C., de Bdmbal, F.T., WATTS, J.Mc K., and WATKINSON, G. (1968)

ulcerative Colitis.

Bailliere, Tindall \& Cassell, London.

GOOD. A.E. (1965)

Reiter's disease and Ankylosing Spondylitis.

Acta Rheumatologica scandinavica. 11, 305-317. GRABER-DUVERNAY, J. (1957)

A propos de la spondlathrite psoriasique.

Revue du rhumatisme et des maladies osteo-articulaires. 24. 288-298.

GRAHAM, W. and UCHIDA, I.A. (1957)

Heredity in Ankylosing Spondylitis.

Annals of the Rheumatic Diseases, 16, 334-339. 
GRA.IJGER, R.G. (1957)

Discussion on the clinical and radiological aspects of sacro-iliac disease.

Proceedings of the Royal Society of Medicine, 50, 854-858. GRAINGER, R.G. (1960)

The Radiology of Ankylosing Spondylitis.

Fheumatism, 16, $3-10$.

GRAY, B.K., LOCKHART-MUMMERY, M.E. and MORSON, B.C. (1965)

Crohn's disease of the anal region.

GUT, $\underline{6}, 515-524$.

GRAY, I. (1934)

Discussion of Brown, Bargen and Weber, chronic inflanmatory lesions of the small intestine (Regional enteritis). American Journal of Digestive Diseases, 1,431 GRONER, L.J. (1960)

A review of regional enteritis.

Journal of the American Osteopathic Association, 60, 12-15. GUMPEL, J.M., JaHNS, C.J. and SHULMAN, L.E. (1967)

The joint disease of sarcoidosis.

Annals of the Rheumatic Diseases, 26, 194-205.

HADFTEID, G. (1939)

The primary Histological lesion of Regional Ileitis. Lancet, $2,773-775$.

HALL, W.H. and FINEGOLD, S. (1953)

A study of 23 cases of Reiter's syndrme. Annals of Internal Nedicine, 38, 533-550. HAMMER, B., ASHURST, P. and NAISH, J. (1968)

Diseases associated with ulcerative colitis and Crohn's disease.

GUT, 2, 17-21. 
FIARRIS, F.I., BELL, G.H. and BRUNN, H. (1933)

Chronic cicatrizing Enteritis.

Surgery, Gynecology and Obstetrics, 57, 637-645.

HART, F.D.. EMERSON, P.A. and GRBGG, I. (1963)

Thorax in Ankylosing Spondylitis.

Annals of the Rheumatic Diseases, 22, 11-18.

HART, F.D. and MACLAGAN, N.F. (1955)

Ankylosing Spondylitis: a review of 184 cases.

Annals of the Rheumatic Diseases, 14, 77-83.

HART, F.D. and ROBINSON, K.C. (1959)

Ankylosing Spondylttis in women.

Annals of the Rheumatic Diseases, 18, 15-23.

HART, F.D., ROBINSON, K.C., ALLCHIN, F.M. and MACLAGAN, N.F. (194

Ankylosing Spondylitis.

Quarterly Journal of Medicine, 18, 217-234.

HASLOCK, D.I. (1972)

Discussion of Webb, Collins, Southwell and Dick-smith;

Flourine - 18 isotype scans of the sacro-iliacs.

Annals of the Rheumatic Diseases, (in press)

HAWKINS, C.F. (1968)

Pheumatic Diseases and the Alimentary Tract.

Reports on Eheumatic Diseases, 95-97.

HEARD, G.E. and JCHN, E.L. (1956)

Regional Ileitis in Mother and Son.

British Medical Journal, 2., 85.

HETFRRNON, E.W. and KGPKAY, P.H. (1954)

Segmental Esophogitis (sic) Gastritis and Enteritis. Gastroenterology, 26, 83-88. 
HENCH, P.S., BAUER, W.. BOLAND, B., DAWSON, M.H., FREYBERG, R.H. HOLBROOK, W.P., KEY, J.A. LOCKIE, L.M. and MCEWAN, C. (1941)

Rheumatism Review.

Annals of Internal Medicine, 15, 1002-1108.

HENDRIX, T.R. and YARDLEY, J.H. (1970)

Whipple's Disease.

Modern Trends in Gastroeneterology Vol. 4. 229-251.

Card, W.I. and Creamer, B. (Eds.). London, Butterworth. HERSH, A.H., STECHER, R.M., SOLOMON, W.M., WOLPAW, R. and HAUSER, H. (1950)

Heredity in Ankylosing Spondylitis.

American Journal of Human Genetics, 2, 391-408. HILTON, J. (1860)

Pain and the therapuetis influence of mechanical and physiological rest in accidents and surgical diseases. Lancet, 2, 378-382.

HINTON, J.M. (1968)

Personal communication to J.E. Lennard-Jones. BINTON, J.W. (1952)

The surgical management of Ileocolitis.

Bulletin of the New York Academy of Medicine, 28, 714-720. HIRSCHMANN, L.J. (1932)

Discussion of Crohn, Ginsburg and Oppenheimer.

Journal of the American Medical Association, 99, 1328. HISLOP, I.G. and GRANT, A.K. (1969)

Genetic tendency in Crohn's disease. GUT, 10, 994-995.

HORVATH, G. and WOHLSTEIN, E. (1966)

Evaluation of the relation of inflammatory prostate lesions to Ankylosing Spondylitis. Acta rheumatologica scandinavica. 12, 140-145. 
HOUGHTON, E.A.W. and NAISH, J.M. (1958)

Familial Ulcerative Colitis and Ileitis.

Gastroenterologia, 89, 65-74.

HOULI, J. and REZEK, J. (1965)

Articular Diseases in Ulcerative Colitis, Regional

Ileitis and Whipple's Disease.

Acta rheumatologica scandinavica. 11. 291-298.

HOWELL, D.S. (1966)

Hypertrophic Osteoarthopathy and Developmental

Connective Tissue disorders in

Arthritis and Allied Conditions.

Hollander, J.L. (Ed.)Henry Kimpton, iondon.

HUNTIER, D. and BOMFORD, R.R. (1963) Eds.

Futchinson's clinical lethods;

14th Edition, Casse11, London.

HYWEI JONES, J. (1969)

Colonic Cancer and Crohn's disease.

GUT, 10, 651-654.

HYWET JONES, J., LENNARD-JONES, J.E. and YOUNG, A.C. (1969)

Reversibility of radiological appearances during elinical

improvement in colonic Crohn's disease.

GUT. 10, 738-743.

INKSTMR, R.G. (1964)

Osteology in Cunningham's Textbook of Anatomy

10th Edition, G.J. Romanes (Ed.) London, Oxford

University Press, 75-212.

INTERNATIONAI CONFERENCE ON SARCOIDOSIS,

WASHINGTON, D.C. (1.950)

ISRAEL, H.I. (1970)

Discussion of Session III; Conference on Sarcoidosis. Postgraduate Medical Journal, 46, 519-520. 
JACKMAN, R.J., and SMITH, N.D. (1943)

some manifestations of regional ileitis observed sigmoidoscopically.

Surgery, Gynecology and Obstetrics, 76, 444-445. JACOBS, P. (1963)

Ankylosing Spondylitis in children and adolescents. Archives of Disease in Childhood, 38, 492- 498 JACOBS, W.H. (1959)

Erythema lodosum in inflarmatory diseases of the bowel.

Gastroenterology, 37, 286-294.

JACQUELINE, F. and ARLET, J. (1959)

Osteitis Condensans IIii.

Arthritis and Rheumatism, 2, 8-15.

JAJIC, I. (1968)

Radiological changes in the sacro-iliac joints and spine of patients with psoriatic arthritis and pscriasis.

Annals of the Rheumatic Diseases, 27, 1-6. JAMES, D.G. (1967)

Clinical aspects of sarcoidosis.

Hospital Medicine, 2 , 8-13. JANOWITZ, H.D. (1955)

Problems of Regional Enteritis.

Journal of the Mount Sinai Hospital, 22, 223-228. JANUS, W.L. (1948)

Regional Jejunitis.

Radiology, 50, 532-535. JAVETT, S.L. and BROOKE, B.N. (1970)

Acute dilatation of colon in Crohn's Disease. Lancet, 2 , 126-128. 
JAYSON, M.I.V. (1970)

The problem of backache.

Practitioner, 205, 615-621.

JAYSON, M.I.V. (1971)

Personal Communication.

JAYSON, M.I.V. and BOUCHIER, I. (1968)

Ulcerative colitis with ankylosing spondylitis.

Annels of the Rheumatic Diseases, 27, 219-224.

JAYSON, M.I.V., SALMON, R.R. and HARRISON, W.J. (1970)

Inflammatory bowel disease in ankylosing spondylitis. GUT, 11, 506-511.

JOHNSON, W.R. (1943)

Chronic, non-specific, jejunitis with unusual features. Gastroenterology, 1, 347-356.

JONES WILIIAMS, W. (1963)

The laboratory Diagnosis of Crohn's syndrome.

Proceedings of the Royal Society of Medicine, $56,490$. JONES WILIIAMS, W. (1954)

Histology of Crohn's syndrome.

GUT, 5, 510-516.

JONES WILLIAMS, W. (1955)

A study of Crohn's syndrome using tissue extracts and the Kveim and Mantoux tests.

GUT, $\underline{6}$, 503-505.

JONaS VILLINMS, W. (1967)

The pathology of sarcoicosis.

Hospital Medicine, 2, 21-27.

JULKUNEN, H. and ROZWANEN, P. (1969)

Ankylosing spondylitis and osteitis condensans ilil. Microradiographic and tetracycline-flouresence study of liliac bone adjacent to the sacro-iliac joint.

Abstracts, 12 Congress of Rheumatology, 564 . 
KANEV, K., TZONCHEV, V.T., SEBO, M.. SITAT, S.. SIEVERS, K. DANCHOT, J., DELBARRE, F., ASTAPENKO, M.G., PIKHLAK, E.G. KELLGREN, J.H., STREVENS, E,A. and WOOD, P.H.N. (1969)

A collaberative review of diagnostic criteria. Proceedings: Congress of the International League against preumatism, Prague. KANTOR, J.C. (1934)

Regional (Terminal) Ileitis: Its Roentgen Diagnosis. Journal of the American Medical Association, 103, 2016-2021. KELIGREN, J.H. (1962)

Diagnostic criteria for populaticn studies. Bulletin of the Rheumatic Diseases, 13. 291-292. KELIGREN, J.H. (1964)

The Epidemiology of Rheumetic Diseases (Heberden Oration, 1963).

Annals of the Rheumatic Diseases, 23, 109-122. KEILGREN, J.H. and BIER, F. (1.956)

Radiolofical signs of Rheumatoid Arthritis. Annals of the Rheumatic Diseases, 15, 55-60. KELIGREN, J.H., JEFFREY, M.R. and BAIT, J. (sds.). (1963)

The epidemiology of Chronic Rheumatism, ,

Vols. 1 and 2. Blackwel1, Oxford. KELIGREN, J.H. AnC IAMRTHCE, J.S. (1956)

Rheumatoid arthritis in a population sample. Annals of the Rheumatic Diseases, 15, 1-11. KELLGREN, J.H. and LAWRJINCE, J.S. (1957) A Radiological Assessment of Fheumatoid Arthritis. Annals of the Rheumaty.c Diseases, 16, 485-493. KELLGREN, J.H. and LAWRENCE, J.D. (1957) B Radiological assessment of osteo-arthrosis. Annals of the Theumatic Diseases, 16, 494-502. 
KEIJY, J.J. and WSISIGER, B.B. (1963)

The arthritis cr mipple's disease.

Arthritis and Rheumatism, $\underline{6}, 615-632$.

KIEFER, I.D. and ROSS, J.R. (1945)

Criteria in the management of chronic ileitis.

Journal of the Anerican Medical Association, 129, 104-108. KING, A. (1964)

Recent advances in venereology, Churchili, Iondon. KINSELLA, T.D., NORTCN, W.L. and ZIFF, M. (1968)

Complement-fixing antibodies to Bedsonia organisms

in Reiter's syndrome and Ankylosing Spondylttis.

Annals of the Pheumatic Diseases, 27, 241-244.

KIRSNER, J.B., OWENS, F.M. and HUNPYREYS, E.M. (1948)

Regional Enteritis in Father and Son.

Gastroenterclogy, 10, 883-991.

KIRGNER, J.B., SYLAR, M and PALMER, W.J. (1957)

The use of ACHA, Cortisone, Hydrocortisone and related

compounds in the managoment of Ulcerative colitis.

American Jouxnalof Meaicine, 22, 264-274.

KLECIONER, M.S. (1956)

The liver in Regional Enteritis

Gastroenterology, 30, 416-420.

KOFFLER, D., MINKONITI, S., ROTEMAN, W. and GARLOCK, J. (1962)

Inmunocytochemical studies in ulcerative colitis and

Regtonal Ileitis.

Amsrican Journal of Pathology, 41, 733-745.

KOSTER, H., KASIMA, L.P, and SHEINEELD, W. (1936)

Regional Ileitis,

Archives of Surgery, 32, 739-809.

KROSS, I. (1938)

Terminal Ileitis: Conservative Surgical Treatment.

American Journal of Digestive Disorders, $5,313-314$. 
KULONSIT, J. and VINKIE, T.IR. (1932)

Undulant (Isalta) Fever spondylitis.

Journal of the American Hedical Association, 99, 1656-1659. kUSAKCTOCIY, O. and NorTON, R.A. (1967)

Granulomatous Duodenitis, clubbed digitis and Psoriasis. Lahey Clinic Foundation Buljetin, 16, 191-193. KVEIM, A. (1241)

En ny og sposifikk kutan - reaksjon ved boecks sarcoid. Nordisk Medicin, 2, 163-172.

LANCST (1968) Annotation - Aetiology of regional entertits. 1, 1134-1135.

LBADING ARTICLE,

Ulcerative Colitis and Crohn's Disease

Lancet, (1970A) 1, 1325-1327.

LEADING ARTICLS,

Aetiology of Crohn's Disease,

Lancet (1970B) $\underline{2}, 193$.

LATHAM, M.C. (1966)

Flourosis as a cause of finger clubbing.

Lancet, $1,131-132$.

LAWREATCE, J.S. (1965)

A fanily study of Reiter's disease: preliminary results. paper read to the medical society for the prevention of venereal disease.

LAWRENCE, J.S. (1967)

Microcirculatory studies of the skin in the investigation of seronegative polyarthritis - Discussion of Thompson, $M$. and Holei, G.

Proceedings of the 5 th European Congress of Rheumatology. Lisbon. 
LAIREMCE, J.S., BRERIIE, J.M. and BIER, F. (1966)

Osteoarthrosis; prevalence in the population and relationship between symptoms and $\mathrm{x}$-ray changes. Annals of the Fhoumatic Diseases, 25, 1-24. LEE, F.D. and NOY, A.D. (1964)

Ileo-caecal granulomata.

GU工', 5, 517-523.

LEHNARD-JCNIES, J.E. (197CA)

Crohn's Disease. pr. 273-308 in Modern Trends in

Gastroanterology - Vol. 4. London. Butterworths.

Carc, W.I. and Creamer, B. (eds.)

IERINURD-JCINAS, J.E. (1970B)

Iecture - "Crchn's Disease."

Leecis Ganeral InEimany.

IIBERSON, M. and MIMAIDZIC, N. (1966)

Sacro-iliac changes and urinary infection in patients with spirij cord injuries.

British Joirmal of Venereal Diseases. 1966, 42, 96-99. LOCKEART-MUMMRRY, H.E. and MOROCN, B.C. (1960)

Crohn's Disaase (Regional Enteritis) of the large intestine and 1ts distinction from Ulcerative colitis. GUS. 1, 87-105.

LOCYCIDLT-WUMALRY, H.E. and MORSON, B.C. (1964)

Crohn's dacase of the large intestine. GUI, 5, 493-508.

LOEBL, N.Y. (IS67)

leablirement of Spinal posture and Range of spinal movement Annals of Physical Medicine, 2, 103-110. 
LONHOLT, G. (1963)

Psoriasis: prevalence, spontaneous course and genetics

in A census study on the prevalence of skin disease on

the Faroe islands. Gad. Copenhagen.

LONGCOPE, W.T. and FREIMAN, D.G. (1952)

A study of saccoidosis.

Medicine (Baltimore) 31, 1-132.

LORBER, S.H., SHAY, H. and WOLOSHIN, H. (1954)

A roentgen study of the gastrointestinal tract in

proven cases of sarcoidosis with a review of the literature

Gastroenterology, 26, 451-461.

LUCHERINI, T. and PORZIO, F. (1965)

spondiliti anchilosante psoriasica.

Reumatismo, 17, 49-59.

LYALL, A. (1945)

Regional Ileitis.

Glasgow Medical Journal, 143, 1-20.

MCBRIDE, J.A., KING, M.J., BAIKIE, A.G., CREAN, G.P. and SIRCUS, W. (1963)

Ankylosing Spondylitis and chronic inflammatory

diseases of the intestines.

British Medical Journal, 2, 483-486.

MOCONNELL, R.B. (1965)

Genetics and Gastroenterology.

Recent Advances in Gastroenterology. Badenoch, J. and

Brooke, B.N. (eds.) Churchill, London, 1-23.

MCCONNELL, R.B. (1966)

The Genetics of gastro-intestinal Disorders.

London. Oxford University Press. 
MCGOVERN, V.J. and GOULSTON, S.J.M. (1968)

Crohn's disease of the colon.

GUT, 2, 164-176.

RCEWAN, C. (1941)

Personal communication to Barker and Murphy. MCENAN, C., DimATA, D., LINGG, C., PORINI, A., GOOD, A. and RANKIN, T. (1971)

A comparative study of ankylosing spondylitis and spondylitis accompanying ulcerative colitis, regional enteritis, psoriasis and Reiter's disease. Arthritis and Rheumatism, in press. MCEWAN, C., LINGG, C., KIRSINER, J.B. and SPENCER, J.A. (1962) Arthritis accompanying ulcerative colitis. Anerican Journal of Nedicine, 33, 923-941. MCEWAN, C., ZIFF, M., CARNEL, P., DITATA, D. and TANNER, M. (1958)

The relationship to Rheumatoid arthritis of its so-called variants.

Arthritis and Rheumatism, 1, 481-496. MACGREGOR, G.A. (1970)

Agent transmissable from Crohn's aisease tisue. Lancet, 2 , 311. MACKIE, T.T. (1938)

Discussion of Brown and Bargen. American Journal of Digestive Disorders. $\underline{5}, 564-565$. MACRAZ, I.F. (1971)

A Family study of Arthritis Associated with Ulcerative Colitis (in preparation) M.D. Thesis. (University of Iondon). 
MACRAE, I.F., HASLOCK, D.I. and WRIGHT, V. (1971)

The grading of films for sacro-ilittis in population studies. Annals of the Rheumatic Diseases, 30, 58-66. MACRAE, I.F. and WRIGHT, V. (1969)

Measurement of back movement.

Annals of the Rheumatic Diseases, 28, 584-589. MACRAE, I.F. and WRIGHT, V. (1970)

Ulcerative colitis and Sacro-iliitis - A family study. Annals of the Pheumatic diseases, 29, 559-560. MAIZEL, H., RUFFIN, J.M. and DOBBINS, W.O. (1970) Whipple's Disease: A review of 19 patients from one hospital and a review of the literature since 1950. Nedicine, 49, 175-205. MALONE, F.R. (1904)

Relation of chest contour to lung capacity. Journal of the American Medical Association, 43, 783-786. MARIE, P. (1898)

Deux cas de spondylose rhizomelique.

Revista Medica. 18, 285-315. MARTIN, F.R.R. and CARR, R.J. (1953)

Crohn's disease involving the stomach. A report of two cases.

British Medical Journal, 1, 700-702. MASHETER, H.C. (1959)

Behcets syndrome complicated by intracranial thrombophlebitis.

Proceedings of the Royal Society of Medicine, 52, 1039. MASON, R.M. (1965)

Seronegative polyarthritis in Reports on Rheumatic Diseases, (1970 revision) Hawkins, C. and Currey, H.L.F. (eds.) Arthritis and Rheumatism Council for Research . 
MAXWELL, J.D., GREIG, W.R., BOYLE, J.A., PASTECZNY, T. and SCHOFIELD, C.B.S. (1966)

Reiter's syndrome and psoriasis. Scottish Medical Journal. 11, 14. MEISELAS, L.E., FIERSTS, S. and LEVIN, E. (1963)

Studies of incidence and type of arthritis and

abnormal anti-globulins in ulcerative colitis following ileostomy.

Arthritis and Rheumatism, 6, 287-288. MENDLOWITZ, M. (1942)

clubbing and hypertrophic osteoarthropathy. Medicine, 21, 269-306.

METZGRR, H.N. and FROBESE, A.S. (1956)

Terminal ileitis in a fifteen year old boy and in the mother nineteen years previously. Gastroenterology, 31, 439-443. MIKHAIL, J.R. and MITCHBLL, D.N. (1970)

The Kveim test in sarcoidosis.

Postgraduate Medical Journal, 46, 484-485. MITCHELL, D.N., CANNON, P., DYER, N.C., HINSON, K.F.W. and WILLOUGHBY, J.M.T. (1969)

The Kveim Test in Crohn's disease.

Lancet, 2, 571-573.

MITCHELI, D.N., CANNON, P., DYER, N.C., HINSON, K.F.W. and WILLOUGHBY, J.M.T. (1970)

The Kveim Test in Crohn's disease. Postgraduate Medical Journal, 46, 491-494. MITCHELL, D.N. and REES, R.J.W. (1969)

A transmissable agent from Sarcoid tissue. Lancet $\underline{2}, 81-84$ 
MITCHELL, D.N. and RES, R.J.W. (1970A)

Agent transmissable from Crohn's disease tissue. Lancet 2., 168-171.

MITCHELL, D.N. and REES, R.J.W. (19703)

An attempt to demonstrate a transmissable agent from Sarcoid material.

Postgraduate Medical Journal, 46, 510-514.

MOCK, H.:. (1931)

Infective Granuloma.

Surgery, Gynecology, and Obstetrics. $\underline{52}, 672-689$.

MOLL, J.M.H. (1971)

A Family study of psoriatic arthritis.

D.M. Thesis, University of Oxford.

MOLL, J.M.H. and WRIGHT, V. (I971A)

Normal range of spinal mobility; an objective clinical study.

Annals of the Rheumatic Diseases, 30, 381-386.

MOLI, J.M.H. and WRIGHT, V. (1971B)

Chest expansion - an objective study. Paper read to the Heberden Soclety, Belfast.

MOORE, NOrman (1883)

Stricture of the Intestine at the Ileo-caecal valve.

Transaction of the Pathological society of London, 34 $112-113$

MORGAGNI, J.B. (1769)

The seats and causes of diseases investigated by Anatomy. Translated from the latin by Benjamin Alexander. London.. MTLIAR, CADELI, JCHNSON and PAYNE. Vol. 2 Letter the THIRTY FIRST. TREATS OF FLUXES OF THE BELLY, WITH OR WIIHOUT BLOOD. $(75-76)$. 
MORGAN, G. (1959)

Comparative study of the haemagglutination test and a simple latex-fixation test for the detection of the rheumatoid factor.

Annals of the Rheumatic Diseases, 18, 322-324. MOSCHOWITZ, E and WILENSKY, A.O. (1923)

Non-specific granulomata of the intestine.

American Journal of Medical Science, $166,48-66$. MOUNTAIN, J.C. (1970)

Cutaneous ulceration in Crohn's disease. GUT, 11, 18-26.

NEALE, G., KKELSALI, A.R. and DOYLE, F.H. (1968)

Crohn's disease and diffuse symetrical pertostitis. GUT, 2, 383-387.

NEELY, J.C. and GOLDMAN, L. (1962)

Regional Enteritis.

Surgical Clinics of North America, 42, 1257-1266.

NEW ENGLAND JOURNAL OF MEDICINE, (1963)

Case records of the Massachusetts Hospital;

Case 39-1963, 268, 1296-1303.

NEW ENGLAND JOURNAL OF MEDICINE, (1965)

Case records of the Massachusetts Hospital;

Case 14-1965, 272, 585-589.

NEWTON, D.R.I. (1957)

Discussion on the clinical and radiological aspects

of sacro-iliac disease.

Proceedings of the Royal Society of Medicine, $\underline{50}$, 850-853. OATES, J.K. and YOUNG, A.C. (1959)

Sacro-ilitis in Reiter's disease.

British Medical Journal, 1, 1013-1015. 
O' CONNELI, D. (1956)

Ankylosing Spondyiltis: the literature up to the close

of the nineteenth century.

Annals of the Rheunatic Diseases, 15, 119-123. OPPENIIEIMER, A. (1938)

Diseases of the apophyseal (intervertebral) articulations.

Journal of Bone and Joint Surgery. 20, 285-313. ORTHAYER, M. (1945)

Discussion of Eo.ckus (1945) and cave (1945)

Journal of the American Medical Association, 127, 458. OSHIMA, Y., SHIMIZU, T., YOKOHARI, R., MATSUMOTO, T., KANO, K., KAGAMI, T and NAGAYA, N. (1963)

clinical studies on Behcets synarome.

Annals of the Rheumatic diseases, 22, 36-45.

PALMER, W.L., KIRSNER, J.B., GOLDBRABER, M.B. and FUENTES, S.S. (1963)

Disease of the liver in regional enteritis.

American Journal of Medical Science, 246, 663-672. PARONEN, I. (1948)

Reiter's Disease.

Acta Medica Scandinavica. Suppl. 212. PATTERSON, J.F. and WEIRZBINSKI, S.J. (1962)

Digestive system manifestations of collagen diseases. Medical Clinics of North America, 46, (5) 1387-1398. PAULLEY, J.N. (1948)

Regional Ileitis

Lancet $\underline{i}, 923$. PAULLEY, J.W. (1950)

Ulcerative colltis.

Gastroenterology, 16, 566-576. PAYNE, B. and WRIGHT, V. (1971)

Personal Communications. 
PEMBERTON, J de J. and BROWN, P.W. (1937)

Regional Ileitis.

Annals of Surgery, 105, 855-870.

PERBERTON, R. (1934)

Some metabolic and Nutritionel aspects of chronic

Arthritis.

American Journal of Digestive Diseases, $1,438-441$. PERITNS, E.S. (1961)

Opthalmological aspects of Behcets disease.

Proceedings of the Royal Society of Medicine, 54, 106-107. PERRY, H.O. and MAYNE, J.G. (1965)

Psoriasis and Reiter's syndrome.

Archives of Dermatology, 22, 129-136.

PEALEN, G.S., PRICIOMAN, L.E. and KRUSEN, F.H. (1942)

Brucellosis Spondylitis.

Journal of the American Medical Association, 118, 859-862. MHEAR, D.N. (1958)

The relation between Regional Ileitis and sarcoidosis.

Lancet $2,1250-1251$.

POLLEY, H.F. and SLOCUNS, C.H. (1947)

Rheumatoid spondylitis: a study of 1,035 cases.

Annals of Internal Medicine, 26, 240-249.

PORRITT, A., HUNT, T.C, and MORGAN, C.N. (1960)

Three cases of Crohn's disease with ulcerative colitis.

Proceedings of the Royal Society of Medicine, 53, 373. PUGH, H.I. (1945)

Regional Enteritis.

Annals of surgery, 122, 845-861.

PUITE, R.H. and TESLUK,H. (1955)

Whipple's disease.

American Journal of medicine, 19, 383-400. 
PUNFHERZ, M.D. (1938)

Studies on the Etiology of Regional Ileitis.

Proccedings of the Staff Neetings of the Mayo Clinic,

13, 539-541.

PYGOTT, F. (1970)

Sarcoidosis in bone.

Postgraduate Medical Journal, 46, 505-506.

REED, W.D. (1961)

Psoriatic arthritis. A corplete clinfcal study of

86 patients.

Acta dermato-venereologica. $41,396-40$.

REED, W.B. and WRIGIT, V. (1966)

in Niodern Trends in Rheumatology. Hill, A.S.S. (ed.)

Butterworth, Iondon.

REFVEM, 0. (1958)

Enteric Mycosis (Regional Enteritis)

Gastroenterology, 35, 321-325.

RILEY, M.J., ANSELI, B.M. and EYWATERS, E.G.L. (1971)

Radiological manifestations of anisylosing spondylitis according to age of onset.

Annals of the Rheumatic Diseases, 30, 138-148.

ROBECCII, $A$ and di VITTORIO, S. (1965)

La spondilartrite psoriasica.

Minerva dermatologica, 느, 129-134.

ROBINSON, H.M. and MOCRUMB, F.R. (1950)

Comparative analysis of the mucocutaneous-ocular syndrome.

Archives of Dermatology and Syphilology. 61, 539-560. RODANICHE, R.C., KIRSNJER, J.B. and PALMER, W.I. (1943)

The relationship between lymphogranuloma venereum and regional enteritis.

Gastroenterology, 1, 687-689. 
ROGERS, M.H. and CLFAVES, E.N. (1935)

The adolescent sacro-iliac joint syndrome.

Journal of Bone and Joint Surgery, 17, 759-768.

ROJKO, A. and FARIEAS, K. (1959)

Osteitis Condensans Ossis Ilii.

Acta Crthopaedica Scandinavica. 29, 108-120.

ROLIESTON, G.L. (1948)

The early radiological diagnosis of ankylosing spondylitis.

Britien Journal of Radiology, 20, 288-293.

ROMANUS, R. and YDIN, S. (1955)

Pelvo-Spondylitis Ossificans Munksgaard. Copenhagen. ROSENBIAATE, A.J., GOLDSMITH, A.A. and STRAUSS, A.A. (1936)

A sunmary of Regional. Ileitis.

Journal of the American Medical Association, 106, 1797-1800, ROSS, J.R. (1949)

Cicatrizing enteritis, colitis and gastritis.

Gastroenterology, 13, 344-350.

ROSSMILLER, H.R. and MESSENGER, H.M. (1948)

Regional Enteritis: Diagnosis and Treatment.

Medical Clinics of North America, 32, 419-427. ROTES-QUEROL, J. (1957)

Osteo-articular sites of Brucellosis.

Annals of the Rheumatic Diseases, 16, 63-68. ROTSTEIN, J.. ENTTLL, I. and ZEVINER, B. (1963)

Arthritis associated with ulcerative colitis.

Annals of the Rheumatic Diseases, 22, 194-197. SAMDERS, R.C. (1964)

An attempt to devise a skin test for regional enteritis. GUT, 5, 194-195. 
SAPHRA, I. añ WINTER, J.W. (1957)

Clinical Vanifestations of Salmonellosis in man.

New England Journal of Medicine, 256, 1128-1134. SCADDING, J.G. (1967)

Sarcoidosis.

London, Eyre \& Spottiswoode. SCHACHTER, H., GOIDSTEIN, M.J., RAPPAPORT, H., FEMNIESSY, J.J. and KIRSNTER, J.B. (1970)

Ulcerative and "granulomatous" colitis - validity of

differential diagnostic features.

Annals of internal teaticine, 72, 841-851.

SCMMIDT, G.T., IENMARD-JONES, J.E. MORSON, B.C. and YOUNIG, A.C. (1968)

Crohn's disease of the colon and its distinction from Diverticulitis.

Gurs, 2, 7-16.

SCHOBER, P. (1937)

Lendenwirbelstule und rrewzschmerzen (The lumbar vertebral column and backache.)

Nunchener Medizinische Wochenscrift, 84, 336-338. SCHWARTZ, K. (1971)

Personal commication.

SEGAL, G. and SERBIN, R. (1956)

Regional Enteritis involving the Duodenum.

Gastroenterology, 30, 503-507.

SHAGRIN, J.W., TRAME, B. and DUNCAN, H. (1969)

polyarthritis in obese patients following jejunocolic bypass.

Arthritis and Rheunatism, 12, 696.

SHARP, J. (1968)

Ankylosing Spondylitis.

Reports on Rheumatic Diseases, 54-56. 
STLRP, J. and EASSON, E.C. (1954)

Deep $x$-ray therapy in spondylitis.

British Medical Journal, 1, 619-623.

SEIATIN, R. (1964)

Small Intestine as site of fundamental lesion in

connective tissue disease.

Wheumatism, 20, 93-97.

SHATIN, R. (1966)

Gluten, the small intestine and Fheumatoid Arthritis.

Rheumatism, 22, 48-52.

SHEEIIN, R.G., NZCIBIES, T.F., LINDEMAN, R.J.. MEYRR, H.J. and PATYESSOH, J.F. (1967)

Regional enteritis and granulomatous colitis associated

with erythrocyte glucose-6-phosphate dehydrogerase

deficiency.

Now England Medical Journal, 277, 1124-1126.

SHERICCK, P., BIII, B.M., STEINEERG, H. and AIMY, T.P. (1963).

Fanilial occurrence of Regional Enteritis and

Ulcerative colitis.

Gastroenterology, $45,413-419$

SIRES, D. (1961)

Arthritis in swine

Rheumatism, 17, 19-24.

SIURAIA, M., JULETUNEN, H., TOIVONEIS, S., PELKONEN, R., SAXEN, I. and PITINANEN, E. (1965).

Digestive tract in collagen diseases.

Âcta Medica Scandinavica, 178, 13-25.

SLANEY, G. (1961)

Alimentary granulomata and the immune response. Postgraduate Medical Journal, 37, 276-281. 
SLOAN, W.P., BARGEN, J.A., and GAGE, R.P. (1950)

Life histories of patients with chronic ulcerative colitis; a review of 2,000 cases.

Gastroenterology, 16, 25-38.

SOLONEN, K.A. (1957)

The sacro-illac joint in the light of anatomical, roentgenological and clinical studies.

Acta orthopaedica Scandinavica, Suppl. 27.

SOREN, A. (1966)

Joint Affections in Regional Ileitis.

Archives of Internal Medidne, 117, 78-83.

SPELLBEER, M.A. and JACKSON, E.L. (1950)

Problems in Diseases of the Small bowel.

Gastroenterology, 16, 425-439.

SPRAGUE, P.IF., ANDERSON, W.S., and AARON, T.H. (1944)

Long standing fever due to regional ileo-colitis.

American Journal of Digestive Diseases, 11, 295-296. STANWORTH, A. and SHARP, J. (1956)

Uveitis and rheumatic disease.

Annals of the Kheumatic Diseases, 15, 140-150. STECHER, R.M. and HERSOH, A.H. (1955)

Familial occurrence of ankylosing spondylitis.

British Joumal of Physical Medicine, 18, 176-183. STEIGHANN, F. and SHAPIRO, S. (1961)

Familial Regional Enteritis,

Gastroenterology, 40, 215-218.

STEINBERG, C.L. (1948)

Brucellosis as a cause of sacro-iliac arthritis. A study of its relationship to rheumatoid spondylitis. Journal of the American Medical Association, 138, 15-19 
STEINBERG, V.L. and STOREY, G. (1957)

Ankylosing spondylitis and chronic inflammatory lesions

of the intestines.

British Medical Journal, 2, 1157-1159.

STEWART, J.S. and ANSEII, B.M. (1963)

Ankylosing Spondylitis Associated with Regional Enteritis. Gastroenterology, 45, 265-268.

STRACHEN, R.W. and WIGZELL, F.W. (1963)

Polyarthritis in Behcets Multiple symptom complex.

Annals of the Rheumatic Diseases, 22, 26-35.

SUIHEIM, O., DALGAARD, J.B. and ANDERSON, S.R. (1959)

Behcets syndrome: report of a case with a complete autopsy performed.

Acta pathologica et microblologica Scandinavica, $45,145-158$. TANJEL, H.I., CLARK, D.H. and LEE, F.D. (1965)

Radiation Enteritis with malabsorption.

GUT, 흐, 560-569.

TAYLOR, K.B. and TRUELOVE, S.C. (1962)

Immunological reactions in gastrointestinal disease:

a review.

GUT, $3,277-288$.

TELEKX, L. (1897)

Beltrage zur lehre von der 'Osteoarthropathie

hypertrophiante pneumique.'

Wiener klinische Wochenschrift, 10, 143-149. THOMPSON, M. (1954)

Osteitis condensans $111 i$ and its differentiation

from ankylosing spondylitis.

Annals of the Pheumatic Diseases, 13, 147-156. 
THOMPSON, M. (1957)

Discussion on the clinical and radiological aspects

of sacro-iliac disease.

Proceedings of the Royal Society of Medicine, 50, 847-850. TODD, I.P. (1954)

An unusual case of ulcerative colitis:

Proceedings of the Society for Experimental Biology

and Medicine, 47, 260-261.

TRAFYORD, H.S. (1956)

The outlook after massive resection of small intestine

with a report of two cases.

British Journal of Surgery, 44, 10-13.

TROUP, J.D.G., HOOD, C.A. and CHAPMAN, A.E. (1968)

Neasurements of the Sagittal Mobility of the Lumbar

Spine and Hips.

Annals of Physical Medicine, 2, 308-321.

TRUELOVE, L.H. (1960)

Articular manifestations of erythema nodosum.

Annals of the Rheumatic Diseases, 19, 174-180.

VAN PATYYR, W.N., BARGEN, J.A., DOCKERTY, M.B., FELDRAN, D.V.M., MAYO, C.W., and WAUCH, J.M. (1954)

Regional Enteritis.

Gastroenterology, 26, 347-450.

VAN WEERDEN, G.K., DEN OUDSTEN, S.A., DE GROOT, A.L., and

VAN DER VEBRE, W. (1960)

spiro-Ergometry in patients suffering from Bechterew's disease.

Annals of the Rheumatic Diseases, 19, 268-271. 
VERRIER JONES, J. (1968)

Aetiology of Regional Enteritis.

Lancet, 1, 1252.

VERRIER JONES, J., HOUSLIT, J., ASTURST, P.M., and HAWKINS, C.F. (1969)

Development of delayed hypersensitivity to dinitrochlorobenzene in patients with Crohn's disease. GUT, 10, 52-56.

VITTORIO, S., VIACA, M and CHIANDANO, M. (1965)

Il quadro radiologico dell artrite psoriasica. Reumatismo, 17, 336.

WAGNER, A. (1969)

Arthralgien und Ileosakralarthritis bei Enteritis regionalis.

Deutsche Medizinische Wochenschrift 24, 13-17\&21. WAIMSLEY, R. (1964)

Syndesmology or Arthrology, pp. 213-264 in Cunninghams Textbook of Anatory, 10th Eaition. G.J. Romanes (ed.) Londion, Oxford University Press.

WARREN S., and SOMMGRS, S.C. (1948)

Cicatrizing enteritis (regional ileitis) as a pathologic entity.

American Journal of Pathology, 24, 475-510. WATSON, C.J., RIGLER, L.G., WALGENSTEEN, O.H., and MCCARTINEY, J.S. (1945)

Isolated sarcoidosis of the small intestine simulating non-specific ileo-jejunitis.

Gastroenterology, $4,30-52$. 
WEEB, J., COLLINS, L.T., SOUIHWELL, P.B., and DICK-SMIII, J.B. (1972).

Flourine - 18 isotype scans of the sacro-iliacs.

Annals of the Fheumetic Diseases, in press.

WEIts, Josephine (1965)

The sacro-iliac joint in anirylosing spondylitis. Rheumatism, 21, 100-1.04.

WHIPPLE, G.H. (1907)

A hitherto undesraibed disease characterised anatomically by deposits of fat and fatty acids in the intestinal and mesenteric lymphatic tissues.

John Hopkins Hospital Bulletin, 13, 382-391. WHITE, M.H. (1895)

Col1tis.

Irancet, 1, 538-539.

WHITE, P.H.H. (1.953)

Reports of 8 th International Congress International

League against Phematism, Geneva, 1953.

Annals of the Pheumatic Diseases, 12, 237.

WILEINSON, M. and BYWATERS, E.G.L. (1958)

clinical features and course of ankylosing spondylitis. Annals of the Rheumatic Diseases, 17, 209-228.

WILKINSON, M. and MEIUEE, J.A.K. (1966)

Tomography of the sacro-11iac joint.

Annals of the Fheumatic Diseases, 25, 433-440.

WILLIAMS, R.II. and NICKERSON, D.A. (1935)

skin reactions in sarcoid.

Proceedings of the Society of Experimental Biology and Medicine, 33, 403-405. 
WILIIS, T.A. (1933)

Sacro-iliac Arthritis.

Surgery, Gynecology and obstetrics, 57, 147-155.

WILSKE, K.R. and DECKEER, J.I. (1965)

The articular manifestations of Intestinal disease.

Bulletin of Rheumatic Diseases, 15, 362-365.

WRIGHT, R., LUMSDEN, K., IUNTTZ, M.H., SEVEL, D. and

TRUELOVE, S.C., (1965)

Abnormalities of the Sacro-iliac joints and uveitis

in ulcerative colitis.

Quarterly Journal of Medicine, 34, 229-236.

WRIGHT, V. (1963)

Arthritis associated with venereal disease.

Annals of the Pheumatic Diseases, 22, 77-90.

WRIGHT, V. (1964)

Discussion of Ansell and Wigley, (1964)

Annals of the Fheumatic Diseases, 23, 70-71. WRIGHT, V. (1965)

Psoriatic Arthopathy in Clinical Rheumatology,

Dixon, A. St. J. (Ea.) Churchill, London,

WRIGHT, V. (1966A)

The arthritis of Ulcerative Colltis, Reiter's disease

and Behcets syndrome.

pp. 337-346 in Modern Trends in Rheumatology, A.G.S. Hill

(Ed.) London, Butterworths.

WRIGITT, V. (1966B)

Ankylosing spondylitis.

Proceedings of the Royal Society of Medicine, 59, 451-453. 
WRIGIT, V., CAIYGRALL, R.D. and COOK, J.B. (1965)

Bone and joint changes in paraplegic men.

Annals of the Phoumatic Diseases, 24, 419-431. WRIGIT, V. and REWD, W.B. (1964)

The links between Reiter's syndrome and Psoriatic arthritis.

Annals of the Rheumatic Diseases, 23, 12-21. WRIGHT, V. and WATKINSON, G. (i959)

The arthritis of Ulcerative colitis. Nedicine, 38, 243-259. WRIGHT, V. and WATKINSON, G. (1965A)

The arthritis of Ulcerative colitis. British Medical Journal, 2, 670-675. WRIGHT, V. and WATKINSON, G. (1965B)

Sacro-iliitis and ulcerative colitis.

British Niedical Journal, 2., 675-680. WYATT, A.P. (1969)

Regional Enteritis leading to carcinoma of the small bowel. GUT, 10, 924-927.

YARDLEY, J.H. and FLEMING, W.H. II (196I)

Whipple's Disease: A note regarding P.A.S. - positive granules in the original case.

Bulletin of the Johns Hopkins Hospital, 109, 76-79. YONKMAN, F.F. (1952)

The pharmacology of newer agents ermployed in the treatment of gastrointestinal disturbances with special reference to Regional Ileitis and Uleerative Colitis. Bulletin of the New York Academy of Medicine, 28, 700-713. 
YOUNG, J.R. (1966)

Ulcerative colltis and finger clubbing.

British Vedical Journal, 1, 278-279.

ZORAB, P.A. (1961)

The IIistorical and Prehistorical Background of Ankylosing spondylitis.

Proceedings of the Royal Society of lisdicine, 54, 4.15. ZVAIFLER, N.J. and MARTEL, W. (1960)

Sponäylitis in chronic ulcerative colitis.

Arthritis and Pheumatism, $3,76-87$.

\section{$\underline{\text { ADDENDUM }}$}

BRIDGEMAN， J.F. (1972)

Periarthritis of the Shoulder and Diabetes Mellitus.

Annals of the Rheumatic Diseases, 31, 69-71. 